\title{
Einfluss von GnRH Analoga auf die Metastasierung humaner Mammakarzinomzellen in vitro und in vivo
}

\author{
Dissertation \\ zur Erlangung des Doktorgrades \\ der Mathematisch-Naturwissenschaftlichen Fakultäten \\ der Georg-August-Universität zu Göttingen
}

vorgelegt von

Antje Schubert

aus Zwickau

Göttingen 2010 
D7

Referent: Prof. Dr. Sigrid Hoyer-Fender Korreferent: Prof. Dr. Gerhard Hunsmann Tag der mündlichen Prüfung: 25.10.2010 


\section{ZUSAMMENFASSUNG}

Das Mammakarzinom zählt zu den Tumorerkrankungen mit einem sehr starken Metastasierungsverhalten, wobei der Knochen als einer der Hauptangriffsorte für Metastasen gilt. Da 50 \% der humanen Mammakarzinome eine Expression von GnRH Rezeptoren aufweisen, ist eine direkte Rezeptor-vermittelte Therapie mit GnRH Analoga in diesen Karzinomzellen von großer Bedeutung. Es wurde gezeigt, dass $\mathrm{GnRH}$ Analoga in der Lage sind die Knochen-gerichtete Invasion von Mammakarzinomzellen in vitro zu hemmen. Die molekularen Mechanismen dieses Effekts sind jedoch weitgehend ungeklärt und wurden im Rahmen dieser Arbeit untersucht. Des Weiteren wurden die Wirkungen von GnRH Analoga auf die Metastasierung des Mammakarzinoms in vivo analysiert.

Es konnte gezeigt werden, dass während der Kokultur von MCF-7 oder MDAMB-231 Zellen mit Osteoblasten-ähnlichen Zellen eine Regulation bestimmter Metastasierungs-assoziierter Gene stattfindet. GnRH Analoga besitzen jedoch keinen Einfluss auf die veränderte Expression dieser Gene. Ein sehr deutlicher Effekt wurde im Bezug auf Faktoren des Knochenstoffwechsels erzielt. In HCC70 Zellen, die sich als RANKL-positiv erwiesen, wurde während der Kokultur mit humanen Osteoblasten eine Regulation des RANKL/OPG-Systems ermittelt, die eine gesteigerte Knochenresorption zur Folge hat. Der Expressionsanstieg von RANKL während der Kokultur konnte durch Triptorelin (GnRH-I Agonist) inhibiert werden.

In vivo wurden deutliche wachstumsinhibierende und antimetastatische Effekte von GnRH Analoga ermittelt. Im Knochen wurde die Metastasierung von MDAMB-435 Zellen durch GnRH-I und GnRH-Il Analoga signifikant gehemmt. Auch in der Lunge sowie im Bezug auf die Metastasierung von MDA-MB-231 Zellen zeigten sich tendenzielle Effekte.

Die Analysen dieser Arbeit leisten einen Beitrag in der Aufdeckung molekularer Mechanismen der Knochenmetastasierung des Mammakarzinoms sowie für die Möglichkeit einer zielgerichteten Therapie mit GnRH Analoga. Insbesonders die in vivo ermittelten antimetastatischen Effekte sind für die endokrine Therapie des metastasierenden Mammakarzinoms sehr wichtig. 


\section{INHALTSVERZEICHNIS}

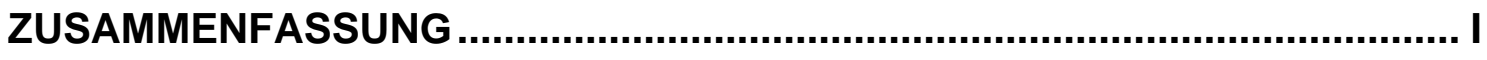

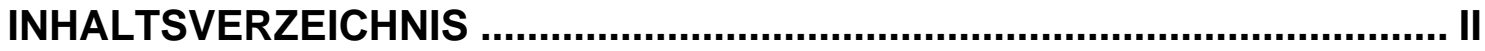

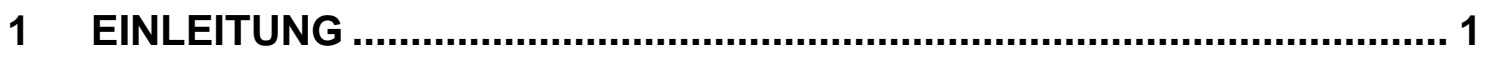

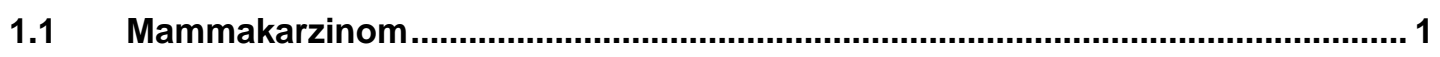

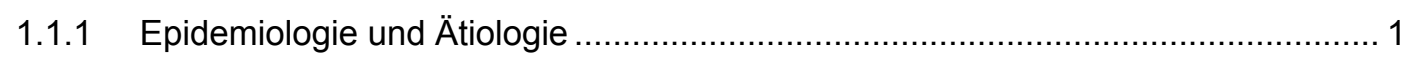

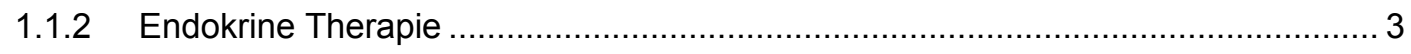

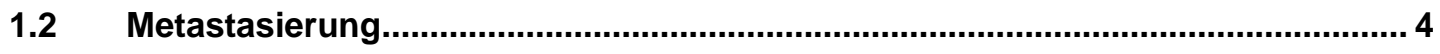

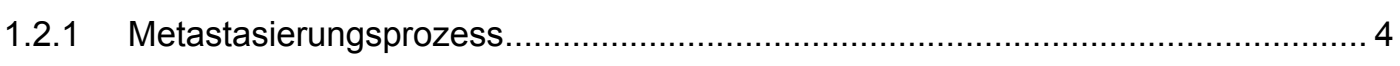

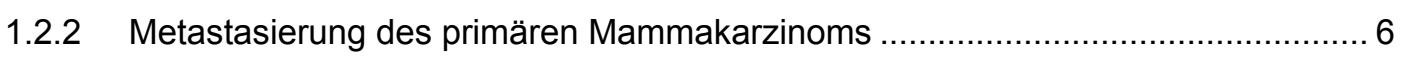

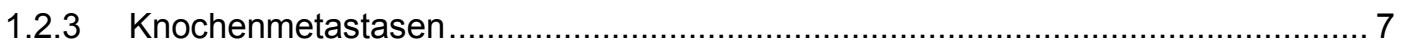

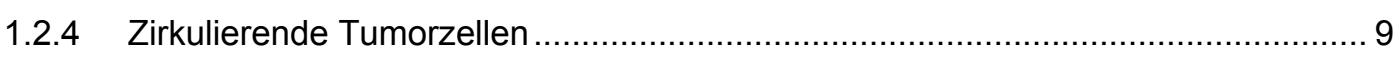

1.2.5 Therapie des metastasierten Mammakarzinoms ............................................... 10

1.3 Gonadotropin-Releasing Hormon-I und -II .................................................. 11

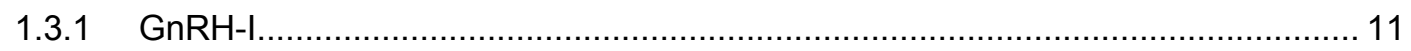

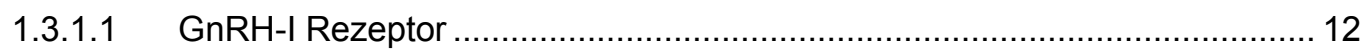

1.3.1.2 Signaltransduktion in der Hypophyse .................................................. 14

1.3.1.3 Signaltransduktion in gynäkologischen Tumoren ..................................... 14

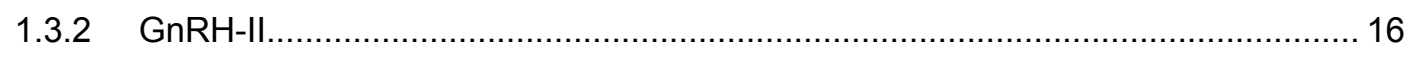

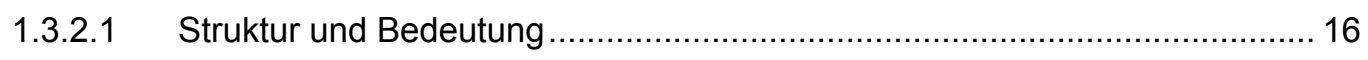

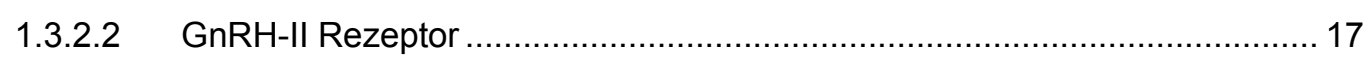

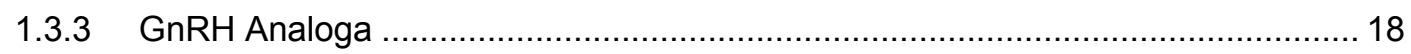

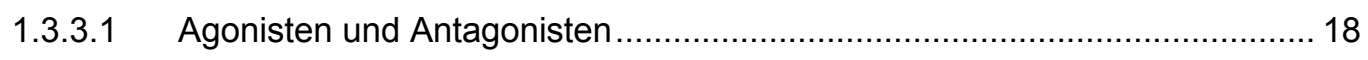

1.3.3.2 Einsatz in der Gynäkologie und Geburtshilfe ......................................... 20

1.3.3.3 Effekte auf die Metastasierung in vitro..................................................... 21

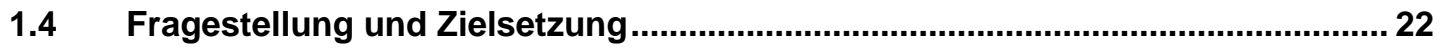

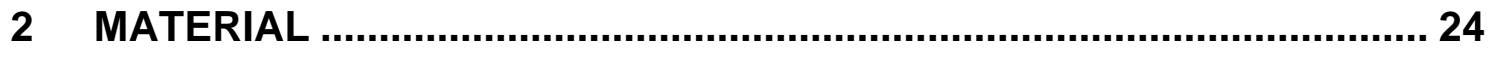

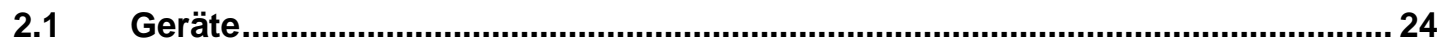

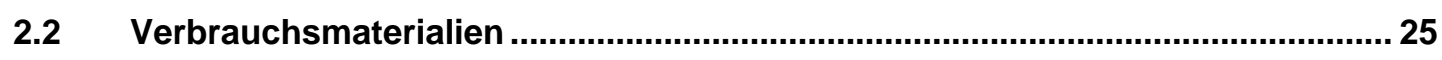

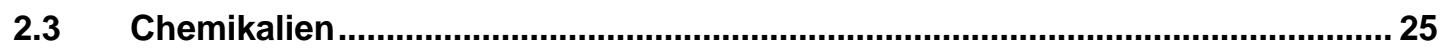

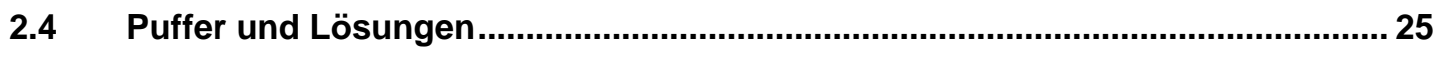

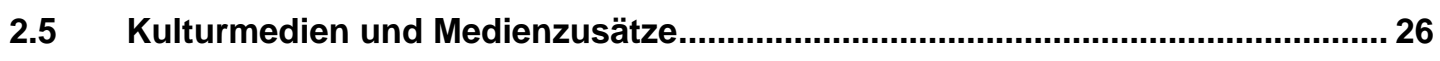

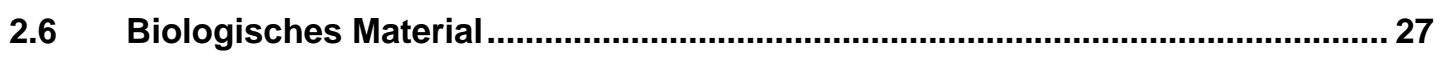

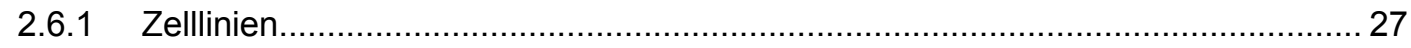




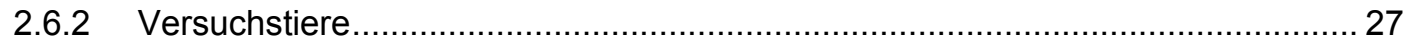

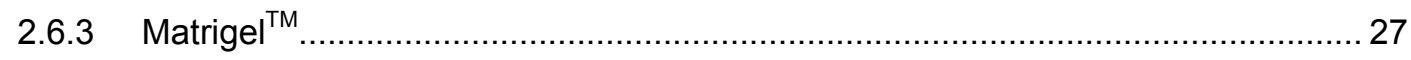

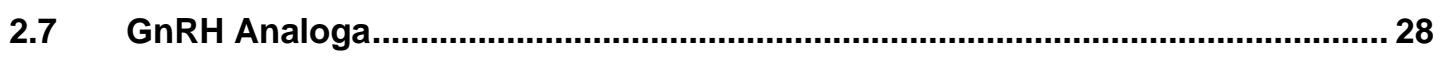

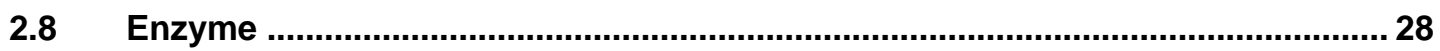

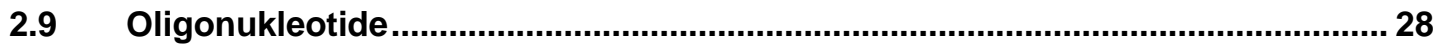

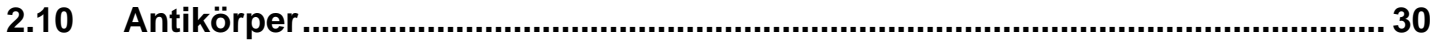

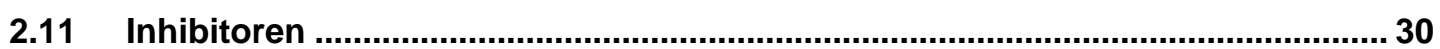

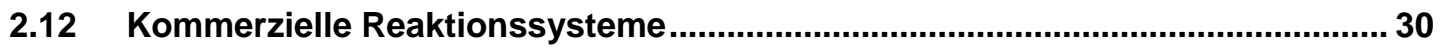

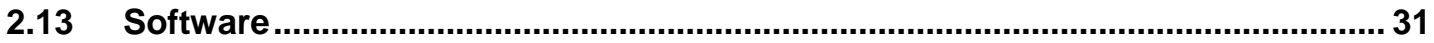

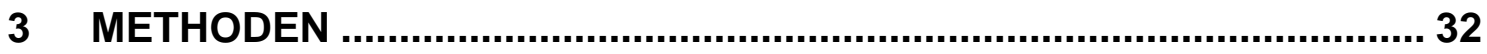

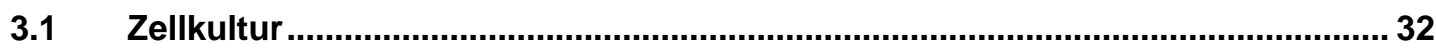

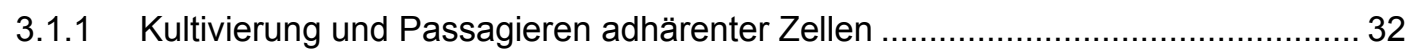

3.1.2 Kryokonservierung und Auftauen eukaryotischer Zellen.................................... 32

3.1.3 Primäre Kultivierung humaner Osteoblasten................................................. 32

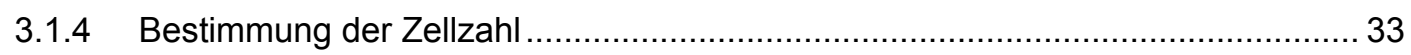

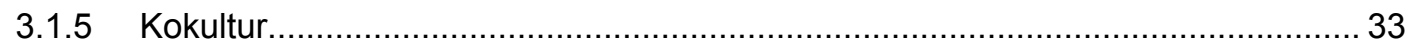

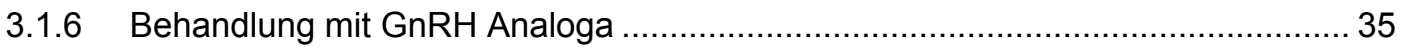

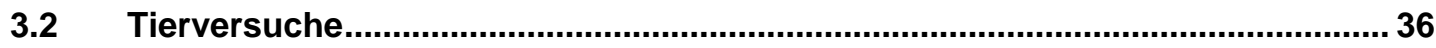

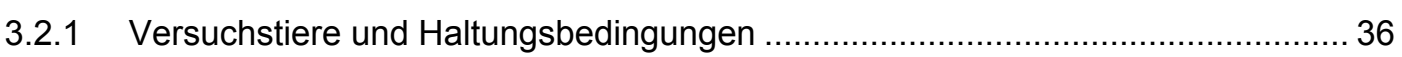

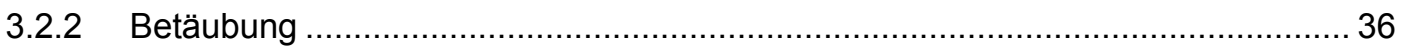

3.2.3 Vorbereitung und Injektion von Tumorzellen .................................................. 36

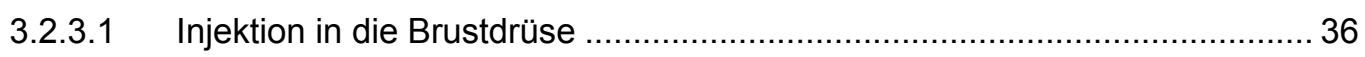

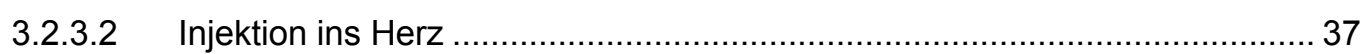

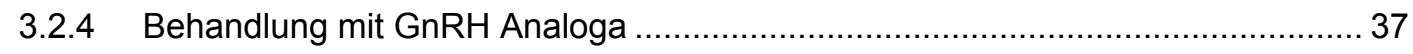

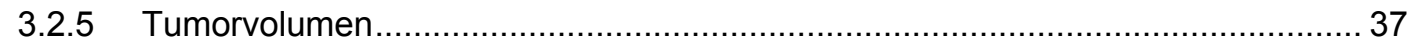

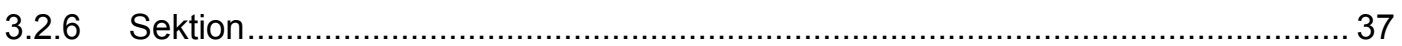

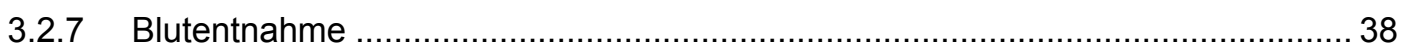

3.2.8 Gewinnung und Aufbereitung von Mausgewebe ............................................. 38

3.3 Molekularbiologische Methoden .............................................................. 38

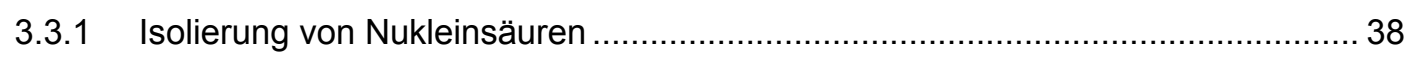

3.3.1.1 Isolierung von DNA aus adhärenten Zellen .............................................. 39

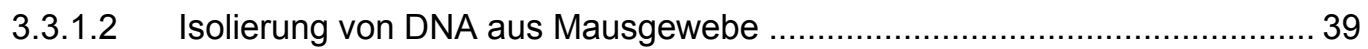

3.3.1.3 Isolierung von RNA aus adhärenten Zellen .............................................. 39

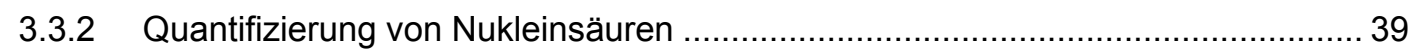

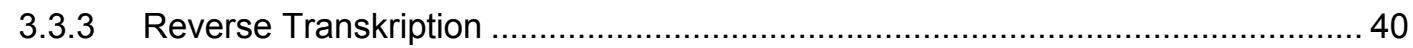

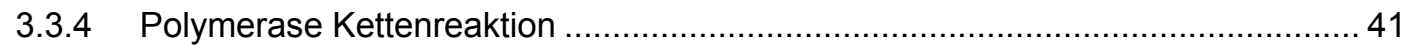

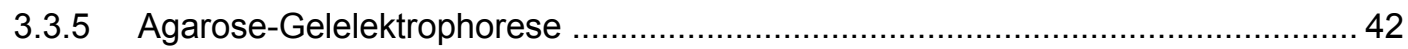




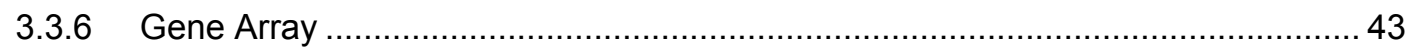

3.3.6.1 Synthese Biotin-16-dUTP-markierter cDNA-Sonden................................. 43

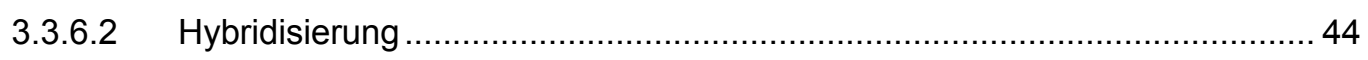

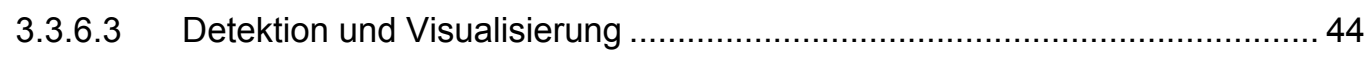

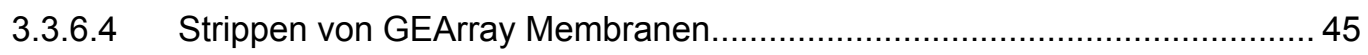

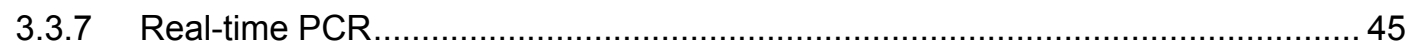

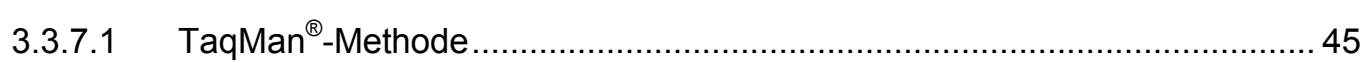

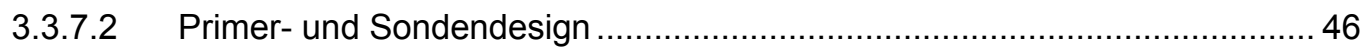

3.3.7.3 Durchführung und Dokumentation.................................................... 47

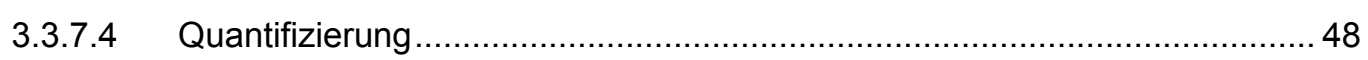

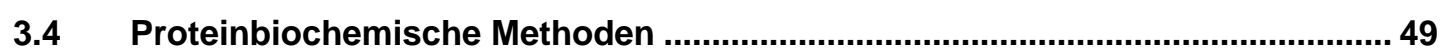

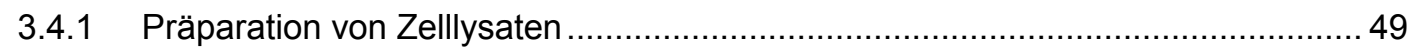

3.4.2 Trennung von zytosolischen und membranständigen Proteinen ......................... 49

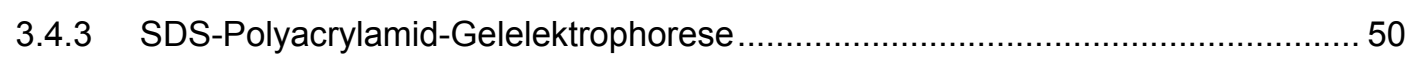

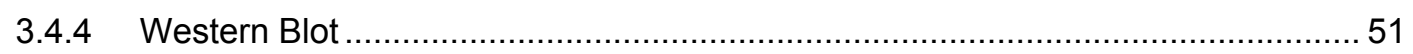

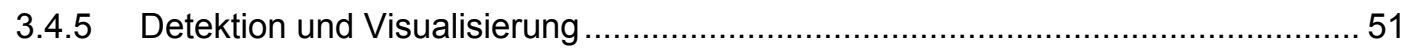

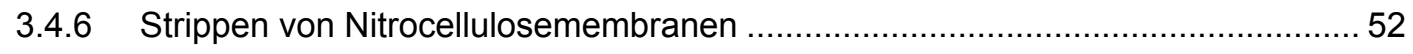

3.5 Immunzytochemische Methoden .............................................................. 52

3.6 Dokumentation und statistische Analysen ................................................. 53

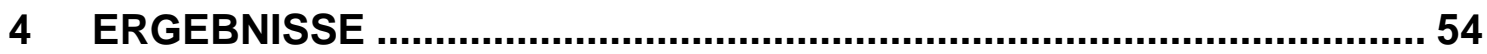

4.1 Einfluss der GnRH Analoga auf das RANKL/OPG-System ................................54

4.1.1 Expression des GnRH-I Rezeptors in Mammakarzinomzellen ............................. 54

4.1.2 Expression von RANKL und OPG in Mammakarzinomzellen................................ 55

4.1.3 Einfluss von Triptorelin auf die Expression von RANKL und OPG ..................... 56

4.2 Einfluss der GnRH Analoga auf die Expression von PTHrP und PTHrP-R........ 58

4.2.1 Expression von PTHrP in MCF-7 und MDA-MB-231 .................................... 58

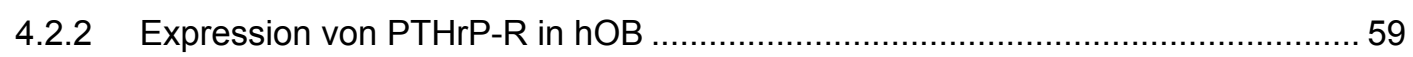

4.3 Interaktion der GnRH Analoga mit weiteren Faktoren der Metastasierung....... 60

4.3.1 Erstellen von Genexpressionsprofilen mittels Gene Array ..................................60

4.3.2 Expression von CDH1 sowie CTSB in MCF-7 und MDA-MB-231 .........................62

4.3.3 Expression von S100A4 sowie CYR61 in MCF-7 und MDA-MB-231 ................... 64

4.4 Effekte der GnRH Analoga in vivo ....................................................................6 68

4.4.1 Bestimmung der Metastasierung mittels TaqMan ${ }^{\circledR}$-Real-time PCR ...................... 68

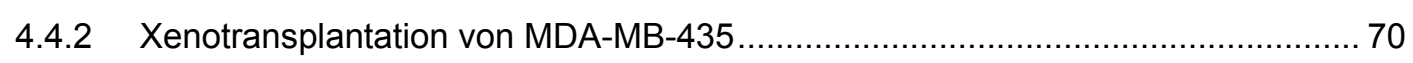

4.4.2.1 Einfluss der GnRH Analoga auf das Tumorwachstum ............................... 70

4.4.2.2 Einfluss der GnRH Analoga auf die Metastasierung ................................. 71

4.4.3 Xenotransplantation von MDA-MB-231 ...................................................... 75 
4.4.3.1 Einfluss der GnRH Analoga auf die Metastasierung ................................ 75

4.4.3.2 Nachweis zirkulierender Tumorzellen im Blut........................................... 78

5 DISKUSSION................................................................................ 80

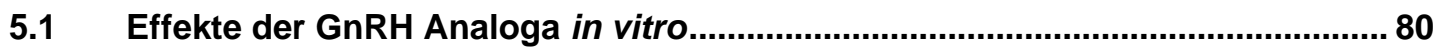

5.1.1 Interaktion mit Faktoren des Knochenstoffwechsels ........................................ 80

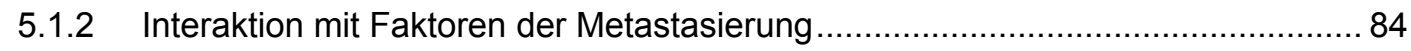

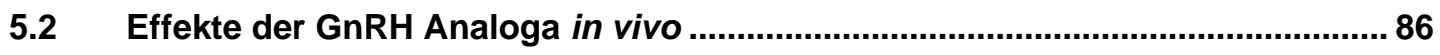

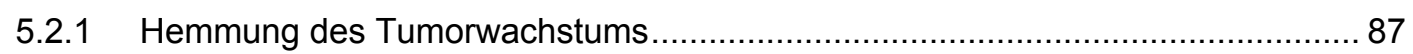

5.2.2 Metastasierungsuntersuchungen mittels TaqMan ${ }^{\circledR}$-Real-time PCR .................... 89

5.2.3 Hemmung der Metastasierungsrate im Femur ................................................... 90

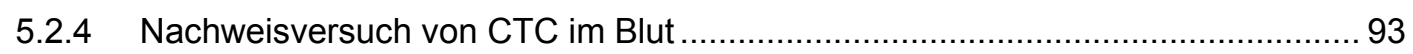

5.2.5 Detektion von Metastasen mit Hilfe des Natrium-lodid-Symporters....................... 94

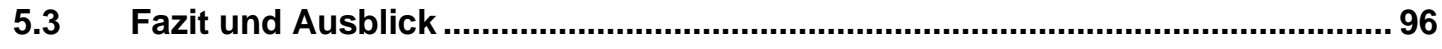

6 LITERATURVERZEICHNIS................................................................. 98

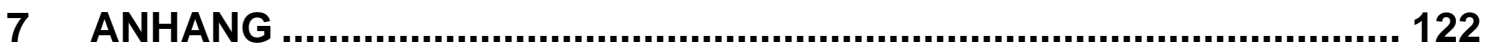

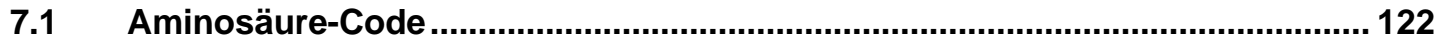

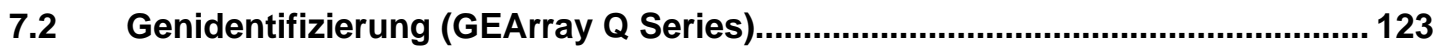

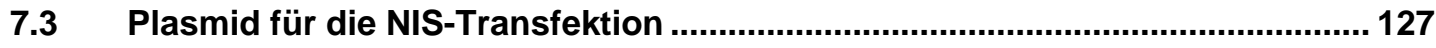

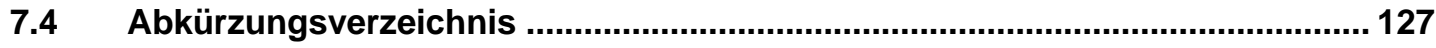

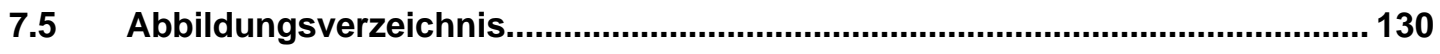

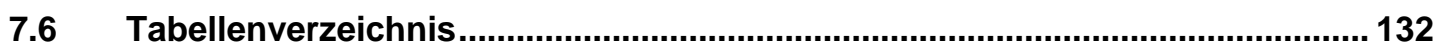

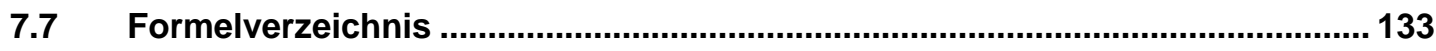

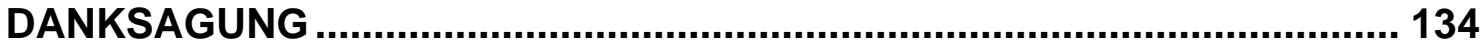

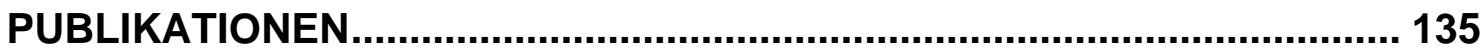

LEBENSLAUF ............................................................................... 136 


\section{EINLEITUNG}

\subsection{Mammakarzinom}

\subsubsection{Epidemiologie und Ätiologie}

Das Mammakarzinom ist mit etwa 1 Mio Neuerkrankungen pro Jahr weltweit die häufigste bösartige Tumorerkrankung der Frau (Parkin et al., 2005). Laut den Schätzungen der GEKID (Gesellschaft der epidemiologischen Krebsregister in Deutschland e.V.) erkrankten in Deutschland im Jahr 2006 etwa 58.000 Frauen am Mammakarzinom mit einer Sterberate von 17.000 der Erkrankten. Mit einem Anteil von 29 \% stellt das Mammakarzinom auch in Deutschland die häufigste Krebsneuerkrankung dar. Das mittlere Erkrankungsalter liegt bei 64 Jahren. Die Inzidenz des Mammakarzinoms ist seit 1980 stetig angestiegen und befindet sich seit dem Jahr 2000 auf ungefähr gleichbleibendem Niveau. Ob das Risiko einer Erkrankung zugenommen hat, ist jedoch nicht gesichert. Die Einführung moderner Diagnostikverfahren und eine höhere Lebenserwartung sind für eine bessere Früherkennung und die gesteigerte Erkrankungsrate mitverantwortlich. Die Ätiologie des Mammakarzinoms ist bis heute nicht vollständig geklärt. Eine Vielzahl epidemiologischer Studien konnte jedoch zeigen, dass die Entstehung des Mammakarzinoms auf ein multifaktorielles Geschehen zurückzuführen ist. Dabei wird die Mehrzahl aller Mammakarzinome nicht familiär vererbt, sondern tritt sporadisch auf. Bei ca. 5 - $10 \%$ der am Mammakarzinom Erkrankten lässt sich eine familiäre Prädisposition nachweisen (Bradbury \& Olopade, 2007). Hier spielen vorallem Mutationen in den DNA-Reparaturgenen BRCA-1 und BRCA-2 eine übergeordnete Rolle, da sie für 20 - $60 \%$ der familiären Mammakarzinome verantwortlich sind und das Risiko einer Erkrankung deutlich erhöhen (Bishop, 1999; Nathanson et al., 2001). Neben der familiären Prädisposition bestehen eine Reihe weiterer Risikofaktoren für die Entstehung des Mammakarzinoms. Frauen, die eine frühe Menarche und eine späte Menopause erleben, besitzen ebenfalls ein erhöhtes Risiko am Mammakarzinom zu erkranken (McPherson et al., 2000). Auch das Alter einer Frau bei der ersten Schwangerschaft hat einen 
Einfluss auf das Erkrankungsrisiko. So erhöhen eine späte erste Geburt sowie Kinderlosigkeit das Lebenszeitrisiko (Newcomb et al., 1994). Zu den weiteren Risikofaktoren zählen Adipositas (Schaffler et al., 2007) und Alkoholkonsum (Longnecker, 1994). Über den Effekt der exogenen Zufuhr von Östrogenen oder der Kombinationsbehandlung mit Östrogenen sowie Gestagenen innerhalb der postmenopausalen Hormonersatztherapie sind bisher kontroverse Meinungen bekannt (Emons, 2001; Shah \& Wong, 2006).

Weltweite epidemiologische Untersuchungen haben bereits 1975 gezeigt, dass die Inzidenz des Mammakarzioms in den westlichen Industrienationen deutlich höher liegt, als in den Entwicklungsländern und in Japan (de Waard, 1975). Die Ursache der großen ethnologischen sowie geographischen Schwankungen wird dabei auf Unterschiede in der Lebensführung und den nutritiven Gewohnheiten zurückgeführt (Kelsey \& Horn-Ross, 1993; Gerber et al., 2003; Porter, 2009).

Das Mammakarzinom zeigt sich in seinem klinischen und morphologischen Erscheinungsbild als sehr vielfältig. Nach einem Vorschlag der World Health Organization (WHO) von 1981 wird das Mammakarzinom grundlegend in zwei histologische Gruppen unterteilt: nicht-invasive Karzinome (Carcinoma in situ) und invasive Karzinome (WHO, 1982). Um den Verlauf der Erkrankung zu reflektieren, wird der prognostischen Beurteilung des Mammakarzinoms eine wichtige Bedeutung zugeordnet. Mit Hilfe der TNM-Klassifikation erfolgt dabei eine Einteilung nach der Größe des Tumors (T), dem Lymphknotenbefall bzw. Nodalstatus (N) und der Metastasierung (M) (Singletary et al., 2002). Mittels histopathologischen Grading nach Bloom \& Richardson (1957) werden zudem auch histo- sowie zytomorphologische Eigenschaften wie Tubulusausbildung, Kernpolymorphie und Mitoserate gekennzeichnet.

Eine sehr breite klinische und therapeutische Relevanz hat im Laufe der Jahre die Bestimmung des Hormonrezeptorstatus erlangt. Dieser ist sowohl für eine prognostische Beurteilung des Mammakarzinoms als auch die Einleitung einer endokrinen Therapie von großer Bedeutung. Hierbei wird neben dem Östrogenund Progesteron-Rezeptorstatus heute auch der Rezeptorstatus von HER2/neu (human epidermal growth factor receptor 2) untersucht (Esteva et al., 2002). Bei einer Überexpression von HER2/neu, die bei 25 - 30 \% der Patientinnen auftritt 
(Slamon et al., 1989), empfiehlt sich eine Antikörpertherapie mit Trastuzumab $\left(\right.$ Herceptin $^{\circledR}$ ). Dieser humanisierte monoklonale Antikörper ist gegen HER2/neu gerichtet und bietet eine vielversprechende Option in der adjuvanten Therapie des Mammakarzinoms (Chang, 2010).

In erster Linie besteht die Therapie des Mammakarzinoms jedoch aus einem operativen Eingriff mit möglichst brusterhaltendem Vorgehen. Dies wird ergänzt durch verschiedene Bestrahlungsmethoden und einer adjuvanten systemischen Behandlung mit Chemo-, Hormon- oder Antikörpertherapie.

\subsubsection{Endokrine Therapie}

Die endokrine Therapie des Mammakarzinoms ist bei prämenopausalen Frauen mit positivem Östrogen- und/oder Progesteronrezeptorstatus als adjuvante und palliative Maßnahme etabliert. Dabei liegen die Ursprünge dieser Therapieform in einer Arbeit von Beatson (1896), der durch die Ovarektomie eine Regression bei fortgeschrittenen Mammakarzinomen erzielen konnte. Auf diese Weise wurde die Ovarfunktion und somit ebenfalls die Synthese der Steroidhormone erstmals verhindert. Als weitere Verfahren folgten die Adrenalektomie (Dao \& Huggins, 1955) sowie die Hypophysektomie (Pearson \& Ray, 1959). Später erfolgte dann die Einführung von Antiöstrogenen, darunter Tamoxifen. Damit wurde eine Blockade der Östrogenrezeptoren erreicht (Ward, 1973; Legha \& Carter, 1976). Seit vielen Jahren gilt Tamoxifen in der Therapie des prä- und postmenopausalen Mammakarzinoms als fest etabliert. Mittlerweile stehen bei postmenopausalen Patientinnen in der adjuvanten Antihormontherapie ebenso Aromatasehemmer der bereits dritten Generation wie Anastrozol (Arimidex ${ }^{\circledR}$ ) und Letrozol (Femara ${ }^{\circledR}$ ) zur Verfügung (Kesisis et al., 2009). Sie wirken als nicht-steroidale kompetitive Inhibitoren der Aromatase und unterbinden auf diesem Weg die Östrogensynthese.

Die Antihormonbehandlung in der Prämenopause war lange Zeit umstritten, gehört jedoch heute zu den Standardtherapien des Mammakarzinoms. Dabei sind der geringe therapeutische Aufwand, eine minimale Toxizität sowie Nebenwirkungen in einem tolerablen Bereich von Vorteil. Die Behandlung von prämenopausalen Frauen kann mit GnRH-I Analoga erfolgen, die eine medikamentöse Kastration hervorrufen und die Patientinnen in den Zustand der 
Postmenopause versetzen (Emons et al., 2003). Diese Patientinnen werden im postmenopausalen Zustand auch mit Antiöstrogenen, wie bereits beschrieben, behandelt. Eine relativ neue Form der Therapie stellt der ÖstrogenrezeptorAntagonist Fulvestrant (Faslodex ${ }^{\circledR}$ ) dar. Fulvestrant gehört zu den selektiven Östrogenrezeptor-Destruktoren (SERD, selective estrogen receptor destructor) und ist in der Lage, die Anzahl der Östrogenrezeptoren zu reduzieren (Howell et al., 2004). Antiöstrogene wie Tamoxifen sind als selektive ÖstrogenrezeptorModulatoren (SERM, selective estrogen receptor modulators) hingegen nicht dazu befähigt.

\subsection{Metastasierung}

\subsubsection{Metastasierungsprozess}

Die Entstehung des primären Mammakarzinoms ist ein multifaktorieller Prozess und beruht auf einer Veränderung zellulärer Regulationsmechanismen, welche einen Anstieg der Proliferation, invasives Wachstum sowie Metastasierung zur Folge haben. Unter dem Begriff der Metastasierung versteht man die Streuung von Tumorzellen aus einem Primärtumor und die damit verbundene Bildung von Tochtergeschwülsten (Metastasen) an weiter entfernten Organen des Körpers (Chambers et al., 1995). Der Prozess der Metastasierung setzt sich dabei aus mehreren Schritten zusammen (siehe Abbildung 1.1). Nachdem sich einzelne Tumorzellen aus dem Gewebsverband des Primärtumors lösen, sind diese in der Lage sich über das Lymph- oder Blutgefäßsystem im Körper zu verbreiten und schließlich zur Bildung von Metastasen zu führen (Zetter, 1998). Sowohl für das Wachstum des Primärtumors als auch für die nachfolgende Metastasierung ist die Fähigkeit zur Angiogenese, d.h. zur Bildung neuer Blutgefäße von großer Bedeutung. Über einem Durchmesser von 1 - $2 \mathrm{~mm}$ hinaus, ist die Neubildung von Blutgefäßen essentiell, um die Versorgung mit Sauerstoff und Nährstoffen sowie den Abtransport toxischer Metabolite zu gewährleisten (Folkman, 2006). Für die weiteren Schritte der Metastasierung spielt die Fähigkeit zur Adhäsion eine wichtige Rolle. Die Tumorzellen sind in der Lage sich über die Regulation verschiedener Adhäsionsmoleküle vom Primärtumor zu trennen, aufgrund ihrer 
Beweglichkeit durch die Basalmembran und das Bindegewebe zu wandern und sich schließlich wieder an andere Zellen anzuheften (Makrilia et al., 2009). Hier stellt das E-Cadherin eines der zentralen Adhäsionsmoleküle dar, das von allen epithelialen Zellen exprimiert wird und für die Bildung von Zell-Zell-Kontakten unverzichtbar ist (Kemler, 1993; Hartsock \& Nelson, 2008). Eine verminderte Expression von E-Cadherin führt zum Verlust der Zell-Zell-Kontakte sowie zur Veränderung der Zellmorphologie und befähigt die Zellen somit zu invasivem Wachstum (Schmalhofer et al., 2009). Eine Vielzahl von Studien belegen, dass der Verlust von E-Cadherin mit Tumorprogression und Invasion verschiedener Karzinome, darunter auch das Mammakarzinom in Verbindung steht (Mareel et al., 1997; Berx \& Van Roy, 2001; Hajra \& Fearon, 2002; Hazan et al., 2004).

A Primärtumor

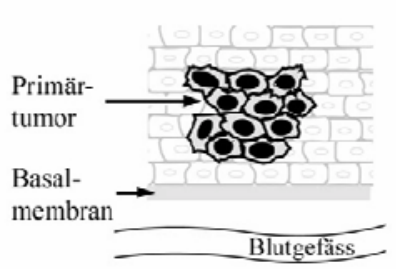

H Mikrometastasen
B Invasion

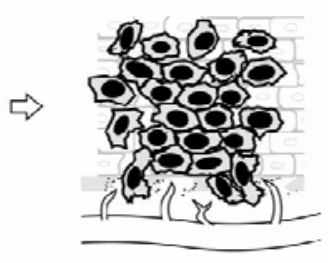

C Angiogenese

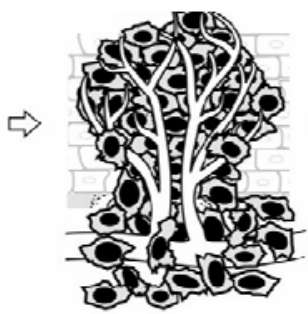

D Intravasation

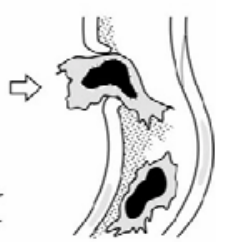

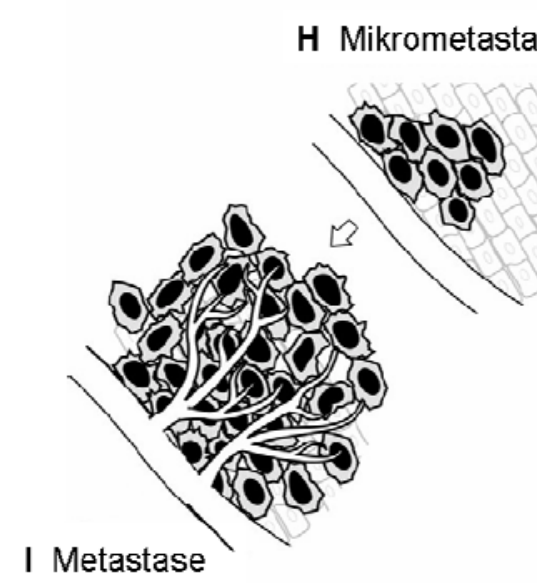
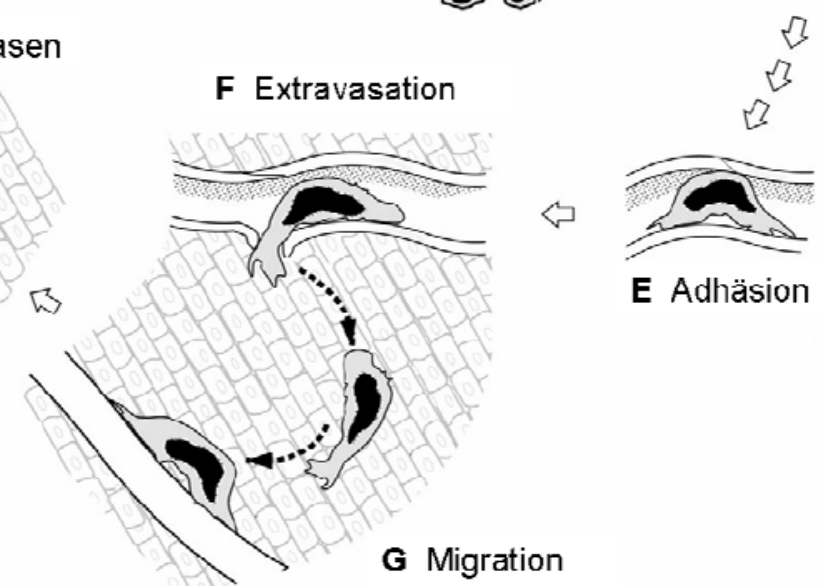

Abb. 1.1: Prozess der Metastasierung. Der Primärtumor $(A)$ besitzt die Fähigkeit zu invasivem Wachstum (B) sowie zur Bildung neuer Blutgefäße (C). Anschließend sind einzelne Zellen in der Lage durch die permeable Endothelschicht in Lymph- oder Blutkreislauf zu gelangen (D) und sich an die Endothelschicht anderer Organe zu heften (E). Nach erneutem Durchbruch der Gefäßwand (F) und der Fähigkeit zur Migration (G), kommt es zunächst zur Bildung von Mikrometastasen $(\mathrm{H})$, was letztlich zur Entstehung von sekundären Tochtergeschwülsten in entfernten Organen führt (I). (Zetter, 1998) 
Um die Barriere der Basalmembran zu durchqueren, müssen die Tumorzellen weiterhin in der Lage zum Abbau bzw. Umbau der extrazellulären Matrix (EZM) sein. In den Prozess der Proteolyse dieser EZM sind eine Reihe von Enzymen involviert, zu denen die Matrixmetalloproteinasen (MMP), Serinproteasen sowie die Cathepsine gehören. Dabei wird die effektive MMP-Aktivität vom Verhältnis der Menge an aktivierten MMP und vorhandenen freien Inhibitoren, den Tissue inhibitors of metalloproteinases (TIMP) bestimmt (Jiang et al., 2002; Chirco et al., 2006). Eine gestörte Balance von MMP und TIMP beeinflusst den invasiven Prozess. Unter den Cathepsinen stehen insbesondere die Cathepsine $B$ und $D$ in Zusammenhang mit Progressions- und Metastasierungsvorgängen (Koblinski et al., 2000; Berchem et al., 2002). Sie werden als Proenzyme synthetisiert und anschließend in ihre aktive Form umgewandelt.

Einen Einfluss auf Migration und Invasion von Tumorzellen zeigen ebenfalls die prometastatischen Faktoren S100A4 und CYR61. Das $\mathrm{Ca}^{2+}$-bindende Protein S100A4 korreliert bei verschiedenen Tumorerkrankungen mit einer schlechten Prognose sowie einem aggressiven Metastasierungsverhalten (Pedersen et al., 2002; Helfman et al., 2005; Ismail et al., 2008). Neben Migration und Invasion wurden im Zuge der Tumorprogression auch Effekte auf die Angiogenese sowie apoptotische Vorgänge beobachtet (Kim \& Helfman, 2003). CYR61 (cystein rich protein) gehört zur Familie der CCN-Proteine (nach den drei erstbeschriebenen Proteinen benannt). Es handelt sich dabei um multifunktionale, EZM-assoziierte Signalproteine, die Prozesse der Proliferation, Differenzierung, Adhäsion und Migration regulieren (Jiang et al., 2004; Leask \& Abraham, 2006).

\subsubsection{Metastasierung des primären Mammakarzinoms}

Das Metastasierungsverhalten verschiedener Karzinomerkrankungen zeigt ein sehr unterschiedliches Erscheinungsbild. Das Mammakarzinom neigt dabei zu einer stark ausgeprägten Metastasierung, die bereits zu einem frühen Zeitpunkt der Primärerkrankung einsetzen kann. Bei der Erstdiagnose werden bei ca. $7 \%$ der Patientinnen schon Fernmetastasen nachgewiesen (Sant et al., 2003). Das Mammakarzinom gilt nach heutigem Wissensstand in der metastasierten Form als nicht heilbar. 
Die Metastasierung des Mammakarzinoms erfolgt zunächst auf lymphogenem Weg, wobei der axilläre Lymphknotenstatus einen etablierten sowie wichtigen Prognosefaktor darstellt (Sunderland \& McGuire, 1990; Tobler \& Detmar, 2006; Quan \& McCready, 2009). Eine hämatogene Metastasierung kann gleichzeitig oder in Folge der Metastasierung über das Lymphsystem einsetzen. Dabei gilt der Knochen neben Lunge und Leber als einer der Hauptangriffsorte (Yoneda, 2000; Chambers et al., 2002; Weigelt et al., 2005). Knochenmetastasen lassen sich bei ca. $70 \%$ der Patientinnen mit einem metastasiertem Mammakarzinom nachweisen (Coleman, 1997; Suva et al., 2009). Ebenso können Haut (Krathen et al., 2003) und Gehirn (Wronski et al., 1997; Bai et al., 2010) von Metastasen des Mammakarzinoms befallen werden.

Es zeichnet sich somit wie auch bei einigen weiteren Tumorerkrankungen beim Mammakarzinom eine bevorzugte Metastasierung in bestimmte Organe ab. Die Metastasierung in die Lunge und Leber kann u.a. mit der hämodynamischen Theorie von Ewing (1928) erklärt werden. Die Tendenz der Metastasierung wird dabei von der organspezifischen Durchblutungsmenge abhängig gemacht. Für die vorwiegend knochenspezifische Metastasierung ist diese Hypothese jedoch eine nur ungenügende Erklärung. Hier kommt die bereits 1889 von Paget (1989) entwickelte „seed and soil“-Theorie zum tragen. Danach hängt das

Wachstum von Metastasen hauptsächlich von den Wechselwirkungen der Tumorzellen (seed) mit dem jeweiligen Organmilieu (soil) bzw. der Produktion bestimmter wachstumsfördernder oder wachstumsinhibierender Stoffe ab. Nur wenn sich Tumorzellen in einer Proliferations-geeigneten Umgebung befinden, kann dies zur Ausbildung klinisch relevanter Metastasen führen.

\subsubsection{Knochenmetastasen}

Das Mammakarzinom zählt zu den Karzinomen mit besonders starker Neigung zur Ausbildung ossärer Metastasen (Coleman, 1997). Neben Lunge und Leber stellen Metastasen im Knochen dabei die häufigste Metastasenlokalisation dar (Weigelt et al., 2005) und beeinflussen Lebensqualität sowie Lebenserwartung der betroffenen Patienten. Abhängig vom Verhältnis zwischen Knochenaufbau und Knochenabbau werden die Metastasen in osteolytisch, osteoblastisch und gemischtförmig unterschieden (Coleman, 1997; Steinborn et al., 2000; Kingsley 
et al., 2007). Die Knochenmetastasen des primären Mammakarzinoms können in allen drei Formen erscheinen, überwiegend kommt es jedoch zur Ausbildung von osteolytischen Metastasen, welche eine verstärkte Knochenresorption zur Folge haben (Kozlow \& Guise, 2005; Coleman, 2006). Bei diesem Vorgang sind die Mammakarzinomzellen nicht selbst dazu in der Lage, sondern vermitteln die Osteolyse über die Differenzierung und Aktivierung von Osteoklasten (Kakonen \& Mundy, 2003). Im Zuge der Knochenresorption sind insbesondere bestimmte proinflammatorische Zytokine sowie Wachstumsfaktoren (TNF- $\alpha$, TGF-ß, IGF-I, IGF-II, IL-1, IL-6) beteiligt, welche vorallem für die Interaktion von Osteoklasten und Osteoblasten, d.h. von entscheidender Bedeutung für die Homöostase des Knochenstoffwechsels sind (Miyamoto \& Suda, 2003; Yoneda \& Hiraga, 2005; Teitelbaum, 2007). Weitere für die Osteoklastogenese essentielle Zytokine sind der Receptor activator of NFKB ligand (RANKL) sowie der Macrophage colonystimulating factor (M-CSF), die u.a. von Zellen des Knochengewebes produziert werden. RANKL, ein der Tumornekrosefaktor(TNF)-Familie angehöriger Faktor, steigert durch die Bindung an seinen osteoklastären Rezeptor RANK die Anzahl, Differenzierung und Aktivität funktionsfähiger Osteoklasten (Hsu et al., 1999; Suda et al., 2001). Die Folge ist eine erhöhte Knochenresorption. Um das Gleichgewicht zwischen Knochenaufbau und Knochenabbau zu erhalten, wird von den Osteoblasten ein direkter regulativer Gegenspieler von RANKL, das so genannte Osteoprotegerin (OPG), produziert. Es handelt sich hierbei um einen löslichen Rezeptor, welcher in der Lage ist RANKL zu binden. Dadurch wird eine kompetitive Hemmung der RANK-Aktivierung ausgeübt (Simonet et al., 1997; Fili et al., 2009). Das RANKL/RANK/OPG-System ist somit ein zentrales molekulares Regulationssystem des Knochenstoffwechsels (siehe Abbildung 1.2).

Eine weitere bedeutende Rolle im Zuge der Knochenmetastasierung spielt das Parathormone-related protein (PTHrP). Es wird von Tumorzellen gebildet und stimuliert indirekt die Aktivität der Osteoklasten, indem es die Produktion von RANKL in Osteoblasten induziert (Kakonen \& Mundy, 2003). Eine Expression von PTHrP zeigt sich beim metastasierenden Mammakarzinom vorrangig in knochenspezifischen Metastasen und in anderen Metastasen nur zu geringem 
Anteil (Vargas et al., 1992). In der Knochenmatrix gespeicherte und während der Knochenresorption freigesetzte Wachstumsfaktoren sind wiederum in der Lage mit den Tumorzellen zu interagieren. So fördert die Sekretion von TGF-ß die Produktion von PTHrP in den Tumorzellen (Thomas et al., 1999; Steeg \& Theodorescu, 2008).

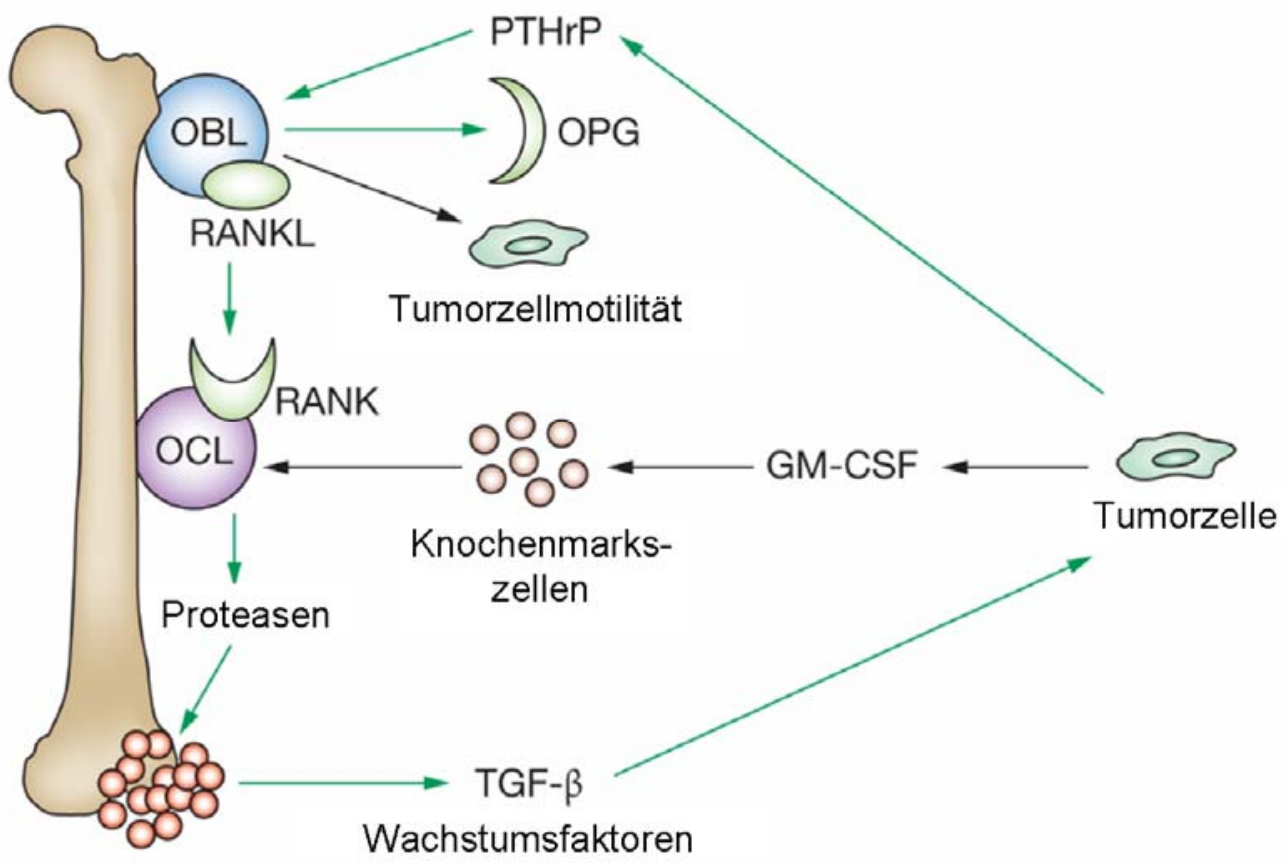

Abb. 1.2: Faktoren der Knochenmetastasierung. Tumorzellen produzieren PTHrP, das in der Lage ist an seinen osteoblastären Rezeptor (OBL - Osteoblasten) zu binden und die Synthese von RANKL stimuliert. Bindet RANKL wiederum an seinen Rezeptor RANK, der sich auf der osteoklastären Oberfläche (OCL - Osteoklasten) befindet, folgt eine Differenzierung und Aktivierung von Osteoklasten. Die Osteoklastogenese wird dabei vom RANKL/OPG-Verhältnis bestimmt, da OPG als neutraler löslicher Rezeptor die Wirkung von RANKL inhibieren kann. Die Knochenresorption führt zur Freisetzung von Wachstumsfaktoren wie TGF-ß, welches Tumorzellen zur Produktion von PTHrP anregt. RANKL ist ebenfalls in der Lage die Tumorzellmotilität zu beeinflussen. GMCSF wird von Tumorzellen gebildet und stimuliert Zellen des Knochenmarks zu einer verstärkten Osteoklastensynthese. (Steeg \& Theodorescu, 2008)

\subsubsection{Zirkulierende Tumorzellen}

Das Auftreten disseminierter Tumorzellen (DTZ) im Knochenmark ist mit einer schlechteren Prognose des Mammakarzinoms verbunden, steht aber aufgrund der langen Überlebenszeiten der DTZ nicht in direktem Zusammenhang mit dem Krankheitsverlauf (Diel et al., 1996; Braun et al., 2005). Im Gegensatz dazu stellt der Nachweis zirkulierender Tumorzellen (CTC, circulating tumor 
cells) im Blut einen wichtigen Indikator für ein erhöhtes Metastasierungsrisiko dar, welcher neben der prognostischen Beurteilung auch eine Aussage über den Therapieverlauf sowie eine frühzeitige Diagnostik ermöglicht (Maheswaran \& Haber, 2010). Die Detektion von CTC im Blut bietet einen weiteren Vorteil, da es sich um eine minimal-invasive Methode handelt. Aufgrund einer Vielzahl von uneinheitlichen Testmethoden und der dabei häufig fehlenden Sensitivität sowie Spezifität, ist der Nachweis von CTC im Blut bisher als Standardmethode noch nicht etabliert (Ross \& Slodkowska, 2009).

Neben unterschiedlichen Methoden wie dem immunozytochemischen Nachweis spezifischer tumorassoziierter Proteine, rückt die PCR-Technik immer mehr in den Blickpunkt dieses Forschungsgebiets und wurde in den letzten Jahren auf vielfältige Weise weiterentwickelt. In vielen Studien wurde die Bedeutung der PCR-Methode für die Detektion von CTC im Blut belegt. Die Identifizierung von CTC im Blut von Mammakarzinompatientinnen stellte dabei einen wichtigen Faktor der Therapieentscheidung dar und konnte mit einer schlechten Prognose in Verbindung gebracht werden (Stathopoulou et al., 2002; Xenidis et al., 2003; Giatromanolaki et al., 2004). Neben der semiquantitativen Analyse mittels einer PCR-Endpunktbestimmung wird der zunehmende Einsatz der Real-time PCRTechnik sichtbar. Hierbei wird die Fluoreszenzstärke der Amplifikation von DNA oder RNA bereits während des Verfahrens detektiert und im Vergleich zur RTPCR das Risiko von Kontaminationen verringert. Die kontinuierliche Messung des Amplifikationssignals ermöglicht zudem positive abnormale Kurvenverläufe zu identifizieren und somit falsch-positive Befunde auszuschließen (Guller et al., 2002). Aufgrund der Heterogenität des Mammakarzinoms ist die Bestimmung eines Einzelgens als spezifischer universal einsetzbarer Tumormarker zudem schwierig. Auch hier zeigt sich die Anwendung der Real-time PCR Methode als vorteilhaft, da eine multiple Detektion innerhalb eines Probengutes durchgeführt werden kann und eine höhere Effektivität erreicht wird (Gilbey et al., 2004).

\subsubsection{Therapie des metastasierten Mammakarzinoms}

Patientinnen mit einem metastasierten Mammakarzinoms sind mit den heutigen therapeutischen Mitteln nicht kurativ therapierbar. Die palliative Therapie wird auf die individuellen Situationen der Erkrankten abgestimmt. Auch hier 
umfasst die derzeitige Behandlung neben chirurgischen Verfahren vorallem die Strahlenbehandlung oder verschiedene Chemotherapien sowie eine endokrine Therapie bzw. die Kombination mehrerer unterschiedlicher Maßnahmen. Für die endokrine Therapie empfehlen sich bei positivem Hormonrezeptorstatus dabei vergleichbare Maßnahmen wie beim primären Mammakarzinom (siehe Kapitel 1.1.2). Im Vordergrund der Behandlung steht es Schmerzen zu lindern, die körperliche Leistungsfähigkeit zu erhalten und im Fall von Metastasen im Knochen Frakturen zu vermeiden. Bei einem Auftreten von Knochenmetastasen werden zusätzlich Bisphosphonate verabreicht (Kohno, 2008). Es handelt sich hierbei um stabile chemische Analoga des Pyrophosphats, welche eine hohe Bindungsaffinität zum Kalziumphosphat besitzen und die Bildung, Aggregation sowie Auflösung von Kristallen des Kalziumphosphats im Knochen hemmen (Fleisch, 2002). Sie werden bei hyperkalzämischen Krisen eingesetzt und reduzieren bei regelmäßiger Anwendung das Auftreten neuer Metastasenbedingter Frakturen, besitzen aber auch direkte antitumorale Eigenschaften (Brown et al., 2004; Neville-Webbe et al., 2010). Die Hyperkalzämie tritt besonders im fortgeschrittenen Stadium einer Knochenmetastasierung auf und wird durch die vermehrte Osteoklastentätigkeit bedingt. Bisphosphonate sind beim metastasierten Mammakarzinom mit weiteren Therapiemaßnahmen gut kombinierbar.

Trotz moderner Therapieoptionen ist die Metastasierung des Mammakarzinoms in ferne Organe mit einer deutlich reduzierten Lebenserwartung der Erkrankten verbunden und bedarf eingehender wissenschaftlicher Forschung.

\subsection{Gonadotropin-Releasing Hormon-I und -II}

\subsubsection{GnRH-I}

Das Gonadotropin-Releasing Hormon ( $\mathrm{GnRH})$ ist ein Neuropeptidhormon, das im Hypothalamus gebildet wird und eine bedeutende Schlüsselrolle in der Regulation reproduktiver Prozesse einnimmt. Es handelt sich hierbei um ein Dekapeptid (siehe Tabelle 1.1), dessen Isolierung sowie Charakterisierung erstmals im Jahr 1971 durch die Forschungsarbeiten von Andrew V. Schally 
und Roger Guillemin erfolgte (Amoss et al., 1971; Schally et al., 1971). Beide wurden 1977 für ihre „Entdeckungen über die Produktion von Peptidhormonen im Gehirn“ mit dem Nobelpreis für Medizin ausgezeichnet. Das Hormon wurde zunächst als Luteinisierendes Hormon-Releasing Hormon (LHRH) bezeichnet, bis nachgewiesen wurde, dass es neben dem Luteinisierenden Hormon (LH) auch für die Sekretion des Follikelstimulierenden Hormons (FSH) verantwortlich ist. Da bis heute weitere Isoformen des $\mathrm{GnRH}$ beschrieben sind, wurde die ursprünglich entdeckte Form als $\mathrm{GnRH}-\mathrm{I}$ bezeichnet.

$\mathrm{GnRH}-\mathrm{I}$ wird in pulsatiler Form im Abstand von Minuten bis wenigen Stunden aus den sekretorischen Vesikeln der Neurone des Hypothalamus (Nucleus arcuatus) in das hypothalamisch-hypophysäre Portalvenensystem sezerniert (Marshall et al., 1993; Ferris \& Shupnik, 2006; Krsmanovic et al., 2009). Über das Portalvenensystem gelangt das Hormon zum Hypophysenvorderlappen und bindet dort spezifisch an membranständige Rezeptoren der gonadotropen Zellen (GnRH-I Rezeptoren). Durch die Bindung an seine Rezeptoren reguliert $\mathrm{GnRH}-\mathrm{I}$ die Produktion und Sekretion der beiden Gonadotropine LH und FSH. Über den Blutkreislauf erreichen LH und FSH die Ovarien, wo sie die Synthese der Steroidhormone (Östrogen, Progesteron) stimulieren und die Follikelreifung steuern. Die Regulation der Hypothalamus-Hypophysen-Gonaden-Achse erfolgt durch spezielle Rückkopplungsmechanismen (Reissmann et al., 1995; Shupnik, 1996).

\subsubsection{GnRH-I Rezeptor}

Der humane GnRH-I Rezeptor wurde erstmals im Jahr 1992 von Kakar et al. (1992) kloniert und sequenziert. Es handelt sich hierbei um einen G-Proteingekoppelten Rezeptor (GPCR, G-protein-coupled receptor). Dieser besteht aus 328 AS. Das GnRH-I Rezeptor-Gen ist auf Chromosom vier lokalisiert und setzt sich aus drei Exons und zwei Introns zusammen.

GPRC gehören zur Familie der Sieben-Transmembran-Rezeptoren (7-TMR), bei denen die sieben Transmembrandomänen durch alternierende intra- und extrazellulär verlaufende Peptidschleifen untereinander verbunden sind (siehe Abbildung 1.3). 

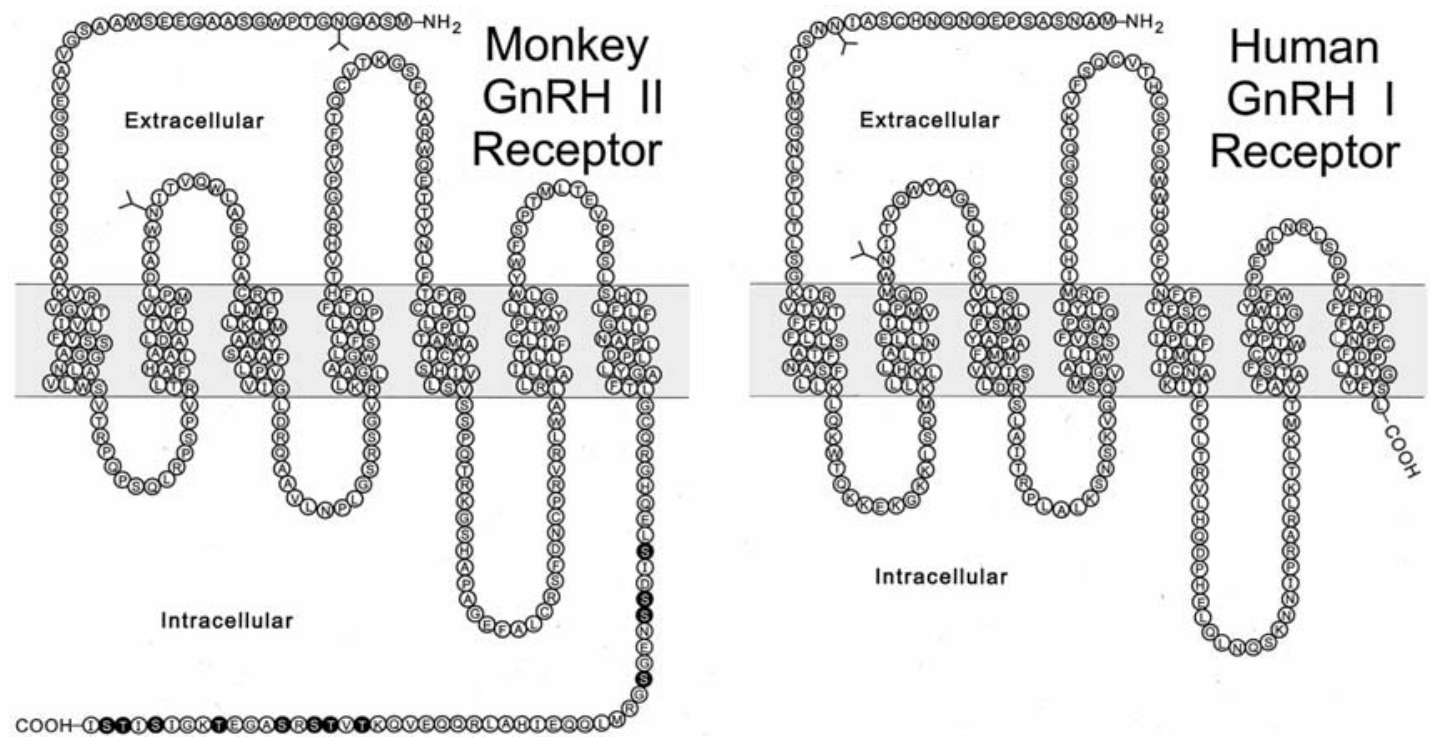

Abb. 1.3: Struktur des humanen GnRH-I Rezeptors (rechts) und des GnRH-II Rezeptors beim Affen (links). Glykosilierungsschnittstellen wurden mit (Y) gekennzeichnet und Phosphorylierungsmöglichkeiten an den AS Serin und Threonin im zytoplasmatischen Schwanz sind schwarz hinterlegt (Neill, 2002).

Der glykosilierte Aminoterminus des GnRH-I Rezeptors liegt extrazellulär an der ersten Transmembrandomäne, während der zytoplasmatische Carboxyterminus hingegen intrazellulär an der siebten Transmembrandomäne lokalisiert und in der Membran verankert ist. Ein für GPRC charakteristischer intrazellulärer Cterminaler Anhang fehlt dem GnRH-I Rezeptor und macht inn zur Besonderheit unter den GPRC (Stojilkovic et al., 1994; Okubo et al., 2001). Hierbei stellen die zweite sowie die dritte intrazelluläre Peptidschleife die Verknüpfung mit den GProteinen her (Millar et al., 2004). Das N-terminale Ende des GnRH-I Rezeptors ist für die Rezeptoraktivierung verantwortlich (Sealfon et al., 1997; Millar et al., 2004). Durch die Bindung von GnRH-I wird der Rezeptor dimerisiert, der GnRH Rezeptorkomplex internalisiert und so eine Kaskade intrazellulärer Reaktionen ausgelöst, an deren Ende die Freisetzung der Gonadotropine steht (Shapiro, 2003). Dabei ist eine Internalisierung jedoch keine essentielle Voraussetzung für die Sekretion von LH und FSH (Hopkins \& Gregory, 1977). Die Signale des GnRH-I Rezeptors werden charakteristisch für GPCR über Guanosintriphosphat (GTP)-bindende Proteine ins Zellinnere weitergeleitet. 


\subsubsection{Signaltransduktion in der Hypophyse}

Für die Zellantwort im hypophysären Gewebe ist im Fall des GnRH-I Rezeptors die Erhöhung des intrazellulären $\mathrm{Ca}^{2+}$-Spiegels verantwortlich, welche über eine Kaskade von mehreren Reaktionsschritten ausgelöst wird (Naor, 1990). Durch die spezifische Bindung von GnRH-I an seinen Rezeptor kommt es zunächst zu einer Konformationsänderung der Rezeptoranteile, die eine Interaktion mit den assoziierten G-Proteinen ermöglicht. In der Hypophyse werden G-Proteine der $\mathrm{G}_{\mathrm{q} / 11}$-Familie aktiviert, das anschließend über die Effekte der Phospholipase C (PLC) in einer $\mathrm{Ca}^{2+}$-abhängigen Signaltransduktion resultiert (Cheng \& Leung, 2000; Naor, 2009). Nach der primären Aktivierung der PLC hydrolysiert diese das an die Membran gebundene Inositol-Phospholipid Phosphatidylinositol-4,5Biphosphat (PIP2). Aus der Hydrolyse gehen die Second messenger-Moleküle Diazylglycerol (DAG) und Inositol-1,4,5-Triphosphat (IP3) hervor. Das IP3 ist in der Lage anschließend an die Oberfläche des Endoplasmatischen Retikulums (ER) zu diffundieren und bindet dort an IP3-spezifische Rezeptoren. Hierdurch wird die Freisetzung der intrazellulären $\mathrm{Ca}^{2+}$-Ionen und ein damit verbundener zytosolischer $\mathrm{Ca}^{2+}$-Anstieg bewirkt (Keizer et al., 1995; Shuttleworth, 1997). DAG bleibt währenddessen membrangebunden und aktiviert $\mathrm{Ca}^{2+}$-abhängig die Proteinkinase C (PKC). Als Serin/Threonin-Kinase führt die PKC wiederum zur Phosphorylierung verschiedener zytoplasmatischer und nukleärer Proteine und zur Aktivierung von Transkriptionsfaktoren. Die Signaltransduktion des GnRH-I Rezeptors resultiert dabei in einer Aktivierung mitogenaktivierter Proteinkinasen (MAPK) (Harris et al., 2002; Zhang \& Roberson, 2006). Die MAPK steuern die Genexpression auf Transkriptionsebene und regulieren auf diesem Weg die Zellantwort. Zusätzlich zur Synthese der Gonadotropine LH und FSH sind die MAPK an der Expression des GnRH-I Rezeptors beteiligt. So wird die Synthese sowie Sekretion der Gonadotropine durch die Regulation der Expressionsdichte des $\mathrm{GnRH}-\mathrm{I}$ Rezeptors in den gonadotropen Zellen gesteuert.

\subsubsection{Signaltransduktion in gynäkologischen Tumoren}

Neben den physiologischen Bindungsstellen in den gonadotropen Zellen der Hypohyse wurde das GnRH-I Rezeptorsystem ebenfalls in einer Reihe von 
extrahypophysären reproduktiven Geweben wie der Plazenta (Bramley et al., 1992) und dem Myometrium (Chegini et al., 1996) entdeckt. Eine Expression des GnRH-I Rezeptorsystems konnte ebenfalls in mehreren gynäkologischen Tumoren nachgewiesen werden. So zeigen sich ca. 80 \% der humanen Ovarialund Endometriumkarzinome sowie ca. $50 \%$ der Mammakarzinome positiv für GnRH-I und seinen Rezeptor (Irmer et al., 1994; Emons et al., 1997; Mangia et al., 2002; Völker et al., 2002). Dabei stimmt die Sequenz des GnRH-I Rezeptors in den gynäkologischen Tumoren mit der Sequenz des GnRH-I Rezeptors in der Hypophyse überein (Kakar et al., 1994). Aus diesem Grund wurde zunächst angenommen, dass der Signaltransduktionsweg in den Tumoren mit dem der Hypophyse einher geht. Es zeigte sich jedoch, dass die Signaltransduktion des hypophysären GnRH-I Rezeptors in gynäkologischen Tumoren nicht durch GnRH-I aktiviert wird (Emons et al., 1996). Der GnRH-I Rezeptor interagiert hier mit der mitogenen Signaltransduktion, indem vermittelt über das G-Protein $\alpha_{i}$ die Phosphotyrosinphosphatase (PTP) aktiviert und anschließend die TyrosinAutophosphorylierung von Wachstumsfaktorrezeptoren inhibiert wird (Emons et al., 1997; Gründker et al., 2001b). Durch Arbeiten von Gründker et al. (2000b) konnte in diesem Zusammenhang nachwiesen werden, dass die epidermal growth factor (EGF)-induzierte Aktivierung der MAPK/ERK durch GnRH-I sowie $\mathrm{GnRH}-\mathrm{I}$ Analoga gehemmt wird, das in einer Inhibition des Transkriptionsfaktors c-fos resultiert. Zusätzlich erfolgt eine Aktivierung von nuclear factor kappa $B$ (NFKB), die den Tumorzellen Schutz vor Zytostatika-induzierter Apoptose bietet (Gründker et al., 2000a; Fister et al., 2008). Ebenso werden gleichzeitig der Transkriptionsfaktor c-jun sowie das Aktivator-Protein 1 (AP-1) aktiviert und auf diesem Weg der Zellzyklus gehemmt (Gründker et al., 2001a). Die einzelnen Signaltransduktionswege des $\mathrm{GnRH}$-I Rezeptors in gynäkologischen Tumoren sind in Abbildung 1.4 dargestellt. 


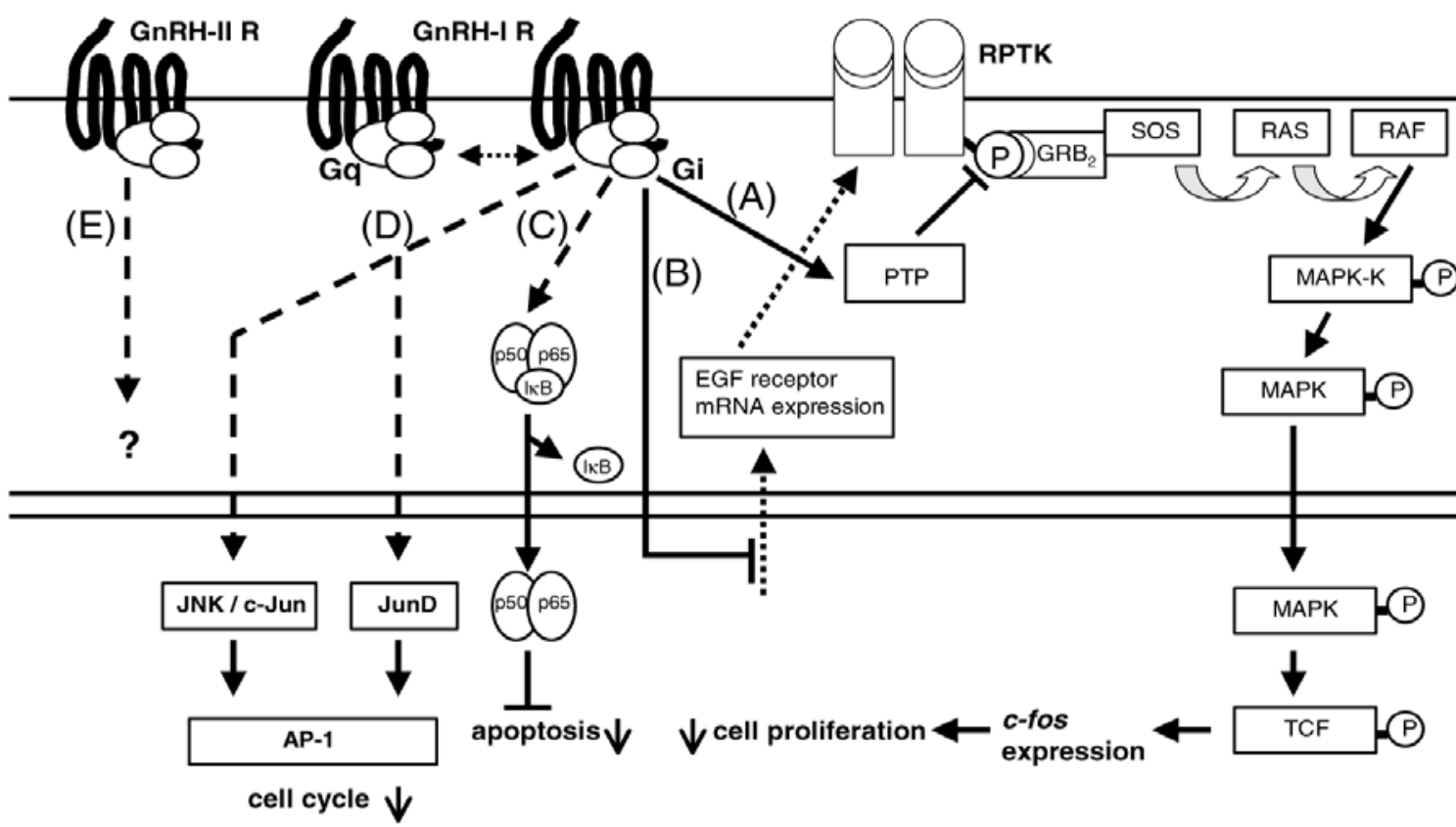

Abb. 1.4: Signaltransduktion des GnRH-I Rezeptors in gynäkologischen Tumoren. GnRH-I aktiviert vermittelt über das G-Protein $\alpha_{i}$ die PTP und inhibiert auf diesem Weg die Autophosphorylierung von Wachstumsfaktorrezeptoren mit folgender Hemmung der Zellproliferation (A). Zusätzlich findet die Down-Regulation der mRNA-Expression des EGF Rezeptors statt (B). Durch die Induktion von NFkB werden die Zellen vor einer Zytostatika-induzierten Apoptose geschützt $(C)$. Über die Aktivierung von $c$-Jun und AP-1 wird eine Hemmung des Zellzyklus erreicht (D). Die Signaltransduktion des $\mathrm{GnRH}-\mathrm{II}$ Rezeptors entspricht der des $\mathrm{GnRH}-\mathrm{I}$ Rezeptors, indem die Zellproliferation ebenfalls durch die Aktivierung der PTP inhibiert wird (Eicke et al., 2006) (E). (Emons et al., 2003)

\subsubsection{GnRH-II}

\subsubsection{Struktur und Bedeutung}

Neben dem ursprünglichen $\mathrm{GnRH}(\mathrm{LHRH}, \mathrm{GnRH}-\mathrm{I})$ sind weitere Isoformen des GnRH bekannt. Die Struktur von GnRH-II wurde im Menschen erstmals 1998 beschrieben (White et al., 1998). Da GnRH-Il zuvor bereits im Hypothalamus des Huhns entdeckt wurde (Miyamoto et al., 1984), wird es auch als Chicken $\mathrm{GnRH}-\mathrm{Il}$ bezeichnet. Beim $\mathrm{GnRH}-\mathrm{Il}$ handelt es sich ebenfalls um ein Dekapeptid (siehe Tabelle 1.1), dessen AS-Sequenz sich zu $70 \%$ homolog zum GnRH-I zeigt ([His $\left.\left.{ }^{5}, \operatorname{Trp}^{7}, \mathrm{Tyr}^{8}\right] \mathrm{GnRH}-\mathrm{I}\right)$ (Chen et al., 1998; White et al., 1998). Diese starke Homologie lässt annehmen, dass $\mathrm{GnRH}-\mathrm{Il}$ durch Genduplikation von $\mathrm{GnRH}-\mathrm{I}$ entstanden ist. 
Tab. 1.1: Aminosäuresequenz der Dekapeptide GnRH-I und GnRH-Il. Unterschiede in der Aminosäuresequenz sind als „fett" markiert.

\begin{tabular}{|l|l|l|l|l|l|l|l|l|l|l|}
\hline AS-Position & 1 & 2 & 3 & 4 & 5 & 6 & 7 & 8 & 9 & 10 \\
\hline GnRH-I & pGlu & His & Trp & Ser & Tyr & Gly & Leu & Arg & Pro & Gly-NH \\
\hline GnRH-II & pGlu & His & Trp & Ser & His & Gly & Trp & Tyr & Pro & Gly-NH \\
\hline
\end{tabular}

Die vom Fisch bis zum Säugetier hochkonservierte Struktur von GnRH-Il deutet auf eine wichtige physiologische Funktion dieses Hormons hin, die jedoch bis heute nicht vollständig aufgeklärt werden konnte (Gault et al., 2003). Da GnRHII im Menschen bereits in unterschiedlichen Geweben nachgewiesen wurde, führt dies zu der Annahme, dass $\mathrm{GnRH}-\mathrm{Il}$ nicht nur in der Reproduktion eine Rolle spielt, sondern an vielen weiteren physiologischen Prozessen beteiligt ist (Kaufmann et al., 1991).

\subsubsection{GnRH-II Rezeptor}

Der GnRH-Il Rezeptor konnte bisher nur bis zu den Primaten beschrieben und lokalisiert werden. Im Jahr 2001 erfolgte die Charakterisierung zeitgleich durch Millar et al. (2001) im Weißbüschelaffen (Callithrix jacchus) sowie durch Neill et al. (2001) im Rhesusaffen (Macaca mulatta). Im Gegensatz zum Rezeptor des $\mathrm{GnRH}-\mathrm{I}$ besitzt der GnRH-II Rezeptor einen C-terminalen zytoplasmatischen Schwanz, der nach Phosphorylierung zu einer schnelleren Internalisierung des Rezeptors führt (siehe Abbildung 1.3). Das GnRH-II Rezeptor-Gen befindet sich hierbei auf Chromosom eins, besteht wie das GnRH-I Rezeptor-Gen aus drei Exons und zwei Introns und kodiert für ein Protein aus 379 AS.

Ein vollständiges humanes Transkript des GnRH-II Rezeptors konnte bis heute noch nicht nachgewiesen werden. Die Identifikation wird durch die Existenz eines Stopcodons im zweiten Exon sowie einer Frameshift-Mutation zwischen der neunten und zehnten AS erschwert (Neill et al., 2001; Millar, 2003). Dabei wird vermutet, dass der funktionsfähige $\mathrm{GnRH}-\mathrm{Il}$ Rezeptor in unterschiedlichen Splice-Varianten exprimiert wird oder lediglich als Fünf-Membran-Rezeptor (5TMR) aktiv ist (Neill, 2002; Neill et al., 2004). Der Nachweis eines zusätzlichen 5-TMR-Typs des GnRH-II beim Schwein, der durch alternatives Splicen von Exon 1 entsteht, unterstützt diese Hypothese (Neill et al., 2004). Dieser 5-TMR 
ist durch einen vollständigen Verlust der ersten beiden Transmembrandomänen gekennzeichnet, wobei der extrazelluläre Aminoterminus direkt mit der dritten Transmembrandomäne verknüpft ist.

Die mRNA-Expression des putativen GnRH-II Rezeptors findet in einer Vielzahl von menschlichen Geweben statt, wobei davon ausgegangen wird, dass es sich hierbei um unvollständige GnRH-II Rezeptor-Transkripte handelt (Neill, 2002). Ein humanes $\mathrm{GnRH}-\mathrm{Il}$ Rezeptor-ähnliches Protein, dessen Molekulargewicht (43 kDa) auf einen 5-TMR hinweist, wurde sowohl in der Plazenta als auch in gynäkologischen Tumoren nachgewiesen (Eicke et al., 2005).

In humanen Endometrium- und Ovarialkarzinomzellinien wird die Proliferation durch das native $\mathrm{GnRH}-$ Il zeit- sowie dosisabhängig gehemmt (Gründker et al., 2002). Knock-Down Versuche am GnRH-I Rezeptor konnten zeigen, dass nach dem GnRH-I Rezeptor Knock-Down die proliferationshemmenden Effekte von $\mathrm{GnRH}-I I$ in den Karzinomzelllinien erhalten bleiben, während die Wirkung des GnRH-I Agonisten Triptorelin verloren geht (Gründker et al., 2004). Diese Daten stützen die Vermutung, dass in gynäkologischen Tumoren neben dem GnRH-I Rezeptorsystem auch ein GnRH-Il Rezeptorsystem existiert. Hierbei entspricht die Signaltransduktion des GnRH-II Rezeptors der des GnRH-I Rezeptors, da nach Bindung von GnRH-II an seinen Rezeptor ebenfalls eine Hemmung der EGF-induzierten Wachstumsfaktorsignalkaskade erfolgt (Eicke et al., 2006).

\subsubsection{GnRH Analoga}

\subsubsection{Agonisten und Antagonisten}

Seit der Entdeckung des ursprünglichen GnRH 1971 wurde mit der Entwicklung unterschiedlicher GnRH Analoga begonnen, mit dem hauptsächlichen Ziel die Hypothalamus-Hypophysen-Gonaden-Achse therapeutisch zu beeinflussen. Die Modifizierung des $\mathrm{GnRH}$ Moleküls zog die erwünschte höhere Bindungsaffinität zum Rezeptor nach sich und verhinderte den rasch eintretenden enzymatischen Abbau des modifizierten Moleküls (Koch et al., 1977). Die Analoga des GnRH-I zeichnen sich dabei im Vergleich zum nativen Protein durch mindestens eine Aminosäuresubstitution aus (siehe Abbildung 1.5). Je nach Anzahl und Position der Substitution handelt es sich um einen Agonisten oder einen Antagonisten. 
Bei GnRH-I Agonisten findet eine Aminosäuresubstitution an Position sechs des Dekapeptids statt. Diese Substitution führt zur Stabilisierung der Tertiärstruktur sowie einer verstärkten Bindungsaffinität zum Rezeptor (Kenakin, 1995; Sealfon et al., 1997). Weiterhin führt der Austausch zu D-Aminosäuren zu einer deutlich erhöhten Halbwertszeit, die beim nativen Hormon nur wenige Minuten beträgt und damit ausgesprochen kurz ist. Die kontinuierliche Verabreichung von GnRH Agonisten führt anfänglich zu einem Flare up-Effekt, d.h. zu einem plötzlichen Anstieg der LH/FSH-Sekretion (Limonta et al., 2001; Hayden, 2008). Nach dem Sekretionsanstieg in der initialen Phase kommt es durch Down-Regulation der Rezeptoren zur Desensibilisierung in den gonadotropen Zellen der Hypophyse. Die Synthese der Steroidhormone wird folglich gestoppt. GnRH-I Agonisten wie z.B. Triptorelin ([D-Trp $\left.\left.{ }^{6}\right] \mathrm{GnRH}-\mathrm{I}\right)$, Nafarelin ([D-2Nal $\left.\left.{ }^{6}\right] \mathrm{GnRH}-\mathrm{I}\right)$, Buserelin ([D-Ser $(\mathrm{tBu})^{6}$, Gly-NHEt $\left.\left.{ }^{10}\right] \mathrm{GnRH}-\mathrm{I}\right)$ sowie Goserelin ([D-Ser(tBu) ${ }^{6}$, Azagly- $\left.\mathrm{NH}_{2}{ }^{10}\right] \mathrm{GnRH}-$ I) haben sich in der Verwendung als Pharmazeutika bereits bewährt und finden neben einigen weiteren $\mathrm{GnRH}-\mathrm{I}$ Agonisten ein breites Anwendungsspektrum in der Klinik.

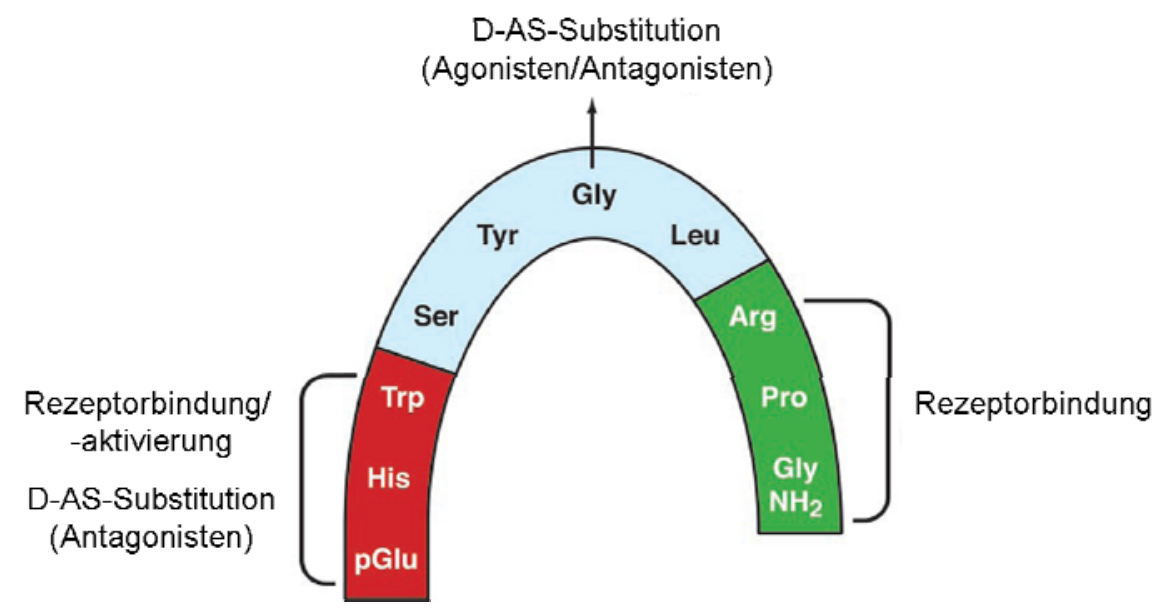

Abb. 1.5: Aminosäuresubstitutionen des nativen GnRH-I. Je nach Position führt eine D-ASSubstitution zu einer Erhöhung der Rezeptorbindung sowie Rezeptoraktivierung und einer Steigerung der Stabilität sowie der Aktivität des modifizierten GnRH-I Moleküls (Millar et al., 2004).

Parallel zur Einführung der GnRH-I Agonisten wurde das native GnRH Molekül auch an weiteren AS-Positionen modifiziert und eine Entwicklung von GnRH-I Antagonisten (siehe Abbildung 1.5) begonnen. Hierbei erfolgte ein zusätzlicher 
AS-Austausch an den Positionen eins bis drei sowie an Position zehn, die eine essentielle Bedeutung für die Rezeptoraffinität und dessen Aktivierung besitzen. Durch den Einsatz von nicht-natürlichen D-Aminosäuren wird außerdem die Stabilität des modifizierten GnRH Moleküls deutlich erhöht. Im Gegensatz zu den $\mathrm{GnRH}$ Agonisten verursachen $\mathrm{GnRH}$ Antagonisten keine vorübergehende Stimulation der gonadotropen Zellen und führen zu einer umgehenden Inhibition der LH/FSH-Sekretion (Murase et al., 2005). GnRH Antagonisten konkurrieren somit als kompetitive Inhibitoren mit dem nativen $\mathrm{GnRH}$ und verhindern die Aktivierung der G-Proteine und die damit verbundene Signaltransduktion. Der fehlende Flare up-Effekt bietet einen eindeutigen Vorteil der Antagonisten, da die Wirkung sofort (8 - $24 \mathrm{~h}$ ) einsetzt und nicht wie bei den Agonisten eine Vorlaufzeit von ungefähr zehn bis zwanzig Tagen benötigt wird (Weckermann \& Harzmann, 2004). Die Einführung der GnRH-I Antagonisten nahm jedoch einen wesentlich längeren Zeitraum in Anspruch. Cetrorelix ([D-2Nal ${ }^{1}, \mathrm{D}-4 \mathrm{Cpa}^{2}, \mathrm{D}-$ $3 \mathrm{Pal}^{3}, \mathrm{D}-\mathrm{Cit}^{6}$, D-Ala- $\left.\mathrm{NH}_{2}{ }^{10} \mathrm{G} \mathrm{GnRH}-\mathrm{I}\right)$, der erste GnRH-I Antagonist wurde im Jahr 1999 zugelassen. Während GnRH-I Antagonisten der ersten Generation zu starken Nebenwirkungen wie dem Auftreten von Ödemen oder einer Anaphylaxie durch Histaminfreisetzung führten, sind Antagonisten der neueren Generation weitgehend frei von Nebenwirkungen und gut tolerabel (Reissmann et al., 1996).

Im Gegensatz zu den GnRH-I Analoga befinden sich GnRH-Il Analoga in der Verwendung als Pharmazeutika noch in verschiedenen Entwicklungsstadien. Die Modifizierung des GnRH-II Moleküls wird aufgrund der starken Homologie äquivalent zu den strukturellen Veränderungen des nativen $\mathrm{GnRH}$-I Moleküls vorgenommen.

\subsubsection{Einsatz in der Gynäkologie und Geburtshilfe}

Mit der Entdeckung des nativen $\mathrm{GnRH}$ und der Entwicklung unterschiedlicher Analoga ergab sich die Möglichkeit, die Hypothalamus-Hypophysen-GonadenAchse therapeutisch zu beeinflussen. Durch die physiologisch pulsatile Gabe von GnRH wurde auf diesem Weg eine Stimulation der Gonaden bei Infertilität erreicht (Reissmann et al., 1995). Auch die Behandlung weiterer Erkrankungen des reproduktiven Systems, wie der hypothalamischen Amenorrhoe sowie des 
polyzystischen Ovarsyndroms wurde ermöglicht. GnRH-I Analoga finden dabei gegenüber dem nativen $\mathrm{GnRH}$ aufgrund der erhöhten Stabilität sowie Affinität zum Rezeptor ein breites Anwendungsfeld. Der Einsatz von GnRH-I Analoga findet vorallem in der Behandlung der frühzeitigen Pubertät (Pubertas praecox) im Kinder- oder Jugendalter (Roth, 2002) sowie der kontrollierten ovariellen Hyperstimulation statt, die als Voraussetzung für eine in vitro-Fertilisation (IVF) im Rahmen der Sterilitätsbehandlung gilt (Griesinger et al., 2005). Des Weiteren wird durch eine kontinuierliche Verabreichung von GnRH-I Analoga während der Chemotherapie bei prämenopausalen Frauen eine Desensibilisierung in der Hypophyse erreicht, die zu einer reversiblen medikamentösen Kastration führt und somit zur Gonadenprotektion beiträgt (Clowse et al., 2009).

Da sich eine Expression von GnRH-I Rezeptoren ebenfalls in gynäkologischen Tumoren nachweisen lässt, sind GnRH Analoga auch für die Krebstherapie von großer Bedeutung. Ein Einsatz zeigt sich bereits bei steroidhormonabhängigen Erkrankungen, wie dem Mamma-, Ovarial- und Endometriumkarzinom (Emons et al., 2003). GnRH-I Analoga werden ebenfalls in der endokrinen Therapie des androgenabhängigen Prostatakarzinoms beim Mann eingesetzt, da auch hier die Steroidhormonsynthese gehemmt wird (Damber, 2005).

Die Nebenwirkungen der endokrinen Therapie mit GnRH Analoga sind primär Folge eines hervorgerufenen Östrogenmangels. So setzt bei prämenopausalen Patientinnen eine künstliche Menopause mit den damit verbundenen typischen Beschwerden ein. Länger andauernde Behandlungen können sich zudem sehr ungünstig auf die Knochendichte auswirken, so dass Gefahr einer Osteoporose besteht (Khan \& Khan, 2008).

\subsubsection{Effekte auf die Metastasierung in vitro}

Da sich eine Expression von GnRH Rezeptoren in gynäkologischen Tumoren nachweisen lässt, werden die Wirkungen von GnRH Analoga auf verschiedene Ovarial-, Endometrium- sowie Mammakarzinomzelllinien in den letzten Jahren untersucht. Zunächst wurde gezeigt, dass diese für GnRH Rezeptoren positiven Zelllinien in ihrer Proliferation zeit- sowie dosisabhängig durch GnRH-I Analoga gehemmt werden. Dies konnte für den GnRH-I Agonisten Triptorelin bereits in einer Konzentration von $1 \mathrm{nM}$ beobachtet werden (Emons et al., 1993a; Emons 
et al., 1993b; Völker et al., 2002). Vergleichbare Effekte wurden für den GnRH-I Antagonisten Cetrorelix ermittelt (Segal-Abramson et al., 1992; Gründker et al., 2004; Castellon et al., 2006). Durch das native GnRH-Il konnten noch stärkere antiproliferative Wirkungen in gynäkologischen Tumoren nachgewiesen werden (Gründker et al., 2002). Eicke et al. (2006) zeigten in diesem Zusammenhang, dass GnRH-Il nicht über den GnRH-I Rezeptor reguliert wird, da der GnRH-II Agonist [D-Lys $\left.{ }^{6}\right] \mathrm{GnRH}-$ Il seine wachstumsinhibierenden Wirkungen in GnRH-II Rezeptor-negativen Zelllinien verliert. Der $\mathrm{GnRH}-\mathrm{I}$ Antagonist Cetrorelix zeigt hingegen auch nach Knock down des GnRH-I Rezeptors Effekte und wirkt antagonistisch am GnRH-I Rezeptor sowie agonistisch am GnRH-Il Rezeptor (Sun et al., 2001; Gründker et al., 2004). Weiterhin wurde nachgewiesen, dass neu entwickelte GnRH-Il Antagonisten in gynäkologischen Tumoren zu einer Induktion der Caspase-3 vermittelten Apoptose führen, deren Ursache in einer Aktivierung proapoptotischer Signale (Bax) sowie Stress-aktivierter MAPK (p38, JNK) liegt (Fister et al., 2007; Fister et al., 2009).

Ein Einfluss von GnRH Analoga auf die Migration und Invasion verschiedener Mammakarzinomzellen konnte erstmals durch von Alten et al. (2006) aufgezeigt werden. In einem speziell für diese Untersuchungen etablierten Kokultursystem wurde die Knochen-gerichtete Invasion der Mammakarzinomzellen durch eine Matrigel-beschichtete Membran inhibiert. Dieser Effekt lässt sich u.a. auf eine Regulation des Chemokins SDF-1 (stromal cell-derived factor-1) in den für die Kokultur verwendeten humanen Osteoblasten zurückführen. Sowohl der GnRHI Agonist Triptorelin und der GnRH-I Antagonist Cetrorelix als auch der GnRH-II Agonist $\left[\mathrm{D}-\mathrm{Lys}^{6}\right] \mathrm{GnRH}-\mathrm{Il}$ zeigten dabei diese Wirkung.

\subsection{Fragestellung und Zielsetzung}

Ziel dieser Arbeit ist zum einen die Aufklärung molekularer Mechanismen der Knochen-gerichteten Invasion von Mammakarzinomzellen und in diesem Bezug den Einfluss von GnRH Analoga in vitro zu untersuchen. Des Weiteren sollen in vivo die Auswirkungen einer GnRH Analoga Therapie auf das Tumorwachstum sowie die Metastasierung des Mammakarzinoms analysiert werden. 
Die in vitro Untersuchungen werden unter Verwendung eines Kokultursystems durchgeführt, welches es ermöglicht humane Mammakarzinomzellen mit hOB bzw. Osteoblasten-ähnlichen Zelllinien zu kultivieren. Die Expressionsregulation verschiedener in den Metastasierungsprozess sowie den Knochenstoffwechsel involvierter Gene soll in beiden Zelltypen ohne und während der Kokultur sowie nach Behandlung der Mammakarzinomzellen mit GnRH Analoga untersucht werden. Dafür werden RT-PCR und Western Blot Analysen durchgeführt sowie Genexpressionsprofile mittels Gene Array erstellt.

Als zweiter Schwerpunkt der Arbeit sollen die Effekte der GnRH Analoga in vivo im Nacktmausmodell untersucht werden. Dabei wird ein möglicher Einfluss auf das Tumorwachstum sowie die Metastasierung nach Xenotransplantation der Nacktmäuse mit unterschiedlichen Mammakarzinomzellen und anschließender Behandlung mit GnRH Analoga analysiert. Der Einfluss auf die Metastasierung soll vergleichsweise in verschiedenen Organen der Nacktmäuse untersucht und mit einer speziellen TaqMan ${ }^{\circledR}$-Real-time PCR-Methode detektiert werden. Durch den Einsatz einer humanspezifischen Alu-Sequenz wird hierbei der Anteil von humaner DNA in muriner DNA bestimmt.

Die Untersuchungen dieser Arbeit sollen zur Aufklärung der molekularen Mechanismen der Knochenmetastasierung des Mammakarzinoms beitragen und in diesem Zusammenhang die Möglichkeit einer zielgerichteten Therapie mit GnRH Analoga aufzeigen. Zudem können die in vivo Ergebnisse der vorliegenden Arbeit hilfreich für den Einsatz und die Etablierung von $\mathrm{GnRH}$ Analoga in der endokrinen Therapie des metastasierenden Mammakarzinoms sein. 


\section{MATERIAL}

\subsection{Geräte}

ABI PRISM ${ }^{\mathrm{TM}} 7700$ Sequence Detector Analysenwaage BP161P

Autoklav $2540 \mathrm{EL}$

Biofuge pico

Brutschrank 3121 S/N 28439532

Elektrophoresekammer, DNA

Hybridisierungsofen $6 / 12 \mathrm{~V}$

Labofuge 400R

Magnetrührer, MR3000

Mikro-Dismembrator S

Mikroskop IX51

Mikrowaage M2P, elektronisch

Mini-PROTEAN ${ }^{\circledR}$ III Cell-System

Netzgerät 1000/500

Netzgerät 200/2.0

pH-Meter CG 22

Phasenkontrastmikroskop Axiovert 25

Photometer (BioPhotometer 6131)

Schüttler Titramax 1000

Sterilwerkbank LaminAir ${ }^{\circledR}$ HA 2448 GS

Thermocycler T3000

Thermomixer compact

Überkopfschüttler RK 10-VS

Ultrazentrifuge $\left(U Z^{6}\right)$ Sorvall

UV-Transilluminator

Vortex Genie $2^{\mathrm{TM}}$

Waage Kern 440-47
Applied Biosystems, Darmstadt

Sartorius, Göttingen

Tuttnauer, Breda, NL

Heraeus Holding, Hanau

Forma Scientific, San Bruno, USA

OWL Separation Systems, Portsmouth, USA

Peqlab, Erlangen

Heraeus Holding, Hanau

Heidolph, Schwabach

B. Braun Biotech Int., Melsungen

Olympus, Hamburg

Sartorius, Göttingen

Bio-Rad, München

Bio-Rad, München

Bio-Rad, München

Schott Geräte, Mainz

Zeiss, Jena

Eppendorf, Hamburg

Heidolph, Schwabach

Heraeus Holding, Hanau

Biometra, Göttingen

Eppendorf, Hamburg

Heto, Allered, DK

Thermo Fisher Scientific, Bonn

Biometra, Göttingen

Bender \& Hobein, Zürich, $\mathrm{CH}$

Kern, Balingen 
Wasserbad

X-Ray Röntgenfilmentwickler SRS-101A
Memmert, Schwabach

Konica, Langenhagen

\subsection{Verbrauchsmaterialien}

Die in dieser Arbeit verwendeten Verbrauchsmaterialien (Einmalartikel) wurden von den Firmen Biozym (Hessisch Oldenburg), Eppendorf (Hamburg), Greiner Bio-One (Frickenhausen), Nunc (Langenselbold), Sarstedt (Nümbrecht) sowie Starlab (Ahrensburg) bezogen.

\subsection{Chemikalien}

Alle verwendeten Chemikalien wurden, falls nicht gesondert vermerkt, von den Firmen Merck (Darmstadt), PAA (Cölbe), Carl Roth (Karlsruhe) und SigmaAldrich (München) bezogen. Die Chemikalien entsprechen, falls nicht anders angegeben, dem höchsten zur Verfügung stehenden Reinheitsgrad.

\subsection{Puffer und Lösungen}

Für das Ansetzten von Puffern sowie anderen Lösungen wurde $\mathrm{H}_{2} \mathrm{O}$ aus einer Reinstwasseranlage der Firma Sartorius (Göttingen) verwendet.

blocking-Lösung

DNA- Ladepuffer (10x)

Ethidiumbromid-Bad

Laemmli-Probenpuffer (2x)

Lysispuffer

PBS
TBST + $5 \%(w / v)$ Magermilchpulver

$50 \%$ (v/v) Glycerin, $10 \mathrm{mM}$ Tris/HCl, $1 \mathrm{mM}$ EDTA, 0,25 \% (w/v) Bromphenolblau, $0,05 \%(w / v)$ Xylencyanol

$0,007 \%(v / v) E t B r$

62,5 mM Tris/HCL (pH 6,8), 4 \% (w/v) SDS, $5 \%$ (v/v) Glycerol, 0,05\% (v/v) ß-Mercaptoethanol, 0,025\% (w/v) Bromphenolblau

$10 \mathrm{mM}$ Tris/ $\mathrm{HCl}(\mathrm{pH} 7,4), 150 \mathrm{mM} \mathrm{NaCl}$, $2 \%(\mathrm{v} / \mathrm{v})$ Triton $\mathrm{X}-114^{\mathrm{TM}}$

$140 \mathrm{mM} \mathrm{NaCl}, 2,7 \mathrm{mM} \mathrm{KCl}, 8,6 \mathrm{mM} \mathrm{Na}_{2} \mathrm{HPO}_{4}$, $1,5 \mathrm{mM} \mathrm{KH}_{2} \mathrm{HPO}_{4}, \mathrm{pH} 7,4$ 
PBST

PBS $+0,2 \%$ BSA, 0,1 \% Triton X-100

PBSTN

PBSTN $+5 \%$ FCS

SDS-Elektrophoresepuffer (10x) 25 mM Tris, 192 mM Glycin, 0,1\% (w/v) SDS

TBE 90 mM Tris, 90 mM Borsäure, 1 mM EDTA, $\mathrm{pH} 8,0$

TBS (10x)

1,5 M NaCl, 500 mM Tris, $\mathrm{pH}$ 7,5

TBST

TBS $+0,1 \%(v / v)$ Tween 20

Transferpuffer

$48 \mathrm{mM}$ Tris, $39 \mathrm{mM}$ Glycin, $0,0375 \%(w / v)$ SDS, $20 \%(v / v)$ Methanol

\subsection{Kulturmedien und Medienzusätze}

Alle für die Zellkultivierung eingesetzten Medien und deren Zusätze wurden von den Firmen Biochrom (Berlin), Invitrogen (Karlsruhe), PAA (Cölbe) und SigmaAldrich (München) bezogen.

DMEM w Phenolrot, ohne Zusätze

DMEM w Phenolrot Kulturmedium $10 \%(\mathrm{v} / \mathrm{v}) \mathrm{FCS}, 1 \%(\mathrm{v} / \mathrm{v}) \mathrm{P} / \mathrm{S}$, $1 \%(v / v)$ L-Gln

DMEM w Phenolrot Einfriermedium

DMEM Kulturmedium + $10 \%$ DMSO

DMEM w/o Phenolrot, ohne Zusätze

DMEM w/o Phenolrot Kulturmedium

$10 \%(v / v)$ CD-FCS, $1 \%(v / v)$ P/S, $1 \%(v / v)$ L-Gln

MEM-Earl w Phenolrot, ohne Zusätze

MEM-Earl w Phenolrot Kulturmedium

$10 \%(v / v)$ FCS, $1 \%(v / v)$ P/S, $0,1 \%(\mathrm{v} / \mathrm{v})$ Transferrin, $50 \mathrm{IU}$ Insulin

MEM-Earl w Phenolrot Einfriermedium MEM-Earl Kulturmedium + $10 \%$ DMSO 


\subsection{Biologisches Material}

\subsubsection{Zelllinien}

Die in dieser Arbeit verwendeten Zelllinien wurden von der American Type Culture Collection (ATCC, Manassas, USA) oder der Deutschen Sammlung von Mikroorganismen und Zelllinien (DSMZ, Braunschweig) bezogen.

Tab. 2.1: Verwendete Zelllinien (Mammakarzinom, Osteosarkom)

\begin{tabular}{|l|l|l|l|}
\hline Zelllinie & Herkunft & Histologie & Referenz \\
\hline HCC-70 & Primärtumor & duktales Karzinom & Gazdar et al. (1998) \\
\hline MCF-7 & Pleuraerguss & Adenokarzinom & Soule et al. (1973) \\
\hline MCF-7 3.1 & Pleuraerguss & Adenokarzinom & Novartis, Basel, CH \\
\hline MCF-7 aro & Pleuraerguss & Adenokarzinom & Novartis, Basel, CH \\
\hline MDA-MB-231 & Pleuraerguss & Adenokarzinom & Brinkley et al. (1980) \\
\hline MDA-MB-435 & Pleuraerguss & duktales Karzinom & Cailleau et al. (1978) \\
\hline MDA-MB-453 & Perikarderguss & Karzinom & Cailleau et al. (1978) \\
\hline T47-D & Pleuraerguss & duktales Karzinom & Freake et al. (1981) \\
\hline ZR-75-1 & Aszites & duktales Karzinom & Engel et al. (1978) \\
\hline CAL-72 & Primärtumor & Osteosarkom & Rochet et al. (1999) \\
\hline MG-63 & Primärtumor & Osteosarkom & Billiau et al. (1977) \\
\hline
\end{tabular}

\subsubsection{Versuchstiere}

Tab. 2.2: Verwendeter Mausstamm

\begin{tabular}{|l|l|l|}
\hline Stamm & Genotyp & Referenz \\
\hline \hline CD1 nu/nu & Crl:Nu-Foxn1nu & Charles River, Sulzfeld \\
\hline
\end{tabular}

\subsubsection{Matrigel $^{\mathrm{TM}}$}

Tab. 2.3: Verwendetes Matrigel ${ }^{\mathrm{TM}}$

\begin{tabular}{|l|l|l|}
\hline Material & Herkunft & Referenz \\
\hline Matrigel $^{\text {TM }}$ Basement & Engelberth-Holm-Swarm & BD Biosciences, \\
Membrane Matrix & $($ EHS)-Maussarkom & Heidelberg \\
\hline
\end{tabular}




\subsection{GnRH Analoga}

Die beiden GnRH-I Analoga Triptorelin (GnRH-I Agonist) und Cetrorelix (GnRHI Antagonist) wurden von Ferring Pharmaceuticals (Kiel) und Aeterna Zentaris (Frankfurt am Main) zur Verfügung gestellt. Die verwendeten $\mathrm{GnRH}$-II Analoga [D-Lys $\left.{ }^{6}\right] \mathrm{GnRH}-$ II (GnRH-II Agonist) und Ant-3 (GnRH-II Antagonist) wurden in unserem Auftrag von der Firma Peptide Specialty (Heidelberg) synthetisiert. Die Lieferung erfolgte als HPLC-aufgereinigtes TFA-Salz.

Tab. 2.4: Verwendete GnRH Analoga

\begin{tabular}{|c|c|c|}
\hline GnRH Analoga & $\begin{array}{l}\text { Strukturabweichung vom nativen } \\
\text { Protein }\end{array}$ & Referenz \\
\hline $\begin{array}{l}\text { Triptorelin } \\
\text { (GnRH-I Agonist) }\end{array}$ & [D-Trp] $^{6}$ & $\begin{array}{l}\text { Ferring } \\
\text { Pharmaceuticals }\end{array}$ \\
\hline $\begin{array}{l}\text { Cetrorelix } \\
\text { (GnRH-I Antagonist) }\end{array}$ & $\begin{array}{l}{\left[\left(\mathrm{AcD}-2 \mathrm{Nal}{ }^{1}\right),\left(\mathrm{D}-4 \mathrm{Cpa}^{2}\right)\right.} \\
\left.\left(\mathrm{D}-3 \mathrm{Pal}^{3}\right),\left(\mathrm{D}-\mathrm{Cit}^{6}\right),\left(\mathrm{D}-\mathrm{Ala} 10^{10}\right)\right]\end{array}$ & Aeterna Zentaris \\
\hline $\begin{array}{l}\left.\text { [D-Lys }{ }^{6}\right] \text { GnRH-II } \\
\text { (GnRH-II Agonist) }\end{array}$ & {$\left[D-L^{6} s^{6}\right]$} & $\begin{array}{l}\text { Gründker et al. } \\
\text { (2002) }\end{array}$ \\
\hline $\begin{array}{l}\text { GnRH-Il Ant } \\
\text { (GnRH-II Antagonist) }\end{array}$ & $\begin{array}{l}{\left[(\mathrm{AcD}-2 \mathrm{Nal})^{1}\right),\left(\mathrm{D}-4 \mathrm{Cpa}^{2}\right)} \\
\left.\left(\mathrm{D}-3 \mathrm{Pal}{ }^{3,6}\right),\left(\mathrm{D}-\mathrm{Leu}^{8}\right),\left(\mathrm{D}-\mathrm{Ala}^{10}\right)\right]\end{array}$ & $\begin{array}{l}\text { Fister et al. } \\
(2007)\end{array}$ \\
\hline
\end{tabular}

\subsection{Enzyme}

DNase I recombinant, RNase-free

RNase A (100 mg/ml)

SuperScript ${ }^{\mathrm{TM}}$ II Reverse Transcriptase

Taq DNA Polymerase

Trypsin-EDTA $(0,05 \% / 0,02 \%$ in D-PBS)
Roche, Mannheim

Qiagen, Hilden

Invitrogen, Karlsruhe

Roche, Mannheim

PAA, Cölbe

\subsection{Oligonukleotide}

Die verwendeten Oligonukleotide für die RT-PCR wurden von der Firma MWG (Ebersberg) sythetisiert. 
Tab. 2.5: Primer für die RT-PCR

\begin{tabular}{|c|c|c|}
\hline Zielgen & Primersequenz & $\mathrm{bp}$ \\
\hline $\mathrm{CDH} 1$ & $\begin{array}{l}\text { 5`-TTT GGA AAT GAT GTG CAG GA-3` } \\
\text { 5`-ATC AGA GCC TGC GTA GGA AA-3` }\end{array}$ & 200 \\
\hline CTSB & $\begin{array}{l}\text { 5`CCA GGG AGC AAG ACA GAG AC-3` } \\
\text { 5`-GAG ACT GGC GTT CTC CAA AG-3` }\end{array}$ & 162 \\
\hline CYR61 & $\begin{array}{l}\text { 5`-CTC CCT GTT TTT GGA ATG GA-3` } \\
\text { 5`-TGG TCT TGC TGC ATT TCT TG-3` }\end{array}$ & 241 \\
\hline GnRH-I R & $\begin{array}{l}\text { 5`-GAC CTT GTC TGG AAA GAT CC-3` } \\
\text { 5`-CAG GCT GAT CAC CAC CAT CA-3` }\end{array}$ & 319 \\
\hline L7 & $\begin{array}{l}5^{`} \text {-AGA TGT ACA GAA CTG AAA TTC-3` } \\
\text { 5`-ATT TAC CAA GAG ATC GAG CAA-3` }\end{array}$ & 357 \\
\hline OPG & $\begin{array}{l}\text { 5`-GAA CCC CAG AGC GAA ATA CA-3` } \\
\text { 5'-CGC TGT TTT CAC AGA GGT CA-3` }\end{array}$ & 441 \\
\hline PTHrP & $\begin{array}{l}\text { 5'-GTT GGA GTA GCC GGT TGC TA-3` } \\
\text { 5'-TGC GAT CAG ATG GTG AAG GA-3` }\end{array}$ & 242 \\
\hline PTHrP-R & $\begin{array}{l}\text { 5'-CCG CCT ACT GCC CAC TGC CAC CAC-3' } \\
5^{\prime} \text {-TCC ATC CAC TAT GTC AGC AGG TCC-3' }\end{array}$ & 437 \\
\hline RANKL & $\begin{array}{l}\text { 5`-AGC GTC GCC CTG TTC TTC TAT TT-3` } \\
\text { 5`-ACT TGG GAT TTT GAT GCT GGT TTT-3` }\end{array}$ & 567 \\
\hline S100A4 & $\begin{array}{l}\text { 5`-TCT CTC CTC AGC GCT TCT TC-3` } \\
5^{`} \text {-GCT GTC CAA GTT GCT CAT CA-3` }\end{array}$ & 239 \\
\hline
\end{tabular}

Die benötigte $\operatorname{TaqMan}^{\circledR}$-Sonde sowie die zugehörigen Primer für die Real-time PCR wurden von der Firma Eurogentec (Köln) synthetisiert.

Tab. 2.6: TaqMan ${ }^{\circledR}$-Sonde und Primer für die Real-time PCR

\begin{tabular}{|l|l|}
\hline Bezeichnung & Sequenz \\
\hline \hline Alu-Primer & $5^{`}$-CAT GGT GAA ACC CCG TCT CTA-3` \\
& 5 -GCC TCA GCC TCC CGA GTA G-3` \\
\hline Alu-Sonde & $5^{`}$-[YY]-ATT AGC CGG GCG TGG TGG CG-[BHQ-1]-3` \\
\hline
\end{tabular}




\subsection{Antikörper}

Alle verwendeten Antikörper wurden nach Angaben des Herstellers eingesetzt.

Tab. 2.7: Primärantikörper

\begin{tabular}{|l|l|l|}
\hline Antikörper & Herkunft/Beschreibung & Referenz \\
\hline \hline Anti-Actin (Pan) & $\begin{array}{l}\text { Kaninchen, monoklonal } \\
1: 1000\end{array}$ & Epitomics, Hamburg \\
\hline Anti-CTSB & $\begin{array}{l}\text { Kaninchen, polyklonal } \\
1: 1000\end{array}$ & Abcam, Cambridge, UK \\
\hline Anti-OPG & $\begin{array}{l}\text { Maus, monoklonal } \\
1: 1000\end{array}$ & Chemicon, Hampshire, UK \\
& $1: 100$ & \\
\hline Anti-RANKL & $\begin{array}{l}\text { Kaninchen, polyklonal } \\
1: 2500\end{array}$ & Chemicon, Hampshire, UK \\
& $1: 200$ & \\
\hline
\end{tabular}

Tab. 2.8: HRP-gekoppelte Sekundärantikörper

\begin{tabular}{|l|l|l|}
\hline Antikörper & Herkunft/Beschreibung & Referenz \\
\hline \hline Anti-Mouse IgG & $\begin{array}{l}\text { Schaf, monoklonal } \\
1: 10000\end{array}$ & GE Healthcare, Freiburg \\
\hline Anti-Rabbit IgG & $\begin{array}{l}\text { Affe, monoklonal } \\
1: 20000\end{array}$ & GE Healthcare, Freiburg \\
\hline
\end{tabular}

\subsection{Inhibitoren}

Protease Inhibitor Cocktail Sigma-Aldrich, München Recombinant RNasin ${ }^{\circledR}$ Ribonuclease Inhibitor Promega, Mannheim

\subsection{Kommerzielle Reaktionssysteme}

$\mathrm{d}(\mathrm{T})_{15}$ Primer

ECL Immobilon ${ }^{\circledR}$ Western
Roche, Mannheim

Millipore, Schwalbach 
GEArray RT-Labeling Kit

Histostain ${ }^{\circledR}$-SP Kit

Human Tumor Metastasis Gene Array (GEArray Q Series)

NucleoSpin ${ }^{\circledR}$ Filters

NucleoSpin ${ }^{\circledR}$ Tissue Kit

RNeasy ${ }^{\circledR}$ Mini Kit

18S rRNA Control Kit

$\operatorname{TaqMan}^{\circledR}$ Universal PCR Master Mix

\subsection{Software}

ABI PRISM $^{\circledR} 7700$ Sequence Detection Software (SDS 1.9.1)

Adobe Photoshop 7.0

analySIS getIT (Version 5.0)

BioDoc Analyze 2.1

GraphPad Prism $^{\circledR}$ (Version 5.0)

Kodak Digital Science 1D Image Analyse Software (Version 2.0.3)

Microsoft ${ }^{\circledR}$ Office 2003
SuperArray Bioscience

Corporation, Maryland, USA

Zymed, S. San Francisco, USA

SuperArray Bioscience

Corporation, Maryland, USA

Macherey-Nagel, Düren

Macherey-Nagel, Düren

Qiagen, Hilden

Eurogentec, Köln

Applied Biosystems, Darmstadt

Applied Biosystems, Darmstadt

Adobe Systems, München

Olympus, Hamburg

Biometra, Göttingen

GraphPad Software Inc., San Diego, USA

Kodak, Suttgart

Microsoft Corporation, Unterschleißheim 


\section{METHODEN}

\subsection{Zellkultur}

\subsubsection{Kultivierung und Passagieren adhärenter Zellen}

Die verwendeten Zelllinien wurden in MEM-Earl w Phenolrot Kulturmedium oder DMEM w Phenolrot Kulturmedium in einer wasserdampfgesättigten Atmosphäre mit $5 \% \mathrm{CO}_{2}$-Anteil bei $37^{\circ} \mathrm{C}$ kultiviert. Die Kulturmedien wurden mit $10 \%(\mathrm{v} / \mathrm{v})$ FCS (fetal calf serum) und $1 \%$ (v/v) Penicillin/Streptomycin-Mix (P/S) versetzt. Das MEM-Earl Kulturmedium enthielt zusätzlich 0,1\% (v/v) Transferrin sowie $50 \mathrm{IU}$ Insulin, das DMEM Kulturmedium $1 \%$ (v/v) L-Glutamin (L-Gln). Alle Zellkulturarbeiten wurden an einer Sterilwerkbank durchgeführt. Die Zellen wurden bei Erreichen einer Konfluenz von ca. 80 \% oder nach Bedarf zu einem früheren Zeitpunkt passagiert. Dazu wurden die Zellen mit PBS gewaschen und anschließend mit Trypsin/EDTA (0,05\%/0,02 \% in D-PBS) bei $37^{\circ} \mathrm{C}$ inkubiert. Nach dem Ablösen der Zellen wurde die Reaktion mit Kulturmedium abgestoppt und die Zellsuspension für $5 \mathrm{~min}$ bei $300 \times \mathrm{g}$ zentrifugiert. Das gewonnene Zellpellet wurde in Kulturmedium resuspendiert und nach Bestimmung der Zellzahl eine entsprechende Anzahl von Zellen auf Zellkulturgefäße verteilt.

\subsubsection{Kryokonservierung und Auftauen eukaryotischer Zellen}

Um eine langfristige Konservierung der Zellen zu gewährleisten, wurde das Zellpellet mit entsprechender Zellzahl in Einfriermedium aufgenommen und zunächst bei $-80^{\circ} \mathrm{C}$ eingefroren. Anschließend wurden die Zellen in flüssigem Stickstoff gelagert. Das Auftauen der Zellen erfolgte durch eine kurzzeitige Erwärmung bei $37^{\circ} \mathrm{C}$ im Wasserbad. Danach wurde die Zellsuspension mit Kulturmedium gewaschen, $4 \mathrm{~min}$ bei $300 \times \mathrm{g}$ zentrifugiert und das entstandene Zellpellet zur Kultivierung in Kulturmedium resuspendiert.

\subsubsection{Primäre Kultivierung humaner Osteoblasten}

Für das Anlegen einer Primärkultur von humanen Osteoblasten (hOB) wurde in Einvernehmung mit der Ethikkommission (Antrag 13/3/01) und Zusammenarbeit 
mit der Abteilung für Unfallchirurgie der Universitätsmedizin Göttingen humanes Knochenmaterial zur Verfügung gestellt. Das Knochenmaterial wurde in steriler physiologischer Natriumchloridlösung (0,9 \%) übergeben. Zunächst wurden die Knochenfragmente in eine Petrischale mit PBS überführt, unter Verwendung eines Skalpells (TechnoCut, HMD Healthcare, Horsham, UK) von Blut- sowie Bindegewebsrückständen befreit und grob zerkleinert. Dabei wurde soviel trabekulärer Knochen wie möglich freigelegt und dieser weiterhin mehrmals in Petrischalen mit PBS gewaschen und zerkleinert. Die Knochenstücke wurden danach für einen letzten Waschschritt in DMEM w Phenolrot Kulturmedium (zunächst ohne Zusätze) überführt. Um ein Anwachsen von Primärzellen zu ermöglichen, wurde der Boden mehrerer Petrischalen mit DMEM w Phenolrot Kulturmedium leicht bedeckt, die Knochenstücke darin verteilt und für eine Woche bei $37^{\circ} \mathrm{C}$ im Brutschrank inkubiert. Danach wurde alle drei bis vier Tage vorsichtig ein Mediumwechsel durchgeführt. Aus den Knochenstücken bildeten sich dabei zunächst vereinzelt hOB aus, die im weiteren Verlauf zu einem dichten Zellrasen anwuchsen. Nach ca. drei Wochen konnten die Primärzellen aus ihrem Zellverband gelöst (siehe Kapitel 3.1.1) und für entsprechende Experimente verwendet werden.

\subsubsection{Bestimmung der Zellzahl}

Die Zellzahlbestimmung wurde mit Hilfe einer Neubauer-Zählkammer $(0,1 \mathrm{~mm}$ Tiefe, 0,0025 cm² Fläche, Laboroptik, Friedrichsdorf) unter dem Lichtmikroskop durchgeführt. Eine Differenzierung von vitalen und toten Zellen erfolgte mittels Trypanblau-Färbung, bei der sich tote Zellen durch eine Blaufärbung des Zytosols deutlich von vitalen Zellen abgrenzen. Die Zellsuspension wurde im Verhältnis 1:2 mit der Trypanblau-Lösung (Serva, Heidelberg) verdünnt.

\subsubsection{Kokultur}

Um die Mechanismen der Knochenmetastasierung zu untersuchen, wurde ein in vitro System etabliert, bei dem humane Mammakarzinomzellen mit hOB oder Osteoblasten-ähnlichen Zellen kokultiviert werden (von Alten et al., 2006). Dazu wurden zunächst ThinCert $^{\mathrm{TM}}$ Zellkultureinsätze für 6-Well-Platten mit einem Porendurchmesser von $8 \mu \mathrm{m}$ (Greiner Bio-One, Frickenhausen) mit Matrigel ${ }^{\mathrm{TM}}$ 
Basement Membrane Matrix (BD Biosciences, Heidelberg) überschichtet. Es handelt sich hierbei um ein Basalmembran-Präparat, welches aus SarkomaZellen von Engelberth-Holm-Swarm (EHS)-Mäusen gewonnen wird und in vitro einen verbreiteten Einsatz bei Invasionsmodellen findet (Kleinman \& Martin, 2005). Zur Vorbereitung wurden alle verwendeten Materialien auf $4^{\circ} \mathrm{C}$ vorgekühlt und das bei $-20^{\circ} \mathrm{C}$ gelagerte Matrigel $^{\mathrm{TM}}$ langsam auf Eis aufgetaut. Die ThinCert ${ }^{\mathrm{TM}}$ Zellkultureinsätze wurden vorsichtig und unter Vermeidung von

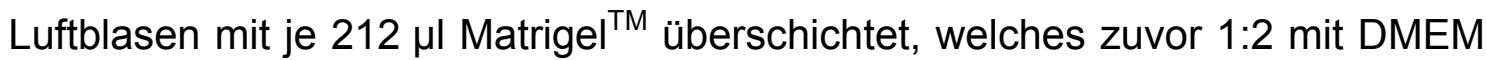
w/o Phenolrot ohne Zusätze verdünnt wurde. Danach wurden die Platten 30 min bei $37^{\circ} \mathrm{C}$ im Brutschrank inkubiert und direkt im Anschluss für Versuchsansätze verwendet.

Das Funktionsprinzip des Kokultursystems beruht auf dem Knochen-gerichteten Migrationsverhalten der Mammakarzinomzellen durch die Matrigel-beschichtete Membran, die eine Extrazellulärmatrix (EZM) simuliert (siehe Abbildung 3.1).

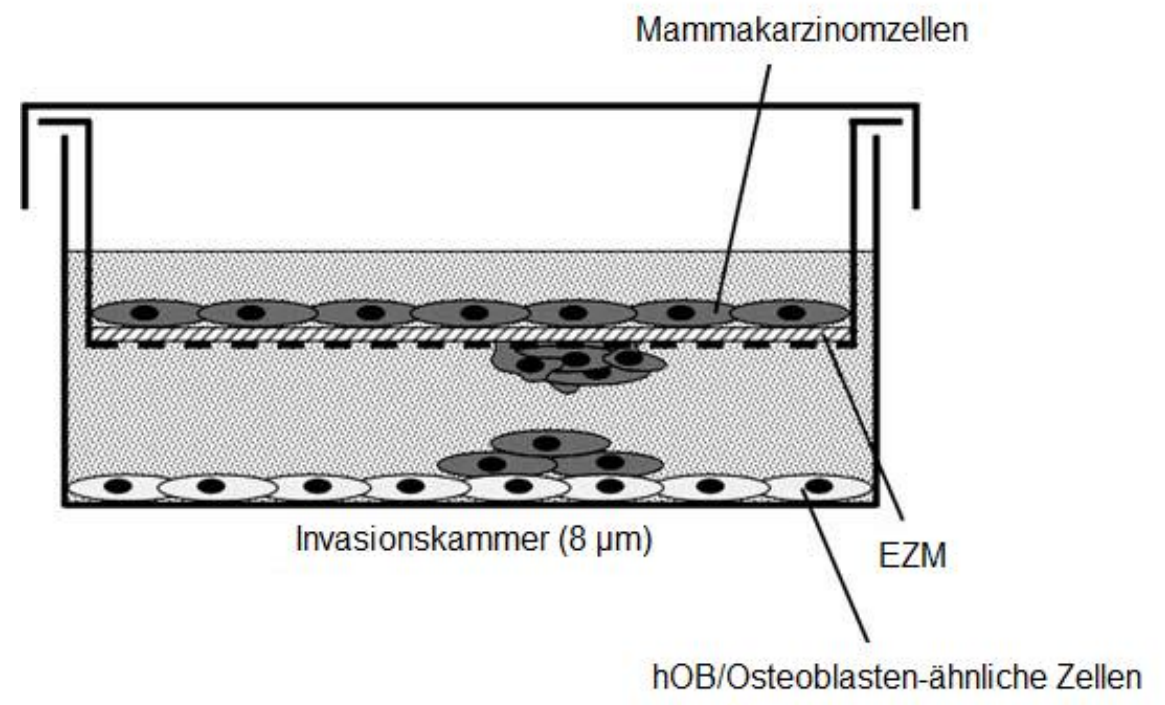

Abb. 3.1: Schematische Darstellung des verwendeten Kokultursystems

Die Zellaussaat erfolgte in DMEM Kulturmedium ohne Phenolrot und mit $10 \%$ (v/v) CD-FCS an Stelle von normalem FCS, um hormonähnliche Wirkungen dieser Substanzen zu vermeiden. Die Mammakarzinomzellen wurden in einer

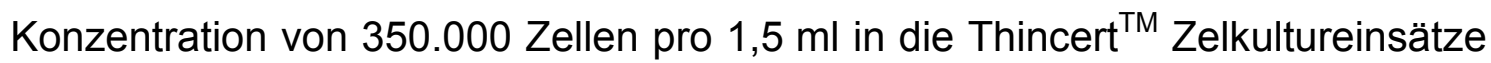
ausgesät. Die Aussaat der hOB bzw. Osteoblasten-ähnlichen Zellen erfolgte in 
6-Well-Platten in einem Konzentrationsbereich von 120.000-150.000 Zellen pro $2 \mathrm{ml}$. Zunächst wurden die Zellen für $24 \mathrm{~h}$ getrennt voneinander kultiviert. Anschließend erfolgte die Behandlung der Mammakarzinomzellen mit den GnRH Analoga (siehe Kapitel 3.1.6) sowie die Überführung der Thincert ${ }^{\mathrm{TM}}$ Zellkultureinsätze auf die 6-Well-Platten mit hOB bzw. Osteoblasten-ähnlichen Zellen (Zeitpunkt $t_{0}$ ).

Nach $48 \mathrm{~h}\left(\mathrm{t}_{48}\right)$ wurden die Zellen für weitere Untersuchungen auf RNA- sowie Proteinebene geerntet. Dafür wurden die Thincert ${ }^{\mathrm{TM}}$ Zellkultureinsätze aus der Invasionskammer entfernt, die Matrigelschicht mit den Mammakarzinomzellen unter Verwendung eines feinen Spatels abgeschabt und in ein Reaktionsgefäß mit RLT-Puffer (White et al.) oder PBS (Protein) überführt. Die Zellen im unteren Well (hOB/Osteoblasten-ähnliche Zellen) wurden direkt in RLT-Puffer oder mit Hilfe eines Zellschabers $(25 \mathrm{~cm}$, Sarstedt, Nümbrecht) in PBS geerntet. Die in RLT-Puffer aufgenommenen Zellen wurden bis zur weiteren Aufarbeitung bei $-80^{\circ} \mathrm{C}$ gelagert. Die Zellsuspension für die Proteingewinnung wurde bei 10000 x g für 5 min zentrifugiert und anschließend der Überstand aus PBS sowie Matrigel abgesaugt. Die dabei gewonnenen Zellpellets wurden in flüssigem Stickstoff eingefroren und ebenfalls bei $-80^{\circ} \mathrm{C}$ aufbewahrt.

\subsubsection{Behandlung mit GnRH Analoga}

Die Behandlung der Mammakarzinomzellen mit den GnRH Analoga erfolgte in unterschiedlichen Konzentrationen (siehe Tabelle 3.1) mit einer Inkubationszeit von $48 \mathrm{~h}$.

Tab. 3.1: Konzentrationen der verwendeten GnRH Analoga

\begin{tabular}{|l|l|}
\hline GnRH-Analoga & Konzentration [M] \\
\hline \hline Triptorelin & $1 \times 10^{-5}$ \\
\hline Cetrorelix & $1 \times 10^{-5}$ \\
\hline$[$ D-Lys
\end{tabular}

Mit diesen Konzentrationen wurde in vorangegangenen Studien (von Alten et al., 2006) die stärkste Hemmung der Invasion von Mammakarzinomzellen im Kokultursystem erreicht. 


\subsection{Tierversuche}

\subsubsection{Versuchstiere und Haltungsbedingungen}

Als Versuchstiere wurden sechs bis acht Wochen alte, thymusdefiziente, weibliche Nacktmäuse des Stammes CD1 nu/nu mit einem durchschnittlichen Gewicht von 20 Gramm verwendet. Diese wurden von der Firma Charles River (Sulzfeld) bezogen. Die Haltung der Tiere erfolgte in mit Filterhauben bedeckten Käfigen mit bis zu fünf Mäusen pro Käfig in der Tierexperimentellen Einrichtung der Universitätsmedizin Göttingen. Dabei wurden die Tiere mit Futter ad libitum sowie autoklaviertem $\mathrm{H}_{2} \mathrm{O}$ versorgt und unter kontrollierten Umweltbedingungen und Simulation eines Tag-Nacht-Zyklus von zwölf Stunden gehalten. Alle in vivo durchgeführten Experimente wurden nach den Richtlinien für tierexperimentelle Forschung angemeldet und genehmigt.

\subsubsection{Betäubung}

Für die Betäubung der Nacktmäuse vor der Injektion von Tumorzellen wurde eine Lösung aus Ketaminhydrochlorid (100 mg/kg KG) und Xylazinhydrochlorid (4 mg/kg KG) in isotonischer Natriumchloridlösung $(0,9 \%)$ hergestellt. Davon wurden pro Maus $200 \mu$ bei Tumorzellinjektion in die Brustdrüse und $150 \mu$ bei Tumorzellinjektion ins Herz intraperitoneal (i.p.) verabreicht.

\subsubsection{Vorbereitung und Injektion von Tumorzellen}

Für die Tierexperimente wurden die benötigten Zellen zunächst in vitro kultiviert und expandiert. Um die ausreichende Menge an Zellen zu erhalten, erfolgte die Kultivierung in Zellkulturflaschen mit Dreifachboden. Die angewachsenen Zellen wurden bei einer Konfluenz von ca. 80 \% trypsiniert und mit PBS gewaschen. Nach der Zellzählung wurde die gewünschte Zellzahl mit dem entsprechenden Kulturmedium ohne Zusätze eingestellt und bis zur Injektion auf Eis aufbewahrt.

\subsubsection{Injektion in die Brustdrüse}

Für die Injektion in die Brustdrüse wurde die Zellzahl auf 1 Mio Zellen pro $100 \mu \mathrm{l}$ Kulturmedium eingestellt. Die Zellsuspension wurde anschließend luftblasenfrei in $1 \mathrm{ml}$ Spritzen (BD Plastipak, Heidelberg) über eine Kanüle (100 Sterican ${ }^{\circledR}$, 
$\varnothing 0,45 \times 12 \mathrm{~mm}, 26 \mathrm{G} \times 1 / 2$ ", B. Braun, Melsungen) aufgezogen und beidseitig jeweils $100 \mu \mathrm{l}$ in das Fettgewebe der zweiten Brustdrüse injiziert.

\subsubsection{Injektion ins Herz}

Vor der Injektion von Tumorzellen ins Herz wurde entlang des Brustbeins und Rippenbogens dessen Lage ertastet. Jeder Maus wurden unter Verwendung von $1 \mathrm{ml}$ Spritzen mit sehr feinen Kanülen (Omnican ${ }^{\circledR} 40, \varnothing 0,30 \times 12 \mathrm{~mm}$, $30 \mathrm{G} \times 1 / 2$ "', B. Braun) $1 \times 10^{5}$ Zellen pro $100 \mu$ Kulturmedium ins Herz injiziert. Um die Lokalisation der Kanüle im Herz zu kontrollieren, wurde kurz vor der Injektion Blut aspiriert.

\subsubsection{Behandlung mit GnRH Analoga}

Die Behandlung der Versuchstiere mit den GnRH Analoga erfolgte alle zwei bis drei Tage und wurde an Tag 2 nach Injektion der Tumorzellen begonnen. Die Verabreichung erfolgte i.p. in einer Konzentration von $25 \mathrm{nmol}$ in $100 \mu \mathrm{l}$ pro Maus.

\subsubsection{Tumorvolumen}

Um den Verlauf des Tumorwachstums zu kontrollieren, wurde mit Hilfe eines digitalen Messschiebers das Tumorvolumen (TV) bestimmt. Dafür wurde der größte Längendurchmesser (a) und im zugehörigen rechten Winkel der größte Breitendurchmesser (b) des jeweiligen Tumors gemessen. Das Tumorvolumen wurde mit folgender Formel berechnet (Streit et al., 2002):

Formel 3.1: Berechnung des Tumorvolumens

$$
\mathrm{TV}=\frac{4}{3} \cdot \pi \cdot\left(\frac{1}{2} \cdot b\right)^{2} \cdot \frac{1}{2} \cdot a
$$

\subsubsection{Sektion}

Nach Beendigung der Tierversuche oder beim Auftreten von Abbruchkriterien erfolgte die Tötung der Nacktmäuse durch Inhalationsnarkose mit $\mathrm{CO}_{2}$ und anschließendem Genickbruch. Alle benötigten Gewebe wurden direkt nach der 
Tötung entnommen. Um eine Blutentnahme aus dem Herzen durchzuführen, wurden die Tiere durch $\mathrm{CO}_{2}$-Narkose ohne nachfolgenden Genickbruch getötet.

\subsubsection{Blutentnahme}

Für die Blutentnahme aus dem Herzen wurden die Nacktmäuse betäubt, der Brustkorb geöffnet und die linke Herzkammer punktiert. Das Blut wurde unter Verwendung einer Kanüle entnommen und bis zur weiteren Aufarbeitung bei $-20^{\circ} \mathrm{C}$ gelagert. Um eine Blutgerinnung zu verhindern, erfolgte die Zugabe von $1,8 \mathrm{mg}$ EDTA pro $\mathrm{ml}$ Blut.

\subsubsection{Gewinnung und Aufbereitung von Mausgewebe}

Nach der Sektion und dem Öffnen des Brustkorbs wurden Lunge, Leber oder Knochen (Femur, beidseitig) der Mäuse freipräpariert und entnommen. In Folge der Präparation wurden Lunge sowie Leber mit PBS gespült und die Knochen zusätzlich mit einem Skalpell von umliegendem Fettgewebe befreit. Direkt im Anschluss wurden die gewonnenen Gewebeproben in flüssigem Stickstoff eingefroren und bei $-80^{\circ} \mathrm{C}$ aufbewahrt.

Um eine DNA-Isolation aus Mausgewebe zu ermöglichen, musste dieses zuvor homogenisiert werden. Die Zerkleinerung von Lunge und Knochen erfolgte mit Hilfe des Mikro-Dismembrators S (B. Braun, Melsungen) in Teflongefäßen mit einer darin enthaltenen Stahlkugel für jeweils $15 \mathrm{~s}$ bei $2500 \mathrm{rpm}$. Während dieser Arbeit wurden sowohl alle Gewebeproben als auch die verwendeten Utensilien in flüssigem Stickstoff gekühlt. Die Leber wurde aufgrund ihrer Größe unter Verwendung des Skalpells zerkleinert und anschließend wieder in flüssigem Stickstoff eingefroren. Bis zur weiteren Aufarbeitung wurden alle Gewebeproben bei $-80^{\circ} \mathrm{C}$ gelagert.

\subsection{Molekularbiologische Methoden}

\subsubsection{Isolierung von Nukleinsäuren}

Die Isolierung der DNA und RNA erfolgte unter Verwendung von Isolierungskits, die auf dem Prinzip der selektiven Bindung von Nukleinsäuren an die Membran einer Trennsäule beruhen. Mit Hilfe einer schnell und einfach durchzuführenden 
Mikrozentrifugentechnik bindet die jeweilige Nukleinsäure an die Membran aus Silikagel und wird nach mehreren Waschschritten von der Säule eluiert.

\subsubsection{Isolierung von DNA aus adhärenten Zellen}

Die Isolierung von DNA aus adhärenten Zellen erfolgte mit dem NucleoSpin ${ }^{\circledR}$ Tissue Kit (Macherey-Nagel, Düren) nach Angaben des Herstellers.

\subsubsection{Isolierung von DNA aus Mausgewebe}

Für die Isolierung von DNA aus Mausgewebe wurde ebenfalls das NucleoSpin ${ }^{\circledR}$ Tissue Kit nach Angaben des Herstellers und unter Zugabe von $4 \mu$ RNase verwendet. Die homogenisierten Gewebeproben (siehe Kapitel 3.2.8) wurden enzymatisch durch die im Kit enthaltene Proteinase $\mathrm{K}$ bei $56^{\circ} \mathrm{C}$ und kräftigem Schütteln (1000 rpm) im Thermomixer (Eppendorf, Hamburg) über Nacht lysiert. Vor der weiteren Aufarbeitung wurden nicht-lysierte Bestandteile mit Hilfe der NucleoSpin ${ }^{\circledR}$ Filters (Macherey-Nagel) abgetrennt.

Die Blutproben der Mäuse wurden ohne Zugabe von RNase und einem Verdau durch die Proteinase K von 25 min identisch zum Mausgewebe aufgearbeitet. Die Lagerung der DNA-Proben erfolgte bei $-20^{\circ} \mathrm{C}$.

\subsubsection{Isolierung von RNA aus adhärenten Zellen}

Die Isolierung von RNA aus adhärenten Zellen wurde mit dem RNeasy ${ }^{\circledR}$ Mini Kit der Firma Qiagen (Hilden) nach den Angaben des Herstellers durchgeführt. Die Zellen wurden direkt in RLT-Puffer geerntet (siehe Kapitel 3.1.5) und bis zur Aufarbeitung sowie danach bei $-80^{\circ} \mathrm{C}$ gelagert.

\subsubsection{Quantifizierung von Nukleinsäuren}

Die Bestimmung der Konzentration von Nukleinsäuren erfolgte photometrisch bei $260 \mathrm{~nm}$, da Nukleinsäuren bei dieser Wellenlänge ihr Absorptionsmaximum besitzen. Eine Absorption von 1,0 entspricht dabei einer Konzentration von $50 \mu \mathrm{g} / \mathrm{ml}$ doppelsträngiger DNA und $40 \mu \mathrm{g} / \mathrm{ml}$ RNA (siehe Tabelle 3.2). Aus dem Verhältnis der Extinktionswerte von $260 \mathrm{~nm} \mathrm{zu} 280 \mathrm{~nm}$ lassen sich Aussagen über den Reinheitsgrad der Nukleinsäuren treffen. Der Quotient dieser beiden Werte $\left(A_{260} / A_{280}\right)$ sollte zwischen 1,8 und 2,0 liegen. Bei einem 
Wert unter 1,8 liegt eine Verunreinigung durch Proteine vor, da diese ihr Absorptionsmaximum bei $280 \mathrm{~nm}$ besitzen (Glasel, 1995). Die Messung wurde im BioPhotometer 6131 der Firma Eppendorf (Hamburg) gegen einen Leerwert durchgeführt.

Tab. 3.2: Faktoren zur Konzentrationsbestimmung von Nukleinsäuren

\begin{tabular}{|l|l|}
\hline Nukleinsäuren & Konzentration $\left(A_{260}=1,0\right)$ \\
\hline \hline dsDNA & $\cong 50 \mu \mathrm{g} / \mathrm{ml}$ \\
\hline ssDNA & $\cong 37 \mu \mathrm{g} / \mathrm{ml}$ \\
\hline Oligonukleotide & $\cong 30 \mu \mathrm{g} / \mathrm{ml}$ \\
\hline RNA & $\cong 40 \mu \mathrm{g} / \mathrm{ml}$ \\
\hline
\end{tabular}

\subsubsection{Reverse Transkription}

Mittels der Reversen Transkription (RT) wird RNA in einen komplementären DNA-Strang (complementary DNA, cDNA) umgeschrieben (Varmus, 1987), der Ausgangspunkt für weitere Untersuchungen darstellt. Die RT wird dabei von RNA-abhängigen DNA-Polymerasen durchgeführt. Oligo-d(T)-Primer dienen als Startpunkt für die Synthese der cDNA und sind in der Lage spezifisch an den Poly(A)-Schwanz der RNA zu binden.

In die RT wurden $1 \mu \mathrm{g}$ RNA eingesetzt und diese zunächst mit $1 \mu$ l DNase und $1 \mu \mathrm{l}$ RNase-Inhibitor für $3 \mathrm{~min}$ bei $37^{\circ} \mathrm{C}$ inkubiert. Danach erfolgte die Zugabe eines Enzym-Mix (siehe Tabelle 3.3) mit einer Inkubationszeit von 60 min bei $37^{\circ} \mathrm{C}$ und abschließend $5 \mathrm{~min}$ bei $95^{\circ} \mathrm{C}$. Die cDNA wurde bei $-20^{\circ} \mathrm{C}$ gelagert und als Matrize für die PCR verwendet.

Tab. 3.3: Enzym-Mix für die Reverse Transkription

\begin{tabular}{|l|l|l|}
\hline Material & Einsatz $[\mu \mathrm{l}]$ & Ausgangskonzentration \\
\hline \hline RT-Puffer & 8 & $5 \mathrm{x}$ \\
\hline DTT & 4 & $100 \mathrm{mM}$ \\
\hline dNTPs & 4 & $10 \mathrm{mM}$ \\
\hline $\mathrm{d}(\mathrm{T})_{15}$ Primer & 8 & $/$ \\
\hline SuperScript II & 2 & $/$ \\
\hline
\end{tabular}




\subsubsection{Polymerase Kettenreaktion}

Die Polymerase Kettenreaktion (polymerase chain reaction, PCR) dient der spezifischen Amplifikation von Nukleinsäuren (Mullis et al., 1986). Dabei wird die zu amplifizierende Zielsequenz der DNA von zwei Oligonukleotiden (Primer) flankiert. Der forward-Primer bindet an den so genannten sense-Strang, der reverse-Primer hingegen an den so genannten antisense-Strang. Von diesem Startpunk aus synthetisiert eine hitzestabile DNA-Polymerase den neuen DNAStrang durch Verknüpfung von Desoxynukleosidtriphosphaten (dNTPs).

Die klassische PCR besteht aus drei Schritten. Nach der Denaturierung der doppelsträngigen DNA bei $95^{\circ} \mathrm{C}$ erfolgt die Anlagerung der Primer an die DNAEinzelstränge bei einer Primer-spezifischen Temperatur (Annealing). Die DNAPolymerase ist anschließend in der Lage an die Primer zu binden und den fehlenden DNA-Strang neu zu synthetisieren (Elongation). Die Elongation findet bei $72^{\circ} \mathrm{C}$ statt, dem Temperaturoptimum der in dieser Arbeit verwendeten TaqDNA-Polymerase, die ihren Ursprung im Organismus Thermus aquaticus (Saiki et al., 1988) besitzt. Die zyklische Wiederholung der Reaktionsschritte führt zu einer exponentiellen Vervielfältung der DNA.

Tab. 3.4: Standard-Reaktionsansatz für die PCR

\begin{tabular}{|l|l|l|}
\hline Material & Einsatz $[\mu \mathrm{l}]$ & Ausgangskonzentration \\
\hline $\mathrm{H}_{2} \mathrm{O}$ & 11,1 & $/$ \\
\hline dNTPs & 1,2 & $1 \mathrm{mM}$ \\
\hline PCR-Puffer & 1,5 & $10 \mathrm{x}$ \\
\hline DNA-template & 0,6 & $10-100 \mathrm{ng} / \mu \mathrm{l}$ \\
\hline forward-Primer & 0,3 & $20 \mu \mathrm{M}$ \\
\hline reverse-Primer & 0,3 & $20 \mu \mathrm{M}$ \\
\hline Taq-Polymerase & 0,075 & $5 \mathrm{U} / \mu \mathrm{l}$ \\
\hline Gesamtvolumen & 15 & $/$ \\
\hline
\end{tabular}


Tab. 3.5: Parameter der spezifischen PCR-Programme

\begin{tabular}{|l|l|l|l|}
\hline Gen & Denaturierung & Annealing & Elongation \\
\hline CDH1 & $30 \mathrm{~s}, 94^{\circ} \mathrm{C}$ & $60 \mathrm{~s}, 61^{\circ} \mathrm{C}$ & $60 \mathrm{~s}, 72^{\circ} \mathrm{C}$ \\
\hline CTSB & $60 \mathrm{~s}, 94^{\circ} \mathrm{C}$ & $60 \mathrm{~s}, 62^{\circ} \mathrm{C}$ & $60 \mathrm{~s}, 72^{\circ} \mathrm{C}$ \\
\hline CYR61 & $60 \mathrm{~s}, 94^{\circ} \mathrm{C}$ & $60 \mathrm{~s}, 55^{\circ} \mathrm{C}$ & $60 \mathrm{~s}, 72^{\circ} \mathrm{C}$ \\
\hline GnRH-I R & $30 \mathrm{~s}, 94^{\circ} \mathrm{C}$ & $30 \mathrm{~s}, 60^{\circ} \mathrm{C}$ & $45 \mathrm{~s}, 72^{\circ} \mathrm{C}$ \\
\hline L7 & $30 \mathrm{~s}, 94^{\circ} \mathrm{C}$ & $60 \mathrm{~s}, 54^{\circ} \mathrm{C}$ & $120 \mathrm{~s}, 72^{\circ} \mathrm{C}$ \\
\hline OPG & $30 \mathrm{~s}, 94^{\circ} \mathrm{C}$ & $60 \mathrm{~s}, 64^{\circ} \mathrm{C}$ & $90 \mathrm{~s}, 72^{\circ} \mathrm{C}$ \\
\hline PTHrP & $30 \mathrm{~s}, 94^{\circ} \mathrm{C}$ & $60 \mathrm{~s}, 58^{\circ} \mathrm{C}$ & $60 \mathrm{~s}, 72^{\circ} \mathrm{C}$ \\
\hline PTHrP-R & $60 \mathrm{~s}, 94^{\circ} \mathrm{C}$ & $60 \mathrm{~s}, 60^{\circ} \mathrm{C}$ & $60 \mathrm{~s}, 72^{\circ} \mathrm{C}$ \\
\hline RANKL & $30 \mathrm{~s}, 94^{\circ} \mathrm{C}$ & $60 \mathrm{~s}, 62^{\circ} \mathrm{C}$ & $45 \mathrm{~s}, 72^{\circ} \mathrm{C}$ \\
\hline S100A4 & $60 \mathrm{~s}, 94^{\circ} \mathrm{C}$ & $60 \mathrm{~s}, 58^{\circ} \mathrm{C}$ & $60 \mathrm{~s}, 72^{\circ} \mathrm{C}$ \\
\hline
\end{tabular}

Als Kontrolle für die semiquantitative PCR wurde zusätzlich eine Amplifikation von L7 durchgeführt. L7 kodiert ein ribosomales Protein, welches in allen Geweben exprimiert wird und wurde als Housekeeping-Gen verwendet. Die Auftrennung der PCR-Produkte erfolgte durch Agarose-Gelelektrophorese. Danach wurden die Ergebnisse dokumentiert und ausgewertet.

\subsubsection{Agarose-Gelelektrophorese}

Die Agarose-Gelelektrophorese ist eine molekularbiologische Methode, die es ermöglicht DNA nach ihrer Größe in einer Matrix aus Agarose aufzutrennen (McDonell et al., 1977). Durch Anlegen einer Gleichspannung wandern dabei die negativ geladenen Nukleinsäure-Stränge zur positiv geladenen Anode, wobei kleinere Moleküle schneller durch das Agarosegel wandern als größere. Um eine Dokumentation der zu analysierenden DNA durchzuführen, werden die Nukleinsäure-Banden durch interkalierende Farbstoffe wie z.B. Ethidiumbromid $(\mathrm{EtBr})$ sichtbar gemacht. Dieser ist in der Lage nach Einlagerung in die DNADoppelhelix unter UV-Licht von 302 nm Wellenlänge zu fluoreszieren.

Für die Herstellung der Gele wurde Agarose (1,5\%) in 1x TBE-Puffer in der Mikrowelle durch Kochen gelöst und in eine Gelkammer mit eingestecktem Kamm gegossen. Nach dem Aushärten wurde das Gel mit 1x TBE-Puffer in der 
Elektrophoresekammer überschichtet und der Gelkamm gezogen. Die DNAProben $(10 \mu \mathrm{l})$ wurden mit jeweils $2 \mu \mathrm{l} 10$ x DNA-Ladepuffer versetzt und in die Geltaschen pipettiert. Als Referenz diente ein DNA-Fragmentlängen-Standard (100 bp Ladder, Invitrogen, Karlsruhe). Die Auftrennung der DNA erfolgte bei $85 \mathrm{~V}$ mit einer Laufzeit von ca. $45 \mathrm{~min}$. Der im 10 x DNA-Ladepuffer enthaltene Farbstoff Bromphenolblau ermöglicht dabei ein Abschätzen der Laufstrecke. Die Gele wurden anschließend für 20 min im EtBr-Bad gefärbt und in $d_{d H_{2}} \mathrm{O}$ gewaschen. Dokumentation und Auswertung der Ergebnisse erfolgten im UVTransilluminator unter Verwendung der BioDocAnalyze 2.1 Software (Biometra, Göttingen).

\subsubsection{Gene Array}

Mit Hilfe der Gene Array-Technik wird die simultane Analyse der Expression einer Vielzahl von Genen ermöglicht (Joussen \& Huang, 2001). Dabei wird die zu untersuchende RNA in eine Biotin-16-dUTP-markierte cDNA umgewandelt und anschließend an eine Membran gebunden, die als Träger der genspezifischen Zielsequenzen dient. Die Bindung von Biotin und Streptavidin führt weiterhin zur Kopplung einer alkalischen Phosphatase an die gelabelten cDNA-Sonden und zur Umsetzung der lumineszierenden Verbindung CDPStar $^{T M}$. Die freigesetzte Chemilumineszenz wird detektiert und stellt ein Maß für die Expressionsrate der analysierten Gene dar.

In dieser Arbeit wurde der Human Tumor Metastasis Gene Array (GEArray Q Series) sowie das zugehörige GEArray RT-Labeling Kit der Firma SuperArray Bioscience Corporation (Maryland, USA) verwendet.

\subsubsection{Synthese Biotin-16-dUTP-markierter cDNA-Sonden}

Die Synthese der Biotin-16-dUTP-markierten cDNA-Sonden wurde mit Hilfe des GEArray RT-Labeling Kits durchgeführt. Die Reaktionsansätze aus $3 \mu \mathrm{g}$ RNA, $3 \mu$ l Puffer A (mit enthaltenem GEA-Primer-Mix) wurden mit RNase-freiem $\mathrm{H}_{2} \mathrm{O}$ auf ein Endvolumen von $10 \mu \mathrm{l}$ gebracht und für $3 \mathrm{~min}$ bei $70^{\circ} \mathrm{C}$ und weitere $2 \mathrm{~min}$ bei $42^{\circ} \mathrm{C}$ inkubiert. Anschließend erfolgte die Zugabe von jeweils $10 \mu \mathrm{l}$ eines Enzym-Mix (siehe Tabelle 3.6) mit einer Inkubationszeit von 90 min bei $42^{\circ} \mathrm{C}$ sowie $5 \min$ bei $94^{\circ} \mathrm{C}$. 
Tab. 3.6: Enzym-Mix für den Gene Array

\begin{tabular}{|l|l|l|}
\hline Material & Einsatz $[\mu \mathrm{l}]$ & Ausgangskonzentration \\
\hline \hline Puffer BN & 4 & $5 \mathrm{x}$ \\
\hline Biotin-16-dUTP & 2 & $1 \mathrm{mM}$ \\
\hline RNase Inhibitor & 1 & $40 \mathrm{U} / \mu \mathrm{l}$ \\
\hline Reverse Transkriptase & 0,5 & $200 \mathrm{U} / \mu \mathrm{l}$ \\
\hline $\mathrm{H}_{2} \mathrm{O}$ (RNase-frei) & 2,5 & $/$ \\
\hline Gesamtvolumen & 10 & $/$ \\
\hline
\end{tabular}

\subsubsection{Hybridisierung}

Die Hybridisierung der GEArray Membranen wurde im Hybridisierungsofen durchgeführt. Zunächst wurden die Membranen in $3 \mathrm{ml}$ vorgewärmter $\left(60^{\circ} \mathrm{C}\right)$ GEAhyb Hybridisierungslösung mit $100 \mu \mathrm{g} / \mathrm{ml}$ Lachssperma DNA (Invitrogen, Karlsruhe) für $1-2 \mathrm{~h}$ unter Rotation prähybridisiert. Dieser Schritt dient der Absättigung unspezifischer Bindungsstellen. Anschließend wurden die fertigen cDNA-Sonden in $750 \mu \mathrm{l}$ GEAhyb Hybridisierungslösung $\left(60^{\circ} \mathrm{C}\right)$ überführt und die Prähybridisierungslösung durch diese ersetzt. Die Hybridisierung der Membranen erfolgte ebenfalls unter Rotation bei $60^{\circ} \mathrm{C}$ über Nacht.

Im Anschluss wurden die Membranen bei $60^{\circ} \mathrm{C}$ zweimal $15 \mathrm{~min}$ mit $5 \mathrm{ml}$ Waschpuffer I ( $2 \times$ SSC, $1 \%$ SDS) und zweimal 15 min mit $5 \mathrm{ml}$ Waschpuffer II $(0,1 \times$ SSC, $0,5 \%$ SDS $)$ gewaschen.

\subsubsection{Detektion und Visualisierung}

Zum Nachweis der hybridisierten cDNA-Sonden wurden die Membranen in $2 \mathrm{ml}$ GEA-Blockierungslösung $Q$ für 40 min und für weitere 10 min in $2 \mathrm{ml}$ Puffer $F$ mit darin enthaltener Streptavidin-gekoppelter alkalischer Phosphatase (1:8000) inkubiert. Es folgten vier Waschvorgänge für jeweils 5 min mit $4 \mathrm{ml}$ Puffer $F$ und zwei Waschvorgänge mit $3 \mathrm{ml} 1$ x AP-Assay-Puffer G. Anschließend wurden die Membranen mit $500 \mu \mathrm{l}$ CDP-Star ${ }^{\mathrm{TM}}$ bei RT inkubiert $(2 \mathrm{~min}$ ). Die ausgelöste Chemilumineszenz wurde unter Verwendung von Röntgenfilmen detektiert. Es wurden Röntgenfilme von der Firma Kodak (Stuttgart) verwendet, die nach ihrer 
Exposition in einer Röntgenfilmkassette (Barthel X-Ray $\mathrm{GmbH}$, München) im SRS-101A Röntgenfilmentwickler (Konica, Langenhagen) entwickelt wurden.

\subsubsection{Strippen von GEArray Membranen}

Für eine erneute Hybridisierung der GEArray Membranen wurden diese gestrippt und somit von den bereits gebundenen cDNA-Sonden befreit. Die verwendete $0,1 \%$-ige SDS-Lösung wurde zunächst auf $60^{\circ} \mathrm{C}$ vorgewärmt und die Membranen mit $1 \mathrm{ml}$ dieser Lösung gespült. Anschließend wurden die Membranen mit jeweils $4 \mathrm{ml}$ SDS-Lösung für $25-30 \mathrm{~min}$ bei $60^{\circ} \mathrm{C}$ unter Rotation im Hybridisierungsofen gewaschen. Dieser Vorgang wurde maximal zweimal pro Membran wiederholt und die Membranen bis zur weiteren Verwendung mit Waschpuffer II (siehe Kapitel 3.3.6.2) benetzt.

\subsubsection{Real-time PCR}

Die Real-time PCR basiert auf der Methode der konventionellen Standard-PCR, wobei die Detektion der PCR-Produkte nicht als Endpunktbestimmung, sondern in Echtzeit (real-time) erfolgt. Dies wird durch die Verwendung fluoreszierender Farbstoffe ermöglicht, deren Fluoreszenzintensität nach jedem einzelnen Zyklus bestimmt wird und mit der akkumulierenden Produktmenge korreliert (Higuchi et al., 1993).

\subsubsection{TaqMan ${ }^{\circledR}$-Methode}

In der vorliegenden Arbeit wurde eine TaqMan ${ }^{\circledR}$-Real-time PCR durchgeführt. Hierbei kommt es neben den üblichen Primern zum zusätzlichen Einsatz einer $\operatorname{TaqMan}^{\circledR}$-Sonde. Die Sequenz der Sonde entspricht einem Sequenzabschnitt, der sich zwischen forward- und reverse-Primer des zu amplifizierenden DNAStranges befindet. An ihrem 5 -Ende verfügt diese Sonde über einen kovalent gebundenen Fluoreszenzfarbstoff (Reporter, Fluoreszein-Derivat), am $3 `$-Ende ist sie über ein Linker-Arm-modifiziertes-Nukleotid (LAN) mit einem ebenfalls fluoreszierenden Farbstoff, dem so genannten Quencher (Rhodamin-Derivat) gekoppelt. Außerdem befindet sich am 3`-Ende eine Phosphatgruppe, damit die Sonde bei der Elongation nicht als Primer fungieren kann. Wird die Sonde bei einer spezifischen Wellenlänge von $488 \mathrm{~nm}$ zur Fluoreszenz angeregt, so 
bleibt das Fluoreszenzsignal des Reporterfarbstoffes aufgrund der Nähe zum Quencher unterdrückt (FRET, fluorescence resonance energy transfer). Erst bei der Synthese des neuen DNA-Stranges während der PCR-Reaktion wird die TaqMan $^{\circledR}$-Sonde durch die Endonukleaseaktivität der DNA-Polymerase geschnitten, Reporter und Quencher räumlich voneinander getrennt und das Fluoreszenzsignal des Reporterfarbstoffes messbar. Sonden, die frei und nicht hybridisiert vorliegen, werden hingegen nicht hydrolysiert. In jedem Zyklus der TaqMan ${ }^{\circledR}$-Real-time PCR kommt es zur Freisetzung neuer Reporter-Moleküle. Die Fluoreszenz steigt folglich proportional zur Anzahl synthetisierter PCRProdukte an.

\subsubsection{Primer- und Sondendesign}

Mit der TaqMan ${ }^{\circledR}$-Real-time PCR wurde der Anteil von humaner DNA in muriner DNA unter Verwendung einer humanspezifischen Alu-Sequenz bestimmt. Diese Alu-Sequenz gehört zu einer Familie repetitiver DNA-Sequenzen, die sich nur im Genom von Primaten befinden (Batzer \& Deininger, 2002) und in murinem Gewebe nicht detektierbar sind. Primer- und Sondendesign der eingesetzten Alu-Sequenz erfolgte nach Munoz et al. (2005). Als Reporterfarbstoff wurde Yakimo Yellow ${ }^{\circledR}$ und als Quencherfarbstoff der nicht-fluoreszierende Black Hole Quencher-1 (BHQ-1) eingesetzt. Dieser Quencher emittiert das aufgenommene Licht nicht als Licht anderer Wellenlänge, sondern als Wärme und eignet sich insbesondere für die Multiplex-PCR, da er nicht mit der Messung interferiert. Um eine relative Quantifizierung der TaqMan ${ }^{\circledR}$-Real-time PCR durchführen zu können, wurde parallel zur Alu-Sequenz die Amplifikation eines HousekeepingGens durchgeführt, das sowohl humane als auch murine DNA detektiert. Dafür wurde das 18S rRNA Control Kit der Firma Eurogentec (Köln) verwendet, das sowohl spezifische Primer als auch eine Sonde enthält. Die Sonde ist mit dem Reporterfarbstoff FAM (6-Carboxy-Fluoreszein) und dem Quencherfarbstoff TAMRA (6-Carboxy-Tetramethyl-Rhodamin) gekoppelt.

Durch spezifische Emissionspektren der beiden eingesetzten Reporterfarbstoffe Yakimo Yellow $^{\circledR}(\lambda=552 \mathrm{~nm})$ und FAM $(\lambda=518 \mathrm{~nm})$ können sowohl die Alu- als auch die 18S rRNA-Sequenz gleichzeitig in einer Reaktion amplifiziert werden. Die Anregung der Fluoreszenzfarbstoffe erfolgte bei $488 \mathrm{~nm}$. 


\subsubsection{Durchführung und Dokumentation}

Die TaqMan ${ }^{\circledR}$-Real-time PCR wurde im ABI PRISM ${ }^{T M} 7700$ Sequence Detector (Applied Biosystems, Darmstadt) durchgeführt. Um die verwendeten TaqMan ${ }^{\circledR}$ Sonden zu schützen, erfolgten alle Vorarbeiten ohne direkte Lichteinstrahlung. Die Reaktionen wurden mit jeweils $25 \mu$ Ansätzen gefahren. Zunächst wurde ein Enzym-Mix hergestellt (siehe Tabelle 3.7) und in einer 96 Well Multiply ${ }^{\circledR}$ PCR-Platte (Sarstedt, Nümbrecht) vorgelegt. Im Anschluss erfolgte die Zugabe von $1 \mu$ l DNA-Template, wobei alle DNA-Proben zuvor auf $50 \mathrm{ng} / \mu \mathrm{l}$ verdünnt wurden. Die Platte wurde mit Hilfe der zugehörigen Multiply ${ }^{\circledR}$ 8er-Deckelketten fest verschlossen, kurz anzentrifugiert und in den ABI PRISM ${ }^{\mathrm{TM}} 7700$ Sequence Detector überführt. Dem eigentlichen PCR-Programm wurde eine zweiminütige Inkubation bei $50^{\circ} \mathrm{C}$ vorgeschalten. Dabei wurde die im Enzym-Mix enthaltene Uracil-N-Glycosylase aktiviert, welche zur Vermeidung falscher Signale durch PCR-Kontaminationen dient (Longo et al., 1990). Im weiteren Verlauf erfolgte eine Inkubation für $10 \mathrm{~min}$ bei $95^{\circ} \mathrm{C}, 15 \mathrm{~s}$ bei $95^{\circ} \mathrm{C}$ sowie $1 \mathrm{~min}$ bei $60^{\circ} \mathrm{C}$. Die letzten beiden Zyklen wurden 39 Mal wiederholt.

Alle Proben wurden in Dreifachbestimmung vermessen. Zusätzlich wurde bei jedem Reaktionslauf zur Kontrolle eine Probe ohne DNA-Template (no template control, NTC) mitgeführt.

Tab. 3.7: Enzym-Mix für die TaqMan $^{\circledR}$-Real-time PCR

\begin{tabular}{|l|l|l|}
\hline Material & Einsatz $[\mu \mathrm{l}]$ & Ausgangskonzentration \\
\hline \hline TaqMan $\left.{ }^{(}\right)$PCR U. Master Mix & 12,5 & $2 \mathrm{x}$ \\
\hline Alu forward-Primer & 1 & $22,5 \mathrm{pmol} / \mu \mathrm{l}$ \\
\hline Alu reverse-Primer & 1 & $22,5 \mathrm{pmol} / \mu \mathrm{l}$ \\
\hline Alu Sonde & 1 & $6,25 \mathrm{pmol} / \mu \mathrm{l}$ \\
\hline 18S rRNA Primermix & 1,5 & $10 \mu \mathrm{M}$ \\
\hline 18S rRNA Sonde & 0,5 & $6,25 \mu \mathrm{M}$ \\
\hline DNA-Template & 1 & $50 \mathrm{ng} / \mu \mathrm{l}$ \\
\hline $\mathrm{H}_{2} \mathrm{O}$ & 6,5 & $/$ \\
\hline Gesamtvolumen & 25 & $/$ \\
\hline
\end{tabular}


Im verwendeten TaqMan ${ }^{\circledR}$ Universal Master Mix (Applied Biosystems) ist als weiterer Fluoreszenzfarbstoff ROX (6-Carboxy-X-Rhodamin) enthalten. Dieser dient als passive Referenz zur Normalisierung des Reporterfluoreszenzsignals während der Datenaufnahme. So können Fluoreszenzschwankungen aufgrund von Konzentrations- oder Volumenunterschieden in den einzelnen Reaktionen korrigiert werden. Zusätzlich wird das binnen der ersten PCR-Zyklen erfasste Hintergrundsignal abgezogen (siehe Formel 3.2).

Formel 3.2: Normalisierung der Emissionsintensität durch eine passive Referenz

$$
\Delta R_{n}=\left(R_{n}^{+}\right)-\left(R_{n}^{-}\right)
$$

$\mathrm{R}_{\mathrm{n}}{ }^{+}$: Emissionsintensität des Reporters/Emissionsintensität der passiven Referenz einer Probe

$\mathrm{R}_{\mathrm{n}}{ }^{-}$: Emissionsintensität des Reporters/Emissionsintensität der passiven Referenz einer Probe während der ersten PCR-Zyklen (Hintergrundsignal)

Die Zyklenanzahl, bei welcher das Fluoreszenzsignal $\left(\Delta R_{n}\right)$ einer Probe das Hintergrundsignal signifikant überschreitet, wird als Schwellenwertzyklus (Cycle Threshold, $\mathrm{C}_{\mathrm{t}}$ ) definiert. Durch den $\mathrm{C}_{\mathrm{t}}$-Wert lassen sich vergleichende Aussagen zur quantitativen Ausgangsmenge der DNA treffen. Der Schwellenwert wird für alle Messwerte innerhalb eines Reaktionslaufes gleich gehalten.

Dokumentation und Berechnung der $\mathrm{C}_{\mathrm{t}}$-Werte wurden unter Verwendung der ABI PRISM ${ }^{\mathrm{TM}} 7700$ Sequence Detection Software 1.9.1 (Applied Biosystems) durchgeführt.

\subsubsection{Quantifizierung}

Um die gewonnenen Daten zu normalisieren, wurden die $\mathrm{C}_{\mathrm{t}}$-Werte des Zielgens (Alu-Sequenz) auf die $\mathrm{C}_{\mathrm{t}}$-Werte des Housekeeping-Gens (18S rRNA) bezogen (siehe Formel 3.3).

Formel 3.3: Normalisierung der $\mathrm{C}_{\mathrm{t}}$-Werte durch ein Housekeeping-Gen

$$
\Delta \mathrm{C}_{\mathrm{t}}=\mathrm{C}_{\mathrm{t}}(\text { Zielgen })-\mathrm{C}_{\mathrm{t}}(\text { Housekeeping-Gen })
$$


Die $\Delta \mathrm{C}_{\mathrm{t}}$-Werte wurden weiterhin mit einer 1:10 Standardverdünnungsreihe von humaner DNA in muriner DNA im Bereich von $100 \%-0,0001 \%$ verglichen. Dazu wurde die DNA aus den im Mausversuch verwendetet Zellen isoliert und in muriner DNA verdünnt. Sowohl humane als auch murine DNA wurden zuvor auf $50 \mathrm{ng} / \mu \mathrm{l}$ eingestellt. In jedem Lauf der TaqMan ${ }^{\circledR}$-Real-time PCR wurde die spezifische Standardverdünnungsreihe des untersuchten Mausmaterials (Blut, Lunge, Leber oder Knochen) mitgeführt. Anschließend wurden die $\Delta \mathrm{C}_{\mathrm{t}}-$ Werte der Standardverdünnungsreihe halblogarithmisch über den Anteil humaner DNA in muriner DNA (\%) aufgetragen. Beträgt die Steigung der so erstellten Kalibrierungskurve -3,32, handelt es sich um eine $100 \%$ effiziente PCR. Der gesuchte Anteil humaner DNA in muriner DNA der einzelnen Proben wurde über die Geradengleichung der Kalibrierungskurve ermittelt.

\subsection{Proteinbiochemische Methoden}

\subsubsection{Präparation von Zelllysaten}

Für die Herstellung von Zelllysaten wurden die Zellpellets mit PBS gewaschen, bei $300 \times g$ für 5 min zentrifugiert und anschließend in Triton X-114 ${ }^{\mathrm{TM}}$-Puffer (Sigma-Aldrich, München) resuspendiert (Bordier, 1981). Um den Abbau der Proteine zu verhindern, erfolgte zusätzlich die Zugabe eines Protease-InhibitorCocktails (Sigma-Aldrich). Die resuspendierten Zellpellets wurden bei $4^{\circ} \mathrm{C}$ über Nacht im Überkopfschüttler (Heto, Allered, DK) inkubiert und am folgenden Tag in der Kühlzentrifuge $\left(12.000 \times \mathrm{g}, 25 \mathrm{~min}, 4^{\circ} \mathrm{C}\right)$ von unlöslichen Rückständen abgetrennt. Anschließend wurde der Überstand abgenommen und eine Auftrennung der zytosolischen und membranständigen Proteinfraktion vorgenommen.

\subsubsection{Trennung von zytosolischen und membranständigen Proteinen}

Nachdem die Überstände für $10 \mathrm{~min}$ bei $37^{\circ} \mathrm{C}$ und $800 \mathrm{rpm}$ im Thermomixer inkubiert wurden, erfolgte ein Zentrifugationsschritt für $5 \mathrm{~min}$ bei $10.000 \mathrm{xg}$ (RT). Dabei wurde das Zelllysat in zwei Phasen, die zytosolische (obere Phase) und membranständige (untere Phase) Proteinfraktion aufgetrennt. Die benötigte Proteinfraktion wurde durch Zugabe von fünf Volumenteilen Aceton über Nacht 
bei $-20^{\circ} \mathrm{C}$ gefällt und anschließend für $25 \mathrm{~min}$ bei $12.000 \mathrm{x} \mathrm{g}\left(4^{\circ} \mathrm{C}\right)$ zentrifugiert. Der Überstand wurde abgenommen und die gewonnenen Proteinpellets in der SDS-Polyacrylamid-Gelelektrophorese aufgetrennt.

\subsubsection{SDS-Polyacrylamid-Gelelektrophorese}

Die eindimensionale SDS-Polyacrylamid-Gelelektrophorese (SDS-PAGE) dient der Auftrennung von Proteinen nach ihrer Größe. Die Proteine binden dabei im Überschuss zugesetztes SDS (sodium dodecyl sulfate) und erhalten somit eine negative Ladung. Diese Ladung verhält sich proportional zum Molekulargewicht und ermöglicht eine Auftrennung der SDS-Protein-Komplexe in einer Gelmatrix. Bei der in dieser Arbeit verwendeten Methode nach Laemmli (1970) werden die Proben zunächst in einem Sammelgel mit $5 \%$ Polyacrylamid (siehe Tabelle 3.8) konzentriert und anschließend in einem Trenngel mit $10 \%$ Polyacrylamid (siehe Tabelle 3.9) separiert.

Tab. 3.8: Zusammensetzung eines 5 \%igen Sammelgels

\begin{tabular}{|l|l|}
\hline Material & Einsatz \\
\hline \hline $\mathrm{H}_{2} \mathrm{O}$ & $3,1 \mathrm{ml}$ \\
\hline Prosieve 50 Gel Solution & $0,5 \mathrm{ml}$ \\
\hline $1 \mathrm{mM}$ Tris & $1,3 \mathrm{ml}$ \\
\hline $10 \%$ SDS & $50 \mu \mathrm{l}$ \\
\hline $10 \%$ APS & $50 \mu \mathrm{l}$ \\
\hline TEMED & $4 \mu \mathrm{l}$ \\
\hline
\end{tabular}

Tab. 3.9: Zusammensetzung von Trenngelen (10\% und $15 \%$, Ansatz für 2 Gele)

\begin{tabular}{|l|l|l|}
\hline Material & $10 \%$ Trenngel & $15 \%$ Trenngel \\
\hline \hline $\mathrm{H}_{2} \mathrm{O}$ & $5,3 \mathrm{ml}$ & $4,3 \mathrm{ml}$ \\
\hline Prosieve 50 Gel Solution & $2,0 \mathrm{ml}$ & $3,0 \mathrm{ml}$ \\
\hline $1 \mathrm{mM}$ Tris & $2,5 \mathrm{ml}$ & $2,5 \mathrm{ml}$ \\
\hline $10 \%$ SDS & $100 \mu \mathrm{l}$ & $100 \mu \mathrm{l}$ \\
\hline $10 \%$ APS & $100 \mu \mathrm{l}$ & $100 \mu \mathrm{l}$ \\
\hline TEMED & $4 \mu \mathrm{l}$ & $4 \mu \mathrm{l}$ \\
\hline
\end{tabular}


Für die SDS-PAGE wurde die Mini-PROTEAN ${ }^{\circledR}$ III Elektrophorese Apparatur (Bio-Rad, München) verwendet und nach Angaben des Herstellers aufgebaut. Die Proben wurden mit zweifach konzentriertem Laemmli-Probenpuffer versetzt und 3 min bei $95^{\circ} \mathrm{C}$ denaturiert. Danach wurden die Proben auf Eis abgekühlt und das Gel mit den Proben sowie einem Molekularmassenmarker (Precision Plus Protein ${ }^{\mathrm{TM}}$ Standards, Bio-Rad) beladen. Die Elektrophorese erfolgte für $30 \mathrm{~min}$ bei $80 \mathrm{~V}_{\text {const }}$ und $60 \mathrm{~min}$ bei $150 \mathrm{~V}_{\text {const }}$ in SDS-Elektrophorese-Puffer. Die aufgetrennten Proteine wurden anschließend auf Nitrocellulosemembranen transferiert.

\subsubsection{Western Blot}

Im Western Blot-Verfahren werden die elektrophoretisch aufgetrennten Proteine auf Nitrocellulosemembranen übertragen (blotting) und unter Verwendung von spezifischen Antikörpern nachgewiesen (Towbin et al., 1979).

Für den Transfer der Proteine auf die Nitrocellulosemembran $(0,2 \mu \mathrm{m}$, Hybond$\mathrm{ECL}^{\circledR}, \mathrm{GE}$ Healthcare, Freiburg) wurde das Tank System von Bio-Rad nach den Angaben des Herstellers verwendet. Dabei wurde das SDS-Gel zunächst luftblasenfrei auf die Membran und danach zwischen je zwei in Transferpuffer getränkte Filterpapiere (Whatman ${ }^{\circledR}$, Schleicher \& Schuell, Dassel) gelegt. Das so genannte Sandwich wurde zwischen zwei Schaumstoffschichten gebracht und in die Blotting-Apparatur überführt. Dabei war die Nitrocellulosemembran der Anode zugewandt. Der Protein-Transfer erfolgte für $1 \mathrm{~h}$ bei $100 \mathrm{~V}_{\text {const. }}$ Der vorgefärbten Molekularmassenmarker diente zur Kontrolle der Transfereffizienz.

\subsubsection{Detektion und Visualisierung}

Zur Absättigung unspezifischer Bindungsstellen wurden die Membranen nach dem Transfer für $1 \mathrm{~h}$ bei RT mit blocking-Lösung inkubiert und anschließend dreimal für 10 min mit TBST gewaschen. Die Inkubation mit dem primären Antikörper erfolgte bei $4^{\circ} \mathrm{C}$ über Nacht. Nach dem Wiederholen des dreimaligen Waschens mit TBST für 10 min wurden die Membranen mit dem Peroxidasegekoppelten Sekundärantikörper für $1 \mathrm{~h}$ bei RT inkubiert. Vor der Visualisierung wurden die Membranen abschließend dreimal 10 min mit TBST gewaschen. 
Zur Detektion der gebundenen Sekundärantikörper wurde der ECL (Enhanced Chemiluminescens Reaction) Kit Immobilon ${ }^{\circledR}$ Western (Millipore, Schwalbach) nach Angaben des Herstellers verwendet. Das enthaltene Reagenz wird durch die Peroxidase katalytisch umgesetzt und so eine Chemilumineszenz mit einem Maximum bei $430 \mathrm{~nm}$ hervorgerufen, welche eine Belichtung der Röntgenfilme ermöglicht (siehe Kapitel 3.3.6.3).

\subsubsection{Strippen von Nitrocellulosemembranen}

Um eine erneute Hybridisierung der verwendeten Nitrocellulosemembranen mit dem Primärantikörper zu ermöglichen, wurden diese gestrippt und von bereits gebundenen Antikörpern befreit. Dazu erfolgte eine Inkubation der Membranen mit dem Antibody Stripping Buffer der Firma Uptima Interchim (Montlucon, F) für $15 \mathrm{~min}$ bei RT und $1000 \mathrm{rpm}$. Anschließend wurden die Membranen mit $\mathrm{ddH}_{2} \mathrm{O}$ gespült, erneut mit blocking-Lösung behandelt und danach mit dem neuen Primärantikörper inkubiert. Dieser Vorgang wurde maximal zweimal pro Nitrocellulosemembran wiederholt.

\subsection{Immunzytochemische Methoden}

Für die Durchführung einer immunzytologischen Färbung wurden die Zellen in Lab-Tek $^{\mathrm{TM}}$ Chamber Slide ${ }^{\mathrm{TM}}$ Systemen der Firma Nunc (Wiesbaden) ausgesät und über $24 \mathrm{~h}$ kultiviert. Um freie Aldehydgruppen zu blockieren, wurden die Zellen mit PBS gewaschen und anschließend 30 min mit $1 \mathrm{M}$ Glycin inkubiert. Nach zwei weiteren Waschschritten mit PBST für jeweils 15 min erfolgte eine Behandlung der Zellen mit PBSTN für 10 min zur zusätzlichen Abdeckung unspezifischer Proteinbindungen. Die Inkubation mit dem Primärantikörper erfolgte bei $4^{\circ} \mathrm{C}$ über Nacht. Danach wurden die Zellen mit PBST gewaschen und für 30 min mit PBSTN inkubiert. Für die Immunfärbung wurde je nach Primärantikörper aus Kaninchen oder Maus der Histostain ${ }^{\circledR}$-SP Kit der Firma Zymed (South San Francisco, USA) nach Angaben des Herstellers verwendet. Das Diaminobenzidin (DAB) Substrat-Chromogen System von Dako (Hamburg) diente dabei als Substrat. 


\subsection{Dokumentation und statistische Analysen}

Die Dokumentation der immunzytochemisch behandelten Zellen erfolgte unter dem Mikroskop (IX51) mit Hilfe der Software analySIS getIT von Olympus. Die Ergebnisse der Western Blots wurden mittels der Kodak Digital Science 1D Image Analyse Software (Version 2.0.3) dokumentiert und analysiert. Mit Hilfe des UV-Transilluminators von Biometra und der zugehörigen BioDoc Analyze 2.1 Software erfolgte eine Dokumentation sowie Auswertung von Agarosegelen. Die Daten wurden aus mindestens drei unabhängig voneinander wiederholten Versuchen gewonnen. Für eine statistische Auswertung sowie die graphische Darstellung der Ergebnisse wurde die Software GraphPad Prism ${ }^{\circledR}$ (Version 5.0) verwendet. Die signifikanten Unterschiede wurden mittels one-way ANOVA, Newman Keuls-Test oder t-Test (gepaart) berechnet und wie folgt dargestellt: ${ }^{*} p<0,05,{ }^{* *} p<0,01$ und ${ }^{* *} p<0,001$ (nicht signifikant: n.s.). 


\section{ERGEBNISSE}

\subsection{Einfluss der GnRH Analoga auf das RANKL/OPG-System}

Das RANKL/OPG-System stellt einen wichtigen Regulationsmechanismus im Knochenstoffwechsel dar. Eine Verschiebung des Expressionsverhältnisses von RANKL zu OPG zugunsten von RANKL führt zu einer Differenzierung und Aktivierung von Osteoklasten. Dadurch wird das empfindliche Gleichgewicht von Osteoblasten und Osteoklasten gestört und es kommt folglich zum Abbau von Knochengewebe. In diesem Teil der Arbeit wurde untersucht, ob sowohl RANKL als auch OPG von humanen Mammakarzinomzellen exprimiert werden und eine Regulation dieser Faktoren durch die Anwesenheit von hOB sowie die Behandlung mit GnRH Analoga gegeben ist.

\subsubsection{Expression des GnRH-I Rezeptors in Mammakarzinomzellen}

Der Einfluss von GnRH Analoga auf das RANKL/OPG-System wurde mit dem GnRH-I Agonisten Triptorelin untersucht. Aus diesem Grund wurde zunächst eine Reihe von humanen Mammakarzinomzelllinien auf die Expression des GnRH-I Rezeptors getestet. Die Expression wurde auf mRNA-Ebene mittels RT-PCR bestimmt (siehe Abbildung 4.1).

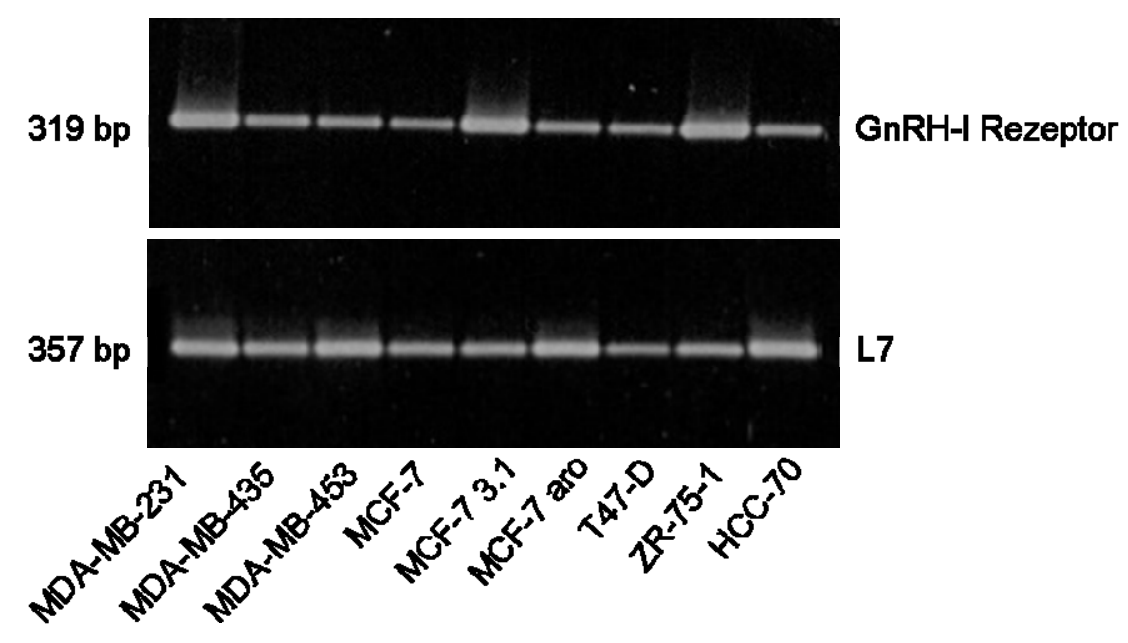

Abb. 4.1: Expression des GnRH-I Rezeptors in Mammakarzinomzellen. Die Expression des GnRH-I Rezeptors wurde auf mRNA-Ebene mittels RT-PCR bestimmt. Als Kontrolle diente das Housekeeping-Gen L7. 
In den Mammakarzinomzelllinien MDA-MB-231, MDA-MB-435, MDA-MB-453, MCF-7, MCF-7 3.1, MCF-7 aro, T47-D, ZR-75-1 sowie HCC-70 wurde eine Expression des GnRH-I Rezeptors auf mRNA-Ebene nachgewiesen. Auf eine semiquantitative Auswertung der Ergebnisse wurde verzichtet, da hier nur ein Überblick über die Rezeptor-Expression erstellt wurde.

\subsubsection{Expression von RANKL und OPG in Mammakarzinomzellen}

Im Anschluss wurden die unterschiedlichen Mammakarzinomzelllinien auf die mRNA-Expression von RANKL und OPG untersucht (siehe Abbildung 4.2).

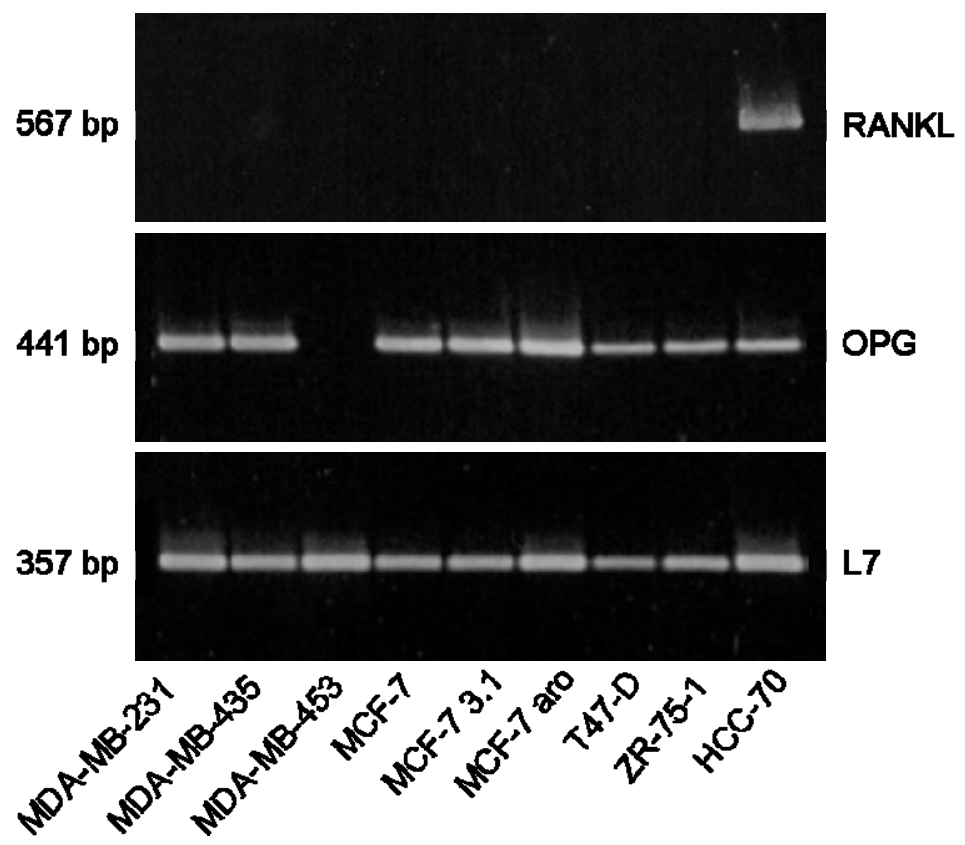

Abb. 4.2: Expression von RANKL und OPG in Mammakarzinomzellen. Die Expression von RANKL und OPG wurde auf mRNA-Ebene mittels RT-PCR bestimmt. Als Kontrolle diente das Housekeeping-Gen L7.

In den meisten Mammakarzinomzelllinien zeigte sich eine Expression von OPG. Lediglich die Zelllinie MDA-MB-453 wurde als OPG-negativ charakterisiert. Die Expression von RANKL konnte hingegen nur in HCC-70 Zellen nachgewiesen werden. Aufgrund dieser Ergebnisse wurden alle weiteren Untersuchungen in dieser Mammakarzinomzellinie durchgeführt.

Neben der mRNA-Expression sollte nun die Expression von RANKL und OPG auf Proteinebene untersucht werden. Hierfür wurden die zuvor ausgewählten 
HCC-70 Zellen immunzytochemisch mit spezifischen Antikörpern gegen RANKL und OPG gefärbt (siehe Abbildung 4.3).
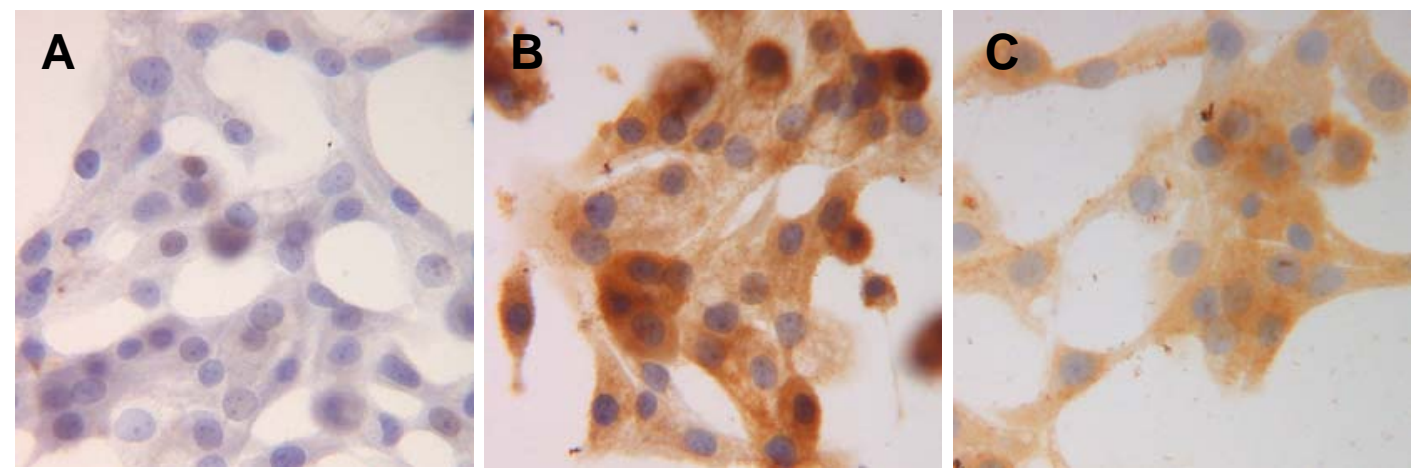

Abb. 4.3: Immunzytochemischer Nachweis der Proteinexpression von RANKL und OPG in HCC-70 Zellen. Die Proteinexpression von RANKL (B) und OPG (C) erfolgte durch immunzytologische Färbung der Zellen mit spezifischen Antikörpern. Als Kontrolle (A) wurde die Immunfärbung ohne Primärantikörper durchgeführt.

Sowohl für RANKL (B) als auch OPG (C) wurde im Vergleich zur Kontrolle (A) eine deutliche Färbung der Zellen durch die Behandlung mit den spezifischen Antikörpern sichtbar. Die Expression von RANKL und OPG findet somit in HCC70 Zellen nicht nur auf mRNA-Ebene, sondern auch auf Proteinebene statt.

\subsubsection{Einfluss von Triptorelin auf die Expression von RANKL und OPG}

Der Einfluss von Triptorelin auf die Expression von RANKL und OPG wurde im Kokultursystem analysiert. Hierbei wurden die HCC-70 Zellen ohne (Kontrolle) sowie mit hOB (Kokultur) kultiviert. Die Inkubationszeit mit Triptorelin betrug $48 \mathrm{~h}$ mit einer Konzentration von $1 \times 10^{-5} \mathrm{M}$. Die Untersuchungen wurden auf mRNA-Ebene (RT-PCR) sowie auf Proteinebene (Western Blot) durchgeführt (siehe Abbildung 4.4).

In den HCC-70 Zellen konnte während der Kokultur mit hOB ein zweifacher Anstieg der mRNA-Expression von RANKL (A) $(194,80 \pm 10,76 \%$, p<0,001) im Vergleich zur Kontrolle (100 $\pm 3,37 \%)$ nachgewiesen werden. Die gesteigerte Expression wurde durch die 48-stündige Behandlung der HCC-70 Zellen mit Triptorelin $(153,30 \pm 13,66 \%, p<0,05)$ wieder signifikant gehemmt. Die mRNAExpression von OPG (B) zeigte sowohl während der Kokultur mit hOB (112,00 $\pm 5,12 \%$, n.s.) im Vergleich zur Kontrolle (100 $\pm 4,20 \%)$ als auch durch die 
Behandlung mit Triptorelin $(108,80 \pm 6,66 \%$, n.s.) im Vergleich zur Kokultur keine Veränderung.

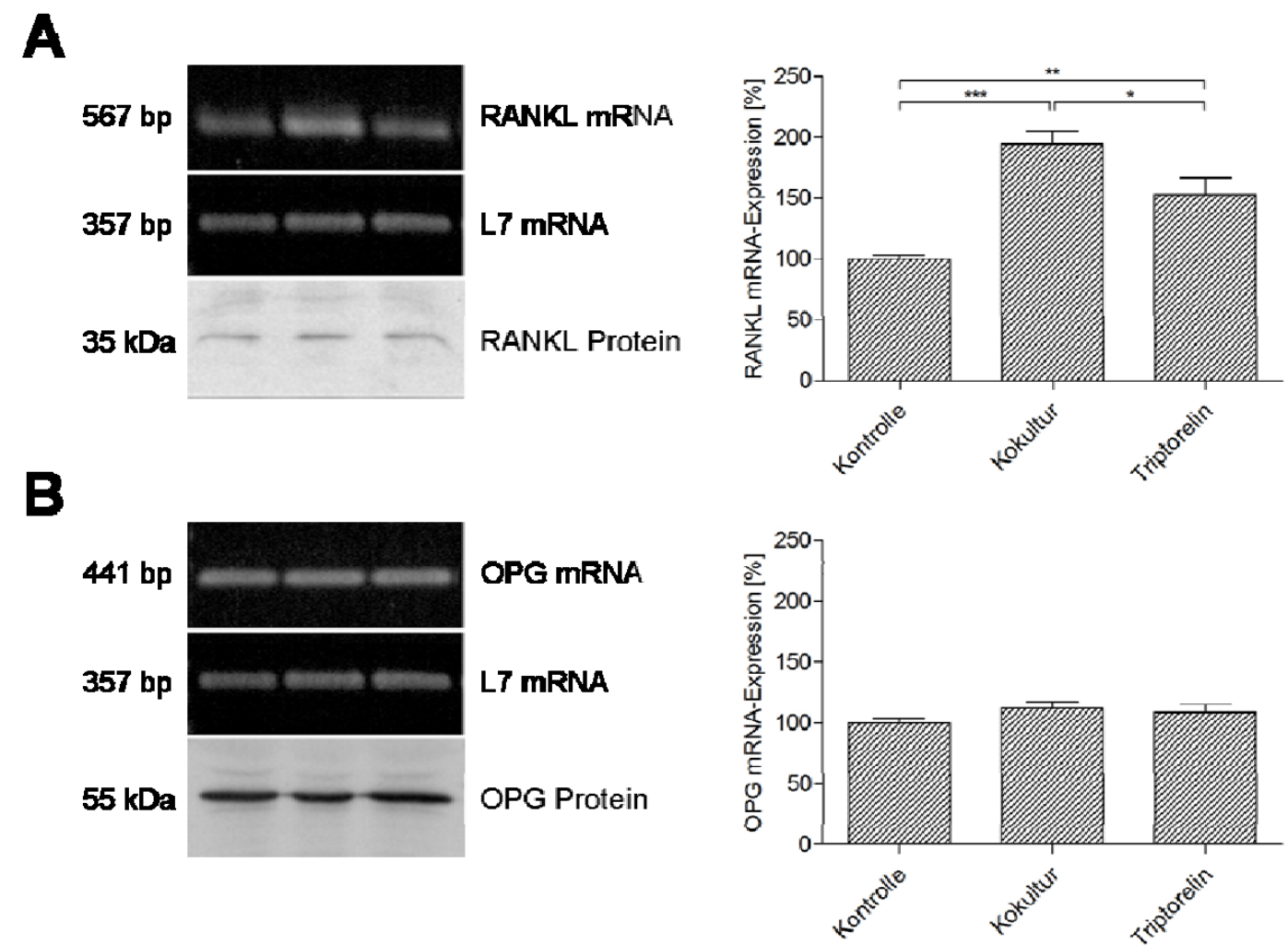

Abb. 4.4: Einfluss von Triptorelin auf die Expression von RANKL und OPG in HCC-70 Zellen. Unterschiede in der Expression von RANKL (A) und OPG (B) wurden sowohl auf mRNA-Ebene (RT-PCR) als auch auf Proteinebene (Western Blot) bestimmt. Die HCC-70 Zellen wurden ohne (Kontrolle) sowie mit hOB (Kokultur) kultiviert und für $48 \mathrm{~h}$ mit Triptorelin $\left(1 \times 10^{-5} \mathrm{M}\right)$ behandelt. Die Ergebnisse der RT-PCR wurden auf das Housekeeping Gen L7 normalisiert. Angegeben sind MW \pm SEM, Signifikanzen wurden mit one-way ANOVA, Newman Keuls-Test errechnet: * $p<0,05$ vs. Kokultur, ${ }^{* *} p<0,01$ vs. Kontrolle, ${ }^{* * *} p<0,001$ vs. Kontrolle.

In den Western Blot Analysen konnten die Ergebnisse der mRNA-Expression auf Proteinebene bestätigt werden. Hier zeigte sich in HCC-70 Zellen während der Kokultur mit hOB ebenfalls ein signifikanter Anstieg der Expression von RANKL $(217,41 \pm 7,26 \%, p<0,001)$ im Vergleich zur Kontrolle (100 \%). Durch die Behandlung mit Triptorelin wurde die Proteinexpression von RANKL $(126,67 \pm 5,23 \%, p<0,001)$ in den HCC-70 Zellen im Vergleich zur Kokultur wiederum signifikant reduziert. Eine Regulation der Expression von OPG wurde auch auf Proteinebene nicht nachgewiesen. 


\subsection{Einfluss der GnRH Analoga auf die Expression von PTHrP und PTHrP-R}

Die zuvor dargestellten Ergebnisse (siehe Kapitel 4.1.3) zeigen eine Regulation des RANKL/OPG-Systems in HCC-70 Zellen während der Kokultur mit hOB sowie durch eine Behandlung mit dem GnRH-I Agonisten Triptorelin. Bei der Aktivierung von Osteoklasten kommt neben RANKL einem weiteren Faktor, dem PTHrP eine wesentliche Rolle zu. So führt eine verstärkte Expression von PTHrP in Tumorzellen und die nachfolgende Bindung an dessen Rezeptor zu einer gesteigerten osteoklastären Aktivität (Thomas et al., 1999). Dabei ist die Stimulation der Osteoklastenaktivität nicht auf dem direkten Effekt begründet, sondern auf einer Interaktion von PTHrP mit hOB, welche den PTHrP-Rezeptor exprimieren und darauf mit einer erhöhten Expression von RANKL reagieren (Goltzman, 2001).

Für die Untersuchungen der Expression von PTHrP wurden MCF-7 und MDAMB-231 Mammakarzinomzellen verwendet. Diese unterscheiden sich in ihrer Aggressivität (MDA-MB-231 > MCF-7) und wurden ebenfalls für alle weiteren in vitro Analysen genutzt. Weiterhin wurde während der Kokultur die Expression des PTHrP-Rezeptors (PTHrP-R) in hOB untersucht.

Die Behandlung der Zellen erfolgte mit den drei GnRH-Analoga Triptorelin ( $1 \mathrm{x}$ $\left.10^{-5} \mathrm{M}\right)$, Cetrorelix $\left(1 \times 10^{-5} \mathrm{M}\right)$ sowie $\left[\mathrm{D}-\mathrm{Lys}^{6}\right] \mathrm{GnRH}-\mathrm{II}\left(1 \times 10^{-9} \mathrm{M}\right)$ für $48 \mathrm{~h}$ und die Expression wurde auf mRNA-Ebene mittels RT-PCR bestimmt.

\subsubsection{Expression von PTHrP in MCF-7 und MDA-MB-231}

Sowohl in MCF-7 (A) (Kontrolle: $100 \pm 20,79 \%$, Kokultur: 126,10 $\pm 30,22 \%$, n.s.) als auch in MDA-MB-231 Zellen (B) (Kontrolle: $100 \pm 19,77 \%$, Kokultur: $109,30 \pm 20,08 \%$, n.s.) wurde während der Kokultur mit hOB im Vergleich zur Kontrolle keine signifikant veränderte mRNA-Expression von PTHrP ermittelt (siehe Abbildung 4.5). Die Behandlung mit Triptorelin (A: 131,80 $\pm 26,84 \%$, B: $94,87 \pm 25,73 \%$, n.s.), Cetrorelix (A: 109,60 $\pm 18,05 \%$, B: 128,10 $\pm 17,39 \%$, n.s.) sowie [D-Lys $\left.{ }^{6}\right] \mathrm{GnRH}-$ II (A: 105,70 $\pm 21,73 \%$, B: $130,30 \pm 20,41 \%$, n.s.) zeigte im Vergleich zur Kokultur ebenfalls keinen Einfluss auf die mRNAExpression von PTHrP. 
A
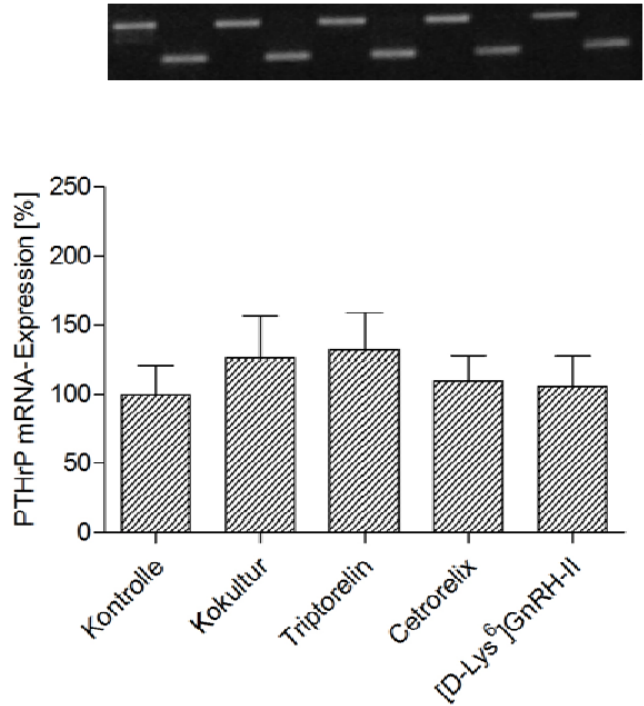

B
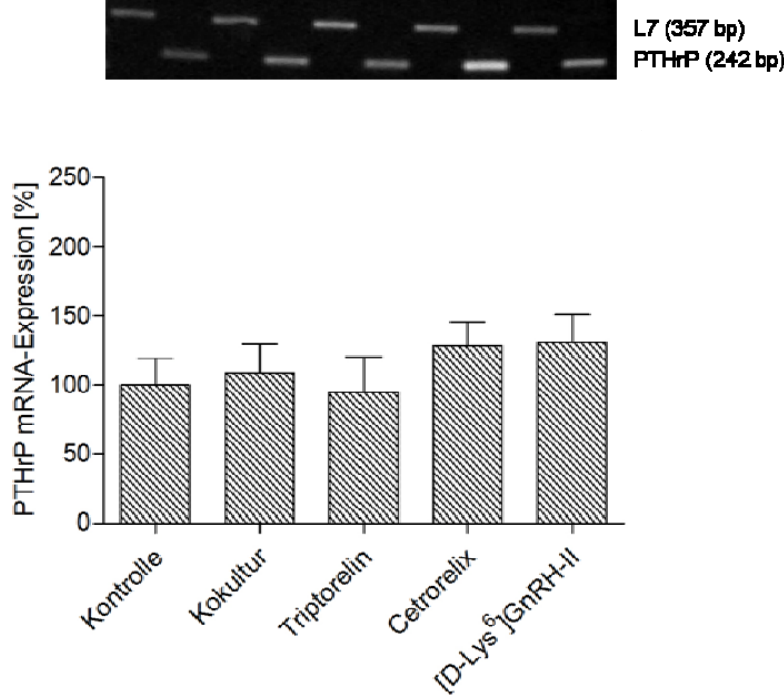

Abb. 4.5: Einfluss von GnRH Analoga auf die mRNA-Expression von PTHrP in MCF-7 (A) und MDA-MB-231 (B) Zellen. Unterschiede in der mRNA-Expression wurden mittels RT-PCR bestimmt. Die Zellen wurden ohne (Kontrolle) sowie mit hOB (Kokultur) kultiviert und für $48 \mathrm{~h}$ mit Triptorelin $\left(1 \times 10^{-5} \mathrm{M}\right)$, Cetrorelix $\left(1 \times 10^{-5} \mathrm{M}\right)$ und [D-Lys ${ }^{6}$ ] $\mathrm{GnRH}-\mathrm{II}\left(1 \times 10^{-9} \mathrm{M}\right)$ behandelt. Die Ergebnisse wurden auf das Housekeeping Gen L7 normalisiert. Angegeben sind MW \pm SEM.

\subsubsection{Expression von PTHrP-R in hOB}

Neben den beiden Mammakarzinomzelllinien MCF-7 und MDA-MB-231 wurden die verwendeten hOB auf eine mögliche Regulation der Expression von PTHrP$\mathrm{R}$ analysiert (siehe Abbildung 4.6). In den hOB, die ohne sowie mit MCF-7 Zellen (A) kultiviert wurden, fand während der Kokultur $(99,28 \pm 9,36 \%$, n.s.) im Vergleich zur Kontrolle $(100 \pm 16,81 \%)$ sowie durch die Behandlung mit den GnRH Analoga (Triptorelin: 97,25 $\pm 15,33 \%$, n.s., Cetrorelix: 71,70 $\pm 10,93 \%$, n.s., [D-Lys ${ }^{6}$ ]GnRH-II: $72,48 \pm 13,23 \%$, n.s.) im Vergleich zur Kokultur keine Modulation der mRNA-Expression von PTHrP-R statt. Wurden die hOB ohne oder mit MDA-MB-231 Zellen (B) kultiviert, zeigte sich eine tendenzielle, jedoch nicht signifikante Reduzierung der mRNA-Expression von PTHrP-R während der Kokultur $(70,62 \pm 18,07 \%$, n.s.) im Vergleich zur Kontrolle (100 $\pm 21,13 \%)$. Auch hier konnte kein Einfluss der verwendeten GnRH Analoga (Triptorelin: $65,40 \pm 11,37 \%$, n.s., Cetrorelix: 93,77 $\pm 21,61 \%$, n.s., [D-Lys ${ }^{6}$ ]GnRH-II: 83,85 $\pm 17,97 \%$, n.s.) im Vergleich zur Kokultur nachgewiesen werden. 
A
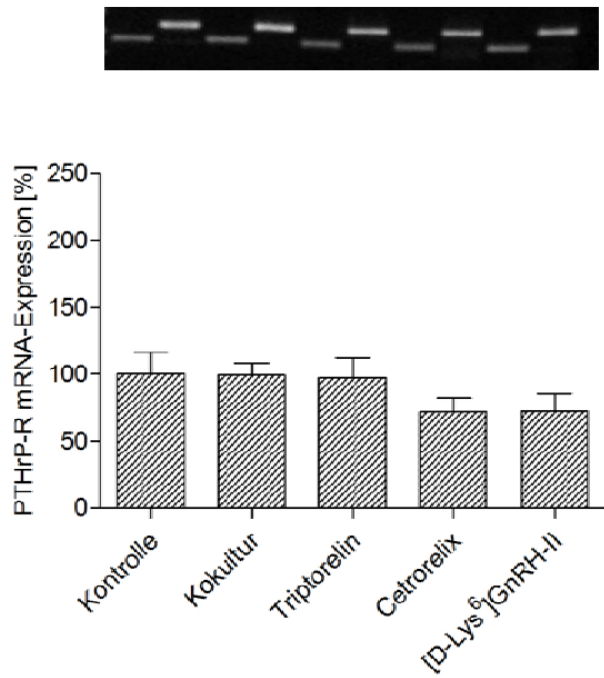

B
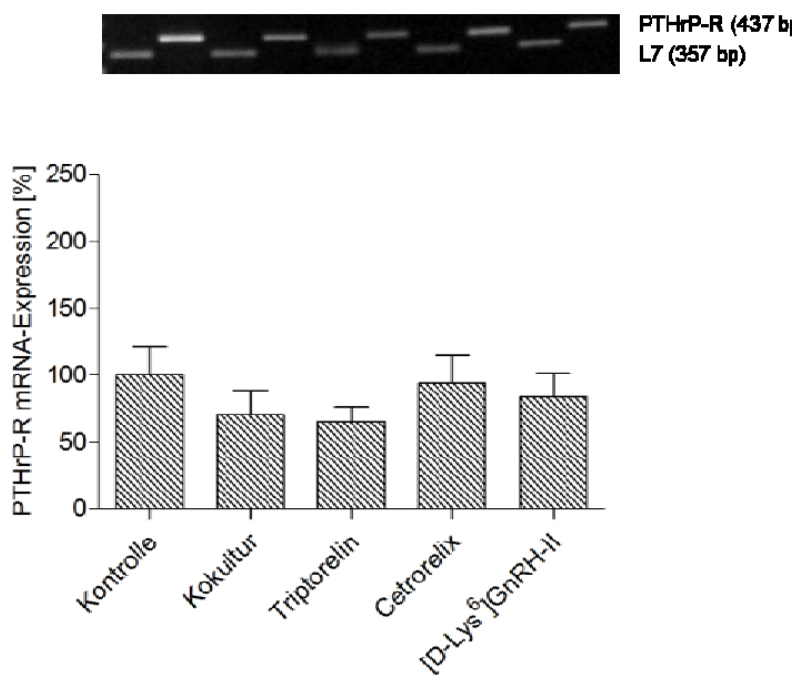

Abb. 4.6: Einfluss von GnRH Analoga auf die mRNA-Expression von PTHrP-R in hOB. Unterschiede in der mRNA-Expression wurden mittels RT-PCR bestimmt. Die hOB wurden ohne (Kontrolle) sowie mit MCF-7 (A) und MDA-MB-231 (B) Zellen (Kokultur) kultiviert. Die Inkubation der Mammakarzinomzellen erfolgte für $48 \mathrm{~h}$ mit Triptorelin $\left(1 \times 10^{-5} \mathrm{M}\right)$, Cetrorelix $\left(1 \times 10^{-5} \mathrm{M}\right)$ und [D-Lys $]$ GnRH-II $\left(1 \times 10^{-9} \mathrm{M}\right)$. Die Ergebnisse wurden auf das Housekeeping Gen L7 normalisiert. Angegeben sind MW \pm SEM.

\subsection{Interaktion der GnRH Analoga mit weiteren Faktoren der Metastasierung}

Um weitere molekulare Mechanismen der Knochen-gerichteten Invasion von Mammakarzinomzellen aufzudecken, wurde die Expression weiterer Faktoren untersucht, die direkt in den Prozess der Metastasierung involviert sind.

\subsubsection{Erstellen von Genexpressionsprofilen mittels Gene Array}

Um einen Überblick über die Expression und Regulierung Metastasierungsrelevanter Gene zu gewinnen, wurden Gene Array-Analysen durchgeführt. Auf dem dabei verwendeten Human Tumor Metastasis Gene Array (GEArray $Q$ Series) befinden sich Gene, die an Zelladhäsion, Abbau der EZM, Zellzyklus, Zellproliferation, Apoptose sowie Transkription beteiligt sind und eine wichtige Rolle in der Tumorprogression und im Prozess der Metastasierung einnehmen. Die Untersuchungen wurden sowohl in MCF-7 als auch in MDA-MB-231 Zellen vorgenommen (siehe Abbildung 4.7). 
Da nicht immer humanes Knochenmaterial für die Gewinnung von hOB zur Verfügung stand, wurden für diese und auch die folgenden in vitro Versuche Osteoblasten-ähnliche Zelllinien (MG-63 oder CAL-72) verwendet. In diesem Fall wurden MCF-7 und MDA-MB-231 Zellen ohne (Kontrolle) und mit (Kokultur) MG-63 Zellen kultiviert und für $48 \mathrm{~h}$ mit den GnRH Analoga Triptorelin $\left(1 \times 10^{-5}\right.$ $\mathrm{M})$, Cetrorelix $\left(1 \times 10^{-5} \mathrm{M}\right)$ sowie $\left[\mathrm{D}-\mathrm{Lys}^{6}\right] \mathrm{GnRH}-\|\left(1 \times 10^{-9} \mathrm{M}\right)$ behandelt.

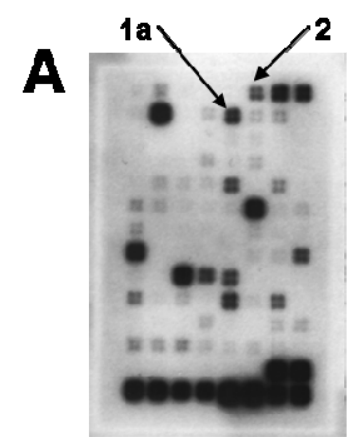

Kontrolle

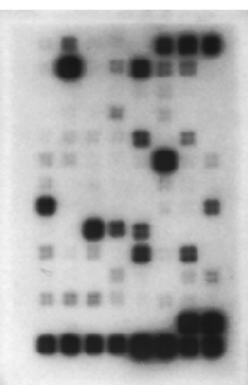

Kokultur

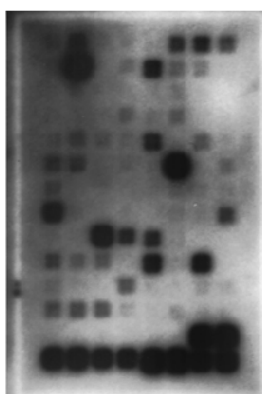

Triptorelin

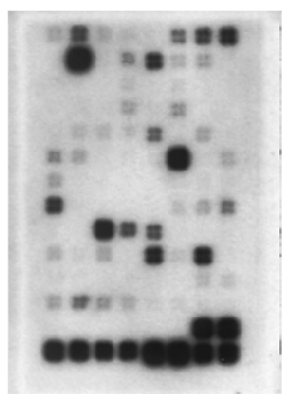

Cetrorelix

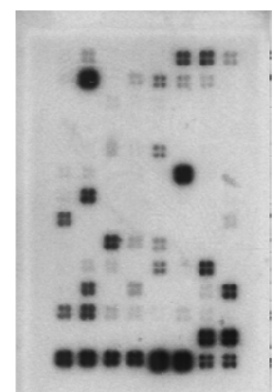

Cetrorelix
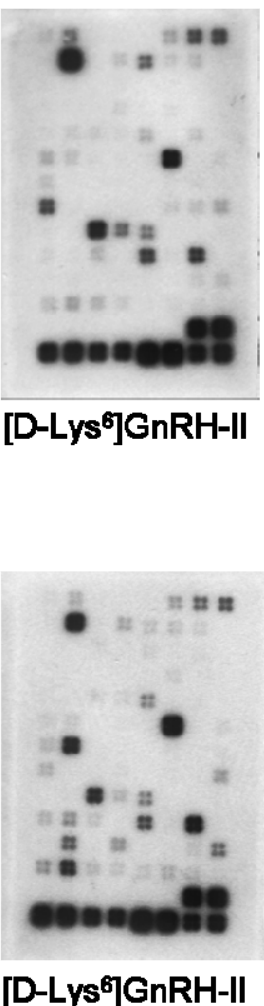

Abb. 4.7: Analysen zur Genexpression in MCF-7 (A) und MDA-MB-231 (B) Zellen mittels Human Tumor Metastasis Gene Array. Die Zellen wurden ohne (Kontrolle) sowie mit MG-63 (Kokultur) kultiviert und für $48 \mathrm{~h}$ mit Triptorelin $\left(1 \times 10^{-5} \mathrm{M}\right)$, Cetrorelix $(1 \mathrm{x}$ $\left.10^{-5} \mathrm{M}\right)$ und $\left[\mathrm{D}-\mathrm{Lys}^{6}\right] \mathrm{GnRH}-\mathrm{II}\left(1 \times 10^{-9} \mathrm{M}\right)$ behandelt. Eine Übersicht der untersuchten Gene befindet sich im Anhang (siehe Kapitel 7.2).

Die Membranen wurden auf einem Leuchtschirm unter Berücksichtigung der Genexpression der auf dem Gene Array befindlichen Housekeeping-Gene ausgewertet (siehe Tabelle 4.1) sowie geeignete Kandidatengene für weitere Untersuchungen gewählt.

In beiden Zelllinien zeigte sich eine Regulation von Cathepsin B (CTSB). CTSB ist für den hydrolytischen Abbau der EZM verantwortlich und wurde im Gene 
Array während der Kokultur mit MG-63 Zellen stärker exprimiert sowie durch alle drei getesteten GnRH Analoga wieder gehemmt. In MCF-7 Zellen zeigte sich dieser Effekt ebenfalls für das Tumorsuppressorgen Caveolin 1 (CAV1). In MDA-MB-231 Zellen wurde zusätzlich eine veränderte Expression von Cadherin $1(\mathrm{CDH} 1)$ nachgewiesen, das als Adhäsionsmolekül eine bedeutende Rolle für Zell-Zell-Kontakte spielt. Die Expression von CDH1 wurde während der Kokultur vermindert und durch Triptorelin und [D-Lys $\left.{ }^{6}\right] \mathrm{GnRH}-I I$ wieder hochreguliert. Für den Tissue inhibitor of metalloproteinases 3 (TIMP3) wurde in den MDA-MB231 Zellen ebenfalls eine Regulierung nachgewiesen. Dieser wurde während der Kokultur hochreguliert und die gesteigerte Expression wiederum durch alle drei GnRH Analoga inhibiert.

Tab. 4.1: Ausgewählte Kandidatengene des Human Tumor Metastasis Gene Array

\begin{tabular}{|l|c|c|c|c|}
\hline MCF-7 & Kokultur & Triptorelin & Cetrorelix & [D-Lys ${ }^{6}$ ]GnRH-II \\
\hline \hline Cathepsin B (1a) & $\uparrow$ & $\downarrow$ & $\downarrow$ & $\downarrow$ \\
\hline Caveolin 1 (2) & $\uparrow$ & $\downarrow$ & $\downarrow$ & $\downarrow$ \\
\hline MDA-MB-231 & Kokultur & Triptorelin & Cetrorelix & [D-Lys ${ }^{6}$ ]GnRH-II \\
\hline Cathepsin B (1b) & $\uparrow$ & $\downarrow$ & $\downarrow$ & $\downarrow$ \\
\hline Cadherin 1 (3) & $\downarrow$ & $\uparrow$ & - & $\uparrow$ \\
\hline TIMP3 (4) & $\uparrow$ & $\downarrow$ & $\downarrow$ & $\downarrow$ \\
\hline
\end{tabular}

Für intensivere Untersuchungen und zur Bestätigung der hier ermittelten Gene Array-Daten wurden die Gene CDH1 und CTSB ausgewählt.

\subsubsection{Expression von CDH1 sowie CTSB in MCF-7 und MDA-MB-231}

Die Expression von CDH1 und CTSB wurde auf mRNA-Ebene mittels RT-PCR bestimmt. Für diese Untersuchungen wurden die gleichen Bedingungen wie bei den Gene Array-Experimenten gewählt (siehe Kapitel 4.3.1).

In MCF-7 Zellen (A) zeigte sich während der Kokultur mit MG-63 Zellen (78,20 $\pm 11,67 \%$, n.s.) im Vergleich zur Kontrolle (100 $\pm 21,27 \%)$ eine leichte, nicht signifikante Reduktion der Expression von CDH1. Dieser Effekt konnte etwas verstärkt auch für die MDA-MB-231 Zellen (Kontrolle: $100 \pm 16,92 \%$, Kokultur: $67,43 \pm 9,00 \%$, n.s.) ermittelt werden (siehe Abbildung 4.8). 
A
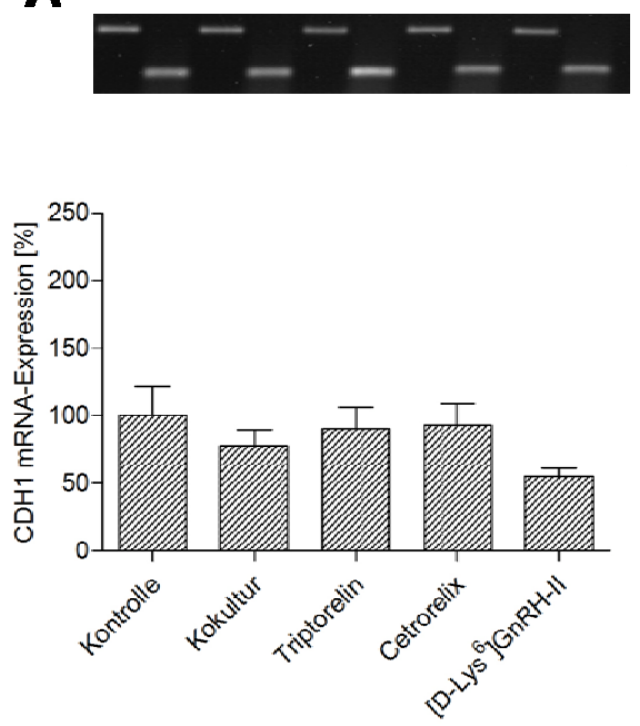

B
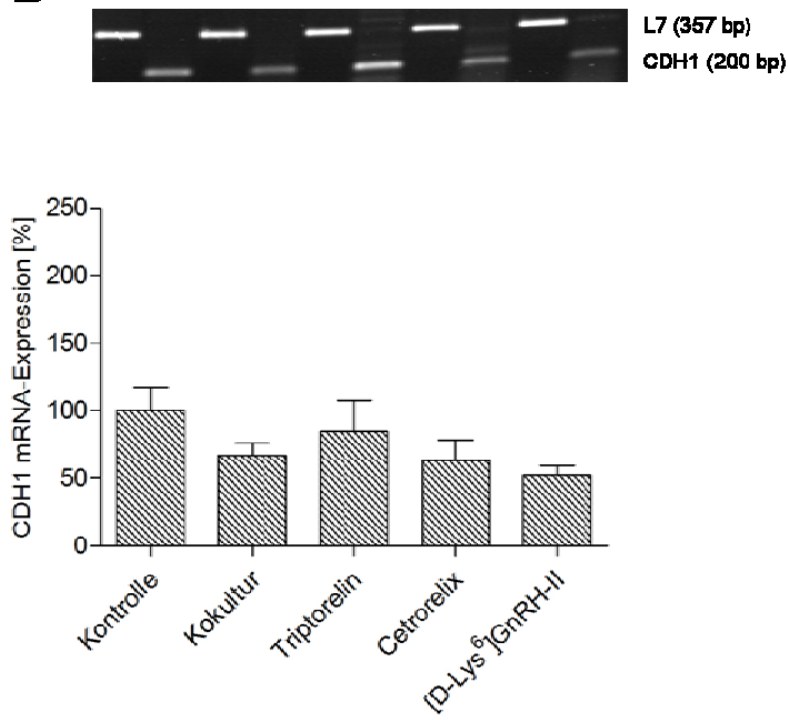

Abb. 4.8: Einfluss von GnRH Analoga auf die mRNA-Expression von CDH1 in MCF-7 (A) und MDA-MB-231 (B) Zellen. Unterschiede in der mRNA-Expression wurden mittels RT-PCR bestimmt. Die Zellen wurden ohne (Kontrolle) sowie mit MG-63 Zellen (Kokultur) kultiviert und für $48 \mathrm{~h}$ mit Triptorelin $\left(1 \times 10^{-5} \mathrm{M}\right)$, Cetrorelix $\left(1 \times 10^{-5} \mathrm{M}\right)$ und [D-Lys $\left.{ }^{6}\right] \mathrm{GnRH}-I I\left(1 \times 10^{-9} \mathrm{M}\right)$ behandelt. Die Ergebnisse wurden auf das Housekeeping Gen L7 normalisiert. Angegeben sind MW \pm SEM.

Durch die Behandlung der Zellen mit den GnRH Analoga wurde im Vergleich zur Kokultur keine signifikante Veränderung der Expression von $\mathrm{CDH} 1$ bewirkt (Triptorelin: 90,60 $\pm 15,64 \%$, n.s. (MCF-7), 84,71 $\pm 22,79 \%$, n.s. (MDA-MB231), Cetrorelix: $93,20 \pm 15,35 \%$, n.s. (MCF-7), 63,29 $\pm 15,15 \%$, n.s. (MDAMB-231, [D-Lys ${ }^{6}$ ]GnRH-II: $55,40 \pm 5,66 \%$, n.s. (MCF-7), 52,57 $\pm 6,85 \%$, n.s. (MDA-MB-231)).

Für CTSB zeigte sich vergleichbar zu den Gene Array Ergebnissen in MCF-7 Zellen während der Kokultur eine deutliche, nicht signifikante Steigerung der Expression (167,30 $\pm 25,96 \%$, n.s.) im Vergleich zur Kontrolle (100 $\pm 16,32 \%)$. Durch die Behandlung mit den GnRH Analoga Triptorelin (157,70 $\pm 18,43 \%$, n.s.), Cetrorelix $\left(149,20 \pm 13,37 \%\right.$, n.s.) und [D-Lys $\left.{ }^{6}\right] \mathrm{GnRH}-\mathrm{II}(138,70 \pm 11,18$ $\%$, n.s.) wurde das Expressionslevel von CTSB im Vergleich zur Kokultur nicht reguliert. Diese Signifikanzen wurden mittels one-way ANOVA, Newman KeulsTest errechnet. Betrachtet man Kontrolle und Kokultur im Einzelnen, zeigte sich im t-Test (gepaart) während der Kokultur eine signifikante Steigerung der CTSB Expression $(p<0,01)$ im Vergleich zur Kontrolle (siehe Abbildung 4.9). Eine 
tendenzielle Steigerung von CTSB während der Kokultur mit MG-63 Zellen $(121,60 \pm 5,88 \%$, n.s.) konnte für MCF-7 Zellen ebenfalls auf Proteinebene in Western Blot Analysen im Vergleich zur Kontrolle (100\%) detektiert werden (nicht gezeigt).

A
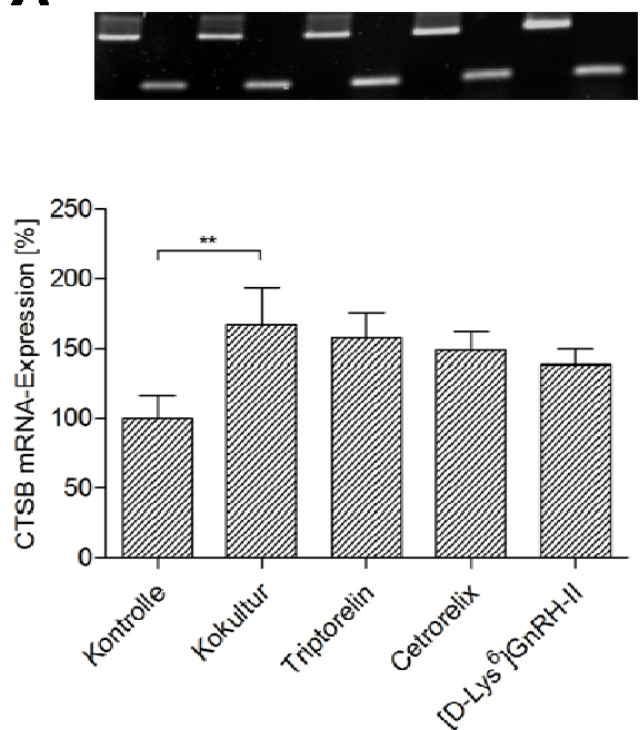

B
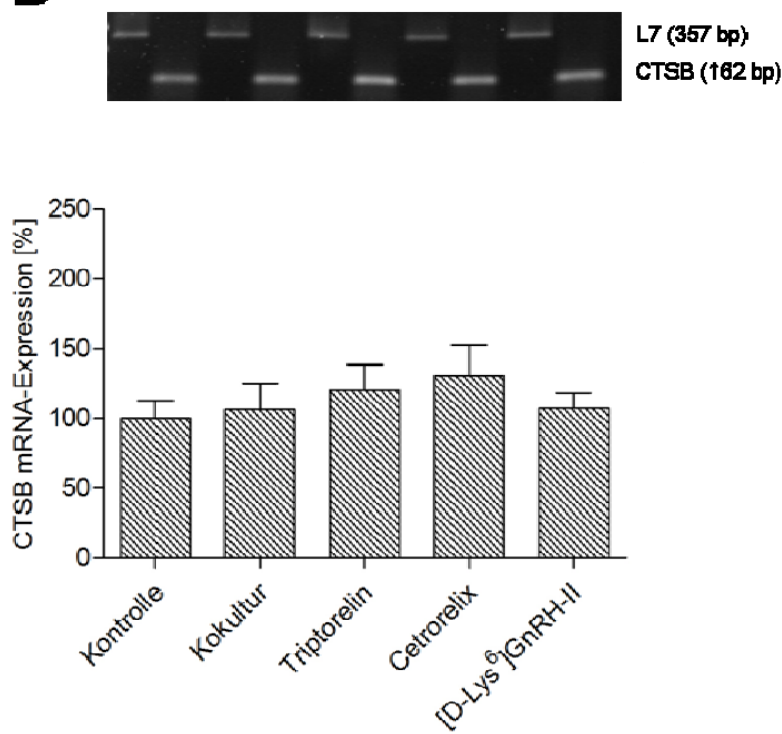

Abb. 4.9: Einfluss von GnRH Analoga auf die mRNA-Expression von CTSB in MCF-7 (A) und MDA-MB-231 (B) Zellen. Unterschiede in der mRNA-Expression wurden mittels RT-PCR bestimmt. Die Zellen wurden ohne (Kontrolle) sowie mit MG-63 Zellen (Kokultur) kultiviert und für $48 \mathrm{~h}$ mit Triptorelin $\left(1 \times 10^{-5} \mathrm{M}\right)$, Cetrorelix $\left(1 \times 10^{-5} \mathrm{M}\right)$ und [D-Lys $\left.{ }^{6}\right] \mathrm{GnRH}-\mathrm{II}\left(1 \times 10^{-9} \mathrm{M}\right)$ behandelt. Die Ergebnisse wurden auf das Housekeeping Gen L7 normalisiert. Angegeben sind MW \pm SEM, Signifikanzen wurden mittels t-Test (gepaart) errechnet: ${ }^{* \star} p<0,01$ vs. Kontrolle.

In den MDA-MB-231 Zellen wurde sowohl während der Kokultur (106,7 \pm 18,88 $\%$, n.s.) im Vergleich zur Kontrolle (100 $\pm 12,95 \%)$ als auch durch den Einfluss von Triptorelin $(120,50 \pm 18,45 \%$, n.s. $)$, Cetrorelix $(131,00 \pm 21,53 \%$, n.s.) und [D-Lys $\left.{ }^{6}\right] \mathrm{GnRH}-\mathrm{Il}(107,30 \pm 11,13 \%$, n.s) keine Regulation der Expression von CTSB nachgewiesen.

\subsubsection{Expression von S100A4 sowie CYR61 in MCF-7 und MDA-MB-231}

Des Weiteren wurden die beiden Metastasierungs-assoziierten Gene S100A4 und CYR61 untersucht. Diese werden mit einer gesteigerten Tumorprogression sowie Invasion in Zusammenhang gebracht (Jiang et al., 2004; Ismail et al., 
2008) und aus diesem Grund auch als so genannte Metastasis-promoting Gene bezeichnet.

Da sich die beiden untersuchten Mammakarzinomzellinien MCF-7 und MDAMB-231 hinsichtlich ihrer Aggressivität unterscheiden, wurde zunächst für einen Vergleich das Expressionslevel von S100A4 sowie CYR61 in beiden Zelllinien bestimmt. Diese Untersuchungen wurden auf mRNA-Ebene mittels RT-PCR durchgeführt (siehe Abbildung 4.10).
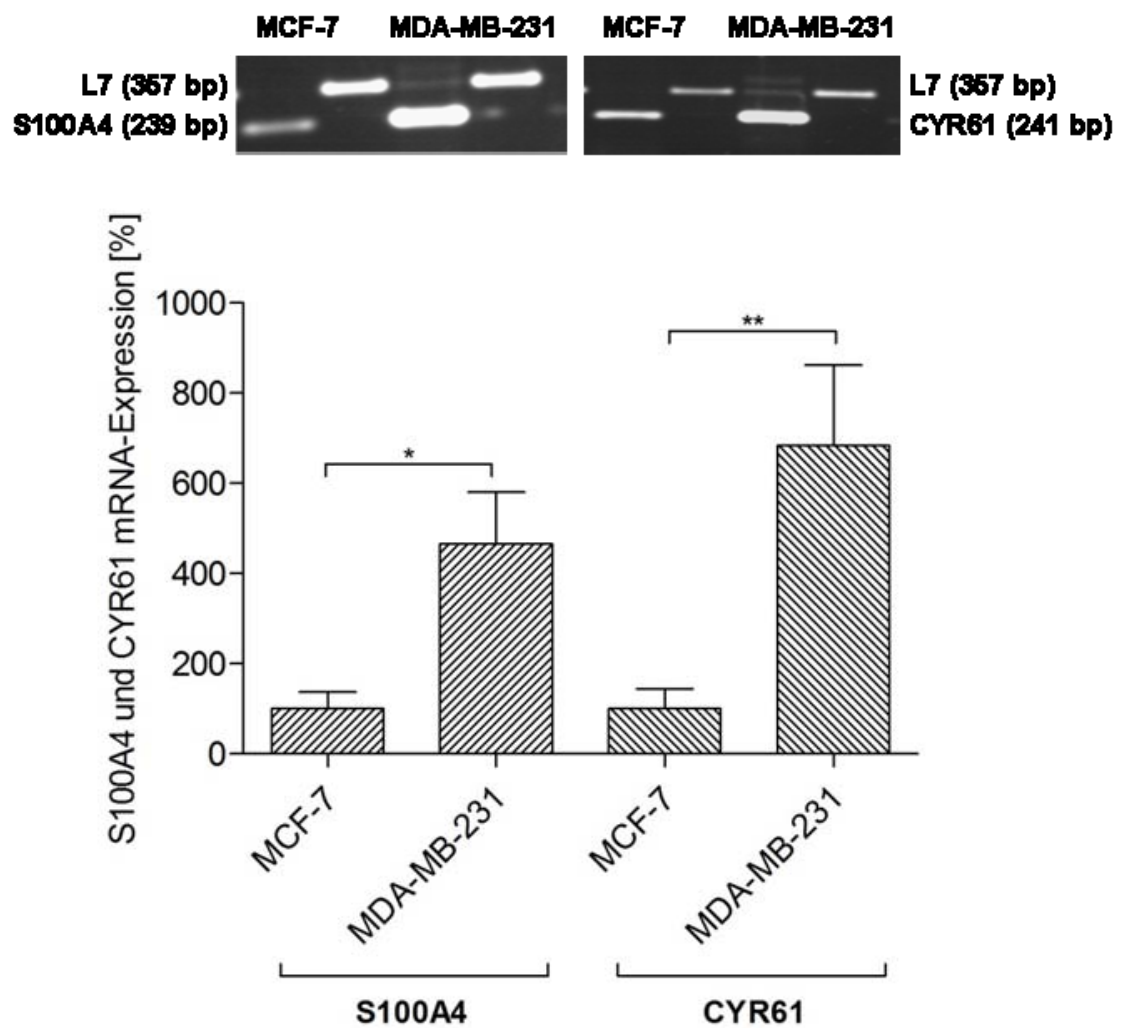

Abb. 4.10: Vergleich der Expression von S100A4 und CYR61 in MCF-7 und MDA-MB-231 Zellen. Die Expression wurde auf mRNA-Ebene mittels RT-PCR bestimmt. Die Daten wurden auf das Housekeeping Gen L7 normalisiert. Angegeben sind $\mathrm{MW} \pm \mathrm{SEM}$, Signifikanzen wurden mit one-way ANOVA, Newman Keuls-Test errechnet: * $p<0,05$ vs. MCF-7 (S100A4), ${ }^{* *} p<0,01$ vs. MCF-7 (CYR61).

Bei der Expressionsanalyse zeigte sich sowohl für S100A4 als auch für CYR61

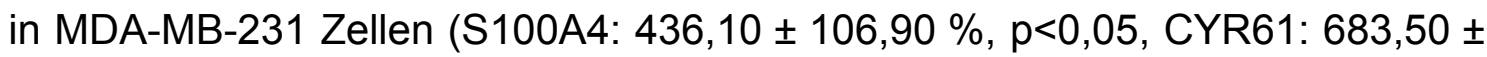
$178,40 \%, p<0,01)$ eine signifikant höhere Expression im Vergleich zu MCF-7 Zellen (S100A4: $100 \pm 37,23 \%$, CYR61: $100 \pm 44,15 \%$ ). 
Der Einfluss von GnRH Analoga auf die Expression von S100A4 und CYR61 wurde ohne (Kontrolle) und während der Kultivierung von MCF-7 und MDA-MB231 Zellen mit CAL-72 Zellen (Kokultur) untersucht. Die Inkubationszeit mit Triptorelin $\left(1 \times 10^{-5} \mathrm{M}\right)$, Cetrorelix $\left(1 \times 10^{-5} \mathrm{M}\right)$ sowie [D-Lys $\left.{ }^{6}\right] \mathrm{GnRH}-\mathrm{II}\left(1 \times 10^{-9}\right.$ M) betrug wie in allen vorangegangenen Versuchen 48 h. Signifikanzen wurden hier ebenfalls zusätzlich mittels t-Test (gepaart) berechnet.

Die Expression von S100A4 wurde während der Kokultur $(115,10 \pm 15,90 \%$, p<0,05) im Vergleich zur Kontrolle $(100 \pm 10,88$ \%) in MCF-7 Zellen signifikant erhöht (siehe Abbildung 4.11). In MDA-MB-231 Zellen wurde eine Veränderung der Expression von S100A4 während der Kokultur nicht ermittelt (Kontrolle: $100 \pm 15,39$, Kokultur: 96,64 $\pm 13,51 \%$, n.s.). Durch die Behandlung mit GnRH Analoga wurde sowohl in MCF-7 Zellen (Triptorelin: 106,90 $\pm 11,24$ \%, n.s., Cetrorelix: $98,11 \pm 10,23 \%$, n.s., [D-Lys ${ }^{6}$ ] GnRH-II: $98,44 \pm 8,18 \%$, n.s.) als auch in MDA-MB-231 Zellen (Triptorelin: 104,50 $\pm 14,87 \%$, n.s., Cetrorelix: $97,14 \pm 12,25 \%$, n.s., [D-Lys ${ }^{6}$ ]GnRH-II: 99,50 $\pm 15,12 \%$, n.s.) keine Regulation der S100A4 Expression im Vergleich zur Kokultur ermittelt.

A
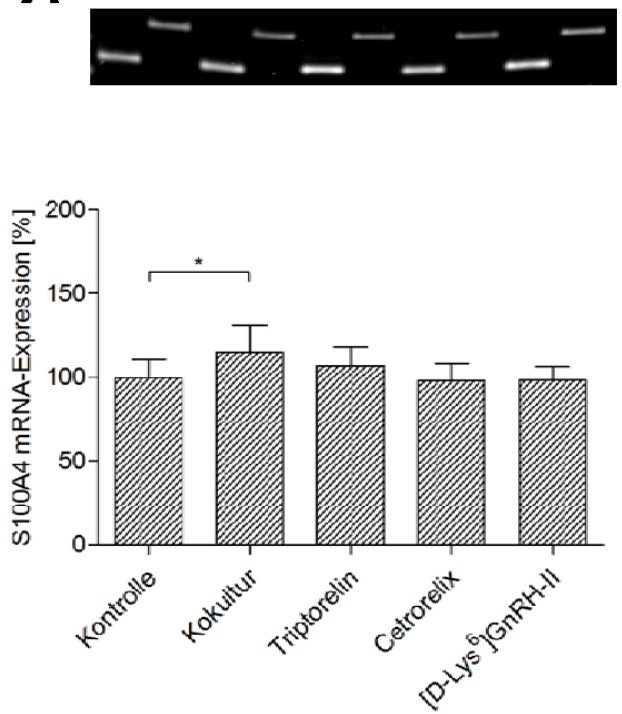

B
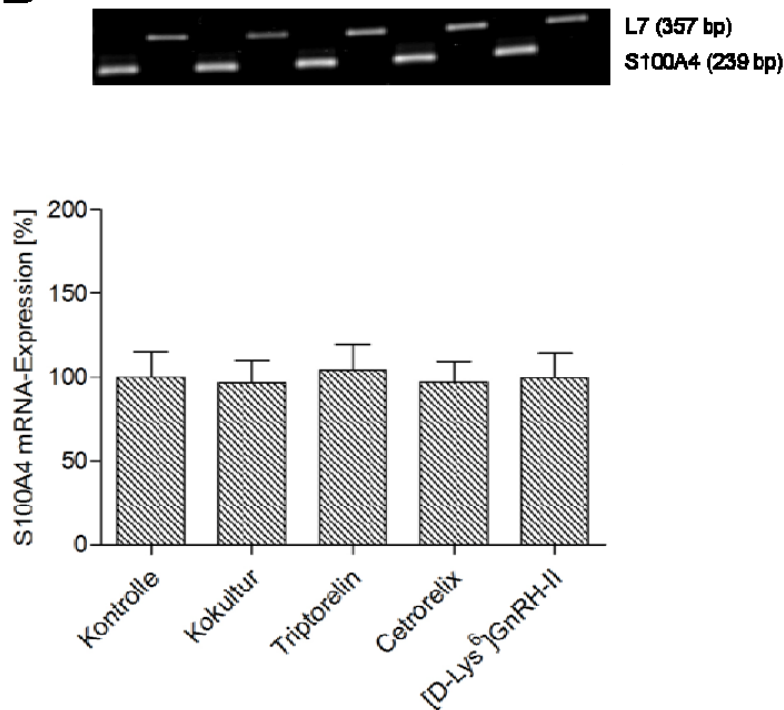

Abb. 4.11: Einfluss von GnRH Analoga auf die mRNA-Expression von S100A4 in MCF-7 (A) und MDA-MB-231 (B) Zellen. Unterschiede in der mRNA-Expression wurden mittels RT-PCR bestimmt. Die Zellen wurden ohne (Kontrolle) sowie mit CAL-72 Zellen (Kokultur) kultiviert und für $48 \mathrm{~h}$ mit Triptorelin $\left(1 \times 10^{-5} \mathrm{M}\right)$, Cetrorelix $(1 \mathrm{x}$ $\left.10^{-5} \mathrm{M}\right)$ und $\left[\mathrm{D}-\mathrm{Lys}^{6}\right] \mathrm{GnRH}-\mathrm{II}\left(1 \times 10^{-9} \mathrm{M}\right)$ behandelt. Die Ergebnisse wurden auf das Housekeeping Gen L7 normalisiert. Angegeben sind MW \pm SEM, Signifikanzen wurden mittels t-Test (gepaart) errechnet: ${ }^{*} p<0,05$ vs. Kontrolle. 
Für CYR61 wurde sowohl in MCF-7 Zellen (148,90 $\pm 22,09 \%, p<0,01)$ als auch in MDA-MB-231 Zellen $(129,10 \pm 22,09 \%, p<0,001)$ während der Kokultur mit CAL-72 Zellen ein signifikanter Anstieg der mRNA-Expression im Vergleich zur Kontrolle (MCF-7: $100 \pm$ 15,73 \% ,MDA-MB-231:100 \pm 13,89\%) nachgewiesen (siehe Abbildung 4.12).

A
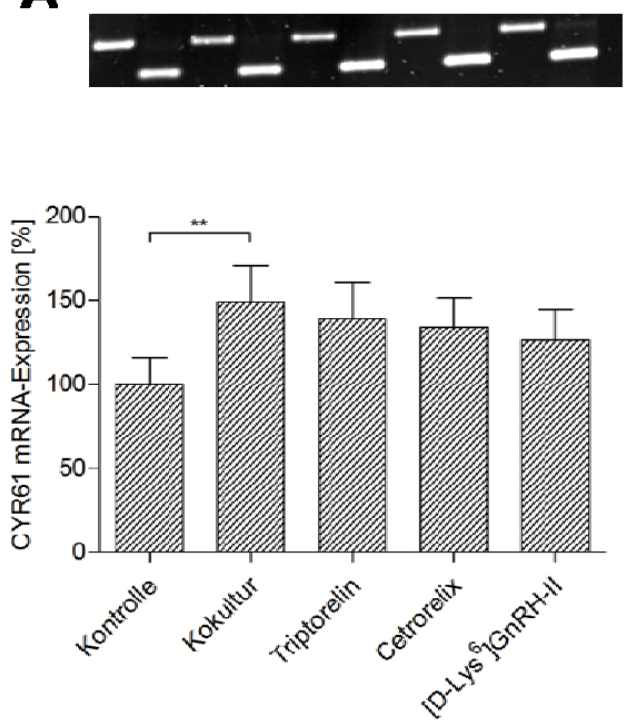

B
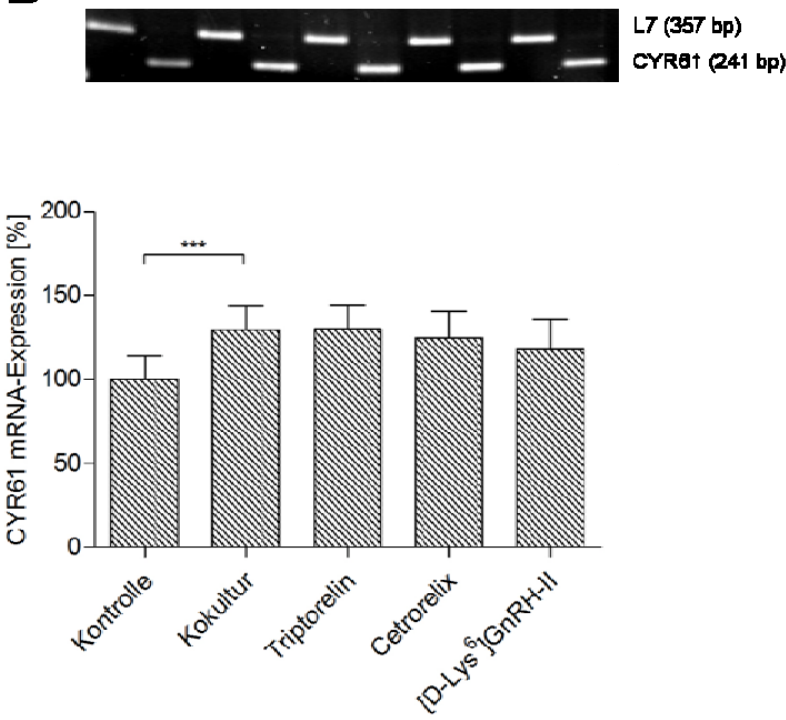

Abb. 4.12: Einfluss von GnRH Analoga auf die mRNA-Expression von CYR61 in MCF-7 (A) und MDA-MB-231 (B) Zellen. Unterschiede in der mRNA-Expression wurden mittels RT-PCR bestimmt. Die Zellen wurden ohne (Kontrolle) sowie mit CAL-72 Zellen (Kokultur) kultiviert und für $48 \mathrm{~h}$ mit Triptorelin $\left(1 \times 10^{-5} \mathrm{M}\right)$, Cetrorelix $(1 \mathrm{x}$ $\left.10^{-5} \mathrm{M}\right)$ und $\left[\mathrm{D}-\mathrm{Lys}^{6}\right] \mathrm{GnRH}-\mathrm{II}\left(1 \times 10^{-9} \mathrm{M}\right)$ behandelt. Die Ergebnisse wurden auf das Housekeeping Gen L7 normalisiert. Angegeben sind MW \pm SEM, Signifikanzen wurden mittels t-Test (gepaart) errechnet: ${ }^{* *} p<0,01,{ }^{* * *} p<0,001$ vs. Kontrolle.

Die Behandlung mit GnRH Analoga führte im Vergleich zur Kokultur zu keiner signifikanten Veränderung der Expression von CYR61 in MCF-7 Zellen (Triptorelin: $139,30 \pm 21,36 \%$, n.s., Cetrorelix: 134,00 $\pm 17,46 \%$, n.s., [D-Lys ${ }^{6}$ ] GnRH-II: 126,00 \pm 18,55 \%, n.s.) oder MDA-MB-231 Zellen (Triptorelin: 129,50 $\pm 14,47 \%$, n.s., Cetrorelix: $124,50 \pm 16,35 \%$, n.s., [D-Lys ${ }^{6}$ ] $\mathrm{GnRH}-\mathrm{II}: 117,80 \pm$ $17,99 \%$, n.s.). 


\subsection{Effekte der GnRH Analoga in vivo}

Die in vivo Effekte der GnRH Analoga wurden im Mausmodell untersucht. Dabei wurden thymusdefiziente, weibliche Nacktmäuse des Stammes CD1 nu/nu mit humanen Mammakarzinomzellen xenotransplantiert und mit GnRH Analoga behandelt. Bei den GnRH Analoga kam es hier zusätzlich zum Einsatz eines GnRH-II Antagonisten (GnRH-II Ant, siehe Tabelle 2.4), dessen Struktur sowie Wirkung im Laufe dieser Arbeit innerhalb der Arbeitsgruppe entwickelt und analysiert wurden (Fister et al., 2007). Dadurch konnten die Untersuchungen auf die Effekte von Antagonisten des GnRH-II Systems erweitert werden.

\subsubsection{Bestimmung der Metastasierung mittels TaqMan ${ }^{\circledR}$-Real-time PCR}

Nach heutigem Stand der Forschung existieren verschiedene Methoden um die Metastasierung von Tumorzellen im Mausmodell zu detektieren. In dieser Arbeit wurde der Nachweis mittels TaqMan ${ }^{\circledR}$-Real-time PCR einer humanspezifischen Alu-Sequenz erbracht. Um eine Normalisierung der Ergebnisse durchzuführen, erfolgte parallel die Amplifikation des Housekeeping-Gens 18S rRNA, welches sowohl in humanem als auch in murinem Gewebe nachweisbar ist. Der gesuchte Anteil von humaner DNA in muriner DNA wurde mit Hilfe einer Standardverdünnungsreihe ermittelt. Diese wurde in einem Bereich von $100 \%$ $0,0001 \%$ angesetzt und in jedem Reaktionslauf der TaqMan ${ }^{\circledR}$-Real-time PCR mitgeführt (siehe Abbildung 4.13).

Kommt es zum Einsatz exakt der gleichen Menge an DNA (50 $\mathrm{ng} / \mathrm{\mu l}$ ), so bleibt das Fluoreszenzsignal $\left(\Delta R_{n}\right)$ des Housekeeping-Gens $18 \mathrm{~S}$ rRNA während der Amplifikation auf ein- und demselben Niveau (B). Die verwendete Alu-Sequenz zeigte hingegen während der Amplifikation Fluoreszenzsignale einer typischen Standardverdünnungsreihe (A). Hierbei wird deutlich, dass Proben mit weniger Ausgangsmaterial mehr Zyklen benötigen bis die gleiche DNA-Menge erreicht wird. Handelt es sich, wie in dieser Arbeit um eine Standardverdünnungsreihe von 1:10, werden im optimalen Fall pro Verdünnungsschritt 3,3 Zyklen mehr für die Amplifikation benötigt. 

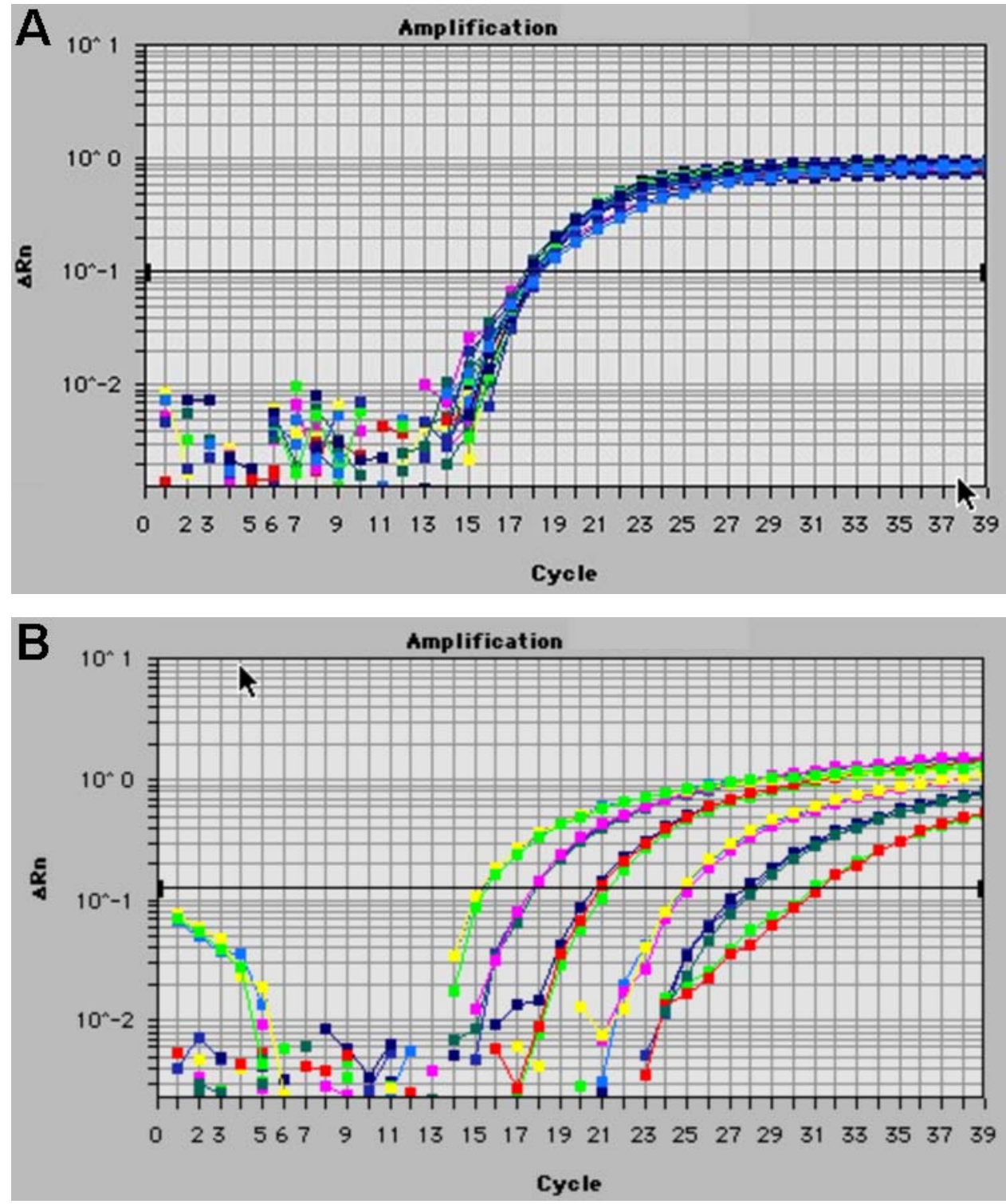

Abb. 4.13: Fluoreszenzsignal der Standardverdünnungsreihe von humaner DNA in muriner DNA während des Laufs einer TaqMan ${ }^{\circledR}$-Real-time PCR. Das Signal der humanen Alu-Sequenz (A) wurde durch den Fluoreszenzfarbstoff Yakimo Yellow ${ }^{\circledR}$ $(\lambda=552 \mathrm{~nm})$, das Signal des Housekeeping-Gens 18S rRNA (B) durch den Fluoreszenzfarbstoff FAM $(\lambda=518 \mathrm{~nm})$ erzeugt. Dargestellt sind die gegen eine passive Referenz (ROX) normalisierten Fluoreszenzsignale $\left(\Delta R_{n}\right)$ während der Amplifikation.

Der Anteil humaner DNA in muriner DNA wurde in Prozent bestimmt. Da es sich bei der TaqMan ${ }^{\circledR}$-Real-time PCR um ein sehr sensitives Verfahren handelt, wurden alle Proben in Dreifachbestimmung gemessen. 


\subsubsection{Xenotransplantation von MDA-MB-435}

Das erste in vivo Experiment wurde mit der humanen Mammakarzinomzellinie MDA-MB-435 durchgeführt. Diese Zellen zeichnen sich zum einen durch ein sehr aggressives und schnelles Tumorwachstum aus und sind außerdem in der Lage spontan zu metastasieren (Price et al., 1990; Rose \& Connolly, 1997). MDA-MB-435 sind somit sowohl für Untersuchungen des Tumorwachstums als auch der Metastasierung geeignet.

Die Zellen wurden in einer Konzentration von 1 Mio pro $100 \mu$ beidseitig in das Fettgewebe der zweiten Brustdrüse injiziert. An Tag 2 nach Tumorzellinjektion wurde die Therapie ohne (Kontrolle) oder mit je $25 \mathrm{nmol}$ Triptorelin, Cetrorelix, [D-Lys $\left.{ }^{6}\right] \mathrm{GnRH}-\mathrm{Il}$ und $\mathrm{GnRH}-\mathrm{Il}$ Ant begonnen und über fünf Wochen alle drei Tage fortgesetzt. Dabei ist zu beachten, dass die Kontrolle bei den Versuchen zur Metastasierung als Tumorgruppe bezeichnet wird, da hier zusätzlich eine Kontrollgruppe von Mäusen ohne Tumorzellinjektion mitgeführt wurde.

\subsubsection{Einfluss der GnRH Analoga auf das Tumorwachstum}

Um einen Einfluss der GnRH Analoga auf das Tumorwachstum zu erkennen, wurde im Laufe des Versuchs alle vier bis sechs Tage das Tumorvolumen bestimmt und dokumentiert. Dabei musste ab Tag 20 (2. Messtag) eine Maus aus der Kontrollgruppe ausgeschlossen werden. Nebenwirkungen während der endokrinen Therapie wurden nicht beobachtet.

Das Tumorwachstum konnte bereits an Tag 16 (1. Messtag) im Vergleich zur Kontrollgruppe $\left(62,67 \pm 9,91 \mathrm{~mm}^{3}\right)$ durch [D-Lys ${ }^{6}$ ] GnRH-II $\left(25,38 \pm 10,58 \mathrm{~mm}^{3}\right.$, $\mathrm{p}<0,05)$ und auch GnRH-II Ant $\left(17,12 \pm 6,08 \mathrm{~mm}^{3}, \mathrm{p}<0,01\right)$ signifikant gehemmt werden (siehe Abbildung 4.14). Die beiden $\mathrm{GnRH}-\mathrm{I}$ Analoga Triptorelin (55,77 \pm $9,12 \mathrm{~mm}^{3}$, n.s.) und Cetrorelix $\left(47,62 \pm 8,68 \mathrm{~mm}^{3}\right.$, n.s. $)$ zeigten im Vergleich zur Kontrollgruppe zu diesem Zeitpunkt keine Wirkung. 


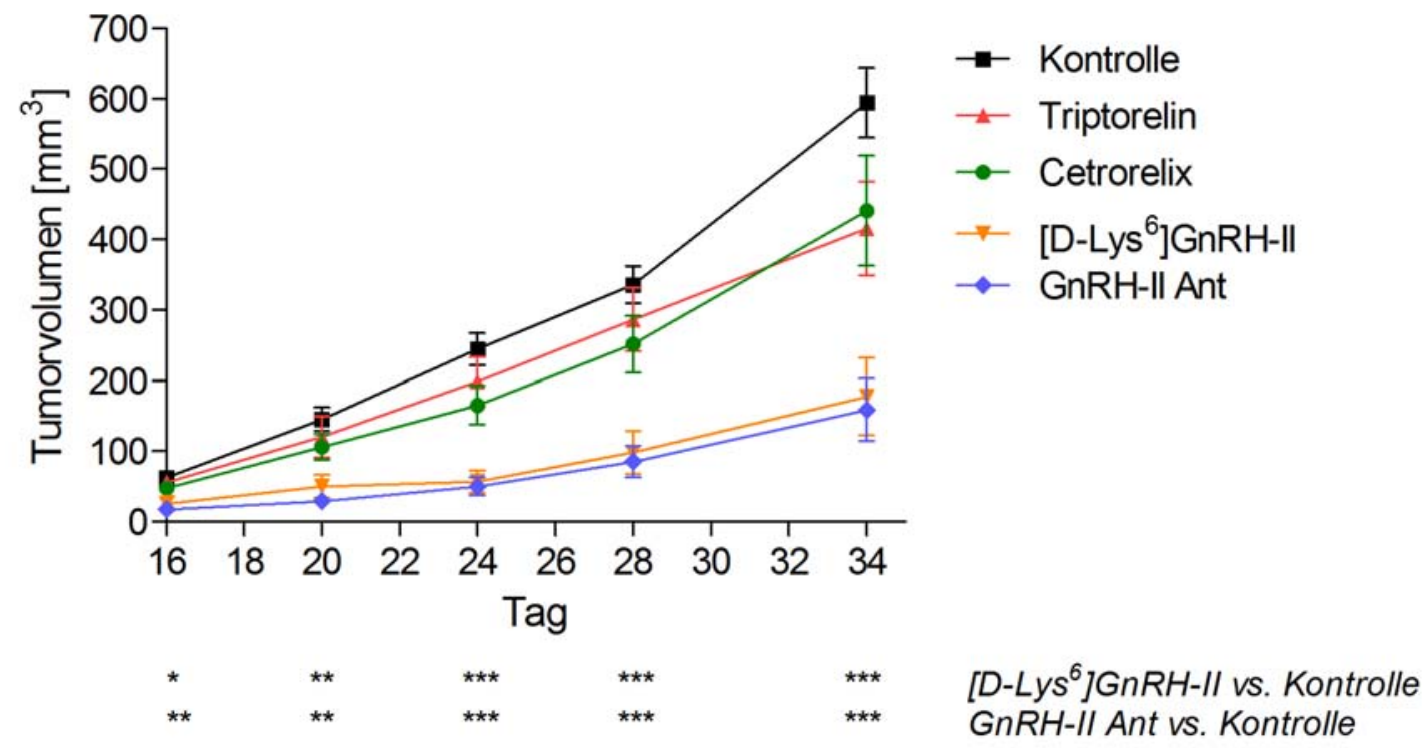

Abb. 4.14: Tumorwachstumsverlauf von MDA-MB-435 in xenotransplantierten CD1 nu/nu Mäusen. Die Mäuse wurden ohne (Kontrolle) oder mit $25 \mathrm{nmol}$ Triptorelin, Cetrorelix, [D-Lys ${ }^{6}$ ] $\mathrm{GnRH}-\mathrm{Il}$ und $\mathrm{GnRH}-\mathrm{II}$ Ant behandelt. Die Behandlung erfolgte alle drei Tage i.p. und die Tiere waren in Gruppen mit $n=5$ (Kontrolle $n=4$ von Tag 20 - Tag 34) eingeteilt. Angegeben sind MW \pm SEM, Signifikanzen wurden mit one-way ANOVA, Newman Keuls-Test errechnet: ${ }^{*} p<0,05,{ }^{* *} p<0,01,{ }^{* * *} p<0,001$ vs. Kontrolle.

Im weiteren Verlauf des Versuchs wurden die hemmenden Effekte der GnRH-II Analoga $\left[\mathrm{D}-\mathrm{Lys}{ }^{6}\right] \mathrm{GnRH}-\mathrm{II}$ und $\mathrm{GnRH}-\mathrm{Il}$ Ant immer deutlicher. Nach Abschluss der fünfwöchigen Therapie (Tag 34) war das Tumorvolumen der behandelten Mäuse im Vergleich zur Kontrollgruppe hoch signifikant gehemmt und auf mehr als ein Drittel reduziert (Kontrollgruppe: $594,10 \pm 49,47 \mathrm{~mm}^{3}$, [D-Lys ${ }^{6}$ ] GnRH-II: $177,20 \pm 55,19 \mathrm{~mm}^{3}, \mathrm{p}<0,001$, GnRH-II Ant: 158,60 $\left.\pm 43,87 \mathrm{~mm}^{3}, p<0,001\right)$. Durch Triptorelin und Cetrorelix wurde am Ende des Versuchs zwar ein tendenziell verringertes Tumorvolumen ermittelt (Triptorelin: 415,50 $\pm 66,39$, n.s., Cetrorelix: $440,60 \pm 78,07$, n.s), beide GnRH-I Analoga zeigten jedoch im gesamten Verlauf der Therapie keine signifikanten Effekte auf das Tumorwachstum.

\subsubsection{Einfluss der GnRH Analoga auf die Metastasierung}

Für eine quantitative Bestimmung der Metastasierungsrate von MDA-MB-435 Zellen wurde den Nacktmäusen nach Ende des Versuchs sowohl die Lunge als auch der Femur (beidseitig) entnommen und anschließend daraus DNA isoliert. 
Der Anteil humaner DNA in muriner DNA wurde mittels TaqMan ${ }^{\circledR}$-Real-time PCR bestimmt (siehe Kapitel 4.4.1).

Aufgrund der Vielzahl an Proben und der durchgeführten Dreifachbestimmung wurden die Ergebnisse in zwei verschiedenen Reaktionsläufen ermittelt. Dabei wurden die Standardverdünnungsreihe, Kontroll- sowie Tumorgruppe und je zwei Behandlungsgruppen mitgeführt. Abbildung 4.15 zeigt den Einfluss der $\mathrm{GnRH}$ Analoga auf die Metastasierungsrate in der Lunge.
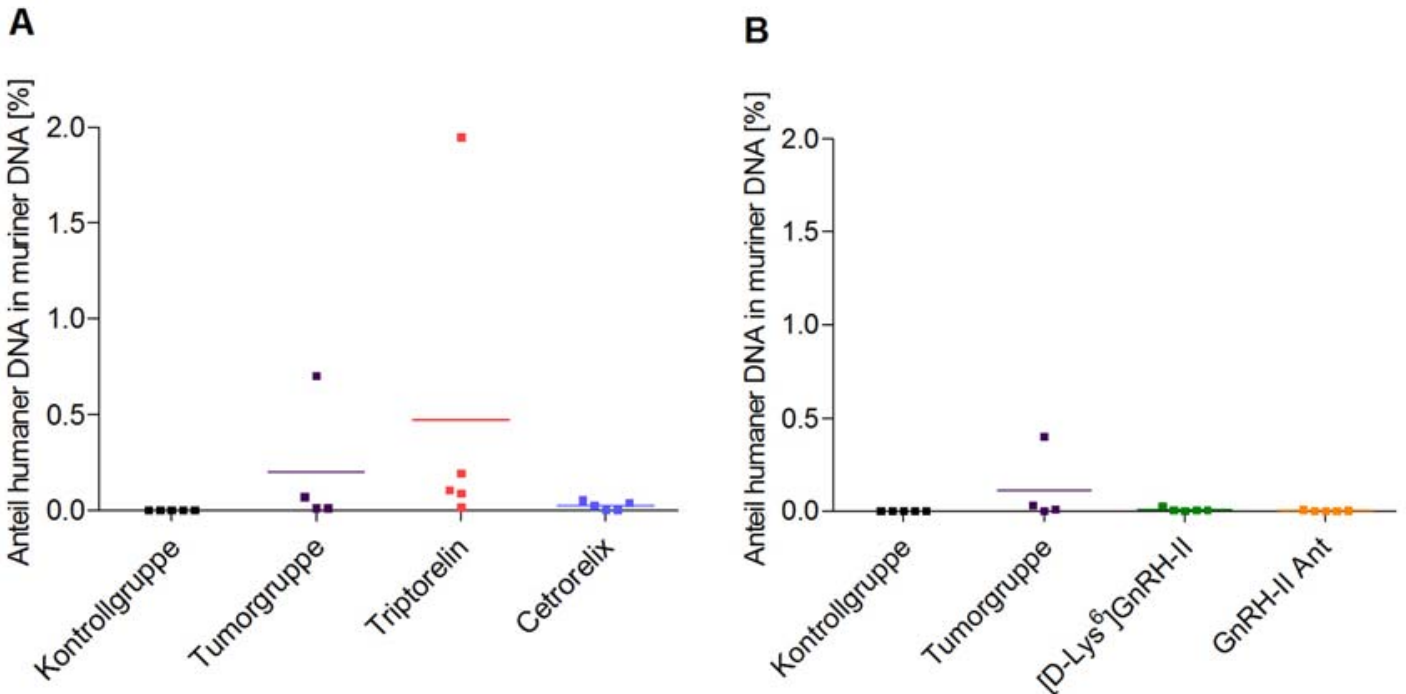

Abb. 4.15: Metastasierungsrate von MDA-MB-435 in der Lunge von xenotransplantierten CD1 nu/nu Mäusen. Die Mäuse wurden ohne (Tumorgruppe) oder mit $25 \mathrm{nmol}$ Triptorelin und Cetrorelix (A) sowie [D-Lys $\left.{ }^{6}\right] \mathrm{GnRH}-\mathrm{Il}$ und $\mathrm{GnRH}-\mathrm{II}$ Ant (B) behandelt. Die Behandlung erfolgte alle drei Tage i.p. und die Tiere waren in Gruppen mit $n=5$ (Tumorgruppe $n=4$ ) eingeteilt. Als Kontrolle wurde eine Gruppe von Mäusen ohne Tumorzellinjektion mitgeführt. Angegeben sind MW \pm SEM.

In der Tumorgruppe (A: $1,99 \times 10^{-1} \pm 1,69 \times 10^{-1} \%$, n.s., B: $1,12 \times 10^{-1} \pm 0,98$ $x 10^{-1} \%$, n.s.) zeigte sich eine tendenzielle Steigerung der Metastasierungsrate im Vergleich zur Kontrollgruppe (A: $2,04 \times 10^{-6} \pm 1,27 \times 10^{-6} \%$, B: $1,76 \times 10^{-3}$ $\left.\pm 0,32 \times 10^{-3} \%\right)$, die sich jedoch als nicht signifikant erwies. Hierbei kam es zwischen den beiden Reaktionsläufen zu einer sehr großen Abweichung der ermittelten Metastasierungsraten in der Kontrollgruppe, welche sich bei $A$ in einem Bereich von $10^{-1} \%$ und bei $B$ in einem Bereich von $10^{-6} \%$ bewegten. Diese Ergebnisse lassen sich darauf zurückführen, dass sich die $\operatorname{TaqMan}^{\circledR}{ }_{-}$ 
Real-time PCR-Methode zu dieser Phase der Untersuchungen noch in einem Optimierungsstatus befand. So wurde für jeden Reaktionslauf eine neue Standardverdünnungsreihe angesetzt sowie die Anzahl geeigneter PCR-Zyklen verändert und aus diesem Grund Schwankungen zwischen den beiden Reaktionsläufen verursacht. Im weiteren Verlauf der Untersuchungen konnten diese durch Optimierung der verwendeten TaqMan ${ }^{\circledR}$-Real-time PCR-Methode behoben werden.

Weiterhin zeigte sich mit keiner der durchgeführten Behandlungen (Triptorelin: $4,71 \times 10^{-1} \pm 3,71 \times 10^{-1} \%$, n.s., Cetrorelix: $2,43 \times 10^{-2} \pm 2,21 \times 10^{-2} \%$, n.s., [DLys $\left.{ }^{6}\right]$ GnRH-II: $1,02 \times 10^{-2} \pm 0,45 \times 10^{-2} \%$, n.s., GnRH-II Ant: $3,71 \times 10^{-3} \pm 1,44$ $x 10^{-3} \%$, n.s.) eine signifikant veränderte Metastasierungsrate im Vergleich zur Tumorgruppe. Tendenziell hemmende Effekte auf die Metastasierung konnten jedoch durch Cetrorelix mit $88 \%$, [D-Lys $\left.{ }^{6}\right] \mathrm{GnRH}-$ II mit $91 \%$ und GnRH-II Ant mit $97 \%$ erfasst werden.

Im Femur der Nacktmäuse konnte hingegen nach fünf Wochen im Vergleich zur Kontrollgruppe (A: $2,35 \times 10^{-4} \pm 0,73 \times 10^{-4} \%$, B: $2,20 \times 10^{-4} \pm 0,92 \times 10^{-4} \%$ ) in der Tumorgruppe ein signifikanter Anstieg der Metastasierung (A: 8,16 x 10 $\pm 2,60 \times 10^{-3} \%, p<0,001$, B: $\left.9,25 \times 10^{-3} \pm 2,58 \times 10^{-3} \%, p<0,001\right)$ nachgewiesen werden (siehe Abbildung 4.16). Hierbei kommt es zwischen den beiden Läufen der TaqMan ${ }^{\circledR}$-Real-time PCR (A und B) nur noch zu geringen Abweichungen in der Kontrollgruppe und in der Tumorgruppe, da zur Methodenoptimierung für beide Reaktionsläufe ein- und dieselbe Standardverdünnungsreihe mitgeführt wurde.

Sowohl durch die Behandlung mit den GnRH-I Analoga Triptorelin $\left(2,48 \times 10^{-3}\right.$ $\left.\pm 0,85 \times 10^{-3} \%, p<0,01\right)$ und Cetrorelix $\left(5,98 \times 10^{-4} \pm 4,50 \times 10^{-4} \%, p<0,001\right)$ als auch mit den GnRH-II Analoga [D-Lys $\left.{ }^{6}\right] \mathrm{GnRH}-\mathrm{II}\left(2,41 \times 10^{-3} \pm 1,50 \times 10^{-3} \%\right.$, $\mathrm{p}<0,01)$ und GnRH-II Ant $\left(7,42 \times 10^{-4} \pm 2,67 \times 10^{-4} \%, p<0,001\right)$ zeigte sich eine signifikante Hemmung der Metastasierungsrate im Vergleich zur Tumorgruppe. Weiterhin wurde deutlich, dass die GnRH Antagonisten mit einer Verminderung der Metastasierungsrate von $93 \%$ (Cetrorelix) sowie $92 \%$ (GnRH-II Ant) eine stärker hemmende Wirkung besitzen als die eingesetzten $\mathrm{GnRH}$ Agonisten mit $70 \%$ (Triptorelin) sowie $74 \%$ ([D-Lys $\left.\left.{ }^{6}\right] \mathrm{GnRH}-\mathrm{II}\right)$. 
A

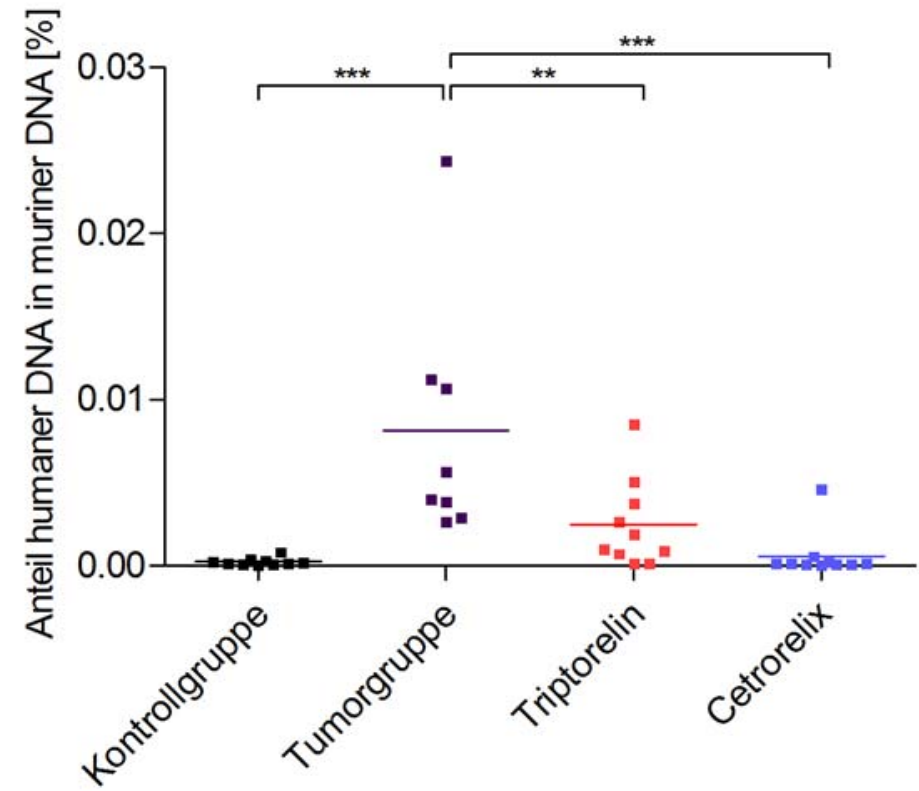

B

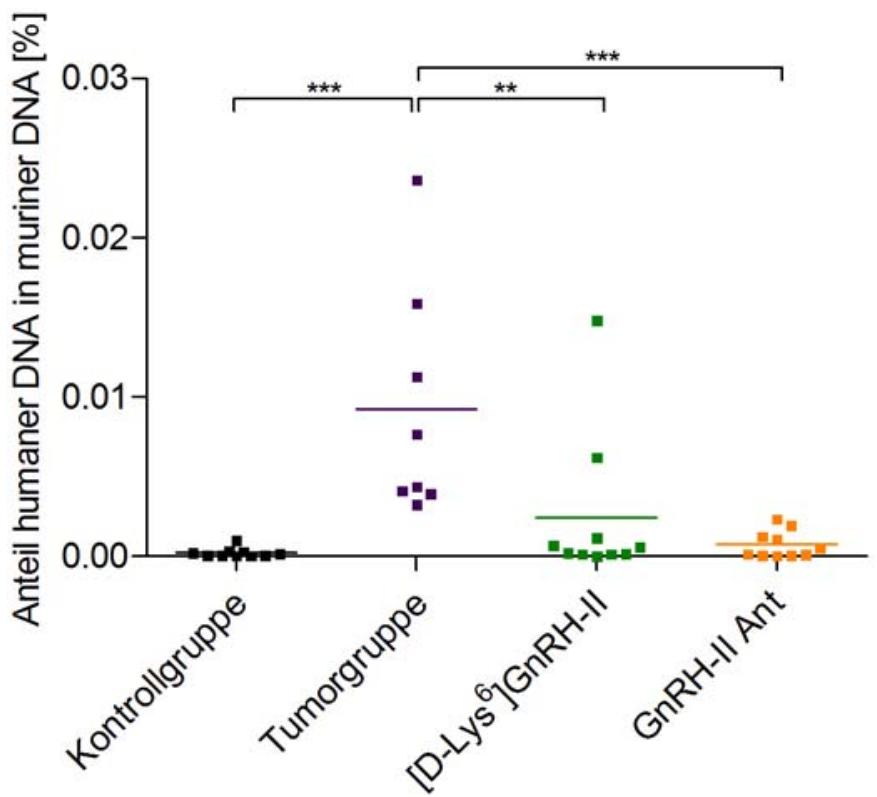

Abb. 4.16: Metastasierungsrate von MDA-MB-435 im Femur von xenotransplantierten CD1 nu/nu Mäusen. Die Mäuse wurden ohne (Tumorgruppe) oder mit $25 \mathrm{nmol}$ Triptorelin und Cetrorelix (A) sowie [D-Lys $\left.{ }^{6}\right] \mathrm{GnRH}-\mathrm{Il}$ und GnRH-II Ant (B) behandelt. Die Behandlung erfolgte alle drei Tage i.p. und die Tiere waren in Gruppen mit $n=5$ (Tumorgruppe $n=4$ ) eingeteilt. Der Femur wurde jeweils beidseitig präpariert, einzeln aufgearbeitet und in die Auswertung aufgenommen. Als Kontrolle wurde eine Gruppe von Mäusen ohne Tumorzellinjektion mitgeführt. Angegeben sind $\mathrm{MW} \pm \mathrm{SEM}$, Signifikanzen wurden mit one-way ANOVA, Newman Keuls-Test errechnet: ${ }^{* * *} p<0,001$ vs. Kontrolle, ${ }^{* *} p<0,01,{ }^{* * *} p<0,001$ vs. Kokultur. 


\subsubsection{Xenotransplantation von MDA-MB-231}

Humane MDA-MB-231 Zellen gehören ebenfalls zu den deutlich aggressiveren Mammakarzinomzellinien, zeichnen sich jedoch im Gegensatz zu MDA-MB435 Zellen durch schlechtere Anwachsraten in vivo aus. In Kombination mit Matrigel $^{\mathrm{TM}}$ führt die Tumorzellinjektion in die Brustdrüse zum nachweisbaren Tumorwachstum, eine Verwendung als in vivo Metastasierungsmodell bleibt jedoch fraglich. Aus diesem Grund wurde die Tumorzellinjektion von MDA-MB$231\left(1 \times 10^{5}\right.$ Zellen pro $\left.100 \mu \mathrm{l}\right)$ direkt ins Herz der Nacktmäuse vorgenommen. Um die Schwankungsbreite der Ergebnisse zwischen den einzelnen Mäusen zu reduzieren und somit die Möglichkeit einer besseren statistischen Auswertung zu erzielen, wurde bei diesem Experiment die Anzahl der Mäuse pro Gruppe auf zehn (Tumorgruppe $n=12$ ) erhöht und zwei ausgewählte $\mathrm{GnRH}$ Analoga (Triptorelin, GnRH-II Ant) eingesetzt.

Die Therapie ohne (Tumorgruppe) oder mit je $25 \mathrm{nmol}$ Triptorelin und GnRH-II Ant wurde an Tag 2 nach Tumorzellinjektion begonnen und jeden zweiten Tag durchgeführt. Nach fünf Wochen wurde der Versuch abgebrochen und DNA aus Lunge, Femur, Leber sowie Blut der Nacktmäuse isoliert. Die Metastasierung nach Tumorzellinjektion ins Herz konnte in der Literatur bereits nachgewiesen werden (Sasaki et al., 1998; Yoneda et al., 2000; Peyruchaud et al., 2001). Als Kontrolle wurde ebenfalls eine Gruppe von Mäusen ohne Tumorzellinjektion mitgeführt.

\subsubsection{Einfluss der GnRH Analoga auf die Metastasierung}

Auch hier wurde die TaqMan $^{\circledR}$-Real-time PCR aufgrund der hohen Probenzahl zunächst in zwei Reaktionsläufen durchgeführt. Abbildung 4.17 zeigt die Effekte von Triptorelin (A) und GnRH-II Ant (B) auf die Metastasierung in der Lunge.

Es konnte sowohl in der Tumorgruppe (A: $2,74 \times 10^{-3} \pm 1,92 \times 10^{-3} \%$, n.s., $B$ : $7,50 \times 10^{-3} \pm 4,93 \times 10^{-3} \%$, n.s.) im Vergleich zur Kontrollgruppe (A: 1,69 $\times 10^{-4}$ $\pm 0,19 \times 10^{-4} \%$, B: $7,72 \times 10^{-5} \pm 1,74 \times 10^{-5}$ ) als auch durch die Behandlung mit Triptorelin $\left(2,55 \times 10^{-3} \pm 1,96 \times 10^{-3} \%\right.$, n.s. $)$ und GnRH-II Ant $\left(3,00 \times 10^{-3} \pm 1,90\right.$ x $10^{-3} \%$, n.s.) im Vergleich zur Tumorgruppe keine signifikante Veränderung der Metastasierungsrate nachgewiesen werden. Bei lediglich zwei Mäusen aus 
der Tumorgruppe wurde eine deutlich sichtbare Erhöhung der Metastasierung beobachtet. Hierbei kam es wie bereits in dem vorangegangenen Versuch mit MDA-MB-435 Zellen (siehe Abbildung 4.15) zu Schwankungen der Ergebnisse in Tumor- sowie Kontrollgruppe zwischen den durchgeführten Reaktionsläufen, welche auf die gleichen Ursachen zurückzuführen sind und in den folgenden Untersuchungen durch methodische Optimierung der TaqMan ${ }^{\circledR}$-Real-time PCR ausgeschlossen wurden.
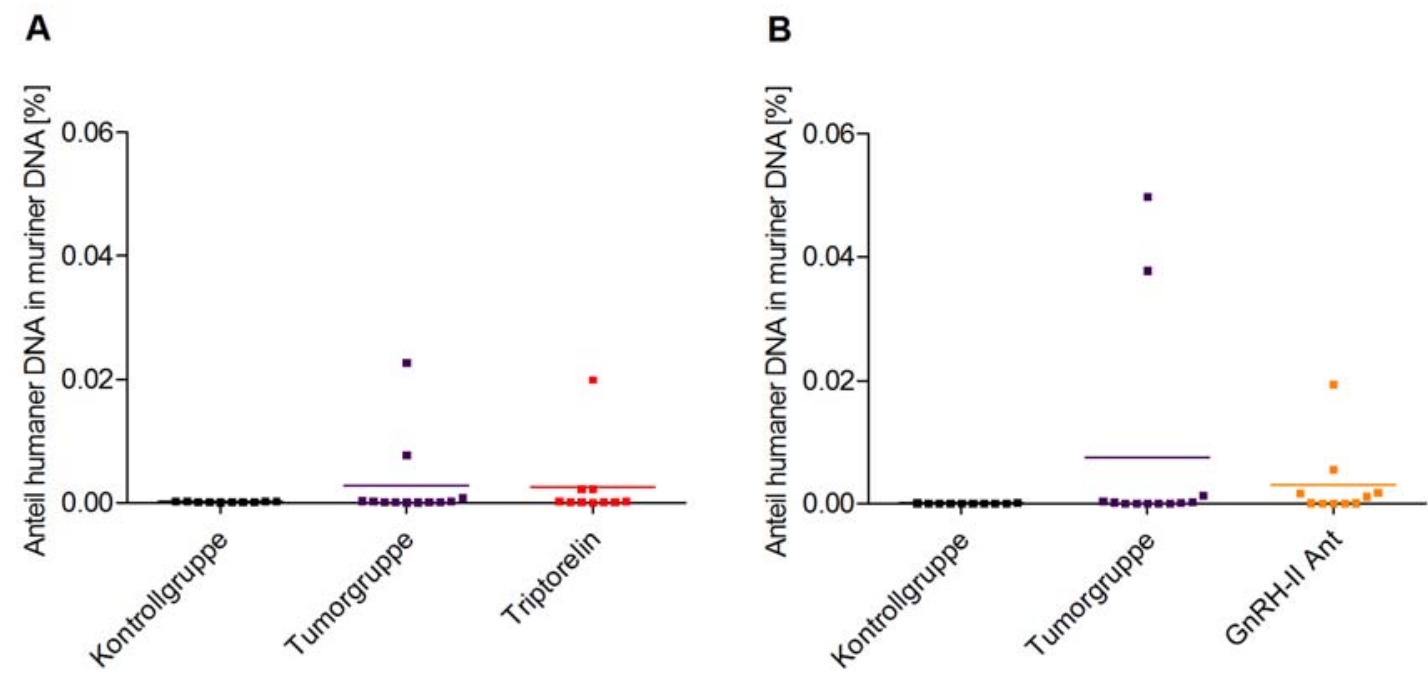

Abb. 4.17: Metastasierungsrate von MDA-MB-231 in der Lunge von xenotransplantierten CD1 nu/nu Mäusen. Die Mäuse wurden ohne (Kontrolle) oder mit $25 \mathrm{nmol}$ Triptorelin (A) und $\mathrm{GnRH}-\mathrm{Il}$ Ant (B) behandelt. Die Behandlung erfolgte alle zwei Tage i.p. und die Tiere waren in Gruppen mit $n=10$ (Tumorgruppe $n=12$ ) eingeteilt. Als Kontrolle wurde eine Gruppe von Mäusen ohne Tumorzellinjektion mitgeführt. Angegeben sind $\mathrm{MW} \pm \mathrm{SEM}$.

Im Femur zeigte sich in der Tumorgruppe $\left(1,64 \times 10^{-2} \pm 1,05 \times 10^{-2} \%\right.$, n.s.) im Vergleich zur Kontrollgruppe $\left(9,89 \times 10^{-5} \pm 1,1810^{-5} \%\right)$ ein ähnliches Bild wie in der Lunge. Auch hier wiesen zwei der Nacktmäuse eine deutliche Steigerung der Metastasierungsrate auf (siehe Abbildung 4.18). Dabei ist zu beachten, dass es sich nicht um die selben Mäuse handelt und die Metastasierung im Femur im Vergleich zur Lunge um das Zehnfache erhöht war. 


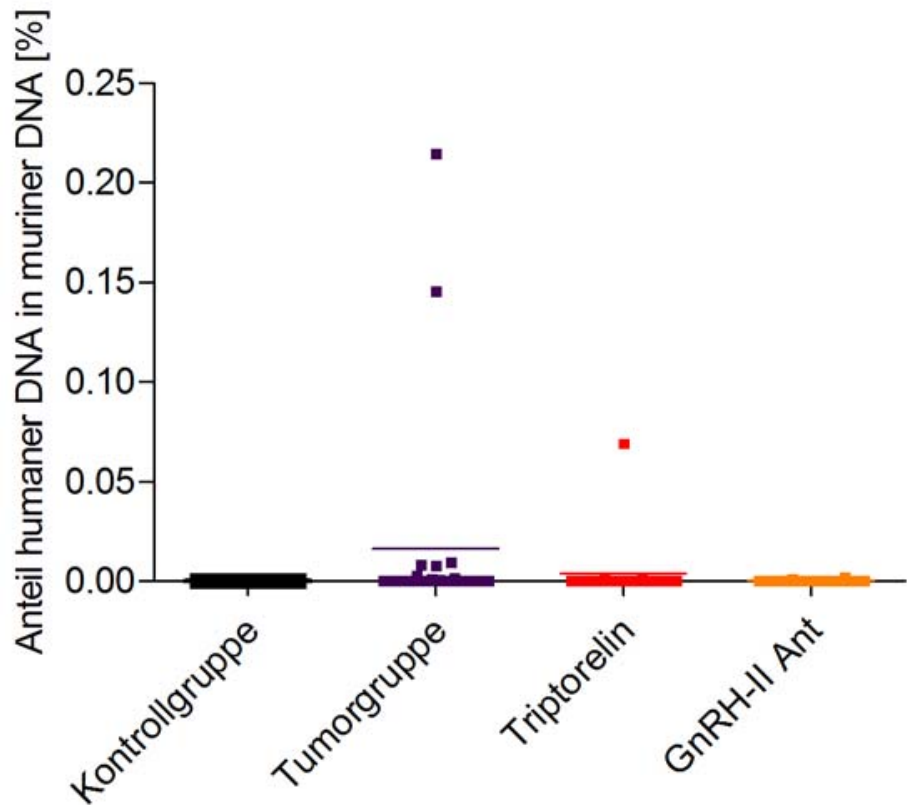

Abb. 4.18: Metastasierungsrate von MDA-MB-231 im Femur von xenotransplantierten CD1 nu/nu Mäusen. Die Mäuse wurden ohne (Tumorgruppe) oder mit $25 \mathrm{nmol}$ Triptorelin und $\mathrm{GnRH}-\mathrm{Il}$ Ant behandelt. Die Behandlung erfolgte alle zwei Tage i.p. und die Tiere waren in Gruppen mit $n=10$ (Tumorgruppe $n=12$ ) eingeteilt. Der Femur wurde jeweils beidseitig präpariert, einzeln aufgearbeitet und in die Auswertung aufgenommen. Als Kontrolle wurde eine Gruppe von Mäusen ohne Tumorzellinjektion mitgeführt. Angegeben sind MW \pm SEM.

Aufgrund der hohen Schwankungen innerhalb der Tumorgruppe konnte auch hier mittels one-way ANOVA, Newman Keuls-Test kein signifikantes Ergebnis erreicht werden. Eine tendenzielle Hemmung der Metastasierung zeigte sich jedoch sowohl durch Triptorelin $\left(3,62 \times 10^{-3} \pm 3,46 \times 10^{-3} \%\right.$, n.s.) mit $78 \%$ als auch GnRH-II Ant $\left(2,45 \times 10^{-4} \pm 1,08 \times 10^{-4} \%\right.$, n.s.) mit $99 \%$. Wie bereits durch die Ergebnisse der MDA-MB-435 Zellen (siehe Abbildung 4.16) deutlich wurde, scheint hier ebenfalls der verwendete GnRH Antagonist eine stärkere Wirkung zu besitzen als der GnRH Agonist.

In der Leber konnte im Gegensatz zu Lunge und Femur in der Tumorgruppe $\left(6,61 \times 10^{-5} \pm 3,74 \times 10^{-5} \%\right.$, n.s. $)$ im Vergleich zur Kontrollgruppe $\left(1,36 \times 10^{-5} \pm\right.$ $0,46 \times 10^{-5} \%$ ) nur eine minimale Metastasierungsrate nachgewiesen werden (siehe Abbildung 4.19). 


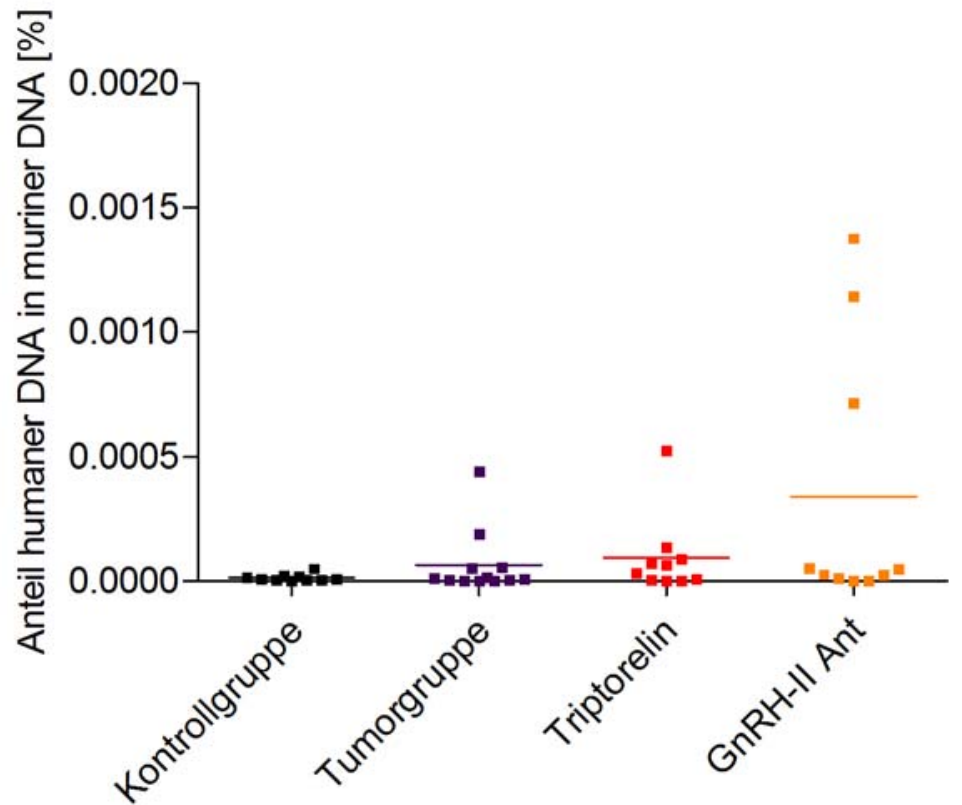

Abb. 4.19: Metastasierungsrate von MDA-MB-231 in der Leber von xenotransplantierten CD1 nu/nu Mäusen. Die Mäuse wurden ohne (Tumorgruppe) oder mit $25 \mathrm{nmol}$ Triptorelin und GnRH-II Ant behandelt. Die Behandlung erfolgte alle zwei Tage i.p. und die Tiere waren in Gruppen mit $n=10$ (Tumorgruppe $n=12$ ) eingeteilt. Als Kontrolle wurde eine Gruppe von Mäuse ohne Tumorzellinjektion mitgeführt. Angegeben sind $\mathrm{MW} \pm \mathrm{SEM}$.

Die Metastasierungsrate nach Behandlung mit Triptorelin $\left(9,46 \times 10^{-5} \pm 5,01 \times\right.$ $10^{-5} \%$, n.s.) befand sich ebenfalls in einem sehr niedrigen Bereich. Für GnRH-II Ant $\left(3,40 \times 10^{-4} \pm 1,69 \times 10^{-4} \%\right.$, n.s. $)$ wurde eine leicht erhöhte, jedoch nicht signifikante Metastasierungsrate ermittelt.

\subsubsection{Nachweis zirkulierender Tumorzellen im Blut}

Neben der Metastasierungsrate in Lunge, Femur und Leber wurde nach Ende des Experiments untersucht, ob sich mittels TaqMan ${ }^{\circledR}$-Real-time PCR CTC im Blut nachweisen lassen. Die Blutentnahme erfolgte dabei nach Betäubung der Nacktmäuse durch Herzpunktion. Nach der DNA-Isolierung wurde auch hier der Anteil humaner DNA in muriner DNA bestimmt (siehe Abbildung 4.20). 


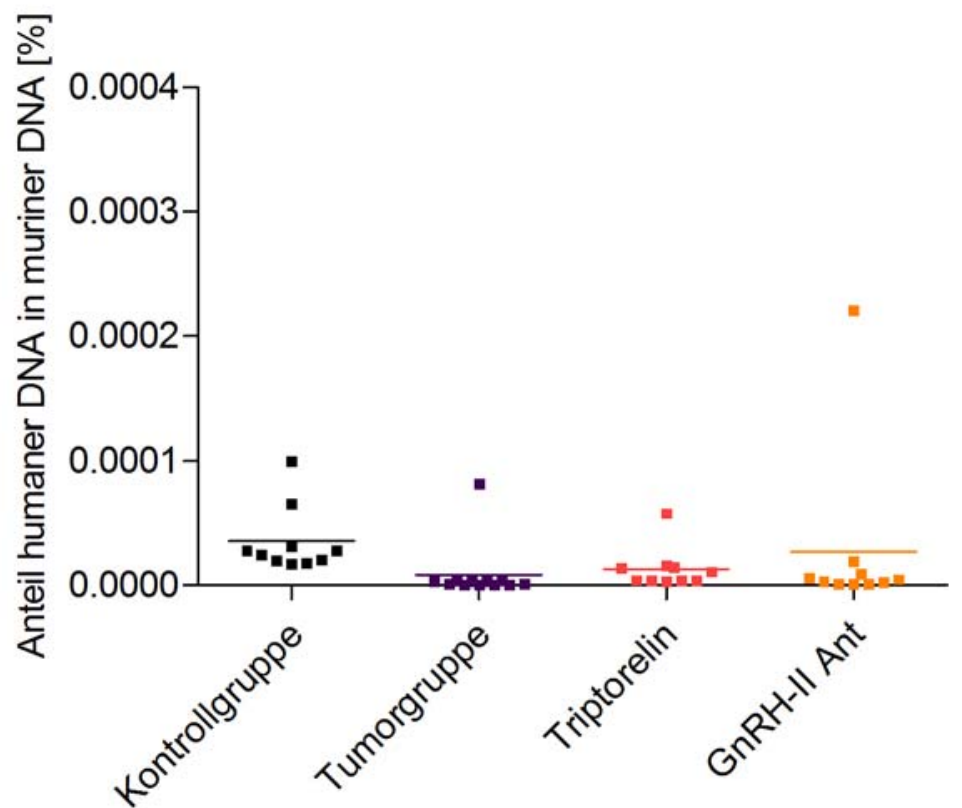

Abb. 4.20: Detektion von CTC (MDA-MB-231) im Blut von xenotransplantierten CD1 nu/nu Mäusen mittels TaqMan ${ }^{\circledR}$-Real-time PCR. Nach der Tumorzellinjektion wurden die Mäuse ohne (Tumorgruppe) oder mit $25 \mathrm{nmol}$ Triptorelin und $\mathrm{GnRH}-\mathrm{II}$ Ant behandelt. Die Behandlung erfolgte alle zwei Tage i.p. und die Tiere waren bis in Gruppen mit $n=10$ (Tumorgruppe $n=12$ ) eingeteilt. Als Kontrolle wurde eine Gruppe von Mäusen ohne Tumorzellinjektion mitgeführt. Angegeben sind $\mathrm{MW} \pm \mathrm{SEM}$

Wie in den vorangehenden Versuchen wurde in der Kontrollgruppe (3,54 x $10^{-5}$ $\pm 0,84 \times 10^{-5} \%$ ) ein sehr geringer Anteil von humaner DNA in muriner DNA detektiert, der als methodischer Fehler angesehen wurde. Nach fünf Wochen Versuchsverlauf konnte in der Tumorgruppe $\left(8,53 \times 10^{-6} \pm 6,65 \times 10^{-6} \%\right.$, n.s. $)$ keine signifikante Veränderung an humaner DNA in muriner DNA beobachtet und somit kein Nachweis von CTC im Blut erbracht werden. Auch der humane DNA-Anteil der Behandlungsgruppen mit Triptorelin $\left(1,32 \times 10^{-5} \pm 0,52 \times 10^{-5} \%\right.$, n.s.) und $\mathrm{GnRH}-\mathrm{Il}$ Ant $\left(2,68 \times 10^{-5} \pm 2,16 \times 10^{-5} \%\right.$, n.s. $)$ befand sich auf einem vergleichbaren Niveau zur Kontrollgruppe. 


\section{DISKUSSION}

\subsection{Effekte der GnRH Analoga in vitro}

GnRH-I und GnRH-II sowie deren Rezeptoren werden als Teil eines negativen autokrinen Regulationssystems der Zellproliferation (Emons et al., 2000), des Zellzyklus (Günthert et al., 2002) und eines Anti-Apoptose-Systems (Gründker et al., 2000a) in gynäkologischen Karzinomen exprimiert, zu denen auch das Mammakarzinom zählt. Die Signaltransduktion entspricht dabei nicht der des hypophysären $\mathrm{GnRH}$ Rezeptors, vielmehr interagieren die GnRH Rezeptoren mit der mitogenen Signaltransduktion von Wachstumsfaktorrezeptoren (Emons et al., 1997; Gründker et al., 2001b), das in einer Reduktion der Zellproliferation resultiert. Die wachstuminhibierenden Eigenschaften der $\mathrm{GnRH}$ Analoga liegen auch in der Induktion einer Caspase-3 vermittelten Apoptose begründet (Fister et al., 2007).

Neben den Wirkungen von GnRH Analoga auf Zellproliferation, Zellzyklus sowie apoptotische Vorgänge, zeigten sich Effekte auf die Migration und Invasion von Mammakarzinomzellen. Während der Kokultur mit hOB konnte die Knochengerichtete Invasion verschiedener Mammakarzinomzelllinien durch Behandlung mit den GnRH Analoga Triptorelin, Cetrorelix sowie [D-Lys $\left.{ }^{6}\right] \mathrm{GnRH}$-II zum Teil dosisabhängig gehemmt werden (von Alten et al., 2006). Dieser Effekt steht mit der Regulation des Chemokins SDF-1 der hOB in Verbindung, dessen mRNAExpression sowie Proteinsekretion während der Kokultur verstärkt und durch den Einfluss der GnRH Analoga wiederum inhibiert wird. Weitere molekulare Mechanismen, welche dieser Wirkung zugrunde liegen, sind nicht bekannt und wurden in der vorliegenden Arbeit in vitro im Kokultursystem untersucht.

\subsubsection{Interaktion mit Faktoren des Knochenstoffwechsels}

Während der Metastasierung des primären Mammakarzinoms in den Knochen werden die Aufbau- und Abbauvorgänge des Knochengewebes vorallem durch eine Interaktion zwischen den eingewanderten Mammakarzinomzellen und den Knochenzellen reguliert. Bei der Bildung von osteolytischen Metastasen, welche 
charakteristisch für metastasierende Mammakarzinomzellen sind, kommt dem RANKL/OPG-System eine bedeutende Rolle zu (Goltzman, 2001; Hofbauer et al., 2004). Eine Verschiebung des RANKL/OPG-Verhältnisses zugunsten von RANKL führt zu einer gesteigerten Osteoklastogenese und steht ebenfalls in Verbindung mit einer Reihe weiterer maligner Erkrankungen. So ist die Bildung osteolytischer Läsionen beim multiplen Myelom mit einer gesteigerten RANKLExpression assoziiert (Giuliani et al., 2001; Roux \& Mariette, 2004). Auch im Prostatakarzinom wird die Expression des RANKL/OPG-Systems beschrieben, wobei hier vorallem osteoblastische Metastasen gebildet werden (Brown et al., 2001; Zhang et al., 2001; Chen et al., 2006).

Für das Mammakarzinom wurde eine Expression von RANKL sowie OPG in verschiedenen Tumorbiopsien gezeigt, die jedoch einer starken Heterogenität unterliegt (Bhatia et al., 2005; Van Poznak et al., 2006). In einer Studie von Cross et al. (2006) wurden $86 \%$ verschiedener Mammakarzinome als RANKLnegativ detektiert. Auch Thomas et al. (1999) konnten eine mRNA-Expression von RANKL in verschiedenen primären Mammakarzinomen nicht nachweisen, die mRNA-Expression von OPG wurde hingegen in allen getesteten Biopsien ermittelt. Die in dieser Arbeit analysierten Mammakarzinomzelllinien zeigten alle eine mRNA-Expression von OPG, nur MDA-MB-453 Zellen wurden als OPGnegativ detektiert. Damit werden Arbeiten von Holen et al. (2005) und Rachner et al. (2009) bestätigt, die eine Expression von OPG in Mammakarzinomzellen ebenfalls ergaben. Hierzu zählen MCF-7, MDA-MB-231 und T47-D Zellen, für die hingegen eine mRNA-Expression von RANKL in verschiedenen Studien nicht ermittelt werden konnte (Thomas et al., 1999; Park et al., 2003; Nakamura et al., 2008). Dieses Ergebnis zeigt sich auch in dieser Arbeit, da die mRNAExpression von RANKL lediglich in der HCC-70 Zelllinie nachgewiesen wurde, alle anderen Zellen wurden als RANKL-negativ detektiert. Die RANKL und OPG Expression konnte in HCC-70 Zellen auch auf Proteinebene bestätigt werden, was diese Mammakarzinomzelllinie für weitere Untersuchungen prädestiniert. In allen untersuchten Mammakarzinomzelllinien wurde eine mRNA-Expression des GnRH-I Rezeptors ermittelt, die grundlegend in diesen Zellen eine direkte Rezeptor-vermittelte Therapie ermöglicht. Während der Kokultur von HCC-70 
Zellen mit hOB zeigte sich eine signifikante Steigerung der mRNA- sowie Proteinexpression von RANKL im Vergleich zur Kontrolle. Jones et al. (2006) beobachteten in diesem Zusammenhang, dass die Mammakarzinomzelllinien MCF-7 und MDA-MB-231, welche keine RANKL-Expression zeigen, nach einer Inkubation mit RANKL zur Migration angeregt werden. Diese Wirkung konnte durch zusätzliche Stimulation der Zellen mit OPG gehemmt werden. Ähnliche Effekte wurden von Park et al. (2003) erzielt, die in MDA-MB-231 Zellen eine induzierte RANKL mRNA-Expression während der Kokultur mit Osteoblasten detektieren konnten. Gleichzeitig wurde die OPG mRNA-Expression verringert und so eine Veränderung des RANKL/OPG-Verhältnisses hervorgerufen.

In der vorliegenden Arbeit wurde somit gezeigt, dass ein Anstieg der Knochengerichteten Invasion von Mammakarzinomzellen während der Kokultur mit hOB neben SDF-1 ebenfalls mit einer Regulation von RANKL einher geht. Die Behandlung der HCC-70 Zellen mit dem GnRH-I Agonisten Triptorelin konnte die gesteigerte RANKL-Expression wiederum sowohl auf mRNA- als auch auf Proteinebene inhibieren. Für OPG wurden während der Kokultur mit hOB und nach Behandlung mit Triptorelin keine Unterschiede ermittelt. Die Veränderung des RANKL/OPG-Quotienten zugunsten von RANKL zieht eine verstärkte Aktivierung seines osteoklastären Rezeptors RANK nach sich und führt über die Osteoklastogenese zu einer gesteigerten Knochenresorption (Mancino et al., 2001; Bhatia et al., 2005). Für Patientinnen mit einem RANKL-positivem Mammakarzinom oder einer Induktion von RANKL während der Bildung von Knochenmetastasen könnte die Therapie mit GnRH Analoga somit von Vorteil sein. Es sind jedoch weitere Untersuchungen nötig, um die Effekte von GnRH Analoga auf das RANKL/OPG-System zu studieren. Auch die Expression des osteoklastären Rezeptors RANK konnte in primären Mammakarzinomen sowie in verschiedenen Mammakarzinomzelllinien nachgewiesen werden (Thomas et al., 1999).

Die Aufdeckung molekularer Mechanismen der Knochenmetastasierung des primären Mammakarzinoms ist von großer Bedeutung für die Möglichkeit einer zielgerichteten Therapie. Ein humanisierter monoklonaler Antikörper (Prolia ${ }^{\circledR}$, Denosumab), welcher selektiv an RANKL bindet und dessen Wirkung inhibiert, 
befindet sich beim Mammakarzinom in der klinischen Erprobung (McClung, 2006; Geusens, 2009). Die Ergebnisse dieser Arbeit konnten zeigen, dass der GnRH-I Agonist Triptorelin inhibierende Wirkungen im Bezug auf RANKL in vitro aufweist und weitere Untersuchungen auf diesem Gebiet durchgeführt werden sollten.

Während sich eine Expression von RANKL nicht ubiquitär im Mammakarzinom nachweisen lässt, sind Mammakarzinomzellen auch in der Lage indirekt über eine Expression von PTHrP die RANKL-Produktion in Osteoblasten zu steigern (Thomas et al., 1999; Kozlow \& Guise, 2005). Eine Reihe von Studien konnten die Expression von PTHrP im Mammakarzinom bereits belegen (Southby et al., 1990; Henderson et al., 2006; Bohn et al., 2009). Bundred et al. (1992) zeigten in ihren Analysen eine Expression von PTHrP in $56 \%$ der getesteten primären Mammakarzinome und konnten dies in eine positive Relation zur Entwicklung von Metastasen im Knochen bringen. Ein Einfluss von PTHrP konnte bereits sowohl auf das Tumorwachstum als auch die Metastasierung ermittelt werden. So führte in Mäusen eine Überexpression von PTHrP zu einem vermehrten Tumorwachstum (Wysolmerski et al., 2002), durch PTHrP-Antikörper konnte die Knochenmetastasierung von MDA-MB-231 Zellen in Mäusen verhindert werden (Guise et al., 1996). Dieser Effekt wird u.a. auf die Regulation der Intergrine a6 und B4 zurückgeführt, deren Expression in MCF-7 und MDA-MB-231 Zellen durch PTHrP gefördert wird und die Migrations- sowie Invasionsfähigkeit der Mammakarzinomzellen erhöht (Shen \& Falzon, 2006).

Die verstärkte Invasion von Mammakarzinomzellen während der Kokultur mit hOB konnte in dieser Arbeit nicht mit einer Steigerung der PTHrP Expression in Zusammenhang gebracht werden. Sowohl in MCF-7 als auch in MDA-MB-231 Zellen zeigte sich keine Veränderung der mRNA-Expression von PTHrP. Auch für den osteoblastären Rezeptor PTHrP-R wurde in den verwendeten hOB eine Regulation der mRNA-Expression nicht detektiert. Durch die Behandlung der Mammakarzinomzellen mit den GnRH Analoga Triptorelin, Cetrorelix sowie [DLys $\left.^{6}\right] \mathrm{GnRH}-\mathrm{Il}$ wurde ein signifikanter Einfluss auf die mRNA-Expression von PTHrP sowie seinem Rezeptor ebenfalls nicht sichtbar. Da eine Verbindung von PTHrP mit dem RANKL/OPG-System bereits in einigen Studien belegt wurde, 
empfehlen sich zusätzliche Untersuchungen in der HCC-70 Zelllinie, die sowohl eine Expression von RANKL als auch eine Regulation dieses Faktors durch GnRH Analoga aufweist.

\subsubsection{Interaktion mit Faktoren der Metastasierung}

Eine Reihe von Genen konnte bereits identifiziert werden, die eine bedeutende Funktion im Zuge der Migration sowie Invasion von Tumorzellen besitzen und den Metastasierungsprozess auf unterschiedliche Weise regulieren. Dem CDH1 (E-Cadherin) kommt als Adhäsionsmolekül dabei eine Schlüsselrolle zu. Dieser epitheliale Faktor bildet zusammen mit Cateninen, weiteren zytoplasmatischen Proteinen wie auch transmembranen Rezeptoren einen signaltransduzierenden Komplex und hemmt über die entstandenen Zell-Zell-Kontakte die Invasion von Tumorzellen (Bracke et al., 1996; Mareel et al., 1997; Hajra \& Fearon, 2002). In der vorliegenden Arbeit konnte eine Regulation der CDH1 mRNA-Expression nur tendenziell beobachtet werden. Sowohl in MDA-MB-231 Zellen (33\%) als auch in MCF-7 Zellen (22 \%) zeigte sich eine nicht signifikante Reduktion der mRNA-Expression von CDH1 während der Kokultur mit MG-63 Zellen. Eine Aussage, ob $\mathrm{CDH} 1$ in die Invasionsvorgänge dieser Zellen im Kokultursystem involviert ist, kann anhand dieser Ergebnisse nicht getroffen werden. Arbeiten von Sarrio et al. (2009) und Wong \& Gumbiner (2003) konnten jedoch zeigen, dass die Invasionsfähigkeit von MDA-MB-231 Zellen durch eine Matrigelbeschichtete Membran über eine gesteigerte CDH1 Expression gehemmt wird. Außerdem wurde durch die CDH1 Expression eine Regulation weiterer an Migration und Invasion beteiligter Gene wie MMP und Integrinen hervorgerufen (Sarrio et al., 2009). Der umgekehrte Effekt, die Reduktion von CDH1 im Zuge der gesteigerten Invasion, zeigte sich in dieser Arbeit nur ansatzweise und nicht signifikant. Eine Interaktion von $\mathrm{GnRH}$ Analoga mit der Expression von $\mathrm{CDH} 1$ konnte ebenfalls nicht ermittelt werden. Es muss dabei beachtet werden, dass MDA-MB-231 Zellen in den aufgeführten sowie einigen weiteren Arbeiten im Gegensatz zu MCF-7 Zellen als CDH1-negativ geführt werden (Mbalaviele et al., 1996; Nawrocki Raby et al., 2001; Wong \& Gumbiner, 2003; Sarrio et al., 2009), wohingegen eine Expression von CDH1 in den hier durchgeführten Versuchen auf mRNA-Ebene stattfand. 
Weiterhin involviert in die Invasionsprozesse während der Metastasierung von Tumorzellen ist das proteolytische Enzym CTSB (Podgorski \& Sloane, 2003). CTSB führt zum Abbau der EZM und ist in der Lage die Invasionsfähigkeit von Mammakarzinomzellen in vitro zu steigern (Premzl et al., 2003). Dieser Effekt konnte auch in der vorliegenden Arbeit in MCF-7 Zellen während der Kokultur mit MG-63 Zellen nachgewiesen werden. Die CTSB Expression wurde in diesen Zellen auf mRNA-Ebene signifikant gesteigert und auf Proteinebene tendenziell erhöht. In den Arbeiten von Bervar et al. (2003) stand die CTSB Expression in direktem Zusammenhang mit der Invasivität von Mammakarzinomzellen, da die Invasion durch Behandlung der Zellen mit synthetisch hergestellte CathepsinInhibitoren gehemmt werden konnte. Eine signifikante Veränderung der CTSB Expression wurde durch die Behandlung mit den GnRH Analoga Triptorelin, Cetrorelix und [D-Lys $\left.{ }^{6}\right] \mathrm{GnRH}-$ II nicht erzielt.

Eine Regulation während der Kokultur konnte auch für die Gene S100A4 sowie CYR61 beobachtet werden. Diese sind als prometastatische Faktoren bekannt, sie nehmen Einfluss auf die Prozesse der Adhäsion, Migration und Invasion von Tumorzellen (Kim \& Helfman, 2003; Leask \& Abraham, 2006). Zunächst wurden für beide Gene Expressionsunterschiede in Mammakarzinomzellen beobachtet. Sowohl S100A4 als auch CYR61 zeigten in invasiven und aggressiveren MDAMB-231 Zellen eine signifikant höhere mRNA-Expression gegenüber der nichtinvasiven Zelllinie MCF-7. Dieses Ergebnis bestätigt die Daten von Jiang et al. (2004), welche diesen Effekt für CYR61 ebenfalls nachweisen konnten. Zudem wurde im Mammakarzinom ein signifikanter Expressionsanstieg von CYR61 im Vergleich zum normalen Gewebe detektiert, der in Verbindung mit schlechter Prognose, Lymphknotenstatus sowie der metastatischen Ausbreitung steht (Xie et al., 2001; Jiang et al., 2004). Auch die Ergebnisse der vorliegenden Arbeit zeigen, dass eine gesteigerte Expression von CYR61 mit der Aggressivität von Mammakarzinomzellen korreliert. CYR61 steht ebenso in Zusammenhang mit einer erhöhten Invasionsfähigkeit der Zellen. Sowohl in MCF-7 als auch MDAMB-231 Zellen wurde während der Kokultur eine signifikant gesteigerte mRNAExpression von CYR61 ermittelt. Nguyen et al. (2006) konnten den Migrationsfördernden Effekt von CYR61 auf die Expression der MMP-1 zurückführen. Der 
Verlust von CYR61 in Mammakarzinomzellen führte in einem Fibroblastengerichteten Migrationsassay zu einer MMP-1 Inhibition in diesen Zellen und ein Fehlen der Aktivität von MMP-1 in Fibroblasten hemmte umgekehrt die CYR61vermittelte Migration der Mammakarzinomzellen. GnRH Analoga zeigten in der vorliegenden Arbeit jedoch keine Auswirkungen auf die mRNA-Expression von CYR61. Eine Überexpression von CYR61 wurde auch bei Patientinnen einer Endometriose detektiert, die nach der Therapie mit dem GnRH-I Agonisten Leuprorelin ebenso unverändert war (Absenger et al., 2004). Ein signifikanter Einfluss der GnRH Analoga auf die S100A4 mRNA-Expression konnte ebenfalls nicht beobachtet werden. Während der Kokultur zeigte sich aber in MCF-7 Zellen ein signifikanter Anstieg der Expression von S100A4. Jenkinson et al. (2004) konnten einen deutlichen Einfluss von S100A4 auf die Invasionsfähigkeit von Mammakarzinomzellen erzielen. Hierbei war die Invasivität von speziellen S100A4-transfizierten Mammakarzinomzellen durch eine Matrigel-beschichtete Membran im Vergleich zu nicht-transfizierten Zellen stark erhöht.

\subsection{Effekte der GnRH Analoga in vivo}

GnRH-I Analoga werden für eine Therapie steroidhormonabhängiger Tumore in der Klinik bereits eingesetzt. Durch die Blockade der Hypothalamus-GonadenAchse kommt es zum Erliegen der Steroidhormonsynthese, das wiederum die wachstumsstimulierenden Effekte dieser Hormone auf die Entwicklung des Tumors hemmt. Auch beim metastasierten Mammakarzinom wird bei einem positiven Hormonrezeptorstatus eine Therapie mit GnRH-I Analoga empfohlen. GnRH-I Agonisten sind bisher nur in Kombination mit weiteren antihormonellen Optionen wie z.B. dem Einsatz von Tamoxifen etabliert (Martinetti et al., 2000; Jonat, 2001; Klijn et al., 2001; Goel et al., 2009). Hierbei könnten sich GnRH Antagonisten gegenüber $\mathrm{GnRH}$ Agonisten jedoch als vorteilhaft erweisen, da ihre Wirkungen aufgrund der fehlenden Flare up-Phase direkt einsetzen und keine Down-Regulation der Rezeptoren stattfindet.

Da sich ca. 50 \% der Mammakarzinome als GnRH-I Rezeptor-positiv erweisen, ist eine direkte Rezeptor-vermittelte Therapie mit Analoga des $\mathrm{GnRH}$ auf das Tumorwachstum und die Metastasierung in diesen gynäkologischen Tumoren 
von großer Bedeutung. Die verwendeten GnRH Agonisten Triptorelin und [DLys $\left.^{6}\right] \mathrm{GnRH}-$ II schließen eine unverzögerte Inhibition des Tumorwachstums und der Metastasierung, die sich über die Blockade der Hypothalamus-GonadenAchse ergibt, dabei aus.

\subsubsection{Hemmung des Tumorwachstums}

Die Effekte der GnRH Analoga auf das Tumorwachstum in xenotransplantierten CD1 nu/nu Mäusen wurden unter Verwendung der Mammakarzinomzelllinie MDA-MB-435 analysiert. Es handelt sich dabei um eine aggressive Zelllinie, die sich im Vergleich zu MCF-7 und MDA-MB-231 Mammakarzinomzellen durch bessere Anwachsraten auszeichnet und sich damit sehr gut für das in vivo Tumormodell eignet. Die Herkunft der MDA-MB-435 Zellen war in den letzten Jahren umstritten, da sich sowohl charakteristische Merkmale für Zellen des Mammakarzinoms als auch eines Melanoms nachweisen liesen (Ellison et al., 2002; Sellappan et al., 2004; Rae et al., 2007). Da eine Expression von $\mathrm{GnRH}$ Rezeptoren in MDA-MB-435 Zellen stattfindet, eignen sie sich im Tumormodell für Untersuchungen zur Behandlung mit GnRH Analoga (Chatzistamou et al., 2000). Weiterhin wurden von Chambers (2009) eindeutige Nachweise geliefert, dass es sich hier um eine Mammakarzinomzellinie handelt. Die Wahl dieser Zelllinie wurde somit als sinnvoll erachtet.

Die beiden GnRH-I Analoga Triptorelin und Cetrorelix zeigten während des Versuches keine signifikanten wachstumshemmenden Effekte auf MDA-MB435 Zellen. Am Ende der fünfwöchigen Therapie wurde das Tumorvolumen jedoch tendenziell um $30 \%$ (Triptorelin) und $26 \%$ (Cetrorelix) verringert. Ein Ansprechen der Mammakarzinomzellen auf die Behandlung mit den GnRH-I Analoga konnte somit ansatzweise ermittelt werden. Für Triptorelin entspricht dies den Ergebnissen klinischer Studien, welche wachstumshemmende Effekte nicht durch alleinige Gabe von Triptorelin, sondern vorallem in Kombination mit weiteren Substanzen der Tumorinhibition beim Mammakarzinom zeigen (Celio et al., 1999; Rossi et al., 2008; Jannuzzo et al., 2009). Sowohl für Triptorelin als auch für Cetrorelix konnten in vitro antiproliverative Effekte in gynäkologischen Tumoren bereits nachgewiesen werden (Segal-Abramson et al., 1992; Emons et al., 1997; Gründker et al., 2004). Dabei zeigt der GnRH-I Antagonist stärkere 
proliferationshemmende Effekte gegenüber dem GnRH-I Agonisten (Gründker et al., 2004). Zusätzlich wurden durch Cetrorelix in vivo wachstumsinhibierende Wirkungen im Ovarialkarzinom (Yano et al., 1994a; Manetta et al., 1995) sowie im Mammakarzinom (Reissmann et al., 1996) erzielt. Durch Yano et al. (1994b) wurde in diesem Zusammenhang die Wirkung von Cetrorelix in mit MCF-7/MIII Mammakarzinomzellen xenotransplantierten Nacktmäusen untersucht. Hierbei konnte eine signifikante Tumorwachstumshemmung durch die alleinige Gabe von Cetrorelix erst ab der fünften Woche erreicht werden. Auch in dieser Arbeit zeigten sich während der fünfwöchigen Therapie mit Cetrorelix in MDA-MB-435 Zellen keine signifikanten Effekte auf das Tumorwachstum. Untersuchungen in einem längeren Versuchsverlauf wären hier interessant, müssten jedoch wegen der hohen Wachstumsraten und dem sehr aggressiven Verhalten der MDA-MB435 Zellen mit weniger aggressiven Mammakarzinomzellen wie MDA-MB-231 Zellen durchgeführt werden.

Durch die Behandlung der CD1 nu/nu Mäuse mit den GnRH-II Analoga [D-Lys ${ }^{6}$ ] GnRH-Il und GnRH-II Ant wurde das Tumorwachstum der MDA-MB-435 Zellen während des gesamten Versuchsverlaufs signifikant gehemmt. Für GnRH-II konnten in vitro antiproliferative Effekte in gynäkologischen Tumoren bereits nachgewiesen werden (Yano et al., 1994b; Choi et al., 2001; Gründker et al., 2002; Gründker et al., 2004). Hierbei wurde durch GnRH-Il eine stärkere antiproliferative Wirkung gegenüber dem GnRH-I Agonisten Triptorelin erreicht (Gründker et al., 2002). Dieses Ergebnis spiegelt sich ebenso in den in vivo Untersuchungen dieser Arbeit wider, da auch hier GnRH-II Analoga stärkere wachstumshemmende Eigenschaften gegenüber denen des $\mathrm{GnRH}-\mathrm{I}$ aufweisen. Durch Fister et al. (2007) konnte erstmalig gezeigt werden, dass neuentwickelte GnRH-Il Antagonisten zur Induktion einer Caspase-3 vermittelten Apoptose in gynäkologischen Tumoren führen. Diese Wirkungen wurden bereits in vivo im Ovarial- sowie Endometriumkarzinom bestätigt (Fister et al., 2009). In den mit MDA-MB-435 Zellen xenotransplantierten CD1 nu/nu Mäusen wurden auch im Mammakarzinom sehr starke wachstumsinhibierende Effekte des GnRH-II Ant gezeigt. Diese neuentwickelte Substanzklasse bietet somit gute Möglichkeiten in der endokrinen Therapie gynäkologischer Tumore. Die Therapie beruht hier 
ebenfalls auf den direkten im Mammakarzinom Rezeptor-vermittelten Effekten, die in einer Apoptoseinduktion resultieren (Gründker et al., 2010).

Nebenwirkungen der endokrinen Therapie wurden während des Versuchs nicht beobachtet, müssen aber für den Fall einer längerfristigen Behandlung mit $\mathrm{GnRH}-\mathrm{Il}$ Analoga in weiteren Versuchen abgeklärt werden. Es muss weiterhin beachtet werden, dass sich die mRNA-Expression des GnRH-Il Rezeptors ubiquitär unterschiedlich stark im menschlichen Körper nachweisen lässt (Neill, 2002). Die über GnRH-Il Analoga vermittelten Effekte müssen, falls in diesen Geweben ein funktionelles Protein vorliegt, ausgeschlossen werden.

\subsubsection{Metastasierungsuntersuchungen mittels TaqMan ${ }^{\circledR}$-Real-time PCR}

Das primäre Mammakarzinom gehört zu den Tumoren, die ein sehr aggressives Metastasierungsverhalten aufweisen. Die Metastasierung findet dabei vorallem in Knochen, Lunge und Leber statt (Weigelt et al., 2005). Die Möglichkeit einer Intervention in den Metastasierungsprozess ist besonders aus therapeutischer Sicht von großer Bedeutung, um eine gezielte Behandlung der Erkrankung und eine bessere Lebensqualität für die Patientinnen zu erreichen.

Der Einfluss unterschiedlicher GnRH Analoga auf die Metastasierung von MDAMB-435 sowie MDA-MB-231 Mammakarzinomzellen wurde mit einer speziellen TaqMan $^{\circledR}$-Real-time PCR-Methode analysiert. Hierbei kam es zum Einsatz einer humanspezifischen Alu-Sequenz, welche nur im humanen Genom detektierbar ist (Munoz et al., 2005). Für die molekulare Diagnostik bei Tumorerkrankungen bietet die Real-time PCR-Technik einen erfolgsversprechenden Ansatz, da es sich um eine sehr sensitive Methode handelt, welche wie auch in dieser Arbeit als Multiplexverfahren angewendet werden kann (Bernard \& Wittwer, 2002). So konnten Kurosumi \& Takei (2007) in Sentinel-Lymphknoten (SLN)-Biopsien des Mammakarzinoms Vorteile der Real-time PCR gegenüber histopathologischen Untersuchungen bei der Detektion von Mikrometastasen aufzeigen. Wie auch in vielen weiteren Arbeiten (Ismail et al., 2004; Xenidis et al., 2007; Zheng et al., 2008) wurde hier der Nachweis eines spezifischen Tumormarkers, dem CK-19 (Cytokeratin-19) erbracht. Die Detektion humanspezifischer Alu-Sequenzen ist hingegen ein noch relativ offenes Forschungsfeld. Die ersten Schritte lieferten McKenzie et al. (1991) durch die Verwendung einer ${ }^{32} \mathrm{P}$-markierten Alu-Sonde 
für den Nachweis humaner DNA in einer Mischung aus genomischer DNA von humanen Lungenkarzinomzellen und Lungen von athymischen Mäusen. Durch diese Arbeit konnten weitere Techniken für eine Detektion humanspezifischer Alu-Sequenzen ausgearbeitet werden (Shoemaker et al., 1992; Weisberg et al., 1996).

\subsubsection{Hemmung der Metastasierungsrate im Femur}

Mit der in dieser Arbeit durchgeführten TaqMan ${ }^{\circledR}$-Real-time PCR konnte im Femur von mit MDA-MB-435 Zellen xenotransplantierten CD1 nu/nu Mäusen ein signifikanter Nachweis von Mikrometastasen erzielt werden. Phadke et al. (2006) beobachteten in diesem Zusammenhang eine bevorzugte Lokalisation GFP-markierter MDA-MB-435 Zellen im distalen sowie proximalen Bereich des Femurs. Durch die Behandlung mit den GnRH Analoga Triptorelin, Cetrorelix, [D-Lys $\left.{ }^{6}\right] \mathrm{GnRH}-$ II sowie GnRH-II Ant konnte die Metastasierung im Femur der Mäuse signifikant gehemmt werden. Hierbei wurde deutlich, dass die $\mathrm{GnRH}$ Antagonisten mit $93 \%$ (Cetrorelix) und $92 \%$ (GnRH-II Ant) stärker inhibierende Effekte aufweisen als die GnRH Agonisten mit $70 \%$ (Triptorelin) und $74 \%$ ([DLys $\left.\left.^{6}\right] \mathrm{GnRH}-\mathrm{II}\right)$. Somit konnte erstmals eine direkte Wirkung von $\mathrm{GnRH}$ Analoga auf die Bildung von Mikrometastasen im Femur, der zu den Hauptangriffsorten des metastasierenden Mammakarzinoms zählt, in vivo gezeigt werden. GnRH Antagonisten erweisen sich dabei als vorteilhaft und erzielen einen ca. $20 \%$ stärkeren Effekt gegenüber den GnRH Agonisten. In der Lunge wurde ebenfalls ein tendenzieller Anstieg der Metastasierungsrate von MDA-MB-435 Zellen ermittelt. Durch die zum Teil großen Schwankungen der Metastasierungsraten zwischen einzelnen Mäusen innerhalb einer Gruppe wurde die statistische Auswertung jedoch erschwert. Es konnte aber auch hier eine nicht signifikante Hemmung der Metastasierungsrate durch die GnRH Analoga gezeigt werden. Diese wurde durch Cetrorelix (88\%), [D-Lys $\left.{ }^{6}\right] \mathrm{GnRH}-\mathrm{II}(91 \%)$ sowie GnRH-II Ant $(97 \%)$ erreicht. In einer vergleichenden Arbeit von Becker et al. (2002) zeigten sich in der TaqMan ${ }^{\circledR}$-Real-time PCR einer spezifischen DNA-Sequenz des humanen Genoms Mikrometastasen von MDA-MB-435 Zellen in Lunge und Leber nach 30 Tagen Versuchsdauer. Ähnliche Effekte in der Lunge wurden von Schneider et al. (2002) mittels einer humanspezifischen Alu-Sequenz im 
LightCycler ${ }^{\circledR}$-Real-time PCR-System ermittelt. MDA-MB-435 Zellen eignen sich als spontan metastasierende Zellinie sehr gut im Nacktmausmodell um die direkten Metastasierungsvorgänge des Mammakarzinoms und therapeutische Effekte anti-metastatischer Substanzen zu analysieren (Zhang et al., 2004; Lee et al., 2005; Castillo-Pichardo et al., 2009). Dies wurde auch in der vorliegenden Arbeit bestätigt. Durch GnRH Analoga wurde die Metastasierungsrate im Femur signifikant und in der Lunge tendenziell gehemmt. Bei zukünftigen Versuchen in diesem Rahmen sollte berücksichtigt werden, dass die Anzahl der Mäuse pro Gruppe nicht unter zehn angesetzt wird. Des Weiteren muss beachtet werden, dass sich in in vitro Studien für MDA-MB-435 Zellen ein gegenteiliger Effekt gezeigt hat. Unter einer Reihe verschiedender Mammakarzinomzelllinien wurde während der Kokultur von MDA-MB-435 Zellen mit hOB eine verminderte Zahl an invadierten Zellen im Vergleich zur Kontrolle sowie keine Effekte von GnRH Analoga auf die Migration und Invasion der MDA-MB-435 Zellen ermittelt (von Alten et al., 2006). Dieses Ergebnis verdeutlicht, dass die in vitro Situation nicht ohne Weiteres auf in vivo Modelle übertragbar ist.

Das unterschiedliche Erscheinungsbild einer Erkrankung am Mammakarzinom spiegelt sich beim Einsatz humaner Mammakarzinomzellinien wider, die sich in ihren Eigenschaften ebenso voneinander unterscheiden. Neben den MDA-MB435 Zellen wurden MDA-MB-231 Zellen für die Metastasierungsuntersuchungen gewählt. Die Metastasierung dieser Mammakarzinomzellen findet vorallem nach einer direkten Injektion ins Herz der Nacktmäuse statt. Ca. 3 - 4 Wochen nach der intrakardialen Injektion von MDA-MB-231 Zellen lassen sich Metastasen im Knochen mit speziellen bildgebenden Methoden nachweisen (Saiki et al., 1988; Yoneda et al., 2000; Peyruchaud et al., 2001; Bondareva et al., 2009). Mit der TaqMan $^{\circledR}$-Real-time PCR zeigte sich im Vergleich zur Kontrollgruppe nach fünf Wochen Versuchsdauer ein tendenzieller Anstieg der Metastasierungsrate im Femur der CD1 nu/nu Mäuse. Trotz einer erhöhten Anzahl von Mäusen pro Gruppe, ergaben sich in der Tumorgruppe Schwankungen zwischen einzelnen Metastasierungsraten. Eine nicht signifikante Hemmung der Metastasierung wurde jedoch sowohl für den GnRH-I Agonisten Triptorelin (78\%) als auch für den GnRH-II Antagonisten GnRH-II Ant (93\%) beobachtet. Auch in diesem 
Experiment wurde somit ein möglicher therapeutischer Ansatz der $\mathrm{GnRH}$ Analoga beim metastasierenden Mammakarzinom deutlich. Hierbei scheint der $\mathrm{GnRH}-\mathrm{Il}$ Antagonist ebenfalls eine stärkere inhibierende Wirkung gegenüber dem GnRH-I Agonisten zu besitzen. In der Lunge wurde bei zwei Mäusen der Tumorgruppe eine deutliche Ausbildung von Mikrometastasen detektiert, die im Gesamten zu einem nicht signifikanten Anstieg der Metastasierung im Vergleich zur Kontrollgruppe führte. Tester et al. (2002) konnten Mikrometastasen in der Lunge nach der Injektion von MDA-MB-231 BAG Zellen (LAC-Z-markiert) in die Brustdrüse von Nacktmäusen nach sechs bis acht Wochen nachweisen. Auch hier wurden Schwankungen zwischen dem Ausmaß der Mikrometastasen in den Lungen unterschiedlicher Mäuse beobachtet. Die Real-time PCR-Methode zeigte sich jedoch ebenfalls in der Arbeit von Tester et al. vorteilhaft gegenüber der RT-PCR und histopathologischen Untersuchungen. Ein Einfluss der GnRH Analoga auf die Metastasierungsrate in der Lunge wurde nicht ermittelt.

In der Leber von Nacktmäusen lassen sich Mikrometastasen fünf Wochen nach einer intrakardialen Injektion GFP-markierter MDA-MB-231 Zellen (1,5 x 10-5/ $100 \mu \mathrm{l})$ nachweisen (Richert et al., 2009). Mittels der TaqMan ${ }^{\circledR}$-Real-time PCR wurde in der vorliegenden Arbeit in der Leber der CD1 nu/nu Mäuse nur ein nicht signifikanter und minimaler Anstieg der Metastasierungsrate von MDAMB-231 Zellen $\left(1 \times 10^{-5} / 100 \mu \mathrm{l}\right)$ im Vergleich zur Kontrollgruppe ermittelt. Im Gegensatz zum Femur und zur Lunge befand sich die Metastasierungsrate der Tumorgruppe auf gleichem Niveau mit der Kontrollgruppe. Die Behandlung mit den $\mathrm{GnRH}$ Analoga zeigte auch hier keine signifikanten Auswirkungen auf die Metastasierungsrate, eine minimal erhöhte Metastasierungsrate wurde jedoch nach der GnRH-II Ant Therapie im Vergleich zur Tumorgruppe detektiert.

In den Metastasierungsuntersuchungen dieser Arbeit wurden antimetastatische Effekte sowohl für GnRH-I als auch für GnRH-Il Analoga im Nacktmausmodell nachgewiesen. Dieses Ergebnis zeigt, dass sich neben den bereits in der Klinik angewendeten $\mathrm{GnRH}-\mathrm{I}$ Analoga, $\mathrm{GnRH}-\mathrm{Il}$ Analoga ebenfalls für eine endokrine Therapie des metastasierenden Mammakarzinoms empfehlen. Insbesonders im Femur der CD1 nu/nu Mäuse wurden starke inhibierende Wirkungen ermittelt. Die hierfür verwendete TaqMan ${ }^{\circledR}$-Real-time PCR Methode eignet sich um die 
Bildung von Mikrometastasen sowie Therapieansätze von antimetastatischen Substanzen zu untersuchen. Dabei muss sowohl auf die Wahl einer geeigneten Zelllinie als auch eine hohe Anzahl an Versuchstieren geachtet werden, da sich die Metastasierungsvorgänge zwischen den einzelnen Nacktmäusen zum Teil sehr unterscheiden. MDA-MB-435 Zellen, die in die Brustdrüse injiziert wurden, eignen sich gut für das Nacktmausmodell. Untersuchungen mit langsamer und nicht so aggressiv wachsenden Mammakarzinomzelllinien, wie MDA-MB-231 Zellen sollten dennoch weitergeführt werden, da sich das Mammakarzinom in seinem Erscheinungsbild sehr vielfältig zeigt und sie die menschliche Situation sehr gut widerspiegeln. Nebenwirkungen durch die Metastasierung oder die Behandlung mit GnRH Analoga wurden während der Präparation der Mäuse makroskopisch nicht beobachtet und sprechen für den Einsatz von $\mathrm{GnRH}$ Analoga in der endokrinen Therapie des metastasierenden Mammakarzinoms, müssen jedoch anhand zusätzlicher Analysen abgeklärt werden.

\subsubsection{Nachweisversuch von CTC im Blut}

Die Detektion von CTC im Blut während der Erkrankung am metastasierenden Mammakarzinom spielt sowohl für die Prognose als auch die Möglichkeit einer frühzeitigen Diagnostik sowie Beurteilung des Therapieverlaufs eine wichtige Rolle. Trotz der vielseitigen Weiterentwicklung verschiedener Methoden für den Nachweis von CTC, konnte sich auf diesem Gebiet bisher keine standardisierte Technik etablieren. Mittels der in dieser Arbeit durchgeführten TaqMan ${ }^{\circledR}$-Realtime PCR wurden nach fünf Wochen Versuchsdauer keine CTC im Blut von mit MDA-MB-231 Zellen xenotransplantierten CD1 nu/nu Mäusen detektiert. Da zu diesem Zeitpunkt bereits Mikrometastasen im Femur und auch in der Lunge ansatzweise nachgewiesen werden konnten, wäre eine Untersuchung zu einem früheren Zeitabschnitt im Metastasierungsprozess interessant. Dieses Ergebnis bestätigt jedoch die Daten von Becker et al. (2002), die in einem vergleichbaren Versuch nach vier Wochen im Blut von SDID Mäusen mit der TaqMan ${ }^{\circledR}$-Realtime PCR einer spezifischen DNA-Sequenz des humanen Genoms ebenfalls keine CTC, in diesem Fall MDA-MB-435 Zellen nach Injektion in die Brustdrüse nachweisen konnten. Auch zu einem früheren Zeitpunkt (Blutentnahme einmal pro Woche) wurden CTC im Blut nicht detektiert und u.a. eine Metastasierung 
vorwiegend auf lymphogenem Weg vermutet. Da eine Metastasierung in ferne Organe wie Lunge, Leber und Knochen vorallem hämatogen beschrieben wird (Tobler \& Detmar, 2006) und in der vorliegenden Arbeit die Injektion der MDAMB-231 Zellen direkt ins Herz der Nacktmäuse vorgenommen wurde, scheint die TaqMan ${ }^{\circledR}$-Real-time PCR humanspezifischer Alu-Sequenzen nicht sensitiv genug für den Nachweis von CTC zu sein. In den letzten Jahren wird in diesem Rahmen verstärkt die Kombination von Verfahren der immunomagnetischen Anreicherung von Tumorzellen mit der PCR-Technik untersucht. Dabei werden gezielt membranständige Antigene der Tumorzellen mittels an magnetische Partikel gekoppelter Antikörper erkannt und auf diese Weise eine Separation der Zellen vorgenommen. Die Möglichkeit einer Kombination dieser beiden Methoden konnte in vitro bereits gezeigt werden (Berois et al., 1997; Eaton et al., 1997; Raynor et al., 2002; Lankiewicz et al., 2006). Ob sich in vivo diese Auftrennungsverfahren auch als relevant erweisen, wird zur Zeit in klinischen Studien getestet.

Zusätzliche Untersuchungen müssen zeigen, ob CTC im Blut von Nacktmäusen mittels der entwickelten TaqMan ${ }^{\circledR}$-Real-time PCR einer humanspezifischen AluSequenz nachweisbar sind und ob sich eventuell eine Kombination mit einer Methode der Tumorzellanreicherung empfiehlt. Da die Detektion von CTC nicht möglich war, konnte in diesem Rahmen ein Einfluss von GnRH Analoga ebenso nicht ermittelt werden.

\subsubsection{Detektion von Metastasen mit Hilfe des Natrium-lodid-Symporters}

Zusätzlich zum Nachweis der Metastasierung mittels TaqMan ${ }^{\circledR}$-Real-time PCR wurde mit der Entwicklung einer weiteren Detektionsmethode für die Bildung von Metastasen im Nacktmausmodell begonnen. Die Detektionsmöglichkeit der Metastasierung beruht hierbei auf den Eigenschaften eines transmembranen Proteins, dem Natrium-lodid-Symporter (NIS). Dieses Transportprotein ist in der Lage aktiv lodid-lonen aus dem Blut in die Zellen aufzunehmen und besitzt eine Schlüsselrolle in der Schilddrüsenhormonsynthese (Dai et al., 1996; Dohan \& Carrasco, 2003). Die Expression von NIS findet neben der Schilddrüse ebenso in einigen extrathyreoidalen Geweben wie der Niere (Spitzweg et al., 2001), der Speicheldrüse (Jhiang et al., 1998) sowie der laktierenden Brustdrüse (Tazebay 
et al., 2000) statt. Nach einer totalen Thyreoidektomie ist die NIS-vermittelte lodaufnahme Grundlage für eine Ganzkörperszintigraphie und Therapie mittels radioaktivem lod. Die funktionelle NIS Expression in Schilddrüsenkarzinomen und deren Metastasen ermöglicht hierbei die Erkennung sowie Eliminierung dieser noch im Körper vorhandener Zellen (Spitzweg, 2003). Eine gezielte NIS Expression in extrathyreoidalen Tumoren könnte diese Form der Radiotherapie auch außerhalb der Schilddrüse ermöglichen. Im transgenen Mausmodell des Mammakarzinoms wurde die signifikante Aufnahme und Therapiemöglichkeit von radioaktivem lod bereits in vivo nachgewiesen (Dadachova et al., 2005).

Der tumorspezifische NIS Gentransfer und die damit verbundene Akkumulation von radioaktivem lod bietet ebenfalls eine gute Möglichkeit für die Detektion von Metastasen im Nacktmausmodell der vorliegenden Arbeit und die zielgerichtete Therapie mit GnRH Analoga zu untersuchen. Dafür wurde eine Transfektion der Mammakarzinomzellen MDA-MB-231 sowie MDA-MB-435 mit NIS durchgeführt (nicht gezeigt). Über eine Ampicillin- und Neomycinresistenz kann hierbei eine Selektion von stabil transfizierten Zellen erfolgen (siehe Abbildung 7.1). Die Aufnahme von radioaktivem lod NIS-transfizierter Tumorzellen liegt bis zu 225fach höher im Vergleich zu den nicht-transfizierten Kontrollzellen (Mandell et al., 1999; Boland et al., 2000; Cho et al., 2000). Eine optische Bildgebung mit üblichen Reportergenen wie Luciferase oder GFP (green fluorescent protein) hat zwar den Vorteil einer relativ hohen Sensitivität, macht die Quantifizierung in vivo durch eine starke Streuung und die damit verbundene schlechte Auflösung jedoch schwierig. Bei der Quantifizierung mittels NIS kann die Single photon emission tomography (SPET) angewendet werden, die eine hochauflösende Darstellung der Verteilung des Reportergens ermöglicht. Miyagawa et al. (2005) konnten in kardiologischer Fragestellungen zeigen, dass NIS in diesem System Vorteile gegenüber anderen nuklearmedizinischen Methoden besitzt und durch eine Fusion mit der Magnetresonanztherapie (MRT) ist zudem eine genaue Lokalisation des Reportergens möglich (Schurrat et al., 2003).

Die NIS-Nachweismethode wurde in Zusammenarbeit mit Dr. rer. nat. Martin Béhé (Nuklearmedizinische Klinik, Freiburg) begonnen und bedarf der weiteren Entwicklung. Für die Zukunft bietet diese Technik eine gute und sehr genaue 
Option um die Metastasierung des Mammakarzinoms im Nacktmausmodell zu untersuchen.

\subsection{Fazit und Ausblick}

In der vorliegenden Arbeit konnte grundlegend gezeigt werden, dass während der Kokultur von Mammakarzinomzellen mit hOB bzw. Osteoblasten-ähnlichen Zelllinen verschiedene Metastasierungs-assoziierte Gene reguliert werden. Eine signifikant gesteigerte mRNA-Expression wurde für CTSB, S100A4 und CYR61 in MCF-7 oder MDA-MB-231 Zellen ermittelt. Dies lässt darauf schließen, dass die Invasionsfähigkeit der Mammakarzinomzellen auf der Modulation mehrerer sowie in verschiedenen Zellinien unterschiedlicher Faktoren beruht. Die GnRH Analoga Triptorelin, Cetrorelix und $\left[\mathrm{D}-\mathrm{Lys}^{6}\right] \mathrm{GnRH}-\mathrm{Il}$ sind zwar in der Lage, die Knochen-gerichtete Invasion von Mammakarzinomzellen zu inhibieren, zeigten in dieser Arbeit jedoch keine Effekte auf diese in den Metastasierungsprozess involvierten Gene. Eine eindeutige Regulation während der Kokultur wurde für das RANKL/OPG-System beobachtet. Hier zeigte sich ein signifikanter Anstieg der Expression von RANKL sowohl auf mRNA- als auch auf Proteinebene in den für diese Untersuchungen gewählten HCC-70 Zellen. Die OPG Expression blieb hingegen unverändert. Eine Verschiebung des RANKL/OPG-Verhältnisses zugunsten von RANKL fördert die Knochenresorption. Der GnRH-I Agonist war in der Lage, die erhöhte RANKL Expression während der Kokultur mit hOB zu hemmen. Diese Ergebnisse liefern einen wichtigen Ansatz bei der Entwicklung zielgerichteter Therapiestrategien beim metastasierenden Mammakarzinom und geben Anlass für weitere Analysen auf diesem Gebiet.

In vivo wurden für $\mathrm{GnRH}-$ Il Analoga starke wachstumsinhibierende Wirkungen im Mammakarzinom nachgewiesen. Analoga des $\mathrm{GnRH}-\mathrm{Il}$ empfehlen sich somit neben den in der Klinik bereits eingesetzten GnRH-I Analoga in der endokrinen Therapie des primären Mammakarzinoms. GnRH-I sowie GnRH-II Analoga sind ebenso für die Inhibition der Metastasierung des Mammakarzinoms von großer Bedeutung. Im Knochen konnten signifikante antimetastatische Effekte erzielt werden. GnRH Antagonisten zeigten hierbei noch intensivere antimetastatische Wirkungen gegenüber GnRH Agonisten. Neben direkten Rezeptor-vermittelten 
Effekte besitzen diese weitere Vorteile in der endokrinen Therapie. Aufgrund der fehlenden Flare up-Phase führen sie zu einer unverzögerten Inhibition der Steroidhormonsynthese.

In der vorliegenden Arbeit wurden somit erstmals durch GnRH Analoga direkte antimetastatische Effekte in vivo gezeigt, die einen wichtigen Beitrag für den Einsatz und die Etablierung dieser Hormonanaloga in der endokrinen Therapie des metastasierenden Mammakarzinoms leisten. Weiterhin wurde in vitro das RANKL/OPG-System als potentielles Ziel für eine Therapie mit GnRH Analoga identifiziert. Weitere molekulare Mechanismen, welche den antimetastatischen Wirkungen der $\mathrm{GnRH}$ Analoga zugrunde liegen, bleiben ungeklärt und müssen in weiteren Untersuchungen analysiert werden. 


\section{LITERATURVERZEICHNIS}

Absenger, Y., Hess-Stumpp, H., Kreft, B., Kratzschmar, J., Haendler, B., Schutze, N., Regidor, P. A. and Winterhager, E. (2004). Cyr61, a deregulated gene in endometriosis. Mol Hum Reprod 10, 399-407.

Amoss, M., Burgus, R., Blackwell, R., Vale, W., Fellows, R. and Guillemin, R. (1971). Purification, amino acid composition and N-terminus of the hypothalamic luteinizing hormone releasing factor (LRF) of ovine origin. Biochem Biophys Res Commun 44, 205-10.

Bai, B., Yuan, Z. Y., Liu, D. G., Teng, X. Y. and Wang, S. S. (2010). Clinical features and survival analysis of different subtypes of patients with breast cancer brain metastases. Chin J Cancer 29, 413-9.

Batzer, M. A. and Deininger, P. L. (2002). Alu repeats and human genomic diversity. Nat Rev Genet 3, 370-9.

Beatson, G. T. (1896). On the treatment of inoperable cases of carcinoma of the mamma: suggestions for a new method of treatment, with illustrative cases. The Lancet 148, 104-107.

Becker, M., Nitsche, A., Neumann, C., Aumann, J., Junghahn, I. and Fichtner, I. (2002). Sensitive PCR method for the detection and real-time quantification of human cells in xenotransplantation systems. $\mathrm{Br} J$ Cancer 87, 1328-35.

Berchem, G., Glondu, M., Gleizes, M., Brouillet, J. P., Vignon, F., Garcia, M. and Liaudet-Coopman, E. (2002). Cathepsin-D affects multiple tumor progression steps in vivo: proliferation, angiogenesis and apoptosis. Oncogene 21, 5951-5.

Bernard, P. S. and Wittwer, C. T. (2002). Real-time PCR technology for cancer diagnostics. Clin Chem 48, 1178-85.

Berois, N., Varangot, M., Osinaga, E., Babino, A., Caignault, L., Muse, I. and Roseto, A. (1997). Detection of rare human breast cancer cells. Comparison of an immunomagnetic separation method with immunocytochemistry and RT-PCR. Anticancer Res 17, 2639-46.

Bervar, A., Zajc, I., Sever, N., Katunuma, N., Sloane, B. F. and Lah, T. T. (2003). Invasiveness of transformed human breast epithelial cell lines is related to cathepsin B and inhibited by cysteine proteinase inhibitors. Biol Chem 384, 447-55. 
Berx, G. and Van Roy, F. (2001). The E-cadherin/catenin complex: an important gatekeeper in breast cancer tumorigenesis and malignant progression. Breast Cancer Res 3, 289-93.

Bhatia, P., Sanders, M. M. and Hansen, M. F. (2005). Expression of receptor activator of nuclear factor-kappaB is inversely correlated with metastatic phenotype in breast carcinoma. Clin Cancer Res 11, 162-5.

Billiau, A., Edy, V. G., Heremans, H., Van Damme, J., Desmyter, J., Georgiades, J. A. and De Somer, P. (1977). Human interferon: mass production in a newly established cell line, MG-63. Antimicrob Agents Chemother 12, 11-5.

Bishop, D. T. (1999). BRCA1 and BRCA2 and breast cancer incidence: a review. Ann Oncol 10 Suppl 6, 113-9.

Bloom, H. J. and Richardson, W. W. (1957). Histological grading and prognosis in breast cancer; a study of 1409 cases of which 359 have been followed for 15 years. Br J Cancer 11, 359-77.

Bohn, O. L., Nasir, I., Brufsky, A., Tseng, G. C., Bhargava, R., MacManus, K. and Chivukula, M. (2009). Biomarker profile in breast carcinomas presenting with bone metastasis. Int J Clin Exp Pathol 3, 139-46.

Boland, A., Ricard, M., Opolon, P., Bidart, J. M., Yeh, P., Filetti, S., Schlumberger, M. and Perricaudet, M. (2000). Adenovirus-mediated transfer of the thyroid sodium/iodide symporter gene into tumors for a targeted radiotherapy. Cancer Res 60, 3484-92.

Bondareva, A., Downey, C. M., Ayres, F., Liu, W., Boyd, S. K., Hallgrimsson, B. and Jirik, F. R. (2009). The lysyl oxidase inhibitor, betaaminopropionitrile, diminishes the metastatic colonization potential of circulating breast cancer cells. PLoS One 4, e5620.

Bordier, C. (1981). Phase separation of integral membrane proteins in Triton X114 solution. J Biol Chem 256, 1604-7.

Bracke, M. E., Van Roy, F. M. and Mareel, M. M. (1996). The Ecadherin/catenin complex in invasion and metastasis. Curr Top Microbiol Immunol 213 ( Pt 1), 123-61.

Bradbury, A. R. and Olopade, O. I. (2007). Genetic susceptibility to breast cancer. Rev Endocr Metab Disord 8, 255-67.

Braun, S., Vogl, F. D., Naume, B., Janni, W., Osborne, M. P., Coombes, R. C., Schlimok, G., Diel, I. J., Gerber, B., Gebauer, G., Pierga, J. Y., Marth, C., Oruzio, D., Wiedswang, G., Solomayer, E. F., Kundt, G., Strobl, B., Fehm, T., Wong, G. Y., Bliss, J., Vincent-Salomon, A. and Pantel, K. (2005). A pooled analysis of bone marrow micrometastasis in breast cancer. N Engl J Med 353, 793-802. 
Brinkley, B. R., Beall, P. T., Wible, L. J., Mace, M. L., Turner, D. S. and Cailleau, R. M. (1980). Variations in cell form and cytoskeleton in human breast carcinoma cells in vitro. Cancer Res 40, 3118-29.

Brown, J. E., Neville-Webbe, H. and Coleman, R. E. (2004). The role of bisphosphonates in breast and prostate cancers. Endocr Relat Cancer 11, 207-24.

Brown, J. M., Corey, E., Lee, Z. D., True, L. D., Yun, T. J., Tondravi, M. and Vessella, R. L. (2001). Osteoprotegerin and rank ligand expression in prostate cancer. Urology 57, 611-6.

Bundred, N. J., Walker, R. A., Ratcliffe, W. A., Warwick, J., Morrison, J. M. and Ratcliffe, J. G. (1992). Parathyroid hormone related protein and skeletal morbidity in breast cancer. Eur J Cancer 28, 690-2.

Cailleau, R., Olive, M. and Cruciger, Q. V. (1978). Long-term human breast carcinoma cell lines of metastatic origin: preliminary characterization. In Vitro 14, 911-5.

Castellon, E., Clementi, M., Hitschfeld, C., Sanchez, C., Benitez, D., Saenz, L., Contreras, H. and Huidobro, C. (2006). Effect of leuprolide and cetrorelix on cell growth, apoptosis, and $\mathrm{GnRH}$ receptor expression in primary cell cultures from human prostate carcinoma. Cancer Invest 24, 261-8.

Castillo-Pichardo, L., Martinez-Montemayor, M. M., Martinez, J. E., Wall, K. M., Cubano, L. A. and Dharmawardhane, S. (2009). Inhibition of mammary tumor growth and metastases to bone and liver by dietary grape polyphenols. Clin Exp Metastasis 26, 505-16.

Celio, L., Martinetti, A., Ferrari, L., Buzzoni, R., Mariani, L., Miceli, R., Seregni, E., Procopio, G., Cassata, A., Bombardieri, E. and Bajetta, E. (1999). Premenopausal breast cancer patients treated with a gonadotropinreleasing hormone analog alone or in combination with an aromatase inhibitor: a comparative endocrine study. Anticancer Res 19, 2261-8.

Chambers, A. F. (2009). MDA-MB-435 and M14 cell lines: identical but not M14 melanoma? Cancer Res 69, 5292-3.

Chambers, A. F., Groom, A. C. and MacDonald, I. C. (2002). Dissemination and growth of cancer cells in metastatic sites. Nat Rev Cancer 2, 563-72.

Chambers, A. F., MacDonald, I. C., Schmidt, E. E., Koop, S., Morris, V. L., Khokha, R. and Groom, A. C. (1995). Steps in tumor metastasis: new concepts from intravital videomicroscopy. Cancer Metastasis Rev 14, 279-301.

Chang, H. R. (2010). Trastuzumab-based neoadjuvant therapy in patients with HER2-positive breast cancer. Cancer 116, 2856-67. 
Chatzistamou, L., Schally, A. V., Nagy, A., Armatis, P., Szepeshazi, K. and Halmos, G. (2000). Effective treatment of metastatic MDA-MB-435 human estrogen-independent breast carcinomas with a targeted cytotoxic analogue of luteinizing hormone-releasing hormone AN-207. Clin Cancer Res 6, 4158-65.

Chen, A., Yahalom, D., Ben-Aroya, N., Kaganovsky, E., Okon, E. and Koch, Y. (1998). A second isoform of gonadotropin-releasing hormone is present in the brain of human and rodents. FEBS Lett 435, 199-203.

Chen, G., Sircar, K., Aprikian, A., Potti, A., Goltzman, D. and Rabbani, S. A. (2006). Expression of RANKL/RANK/OPG in primary and metastatic human prostate cancer as markers of disease stage and functional regulation. Cancer 107, 289-98.

Cheng, K. W. and Leung, P. C. (2000). The expression, regulation and signal transduction pathways of the mammalian gonadotropin-releasing hormone receptor. Can J Physiol Pharmacol 78, 1029-52.

Chirco, R., Liu, X. W., Jung, K. K. and Kim, H. R. (2006). Novel functions of TIMPs in cell signaling. Cancer Metastasis Rev 25, 99-113.

Cho, J. Y., Xing, S., Liu, X., Buckwalter, T. L., Hwa, L., Sferra, T. J., Chiu, I. M. and Jhiang, S. M. (2000). Expression and activity of human Na+/lsymporter in human glioma cells by adenovirus-mediated gene delivery. Gene Ther 7, 740-9.

Choi, K. C., Auersperg, N. and Leung, P. C. (2001). Expression and antiproliferative effect of a second form of gonadotropin-releasing hormone in normal and neoplastic ovarian surface epithelial cells. $J$ Clin Endocrinol Metab 86, 5075-8.

Clowse, M. E., Behera, M. A., Anders, C. K., Copland, S., Coffman, C. J., Leppert, P. C. and Bastian, L. A. (2009). Ovarian preservation by $\mathrm{GnRH}$ agonists during chemotherapy: a meta-analysis. $J$ Womens Health (Larchmt) 18, 311-9.

Coleman, R. E. (1997). Skeletal complications of malignancy. Cancer 80, 158894.

Coleman, R. E. (2006). Clinical features of metastatic bone disease and risk of skeletal morbidity. Clin Cancer Res 12, 6243s-6249s.

Cross, S. S., Harrison, R. F., Balasubramanian, S. P., Lippitt, J. M., Evans, C. A., Reed, M. W. and Holen, I. (2006). Expression of receptor activator of nuclear factor kappabeta ligand (RANKL) and tumour necrosis factor related, apoptosis inducing ligand (TRAIL) in breast cancer, and their relations with osteoprotegerin, oestrogen receptor, and clinicopathological variables. J Clin Pathol 59, 716-20. 
Dadachova, E., Nguyen, A., Lin, E. Y., Gnatovskiy, L., Lu, P. and Pollard, J. W. (2005). Treatment with rhenium-188-perrhenate and iodine-131 of NISexpressing mammary cancer in a mouse model remarkably inhibited tumor growth. Nucl Med Biol 32, 695-700.

Dai, G., Levy, O. and Carrasco, N. (1996). Cloning and characterization of the thyroid iodide transporter. Nature 379, 458-60.

Damber, J. E. (2005). Endocrine therapy for prostate cancer. Acta Oncol 44, 605-9.

Dao, T. L. and Huggins, C. (1955). Bilateral adrenalectomy in the treatment of cancer of the breast. AMA Arch Surg 71, 645-57.

de Waard, F. (1975). Breast cancer incidence and nutritional status with particular reference to body weight and height. Cancer Res 35, 3351-6.

Diel, I. J., Kaufmann, M., Costa, S. D., Holle, R., von Minckwitz, G., Solomayer, E. F., Kaul, S. and Bastert, G. (1996). Micrometastatic breast cancer cells in bone marrow at primary surgery: prognostic value in comparison with nodal status. J Natl Cancer Inst 88, 1652-8.

Dohan, O. and Carrasco, N. (2003). Advances in $\mathrm{Na}(+) / \mathrm{l}(-)$ symporter (NIS) research in the thyroid and beyond. Mol Cell Endocrinol 213, 59-70.

Eaton, M. C., Hardingham, J. E., Kotasek, D. and Dobrovic, A. (1997). Immunobead RT-PCR: a sensitive method for detection of circulating tumor cells. Biotechniques 22, 100-5.

Eicke, N., Gunthert, A. R., Emons, G. and Grundker, C. (2006). GnRH-Il agonist [D-Lys6]GnRH-II inhibits the EGF-induced mitogenic signal transduction in human endometrial and ovarian cancer cells. Int J Oncol 29, 1223-9.

Eicke, N., Gunthert, A. R., Viereck, V., Siebold, D., Behe, M., Becker, T., Emons, G. and Grundker, C. (2005). GnRH-II receptor-like antigenicity in human placenta and in cancers of the human reproductive organs. Eur $J$ Endocrinol 153, 605-12.

Ellison, G., Klinowska, T., Westwood, R. F., Docter, E., French, T. and Fox, J. C. (2002). Further evidence to support the melanocytic origin of MDAMB-435. Mol Pathol 55, 294-9.

Emons, G. (2001). [Hormone replacement therapy after menopause]. Dtsch Med Wochenschr 126, 253-4.

Emons, G., Grundker, C., Gunthert, A. R., Westphalen, S., Kavanagh, J. and Verschraegen, C. (2003). GnRH antagonists in the treatment of gynecological and breast cancers. Endocr Relat Cancer 10, 291-9. 
Emons, G., Ortmann, O., Becker, M., Irmer, G., Springer, B., Laun, R., Holzel, F., Schulz, K. D. and Schally, A. V. (1993a). High affinity binding and direct antiproliferative effects of LHRH analogues in human ovarian cancer cell lines. Cancer Res 53, 5439-46.

Emons, G., Ortmann, O., Schulz, K. D. and Schally, A. V. (1997). Growthinhibitory actions of analogues of Luteinizing Hormone Releasing Hormone on tumor cells. Trends Endocrinol Metab 8, 355-62.

Emons, G., Ortmann, O., Teichert, H. M., Fassl, H., Lohrs, U., Kullander, S., Kauppila, A., Ayalon, D., Schally, A. and Oberheuser, F. (1996). Luteinizing hormone-releasing hormone agonist triptorelin in combination with cytotoxic chemotherapy in patients with advanced ovarian carcinoma. A prospective double blind randomized trial. Decapeptyl Ovarian Cancer Study Group. Cancer 78, 1452-60.

Emons, G., Schroder, B., Ortmann, O., Westphalen, S., Schulz, K. D. and Schally, A. V. (1993b). High affinity binding and direct antiproliferative effects of luteinizing hormone-releasing hormone analogs in human endometrial cancer cell lines. J Clin Endocrinol Metab 77, 1458-64.

Emons, G., Weiss, S., Ortmann, O., Grundker, C. and Schulz, K. D. (2000). LHRH might act as a negative autocrine regulator of proliferation of human ovarian cancer. Eur J Endocrinol 142, 665-70.

Engel, L. W., Young, N. A., Tralka, T. S., Lippman, M. E., O'Brien, S. J. and Joyce, M. J. (1978). Establishment and characterization of three new continuous cell lines derived from human breast carcinomas. Cancer Res 38, 3352-64.

Esteva, F. J., Sahin, A. A., Cristofanilli, M., Arun, B. and Hortobagyi, G. N. (2002). Molecular prognostic factors for breast cancer metastasis and survival. Semin Radiat Oncol 12, 319-28.

Ewing, J. (1928). Neoplastic diseases. Saunders WB 3. Auflage.

Ferris, H. A. and Shupnik, M. A. (2006). Mechanisms for pulsatile regulation of the gonadotropin subunit genes by GNRH1. Biol Reprod 74, 993-8.

Fili, S., Karalaki, M. and Schaller, B. (2009). Mechanism of bone metastasis: the role of osteoprotegerin and of the host-tissue microenvironment-related survival factors. Cancer Lett 283, 10-9.

Fister, S., Gunthert, A. R., Aicher, B., Paulini, K. W., Emons, G. and Grundker, C. (2009). GnRH-II antagonists induce apoptosis in human endometrial, ovarian, and breast cancer cells via activation of stress-induced MAPKs p38 and JNK and proapoptotic protein Bax. Cancer Res 69, 6473-81.

Fister, S., Gunthert, A. R., Emons, G. and Grundker, C. (2007). Gonadotropinreleasing hormone type II antagonists induce apoptotic cell death in 
human endometrial and ovarian cancer cells in vitro and in vivo. Cancer Res 67, 1750-6.

Fister, S., Schlotawa, L., Gunthert, A. R., Emons, G. and Grundker, C. (2008). Increase of doxorubicin-induced apoptosis after knock-down of gonadotropin-releasing hormone receptor expression in human endometrial, ovarian and breast cancer cells. Gynecol Endocrinol 24, 249.

Fleisch, H. (2002). Development of bisphosphonates. Breast Cancer Res 4, 304.

Folkman, J. (2006). Angiogenesis. Annu Rev Med 57, 1-18.

Freake, H. C., Marcocci, C., Iwasaki, J. and Maclntyre, I. (1981). 1,25dihydroxyvitamin D3 specifically binds to a human breast cancer cell line (T47D) and stimulates growth. Biochem Biophys Res Commun 101, 1131-8.

Gault, P. M., Maudsley, S. and Lincoln, G. A. (2003). Evidence that gonadotropin-releasing hormone $\mathrm{II}$ is not a physiological regulator of gonadotropin secretion in mammals. J Neuroendocrinol 15, 831-9.

Gazdar, A. F., Kurvari, V., Virmani, A., Gollahon, L., Sakaguchi, M., Westerfield, M., Kodagoda, D., Stasny, V., Cunningham, H. T., Wistuba, II, Tomlinson, G., Tonk, V., Ashfaq, R., Leitch, A. M., Minna, J. D. and Shay, J. W. (1998). Characterization of paired tumor and non-tumor cell lines established from patients with breast cancer. Int J Cancer 78, 76674.

Gerber, B., Muller, H., Reimer, T., Krause, A. and Friese, K. (2003). Nutrition and lifestyle factors on the risk of developing breast cancer. Breast Cancer Res Treat 79, 265-76.

Geusens, P. (2009). Emerging treatments for postmenopausal osteoporosis focus on denosumab. Clin Interv Aging 4, 241-50.

Giatromanolaki, A., Koukourakis, M. I., Kakolyris, S., Mavroudis, D., Kouroussis, C., Mavroudi, C., Perraki, M., Sivridis, E. and Georgoulias, V. (2004). Assessment of highly angiogenic and disseminated in the peripheral blood disease in breast cancer patients predicts for resistance to adjuvant chemotherapy and early relapse. Int J Cancer 108, 620-7.

Gilbey, A. M., Burnett, D., Coleman, R. E. and Holen, I. (2004). The detection of circulating breast cancer cells in blood. J Clin Pathol 57, 903-11.

Giuliani, N., Bataille, R., Mancini, C., Lazzaretti, M. and Barille, S. (2001). Myeloma cells induce imbalance in the osteoprotegerin/osteoprotegerin ligand system in the human bone marrow environment. Blood 98, 352733. 
Glasel, J. A. (1995). Validity of nucleic acid purities monitored by $260 \mathrm{~nm} / 280 \mathrm{~nm}$ absorbance ratios. Biotechniques 18, 62-3.

Goel, S., Sharma, R., Hamilton, A. and Beith, J. (2009). LHRH agonists for adjuvant therapy of early breast cancer in premenopausal women. Cochrane Database Syst Rev, CD004562.

Goltzman, D. (2001). Osteolysis and cancer. J Clin Invest 107, 1219-20.

Griesinger, G., Felberbaum, R. and Diedrich, K. (2005). GnRH antagonists in ovarian stimulation: a treatment regimen of clinicians' second choice? Data from the German national IVF registry. Hum Reprod 20, 2373-5.

Gründker, C., Fost, C., Fister, S., Nolte, N., Gunthert, A. R. and Emons, G. (2010). Gonadotropin-releasing hormone type II antagonist induces apoptosis in MCF-7 and triple-negative MDA-MB-231 human breast cancer cells in vitro and in vivo. Breast Cancer Res 12, R49.

Gründker, C., Gunthert, A. R., Millar, R. P. and Emons, G. (2002). Expression of gonadotropin-releasing hormone II $(\mathrm{GnRH}-\mathrm{II})$ receptor in human endometrial and ovarian cancer cells and effects of $\mathrm{GnRH}-\mathrm{Il}$ on tumor cell proliferation. J Clin Endocrinol Metab 87, 1427-30.

Gründker, C., Schlotawa, L., Viereck, V., Eicke, N., Horst, A., Kairies, B. and Emons, G. (2004). Antiproliferative effects of the $\mathrm{GnRH}$ antagonist cetrorelix and of $\mathrm{GnRH}-\mathrm{Il}$ on human endometrial and ovarian cancer cells are not mediated through the $\mathrm{GnRH}$ type I receptor. Eur $J$ Endocrinol 151, 141-9.

Gründker, C., Schlotawa, L., Viereck, V. and Emons, G. (2001a). Protein kinase $\mathrm{C}$-independent stimulation of activator protein-1 and c-Jun N-terminal kinase activity in human endometrial cancer cells by the LHRH agonist triptorelin. Eur J Endocrinol 145, 651-8.

Gründker, C., Schulz, K., Gunthert, A. R. and Emons, G. (2000a). Luteinizing hormone-releasing hormone induces nuclear factor kappaB-activation and inhibits apoptosis in ovarian cancer cells. J Clin Endocrinol Metab 85, 3815-20.

Gründker, C., Volker, P. and Emons, G. (2001b). Antiproliferative signaling of luteinizing hormone-releasing hormone in human endometrial and ovarian cancer cells through $G$ protein alpha(I)-mediated activation of phosphotyrosine phosphatase. Endocrinology 142, 2369-80.

Gründker, C., Volker, P., Schulz, K. D. and Emons, G. (2000b). Luteinizing hormone-releasing hormone agonist triptorelin and antagonist cetrorelix inhibit EGF-induced c-fos expression in human gynecological cancers. Gynecol Oncol 78, 194-202. 
Günthert, A. R., Grundker, C., Hollmann, K. and Emons, G. (2002). Luteinizing hormone-releasing hormone induces JunD-DNA binding and extends cell cycle in human ovarian cancer cells. Biochem Biophys Res Commun 294, 11-5.

Guise, T. A., Yin, J. J., Taylor, S. D., Kumagai, Y., Dallas, M., Boyce, B. F., Yoneda, T. and Mundy, G. R. (1996). Evidence for a causal role of parathyroid hormone-related protein in the pathogenesis of human breast cancer-mediated osteolysis. J Clin Invest 98, 1544-9.

Guller, U., Zajac, P., Schnider, A., Bosch, B., Vorburger, S., Zuber, M., Spagnoli, G. C., Oertli, D., Maurer, R., Metzger, U., Harder, F., Heberer, M. and Marti, W. R. (2002). Disseminated single tumor cells as detected by real-time quantitative polymerase chain reaction represent a prognostic factor in patients undergoing surgery for colorectal cancer. Ann Surg 236, 768-75; discussion 775-6.

Hajra, K. M. and Fearon, E. R. (2002). Cadherin and catenin alterations in human cancer. Genes Chromosomes Cancer 34, 255-68.

Harris, D., Bonfil, D., Chuderland, D., Kraus, S., Seger, R. and Naor, Z. (2002). Activation of MAPK cascades by GnRH: ERK and Jun N-terminal kinase are involved in basal and $\mathrm{GnRH}$-stimulated activity of the glycoprotein hormone LHbeta-subunit promoter. Endocrinology 143, 1018-25.

Hartsock, A. and Nelson, W. J. (2008). Adherens and tight junctions: structure, function and connections to the actin cytoskeleton. Biochim Biophys Acta 1778, 660-9.

Hayden, C. (2008). GnRH analogues: applications in assisted reproductive techniques. Eur J Endocrinol 159 Suppl 1, S17-25.

Hazan, R. B., Qiao, R., Keren, R., Badano, I. and Suyama, K. (2004). Cadherin switch in tumor progression. Ann N Y Acad Sci 1014, 155-63.

Helfman, D. M., Kim, E. J., Lukanidin, E. and Grigorian, M. (2005). The metastasis associated protein S100A4: role in tumour progression and metastasis. Br J Cancer 92, 1955-8.

Henderson, M. A., Danks, J. A., Slavin, J. L., Byrnes, G. B., Choong, P. F., Spillane, J. B., Hopper, J. L. and Martin, T. J. (2006). Parathyroid hormone-related protein localization in breast cancers predict improved prognosis. Cancer Res 66, 2250-6.

Higuchi, R., Fockler, C., Dollinger, G. and Watson, R. (1993). Kinetic PCR analysis: real-time monitoring of DNA amplification reactions. Biotechnology (N Y) 11, 1026-30. 
Hofbauer, L. C., Kuhne, C. A. and Viereck, V. (2004). The OPG/RANKL/RANK system in metabolic bone diseases. J Musculoskelet Neuronal Interact 4, 268-75.

Holen, I., Cross, S. S., Neville-Webbe, H. L., Cross, N. A., Balasubramanian, S. P., Croucher, P. I., Evans, C. A., Lippitt, J. M., Coleman, R. E. and Eaton, C. L. (2005). Osteoprotegerin (OPG) expression by breast cancer cells in vitro and breast tumours in vivo--a role in tumour cell survival? Breast Cancer Res Treat 92, 207-15.

Hopkins, C. R. and Gregory, H. (1977). Topographical localization of the receptors for luteinizing hormone-releasing hormone on the surface of dissociated pituitary cells. J Cell Biol 75, 528-40.

Howell, S. J., Johnston, S. R. and Howell, A. (2004). The use of selective estrogen receptor modulators and selective estrogen receptor downregulators in breast cancer. Best Pract Res Clin Endocrinol Metab 18, 47-66.

Hsu, H., Lacey, D. L., Dunstan, C. R., Solovyev, I., Colombero, A., Timms, E., Tan, H. L., Elliott, G., Kelley, M. J., Sarosi, I., Wang, L., Xia, X. Z., Elliott, R., Chiu, L., Black, T., Scully, S., Capparelli, C., Morony, S., Shimamoto, G., Bass, M. B. and Boyle, W. J. (1999). Tumor necrosis factor receptor family member RANK mediates osteoclast differentiation and activation induced by osteoprotegerin ligand. Proc Natl Acad Sci U S A 96, 3540-5.

Irmer, G., Burger, C., Ortmann, O., Schulz, K. D. and Emons, G. (1994). Expression of luteinizing hormone releasing hormone and its mRNA in human endometrial cancer cell lines. J Clin Endocrinol Metab 79, 916-9.

Ismail, M. S., Wynendaele, W., Aerts, J. L., Paridaens, R., Gaafar, R., Shakankiry, N., Khaled, H. M., Christiaens, M. R., Wildiers, H., Omar, S., Vandekerckhove, P. and Van Oosterom, A. T. (2004). Detection of micrometastatic disease and monitoring of perioperative tumor cell dissemination in primary operable breast cancer patients using real-time quantitative reverse transcription-PCR. Clin Cancer Res 10, 196-201.

Ismail, N. I., Kaur, G., Hashim, H. and Hassan, M. S. (2008). S100A4 overexpression proves to be independent marker for breast cancer progression. Cancer Cell Int 8, 12.

Jannuzzo, M. G., Di Salle, E., Spinelli, R., Pirotta, N., Buchan, P. and Bello, A. (2009). Estrogen suppression in premenopausal women following 8 weeks of treatment with exemestane and triptorelin versus triptorelin alone. Breast Cancer Res Treat 113, 491-9.

Jenkinson, S. R., Barraclough, R., West, C. R. and Rudland, P. S. (2004). S100A4 regulates cell motility and invasion in an in vitro model for breast cancer metastasis. Br J Cancer 90, 253-62. 
Jhiang, S. M., Cho, J. Y., Ryu, K. Y., DeYoung, B. R., Smanik, P. A., McGaughy, V. R., Fischer, A. H. and Mazzaferri, E. L. (1998). An immunohistochemical study of $\mathrm{Na}+/ \mathrm{l}-$ symporter in human thyroid tissues and salivary gland tissues. Endocrinology 139, 4416-9.

Jiang, W. G., Watkins, G., Fodstad, O., Douglas-Jones, A., Mokbel, K. and Mansel, R. E. (2004). Differential expression of the CCN family members Cyr61, CTGF and Nov in human breast cancer. Endocr Relat Cancer 11, 781-91.

Jiang, Y., Goldberg, I. D. and Shi, Y. E. (2002). Complex roles of tissue inhibitors of metalloproteinases in cancer. Oncogene 21, 2245-52.

Jonat, W. (2001). Goserelin (Zoladex)--its role in early breast cancer in pre- and perimenopausal women. Br J Cancer 85 Suppl 2, 1-5.

Jones, D. H., Nakashima, T., Sanchez, O. H., Kozieradzki, I., Komarova, S. V., Sarosi, I., Morony, S., Rubin, E., Sarao, R., Hojilla, C. V., Komnenovic, V., Kong, Y. Y., Schreiber, M., Dixon, S. J., Sims, S. M., Khokha, R., Wada, T. and Penninger, J. M. (2006). Regulation of cancer cell migration and bone metastasis by RANKL. Nature 440, 692-6.

Joussen, A. M. and Huang, S. (2001). [Possibilities of broad spectrum analysis of gene expression patterns with cDNA arrays]. Ophthalmologe 98, 56873.

Kakar, S. S., Grizzle, W. E. and Neill, J. D. (1994). The nucleotide sequences of human $\mathrm{GnRH}$ receptors in breast and ovarian tumors are identical with that found in pituitary. Mol Cell Endocrinol 106, 145-9.

Kakar, S. S., Musgrove, L. C., Devor, D. C., Sellers, J. C. and Neill, J. D. (1992). Cloning, sequencing, and expression of human gonadotropin releasing hormone $(\mathrm{GnRH})$ receptor. Biochem Biophys Res Commun 189, 289-95.

Kakonen, S. M. and Mundy, G. R. (2003). Mechanisms of osteolytic bone metastases in breast carcinoma. Cancer 97, 834-9.

Kaufmann, M., Jonat, W., Schachner-Wunschmann, E., Bastert, G. and Maass, H. (1991). The depot $\mathrm{GnRH}$ analogue goserelin in the treatment of premenopausal patients with metastatic breast cancer--a 5-year experience and further endocrine therapies. Cooperative German Zoladex Study Group. Onkologie 14, 22-4, 26-8, 30.

Keizer, J., Li, Y. X., Stojilkovic, S. and Rinzel, J. (1995). InsP3-induced Ca2+ excitability of the endoplasmic reticulum. Mol Biol Cell 6, 945-51.

Kelsey, J. L. and Horn-Ross, P. L. (1993). Breast cancer: magnitude of the problem and descriptive epidemiology. Epidemiol Rev 15, 7-16. 
Kemler, R. (1993). From cadherins to catenins: cytoplasmic protein interactions and regulation of cell adhesion. Trends Genet 9, 317-21.

Kenakin, T. (1995). Agonist-receptor efficacy. I: Mechanisms of efficacy and receptor promiscuity. Trends Pharmacol Sci 16, 188-92.

Kesisis, G., Makris, A. and Miles, D. (2009). Update on the use of aromatase inhibitors in early-stage breast cancer. Breast Cancer Res 11, 211.

Khan, M. N. and Khan, A. A. (2008). Cancer treatment-related bone loss: a review and synthesis of the literature. Curr Oncol 15, S30-40.

Kim, E. J. and Helfman, D. M. (2003). Characterization of the metastasisassociated protein, S100A4. Roles of calcium binding and dimerization in cellular localization and interaction with myosin. J Biol Chem 278, 3006373.

Kingsley, L. A., Fournier, P. G., Chirgwin, J. M. and Guise, T. A. (2007). Molecular biology of bone metastasis. Mol Cancer Ther 6, 2609-17.

Kleinman, H. K. and Martin, G. R. (2005). Matrigel: basement membrane matrix with biological activity. Semin Cancer Biol 15, 378-86.

Klijn, J. G., Blamey, R. W., Boccardo, F., Tominaga, T., Duchateau, L. and Sylvester, R. (2001). Combined tamoxifen and luteinizing hormonereleasing hormone $(\mathrm{LHRH})$ agonist versus $\mathrm{LHRH}$ agonist alone in premenopausal advanced breast cancer: a meta-analysis of four randomized trials. J Clin Oncol 19, 343-53.

Koblinski, J. E., Ahram, M. and Sloane, B. F. (2000). Unraveling the role of proteases in cancer. Clin Chim Acta 291, 113-35.

Koch, Y., Baram, T., Hazum, E. and Fridkin, M. (1977). Resistance to enzymic degradation of $\mathrm{LH}-\mathrm{RH}$ analogues possessing increased biological activity. Biochem Biophys Res Commun 74, 488-91.

Kohno, N. (2008). Treatment of breast cancer with bone metastasis: bisphosphonate treatment - current and future. Int J Clin Oncol 13, 1823.

Kozlow, W. and Guise, T. A. (2005). Breast cancer metastasis to bone: mechanisms of osteolysis and implications for therapy. J Mammary Gland Biol Neoplasia 10, 169-80.

Krathen, R. A., Orengo, I. F. and Rosen, T. (2003). Cutaneous metastasis: a meta-analysis of data. South Med J 96, 164-7.

Krsmanovic, L. Z., Hu, L., Leung, P. K., Feng, H. and Catt, K. J. (2009). The hypothalamic $\mathrm{GnRH}$ pulse generator: multiple regulatory mechanisms. Trends Endocrinol Metab 20, 402-8. 
Kurosumi, M. and Takei, H. (2007). Significance and problems of histopathological examination and utility of real-time reverse transcriptase-polymerase chain reaction method for the detection of sentinel lymph node metastasis in breast cancer. Breast Cancer 14, 3429.

Laemmli, U. K. (1970). Cleavage of structural proteins during the assembly of the head of bacteriophage T4. Nature 227, 680-5.

Lankiewicz, S., Rivero, B. G. and Bocher, O. (2006). Quantitative real-time RTPCR of disseminated tumor cells in combination with immunomagnetic cell enrichment. Mol Biotechnol 34, 15-27.

Leask, A. and Abraham, D. J. (2006). All in the CCN family: essential matricellular signaling modulators emerge from the bunker. $J$ Cell Sci 119, 4803-10.

Lee, Y. K., So, I. S., Lee, S. C., Lee, J. H., Lee, C. W., Kim, W. M., Park, M. K., Lee, S. T., Park, D. Y., Shin, D. Y., Park, C. U. and Kim, Y. S. (2005). Suppression of distant pulmonary metastasis of MDA-MB 435 human breast carcinoma established in mammary fat pads of nude mice by retroviral-mediated TIMP-2 gene transfer. J Gene Med 7, 145-57.

Legha, S. S. and Carter, S. K. (1976). Antiestrogens in the treatment of breast cancer. Cancer Treat Rev 3, 205-16.

Limonta, P., Montagnani Marelli, M. and Moretti, R. M. (2001). LHRH analogues as anticancer agents: pituitary and extrapituitary sites of action. Expert Opin Investig Drugs 10, 709-20.

Longnecker, M. P. (1994). Alcoholic beverage consumption in relation to risk of breast cancer: meta-analysis and review. Cancer Causes Control 5, 7382.

Longo, M. C., Berninger, M. S. and Hartley, J. L. (1990). Use of uracil DNA glycosylase to control carry-over contamination in polymerase chain reactions. Gene $93,125-8$.

Maheswaran, S. and Haber, D. A. (2010). Circulating tumor cells: a window into cancer biology and metastasis. Curr Opin Genet Dev 20, 96-9.

Makrilia, N., Kollias, A., Manolopoulos, L. and Syrigos, K. (2009). Cell adhesion molecules: role and clinical significance in cancer. Cancer Invest 27, 1023-37.

Mancino, A. T., Klimberg, V. S., Yamamoto, M., Manolagas, S. C. and Abe, E. (2001). Breast cancer increases osteoclastogenesis by secreting M-CSF and upregulating RANKL in stromal cells. J Surg Res 100, 18-24. 
Mandell, R. B., Mandell, L. Z. and Link, C. J., Jr. (1999). Radioisotope concentrator gene therapy using the sodium/iodide symporter gene. Cancer Res 59, 661-8.

Manetta, A., Gamboa-Vujicic, G., Paredes, P., Emma, D., Liao, S., Leong, L., Asch, B. and Schally, A. (1995). Inhibition of growth of human ovarian cancer in nude mice by luteinizing hormone-releasing hormone antagonist Cetrorelix (SB-75). Fertil Steril 63, 282-7.

Mangia, A., Tommasi, S., Reshkin, S. J., Simone, G., Stea, B., Schittulli, F. and Paradiso, A. (2002). Gonadotropin releasing hormone receptor expression in primary breast cancer: comparison of immunohistochemical, radioligand and Western blot analyses. Oncol Rep 9, 1127-32.

Mareel, M., Boterberg, T., Noe, V., Van Hoorde, L., Vermeulen, S., Bruyneel, E. and Bracke, M. (1997). E-cadherin/catenin/cytoskeleton complex: a regulator of cancer invasion. J Cell Physiol 173, 271-4.

Marshall, J. C., Dalkin, A. C., Haisenleder, D. J., Griffin, M. L. and Kelch, R. P. (1993). GnRH pulses--the regulators of human reproduction. Trans Am Clin Climatol Assoc 104, 31-46.

Martinetti, A., Ferrari, L., Celio, L., Mariani, L., Miceli, R., Zilembo, N., Di Bartolomeo, M., Toffolatti, L., Pozzi, P., Seregni, E., Bombardieri, E. and Bajetta, E. (2000). The luteinising hormone-releasing hormone analogue triptorelin with or without the aromatase inhibitor formestane in premenopausal breast cancer: effects on bone metabolism markers. $J$ Steroid Biochem Mol Biol 75, 65-73.

Mbalaviele, G., Dunstan, C. R., Sasaki, A., Williams, P. J., Mundy, G. R. and Yoneda, T. (1996). E-cadherin expression in human breast cancer cells suppresses the development of osteolytic bone metastases in an experimental metastasis model. Cancer Res 56, 4063-70.

McClung, M. R. (2006). Inhibition of RANKL as a treatment for osteoporosis: preclinical and early clinical studies. Curr Osteoporos Rep 4, 28-33.

McDonell, M. W., Simon, M. N. and Studier, F. W. (1977). Analysis of restriction fragments of T7 DNA and determination of molecular weights by electrophoresis in neutral and alkaline gels. J Mol Biol 110, 119-46.

McKenzie, B. A., Barrieux, A. and Varki, N. M. (1991). A novel detection system for submicroscopic human metastases in athymic mice. Cancer Commun 3, 15-9.

McPherson, K., Steel, C. M. and Dixon, J. M. (2000). ABC of breast diseases. Breast cancer-epidemiology, risk factors, and genetics. Bmj 321, 624-8. 
Millar, R., Lowe, S., Conklin, D., Pawson, A., Maudsley, S., Troskie, B., Ott, T., Millar, M., Lincoln, G., Sellar, R., Faurholm, B., Scobie, G., Kuestner, R., Terasawa, E. and Katz, A. (2001). A novel mammalian receptor for the evolutionarily conserved type II GnRH. Proc Natl Acad Sci U S A 98, 9636-41.

Millar, R. P. (2003). GnRH II and type II GnRH receptors. Trends Endocrinol Metab 14, 35-43.

Millar, R. P., Lu, Z. L., Pawson, A. J., Flanagan, C. A., Morgan, K. and Maudsley, S. R. (2004). Gonadotropin-releasing hormone receptors. Endocr Rev 25, 235-75.

Miyagawa, M., Anton, M., Wagner, B., Haubner, R., Souvatzoglou, M., Gansbacher, B., Schwaiger, M. and Bengel, F. M. (2005). Non-invasive imaging of cardiac transgene expression with PET: comparison of the human sodium/iodide symporter gene and HSV1-tk as the reporter gene. Eur J Nucl Med Mol Imaging 32, 1108-14.

Miyamoto, K., Hasegawa, Y., Nomura, M., Igarashi, M., Kangawa, K. and Matsuo, H. (1984). Identification of the second gonadotropin-releasing hormone in chicken hypothalamus: evidence that gonadotropin secretion is probably controlled by two distinct gonadotropin-releasing hormones in avian species. Proc Natl Acad Sci U S A 81, 3874-8.

Miyamoto, T. and Suda, T. (2003). Differentiation and function of osteoclasts. Keio J Med 52, 1-7.

Mullis, K., Faloona, F., Scharf, S., Saiki, R., Horn, G. and Erlich, H. (1986). Specific enzymatic amplification of DNA in vitro: the polymerase chain reaction. Cold Spring Harb Symp Quant Biol 51 Pt 1, 263-73.

Munoz, J. R., Stoutenger, B. R., Robinson, A. P., Spees, J. L. and Prockop, D. J. (2005). Human stem/progenitor cells from bone marrow promote neurogenesis of endogenous neural stem cells in the hippocampus of mice. Proc Natl Acad Sci U S A 102, 18171-6.

Murase, M., Uemura, T., Gao, M., Inada, M., Funabashi, T. and Hirahara, F. (2005). GnRH antagonist-induced down-regulation of the mRNA expression of pituitary receptors: comparisons with $\mathrm{GnRH}$ agonist effects. Endocr J 52, 131-7.

Nakamura, H., Hiraga, T., Ninomiya, T., Hosoya, A., Fujisaki, N., Yoneda, T. and Ozawa, H. (2008). Involvement of cell-cell and cell-matrix interactions in bone destruction induced by metastatic MDA-MB-231 human breast cancer cells in nude mice. J Bone Miner Metab 26, 642-7.

Naor, Z. (1990). Signal transduction mechanisms of Ca2+ mobilizing hormones: the case of gonadotropin-releasing hormone. Endocr Rev 11, 326-53. 
Naor, Z. (2009). Signaling by G-protein-coupled receptor (GPCR): studies on the GnRH receptor. Front Neuroendocrinol 30, 10-29.

Nathanson, K. L., Wooster, R. and Weber, B. L. (2001). Breast cancer genetics: what we know and what we need. Nat Med 7, 552-6.

Nawrocki Raby, B., Polette, M., Gilles, C., Clavel, C., Strumane, K., Matos, M., Zahm, J. M., Van Roy, F., Bonnet, N. and Birembaut, P. (2001). Quantitative cell dispersion analysis: new test to measure tumor cell aggressiveness. Int J Cancer 93, 644-52.

Neill, J. D. (2002). GnRH and GnRH receptor genes in the human genome. Endocrinology 143, 737-43.

Neill, J. D., Duck, L. W., Sellers, J. C. and Musgrove, L. C. (2001). A gonadotropin-releasing hormone $(\mathrm{GnRH})$ receptor specific for $\mathrm{GnRH}$ II in primates. Biochem Biophys Res Commun 282, 1012-8.

Neill, J. D., Musgrove, L. C. and Duck, L. W. (2004). Newly recognized GnRH receptors: function and relative role. Trends Endocrinol Metab 15, 38392.

Neville-Webbe, H. L., Gnant, M. and Coleman, R. E. (2010). Potential anticancer properties of bisphosphonates. Semin Oncol 37 Suppl 1, S53-65.

Newcomb, P. A., Storer, B. E., Longnecker, M. P., Mittendorf, R., Greenberg, E. R., Clapp, R. W., Burke, K. P., Willett, W. C. and MacMahon, B. (1994). Lactation and a reduced risk of premenopausal breast cancer. $N$ Engl $J$ Med 330, 81-7.

Nguyen, N., Kuliopulos, A., Graham, R. A. and Covic, L. (2006). Tumor-derived Cyr61(CCN1) promotes stromal matrix metalloproteinase-1 production and protease-activated receptor 1-dependent migration of breast cancer cells. Cancer Res 66, 2658-65.

Okubo, K., Nagata, S., Ko, R., Kataoka, H., Yoshiura, Y., Mitani, H., Kondo, M., Naruse, K., Shima, A. and Aida, K. (2001). Identification and characterization of two distinct $\mathrm{GnRH}$ receptor subtypes in a teleost, the medaka Oryzias latipes. Endocrinology 142, 4729-39.

Paget, S. (1989). The distribution of secondary growths in cancer of the breast. 1889. Cancer Metastasis Rev 8, 98-101.

Park, H. R., Min, S. K., Cho, H. D., Kim, D. H., Shin, H. S. and Park, Y. E. (2003). Expression of osteoprotegerin and RANK ligand in breast cancer bone metastasis. J Korean Med Sci 18, 541-6.

Parkin, D. M., Bray, F., Ferlay, J. and Pisani, P. (2005). Global cancer statistics, 2002. CA Cancer J Clin 55, 74-108. 
Pearson, O. H. and Ray, B. S. (1959). Results of hypophysectomy in the treatment of metastatic mammary carcinoma. Cancer 12, 85-92.

Pedersen, K. B., Nesland, J. M., Fodstad, O. and Maelandsmo, G. M. (2002). Expression of S100A4, E-cadherin, alpha- and beta-catenin in breast cancer biopsies. Br J Cancer 87, 1281-6.

Peyruchaud, O., Winding, B., Pecheur, I., Serre, C. M., Delmas, P. and Clezardin, P. (2001). Early detection of bone metastases in a murine model using fluorescent human breast cancer cells: application to the use of the bisphosphonate zoledronic acid in the treatment of osteolytic lesions. J Bone Miner Res 16, 2027-34.

Phadke, P. A., Mercer, R. R., Harms, J. F., Jia, Y., Frost, A. R., Jewell, J. L., Bussard, K. M., Nelson, S., Moore, C., Kappes, J. C., Gay, C. V., Mastro, A. M. and Welch, D. R. (2006). Kinetics of metastatic breast cancer cell trafficking in bone. Clin Cancer Res 12, 1431-40.

Podgorski, I. and Sloane, B. F. (2003). Cathepsin B and its role(s) in cancer progression. Biochem Soc Symp, 263-76.

Porter, P. L. (2009). Global trends in breast cancer incidence and mortality. Salud Publica Mex 51 Suppl 2, s141-6.

Premzl, A., Zavasnik-Bergant, V., Turk, V. and Kos, J. (2003). Intracellular and extracellular cathepsin B facilitate invasion of MCF-10A neoT cells through reconstituted extracellular matrix in vitro. Exp Cell Res 283, 20614.

Price, J. E., Polyzos, A., Zhang, R. D. and Daniels, L. M. (1990). Tumorigenicity and metastasis of human breast carcinoma cell lines in nude mice. Cancer Res 50, 717-21.

Quan, M. L. and McCready, D. (2009). The evolution of lymph node assessment in breast cancer. J Surg Oncol 99, 194-8.

Rachner, T. D., Benad, P., Rauner, M., Goettsch, C., Singh, S. K., Schoppet, M. and Hofbauer, L. C. (2009). Osteoprotegerin production by breast cancer cells is suppressed by dexamethasone and confers resistance against TRAIL-induced apoptosis. J Cell Biochem 108, 106-16.

Rae, J. M., Creighton, C. J., Meck, J. M., Haddad, B. R. and Johnson, M. D. (2007). MDA-MB-435 cells are derived from M14 melanoma cells--a loss for breast cancer, but a boon for melanoma research. Breast Cancer Res Treat 104, 13-9.

Raynor, M., Stephenson, S. A., Walsh, D. C., Pittman, K. B. and Dobrovic, A. (2002). Optimisation of the RT-PCR detection of immunomagnetically enriched carcinoma cells. BMC Cancer 2, 14. 
Reissmann, T., Felberbaum, R., Diedrich, K., Engel, J., Comaru-Schally, A. M. and Schally, A. V. (1995). Development and applications of luteinizing hormone-releasing hormone antagonists in the treatment of infertility: an overview. Hum Reprod 10, 1974-81.

Reissmann, T., Klenner, T., Deger, W., Hilgard, P., McGregor, G. P., Voigt, K. and Engel, J. (1996). Pharmacological studies with cetrorelix (SB-75), a potent antagonist of luteinising hormone-releasing hormone. Eur $J$ Cancer 32A, 1574-9.

Richert, M. M., Vaidya, K. S., Mills, C. N., Wong, D., Korz, W., Hurst, D. R. and Welch, D. R. (2009). Inhibition of CXCR4 by CTCE-9908 inhibits breast cancer metastasis to lung and bone. Oncol Rep 21, 761-7.

Rochet, N., Dubousset, J., Mazeau, C., Zanghellini, E., Farges, M. F., de Novion, H. S., Chompret, A., Delpech, B., Cattan, N., Frenay, M. and Gioanni, J. (1999). Establishment, characterisation and partial cytokine expression profile of a new human osteosarcoma cell line (CAL 72). Int $J$ Cancer 82, 282-5.

Rose, D. P. and Connolly, J. M. (1997). Dietary fat and breast cancer metastasis by human tumor xenografts. Breast Cancer Res Treat 46, 225-37.

Ross, J. S. and Slodkowska, E. A. (2009). Circulating and disseminated tumor cells in the management of breast cancer. Am J Clin Pathol 132, 237-45.

Rossi, E., Morabito, A., De Maio, E., Di Rella, F., Esposito, G., Gravina, A., Labonia, V., Landi, G., Nuzzo, F., Pacilio, C., Piccirillo, M. C., D'Aiuto, G., D'Aiuto, M., Rinaldo, M., Botti, G., Gallo, C., Perrone, F. and de Matteis, A. (2008). Endocrine effects of adjuvant letrozole + triptorelin compared with tamoxifen + triptorelin in premenopausal patients with early breast cancer. J Clin Oncol 26, 264-70.

Roth, C. (2002). Therapeutic potential of GnRH antagonists in the treatment of precocious puberty. Expert Opin Investig Drugs 11, 1253-9.

Roux, S. and Mariette, X. (2004). The high rate of bone resorption in multiple myeloma is due to RANK (receptor activator of nuclear factor-kappaB) and RANK Ligand expression. Leuk Lymphoma 45, 1111-8.

Saiki, R. K., Gelfand, D. H., Stoffel, S., Scharf, S. J., Higuchi, R., Horn, G. T., Mullis, K. B. and Erlich, H. A. (1988). Primer-directed enzymatic amplification of DNA with a thermostable DNA polymerase. Science 239, 487-91.

Sant, M., Allemani, C., Capocaccia, R., Hakulinen, T., Aareleid, T., Coebergh, J. W., Coleman, M. P., Grosclaude, P., Martinez, C., Bell, J., Youngson, J. and Berrino, F. (2003). Stage at diagnosis is a key explanation of 
differences in breast cancer survival across Europe. Int $J$ Cancer 106, 416-22.

Sarrio, D., Palacios, J., Hergueta-Redondo, M., Gomez-Lopez, G., Cano, A. and Moreno-Bueno, G. (2009). Functional characterization of E- and Pcadherin in invasive breast cancer cells. BMC Cancer 9, 74.

Sasaki, A., Alcalde, R. E., Nishiyama, A., Lim, D. D., Mese, H., Akedo, H. and Matsumura, T. (1998). Angiogenesis inhibitor TNP-470 inhibits human breast cancer osteolytic bone metastasis in nude mice through the reduction of bone resorption. Cancer Res 58, 462-7.

Schaffler, A., Scholmerich, J. and Buechler, C. (2007). Mechanisms of disease: adipokines and breast cancer - endocrine and paracrine mechanisms that connect adiposity and breast cancer. Nat Clin Pract Endocrinol Metab 3, 345-54.

Schally, A. V., Arimura, A., Kastin, A. J., Matsuo, H., Baba, Y., Redding, T. W., Nair, R. M., Debeljuk, L. and White, W. F. (1971). Gonadotropinreleasing hormone: one polypeptide regulates secretion of luteinizing and follicle-stimulating hormones. Science 173, 1036-8.

Schmalhofer, O., Brabletz, S. and Brabletz, T. (2009). E-cadherin, beta-catenin, and ZEB1 in malignant progression of cancer. Cancer Metastasis Rev 28, 151-66.

Schneider, T., Osl, F., Friess, T., Stockinger, H. and Scheuer, W. V. (2002). Quantification of human Alu sequences by real-time PCR--an improved method to measure therapeutic efficacy of anti-metastatic drugs in human xenotransplants. Clin Exp Metastasis 19, 571-82.

Schurrat, T., Alfke, H., Behe, M., Maina, T., Nock, B., Macke, H., Heverhagen, J. T., Klose, K. J., Halling, H., Behr, T. M. and Schramm, N. (2003). Molecular gastrin receptor localisation in mice using high-resolution SPET-MRI image fusion. Eur J Nucl Med Mol Imaging 30, 800.

Sealfon, S. C., Weinstein, H. and Millar, R. P. (1997). Molecular mechanisms of ligand interaction with the gonadotropin-releasing hormone receptor. Endocr Rev 18, 180-205.

Segal-Abramson, T., Kitroser, H., Levy, J., Schally, A. V. and Sharoni, Y. (1992). Direct effects of luteinizing hormone-releasing hormone agonists and antagonists on MCF-7 mammary cancer cells. Proc Natl Acad Sci $U$ $S$ A 89, 2336-9.

Sellappan, S., Grijalva, R., Zhou, X., Yang, W., Eli, M. B., Mills, G. B. and Yu, D. (2004). Lineage infidelity of MDA-MB-435 cells: expression of melanocyte proteins in a breast cancer cell line. Cancer Res 64, 347985. 
Shah, N. R. and Wong, T. (2006). Current breast cancer risks of hormone replacement therapy in postmenopausal women. Expert Opin Pharmacother 7, 2455-63.

Shapiro, D. B. (2003). An overview of $\mathrm{GnRH}$ antagonists in infertility treatments. Introduction. Fertil Steril 80 Suppl 1, S1-7; discussion S32-4.

Shen, X. and Falzon, M. (2006). PTH-related protein upregulates integrin alpha6beta4 expression and activates Akt in breast cancer cells. Exp Cell Res 312, 3822-34.

Shoemaker, R. H., Smythe, A. M., Wu, L., Balaschak, M. S. and Boyd, M. R. (1992). Evaluation of metastatic human tumor burden and response to therapy in a nude mouse xenograft model using a molecular probe for repetitive human DNA sequences. Cancer Res 52, 2791-6.

Shupnik, M. A. (1996). Gonadotropin gene modulation by steroids and gonadotropin-releasing hormone. Biol Reprod 54, 279-86.

Shuttleworth, T. J. (1997). Intracellular Ca2+ signalling in secretory cells. J Exp Biol 200, 303-14.

Simonet, W. S., Lacey, D. L., Dunstan, C. R., Kelley, M., Chang, M. S., Luthy, R., Nguyen, H. Q., Wooden, S., Bennett, L., Boone, T., Shimamoto, G., DeRose, M., Elliott, R., Colombero, A., Tan, H. L., Trail, G., Sullivan, J., Davy, E., Bucay, N., Renshaw-Gegg, L., Hughes, T. M., Hill, D., Pattison, W., Campbell, P., Sander, S., Van, G., Tarpley, J., Derby, P., Lee, R. and Boyle, W. J. (1997). Osteoprotegerin: a novel secreted protein involved in the regulation of bone density. Cell 89, 309-19.

Singletary, S. E., Allred, C., Ashley, P., Bassett, L. W., Berry, D., Bland, K. I., Borgen, P. I., Clark, G., Edge, S. B., Hayes, D. F., Hughes, L. L., Hutter, R. V., Morrow, M., Page, D. L., Recht, A., Theriault, R. L., Thor, A., Weaver, D. L., Wieand, H. S. and Greene, F. L. (2002). Revision of the American Joint Committee on Cancer staging system for breast cancer. $J$ Clin Oncol 20, 3628-36.

Slamon, D. J., Godolphin, W., Jones, L. A., Holt, J. A., Wong, S. G., Keith, D. E., Levin, W. J., Stuart, S. G., Udove, J., Ullrich, A. and et al. (1989). Studies of the HER-2/neu proto-oncogene in human breast and ovarian cancer. Science 244, 707-12.

Soule, H. D., Vazguez, J., Long, A., Albert, S. and Brennan, M. (1973). A human cell line from a pleural effusion derived from a breast carcinoma. J Natl Cancer Inst 51, 1409-16.

Southby, J., Kissin, M. W., Danks, J. A., Hayman, J. A., Moseley, J. M., Henderson, M. A., Bennett, R. C. and Martin, T. J. (1990). 
Immunohistochemical localization of parathyroid hormone-related protein in human breast cancer. Cancer Res 50, 7710-6.

Spitzweg, C. (2003). [The sodium-iodide symporter. Pathophysiologic, diagnostic and therapeutic significance]. Internist (Berl) 44, 396-402, 404-8, 410-1.

Spitzweg, C., Dutton, C. M., Castro, M. R., Bergert, E. R., Goellner, J. R., Heufelder, A. E. and Morris, J. C. (2001). Expression of the sodium iodide symporter in human kidney. Kidney Int 59, 1013-23.

Stathopoulou, A., Vlachonikolis, I., Mavroudis, D., Perraki, M., Kouroussis, C., Apostolaki, S., Malamos, N., Kakolyris, S., Kotsakis, A., Xenidis, N., Reppa, D. and Georgoulias, V. (2002). Molecular detection of cytokeratin-19-positive cells in the peripheral blood of patients with operable breast cancer: evaluation of their prognostic significance. J Clin Oncol 20, 3404-12.

Steeg, P. S. and Theodorescu, D. (2008). Metastasis: a therapeutic target for cancer. Nat Clin Pract Oncol 5, 206-19.

Steinborn, M., Tiling, R., Heuck, A., Brügel, M., Stäbler, A. and Reiser, M. (2000). Diagnostik der Metastasierung im Knochenmark mittels MRT. Radiologe 40, 826-834.

Stojilkovic, S. S., Reinhart, J. and Catt, K. J. (1994). Gonadotropin-releasing hormone receptors: structure and signal transduction pathways. Endocr Rev 15, 462-99.

Streit, M., Stephen, A. E., Hawighorst, T., Matsuda, K., Lange-Asschenfeldt, B., Brown, L. F., Vacanti, J. P. and Detmar, M. (2002). Systemic inhibition of tumor growth and angiogenesis by thrombospondin-2 using cell-based antiangiogenic gene therapy. Cancer Res 62, 2004-12.

Suda, T., Kobayashi, K., Jimi, E., Udagawa, N. and Takahashi, N. (2001). The molecular basis of osteoclast differentiation and activation. Novartis Found Symp 232, 235-47; discussion 247-50.

Sun, Y. M., Flanagan, C. A., Illing, N., Ott, T. R., Sellar, R., Fromme, B. J., Hapgood, J., Sharp, P., Sealfon, S. C. and Millar, R. P. (2001). A chicken gonadotropin-releasing hormone receptor that confers agonist activity to mammalian antagonists. Identification of D-Lys(6) in the ligand and extracellular loop two of the receptor as determinants. J Biol Chem 276, 7754-61.

Sunderland, M. C. and McGuire, W. L. (1990). Prognostic indicators in invasive breast cancer. Surg Clin North Am 70, 989-1004.

Suva, L. J., Griffin, R. J. and Makhoul, I. (2009). Mechanisms of bone metastases of breast cancer. Endocr Relat Cancer 16, 703-13. 
Tazebay, U. H., Wapnir, I. L., Levy, O., Dohan, O., Zuckier, L. S., Zhao, Q. H., Deng, H. F., Amenta, P. S., Fineberg, S., Pestell, R. G. and Carrasco, N. (2000). The mammary gland iodide transporter is expressed during lactation and in breast cancer. Nat Med 6, 871-8.

Teitelbaum, S. L. (2007). Osteoclasts: what do they do and how do they do it? Am J Pathol 170, 427-35.

Tester, A. M., Sharp, J. A., Dhanesuan, N., Waltham, M. and Thompson, E. W. (2002). Correlation between extent of osteolytic damage and metastatic burden of human breast cancer metastasis in nude mice: real-time PCR quantitation. Clin Exp Metastasis 19, 377-83.

Thomas, R. J., Guise, T. A., Yin, J. J., Elliott, J., Horwood, N. J., Martin, T. J. and Gillespie, M. T. (1999). Breast cancer cells interact with osteoblasts to support osteoclast formation. Endocrinology 140, 4451-8.

Tobler, N. E. and Detmar, M. (2006). Tumor and lymph node lymphangiogenesis--impact on cancer metastasis. J Leukoc Biol 80, 6916.

Towbin, H., Staehelin, T. and Gordon, J. (1979). Electrophoretic transfer of proteins from polyacrylamide gels to nitrocellulose sheets: procedure and some applications. Proc Natl Acad Sci U S A 76, 4350-4.

Van Poznak, C., Cross, S. S., Saggese, M., Hudis, C., Panageas, K. S., Norton, L., Coleman, R. E. and Holen, I. (2006). Expression of osteoprotegerin (OPG), TNF related apoptosis inducing ligand (TRAIL), and receptor activator of nuclear factor kappaB ligand (RANKL) in human breast tumours. J Clin Pathol 59, 56-63.

Vargas, S. J., Gillespie, M. T., Powell, G. J., Southby, J., Danks, J. A., Moseley, J. M. and Martin, T. J. (1992). Localization of parathyroid hormonerelated protein mRNA expression in breast cancer and metastatic lesions by in situ hybridization. J Bone Miner Res 7, 971-9.

Varmus, H. (1987). Reverse transcription. Sci Am 257, 56-9, 62-4.

Völker, P., Grundker, C., Schmidt, O., Schulz, K. D. and Emons, G. (2002). Expression of receptors for luteinizing hormone-releasing hormone in human ovarian and endometrial cancers: frequency, autoregulation, and correlation with direct antiproliferative activity of luteinizing hormonereleasing hormone analogues. Am J Obstet Gynecol 186, 171-9.

von Alten, J., Fister, S., Schulz, H., Viereck, V., Frosch, K. H., Emons, G. and Grundker, C. (2006). GnRH analogs reduce invasiveness of human breast cancer cells. Breast Cancer Res Treat 100, 13-21.

Ward, H. W. (1973). Anti-oestrogen therapy for breast cancer: a trial of tamoxifen at two dose levels. Br Med J 1, 13-4. 
Weckermann, D. and Harzmann, R. (2004). Hormone therapy in prostate cancer: LHRH antagonists versus LHRH analogues. Eur Urol 46, 279-83; discussion 283-4.

Weigelt, B., Peterse, J. L. and van 't Veer, L. J. (2005). Breast cancer metastasis: markers and models. Nat Rev Cancer 5, 591-602.

Weisberg, T. F., Cahill, B. K. and Vary, C. P. (1996). Non-radioisotopic detection of human xenogeneic DNA in a mouse transplantation model. Mol Cell Probes 10, 139-46.

White, R. B., Eisen, J. A., Kasten, T. L. and Fernald, R. D. (1998). Second gene for gonadotropin-releasing hormone in humans. Proc Natl Acad Sci U S A 95, 305-9.

WHO (1982). The world Health Organization Histological Typing of Breast Tumors--Second Edition. The World Organization. Am J Clin Pathol 78, 806-16.

Wong, A. S. and Gumbiner, B. M. (2003). Adhesion-independent mechanism for suppression of tumor cell invasion by E-cadherin. J Cell Biol 161, 1191203.

Wronski, M., Arbit, E. and McCormick, B. (1997). Surgical treatment of 70 patients with brain metastases from breast carcinoma. Cancer 80, 174654.

Wysolmerski, J. J., Dann, P. R., Zelazny, E., Dunbar, M. E., Insogna, K. L., Guise, T. A. and Perkins, A. S. (2002). Overexpression of parathyroid hormone-related protein causes hypercalcemia but not bone metastases in a murine model of mammary tumorigenesis. J Bone Miner Res 17, 1164-70.

Xenidis, N., Markos, V., Apostolaki, S., Perraki, M., Pallis, A., Sfakiotaki, G., Papadatos-Pastos, D., Kalmanti, L., Kafousi, M., Stathopoulos, E., Kakolyris, S., Mavroudis, D. and Georgoulias, V. (2007). Clinical relevance of circulating CK-19 mRNA-positive cells detected during the adjuvant tamoxifen treatment in patients with early breast cancer. Ann Oncol 18, 1623-31.

Xenidis, N., Vlachonikolis, I., Mavroudis, D., Perraki, M., Stathopoulou, A., Malamos, N., Kouroussis, C., Kakolyris, S., Apostolaki, S., Vardakis, N., Lianidou, E. and Georgoulias, V. (2003). Peripheral blood circulating cytokeratin-19 mRNA-positive cells after the completion of adjuvant chemotherapy in patients with operable breast cancer. Ann Oncol 14, 849-55.

Xie, D., Nakachi, K., Wang, H., Elashoff, R. and Koeffler, H. P. (2001). Elevated levels of connective tissue growth factor, WISP-1, and CYR61 in primary 
breast cancers associated with more advanced features. Cancer Res 61, 8917-23.

Yano, T., Pinski, J., Halmos, G., Szepeshazi, K., Groot, K. and Schally, A. V. (1994a). Inhibition of growth of OV-1063 human epithelial ovarian cancer xenografts in nude mice by treatment with luteinizing hormone-releasing hormone antagonist SB-75. Proc Natl Acad Sci U S A 91, 7090-4.

Yano, T., Pinski, J., Szepeshazi, K., Halmos, G., Radulovic, S., Groot, K. and Schally, A. V. (1994b). Inhibitory effect of bombesin/gastrin-releasing peptide antagonist RC-3095 and luteinizing hormone-releasing hormone antagonist SB-75 on the growth of MCF-7 MIII human breast cancer xenografts in athymic nude mice. Cancer 73, 1229-38.

Yoneda, T. (2000). Cellular and molecular basis of preferential metastasis of breast cancer to bone. J Orthop Sci 5, 75-81.

Yoneda, T. and Hiraga, T. (2005). Crosstalk between cancer cells and bone microenvironment in bone metastasis. Biochem Biophys Res Commun 328, 679-87.

Yoneda, T., Michigami, T., Yi, B., Williams, P. J., Niewolna, M. and Hiraga, T. (2000). Actions of bisphosphonate on bone metastasis in animal models of breast carcinoma. Cancer 88, 2979-88.

Zetter, B. R. (1998). Angiogenesis and tumor metastasis. Annu Rev Med 49, 407-24.

Zhang, J., Dai, J., Qi, Y., Lin, D. L., Smith, P., Strayhorn, C., Mizokami, A., Fu, Z., Westman, J. and Keller, E. T. (2001). Osteoprotegerin inhibits prostate cancer-induced osteoclastogenesis and prevents prostate tumor growth in the bone. J Clin Invest 107, 1235-44.

Zhang, S., Lawson, K. A., Simmons-Menchaca, M., Sun, L., Sanders, B. G. and Kline, K. (2004). Vitamin E analog alpha-TEA and celecoxib alone and together reduce human MDA-MB-435-FL-GFP breast cancer burden and metastasis in nude mice. Breast Cancer Res Treat 87, 111-21.

Zhang, T. and Roberson, M. S. (2006). Role of MAP kinase phosphatases in $\mathrm{GnRH}$-dependent activation of MAP kinases. J Mol Endocrinol 36, 41-50.

Zheng, H. Y., Chen, Q., Ye, Y. B. and Huang, W. W. (2008). [mRNA expression of CK19 and CEA in peripheral blood of patients with breast cancer detected by real-time quantitative PCR]. Zhonghua Yi Xue Za Zhi 88, 2267-70. 


\section{ANHANG}

\subsection{Aminosäure-Code}

Tab. 7.1: Buchstabencode für natürliche und nicht-natürliche Aminosäuren

\begin{tabular}{|l|l|l|}
\hline Natürliche Aminosäuren & Dreibuchstabencode & Einbuchstabencode \\
\hline Alanin & Ala & A \\
\hline Arginin & Arg & R \\
\hline Asparagin & Asn & N \\
\hline Aspartat & Asp & D \\
\hline Cystein & Cys & C \\
\hline Glutamat & Glu & E \\
\hline Glutamin & Gln & Q \\
\hline Glycin & Gly & G \\
\hline Histidin & His & H \\
\hline Isoleucin & Ile & I \\
\hline Leucin & Leu & L \\
\hline Lysin & Lys & K \\
\hline Methionin & Met & M \\
\hline Phenylalanin & Phe & F \\
\hline Prolin & Pro & P \\
\hline Serin & Ser & S \\
\hline Threonin & Thr & T \\
\hline Tryptophan & Trp & W \\
\hline Tyrosin & Tyr & Y \\
\hline Valin & Val & V \\
\hline Nicht-natürliche Aminosäuren & Buchstabencode & \\
\hline D-ß-(2-Naphthyl)-Alanin & D-2Nal & \\
\hline D-ß-(3-Pyridyl)-Alanin & D-3Pal & D-4Cpa \\
\hline D-(4-Chloro)-Phenylalanin & D-Cit & \\
\hline D-Citrullin & & \\
\hline
\end{tabular}




\subsection{Genidentifizierung (GEArray Q Series)}

Tab. 7.2: Gentabelle 1 (Human Metastasis Gene Array). Im Gene Array regulierte Gene sind als "fett“" markiert.

\begin{tabular}{|c|c|c|c|c|c|c|c|}
\hline $\begin{array}{c}\text { API5 } \\
1\end{array}$ & $\begin{array}{c}\text { ARHC } \\
2\end{array}$ & $\begin{array}{c}\text { BRMS1 } \\
3\end{array}$ & $\begin{array}{c}\text { CASP8 } \\
4\end{array}$ & $\begin{array}{c}\text { CASP9 } \\
5\end{array}$ & $\begin{array}{c}\text { CAV1 } \\
6\end{array}$ & $\begin{array}{c}\text { CD44 } \\
7\end{array}$ & $\begin{array}{c}\text { CDH1 } \\
8\end{array}$ \\
\hline COL4A2 & CSF1 & CSF1R & CST3 & CTSB & CTSD & CTSL & DCC \\
\hline 9 & 10 & 11 & 12 & 13 & 14 & 15 & 16 \\
\hline EHM2 & ELA2 & ENPP2 & ERBB2 & ETS1 & ETS2 & ETV4 & FES \\
\hline 17 & 18 & 19 & 20 & 21 & 22 & 23 & 24 \\
\hline FGF1 & FGF2 & FOS & HGF & HPSE & HRAS & ICAM5 & IGF2 \\
\hline 25 & 26 & 27 & 28 & 29 & 30 & 31 & 32 \\
\hline ITGA2 & ITGA3 & ITGA5 & ITGA6 & ITGB1 & ITGB3 & KAI1 & KISS1 \\
\hline 33 & 34 & 35 & 36 & 37 & 38 & 39 & 40 \\
\hline LAMB1 & LAMC1 & LIMK1 & MAP2K4 & MDM2 & MGAT3 & MGAT5 & MGEA5 \\
\hline 41 & 42 & 43 & 44 & 45 & 46 & 47 & 48 \\
\hline MICA & MMP1 & MMP10 & MMP11 & MMP13 & MMP14 & MMP15 & MMP16 \\
\hline 49 & 50 & 51 & 52 & 53 & 54 & 55 & 56 \\
\hline MMP2 & MMP3 & MMP7 & MMP8 & MMP9 & MTA1 & MUC1 & MYC \\
\hline 57 & 58 & 59 & 60 & 61 & 62 & 63 & 64 \\
\hline NCAM1 & NGFB & NM23A & NME4 & ODC1 & PDGFA & PECAM1 & PIK3C2B \\
\hline 65 & 66 & 67 & 68 & 69 & 70 & 71 & 72 \\
\hline PLAU & PLAUR & PTEN & PTGS2 & RAC1 & RAF1 & S100A4 & SERPINB2 \\
\hline 73 & 74 & 75 & 76 & 77 & 78 & 79 & 80 \\
\hline SERPINB2 & SERPINE1 & SNCG & SPP1 & SRC & TGFA & TGFB1 & THBS1 \\
\hline 81 & 82 & 83 & 84 & 85 & 86 & 87 & 88 \\
\hline THBS2 & TIMP1 & TIMP2 & TIMP3 & TMPRS4 & VEGF & VEGFC & VTN \\
\hline 89 & 90 & 91 & 92 & 93 & 94 & 95 & 96 \\
\hline PUC18 & PUC18 & PUC18 & Blank & Blank & Blank & GAPDH & GAPDH \\
\hline 97 & 98 & 99 & 100 & 101 & 102 & 103 & 104 \\
\hline PPIA & PPIA & PPIA & PPIA & RPL13A & RPL13A & ACTB & ACTB \\
\hline 105 & 106 & 107 & 108 & 109 & 110 & 111 & 112 \\
\hline
\end{tabular}

Tab. 7.3: Gentabelle 2 (Human Metastasis Gene Array). Im Gene Array regulierte Gene sind als "fett“" markiert.

\begin{tabular}{|r|l|l|l|}
\hline & Gene & Gene ID & Beschreibung \\
\hline \hline 1 & API5 & U83857 & Apoptosis Inhibitor 5 \\
\hline 2 & ARHC & L25081 & Ras homolog gene family, member C \\
\hline 3 & BRMS1 & AF159141 & Homo sapiens breast cancer metastasis-suppressor 1 \\
\hline
\end{tabular}




\begin{tabular}{|c|c|c|c|}
\hline 4 & CASP8 & NM 001228 & Caspase 8, apoptosis-related cysteine protease \\
\hline 5 & CASP9 & U60521 & Caspase 9, apoptosis-related cysteine protease \\
\hline 6 & CAV1 & NM 001753 & Caveolin 1, caveolae protein, 22kD \\
\hline 7 & CD44 & M59040 & CD44 antigen \\
\hline 8 & CDH1 & Z13009 & Cadherin 1, type 1, E-Cadherin (epithelial) \\
\hline 9 & COL4A2 & $\mathrm{X} 05610$ & Collagen, typelV, alpha 2 \\
\hline 10 & CSF1 & M37435 & Colony stimulating factor 1 (macrophage) \\
\hline 11 & CSF1R & X03663 & Colony stimulating factor 1 receptor \\
\hline 12 & CST3 & NM 000099 & Homo sapiens cystatin C \\
\hline 13 & CTSB & L16510 & Cathepsin B \\
\hline 14 & CTSD & M11233 & Cathepsin D (lysosomal aspartyl protease) \\
\hline 15 & CTSL & $\mathrm{X} 12451$ & Cathepsin L \\
\hline 16 & DCC & NM 005215 & Deleted in colorectal carcinoma \\
\hline 17 & EHM2 & AB032179 & EHM2 gene \\
\hline 18 & ELA2 & NM 001972 & Homo sapiens elastase 2 , neutrophil \\
\hline 19 & ENPP2 & L46720 & Human autotaxin mRNA, complete cds \\
\hline 20 & ERBB2 & M11730 & $\begin{array}{l}\text { v-erb-b2 avian erythroblastic leukemia viral oncogene } \\
\text { homolog } 2\end{array}$ \\
\hline 21 & ETS1 & J04101 & $\begin{array}{l}\text { v-ets avian erythroblastosis virus E26 oncogene } \\
\text { homolog } 1\end{array}$ \\
\hline 22 & ETS2 & J04102 & Human erythroblastosis virus oncogene homolog 2 \\
\hline 23 & ETV4 & D12765 & Human mRNA for E1A-F \\
\hline 24 & FES & $\mathrm{X} 52192$ & Proto-oncogene tyrosine-protein kinase fes/fps \\
\hline 25 & FGF1 & X51943 & Fibroblast growth factor 1 (acidic) \\
\hline 26 & FGF2 & NM 002006 & Fibroblast growth factor 2 (basic) \\
\hline 27 & FOS & V01512 & Human cellular oncogene c-fos \\
\hline 28 & HGF & X57574 & Hepatocyte growth factor (hepapoietin A) \\
\hline 29 & HPSE & AF084467 & Homo sapiens heparanase mRNA \\
\hline 30 & HRAS & NM 005343 & v-Ha-ras Harvey rat sarcoma viral oncogene homolog \\
\hline 31 & ICAM5 & U72671 & Intercellular adhesion molecule 5, telencephalin \\
\hline 32 & IGF2 & M29645 & Insulin-like growth factor 2 (somatomedin A) \\
\hline 33 & ITGA2 & $\mathrm{X} 17033$ & Integrin, alpha 2 (CD49B) \\
\hline 34 & ITGA3 & M59911 & Integrin, alpha 3 (antigen CD49C) \\
\hline 35 & ITGA5 & X06256 & Integrin, alpha 5 (fibronectin receptor, alpha polypeptide) \\
\hline 36 & IGTA6 & X53586 & Integrin, alpha 6 subunit \\
\hline 37 & IGTB1 & BC009469 & Integrin, beta 1 (fibronectin receptor, beta polypeptide) \\
\hline 38 & IGTB3 & J02703 & Integrin, beta 3 (platelet glycoprotein IIla, antigen CD61) \\
\hline 39 & KAl1 & NM 002231 & Kangai 1 (suppression of tumorigenicity 6 ) \\
\hline
\end{tabular}




\begin{tabular}{|c|c|c|c|}
\hline 40 & KISS1 & NM 002258 & KiSS metastasis-suppressor \\
\hline 41 & LAMB1 & M61916 & Laminin B1 chain \\
\hline 42 & LAMC1 & J03202 & Laminin, gamma 1 (formerly LAMB2) \\
\hline 43 & LIMK1 & D26309 & LIM domain kinase 1 \\
\hline 44 & MAP2K4 & L36870 & SAPK/Erk kinase 1, MAP kinase kinase 4 \\
\hline 45 & MDM2 & Z12020 & $\begin{array}{l}\text { Mouse double minute } 2 \text {, human homolog of; p53-binding } \\
\text { protein }\end{array}$ \\
\hline 46 & MGAT3 & D13789 & $\begin{array}{l}\text { Mannosyl (beta-1,4)-glycoprotein beta-1,4-N- } \\
\text { acetylglucosaminyltransferase }\end{array}$ \\
\hline 47 & MGAT5 & NM 002410 & cDNA encoding $\mathrm{N}$-acetylglucosaminyltransferase $\mathrm{V}$ \\
\hline 48 & MGEA5 & NM 012215 & Meningioma expressed antigen 5 (hyaluronidase) \\
\hline 49 & MICA & NM 000247 & Homo sapiens MICA gene, allele MUC-18 \\
\hline 50 & MMP1 & X05231 & Matrix metalloproteinase 1 (interstitial collagenase) \\
\hline 51 & MMP10 & NM 002425 & Matrix metalloproteinase 10 \\
\hline 52 & MMP11 & X57766 & Human stromelysin-3 \\
\hline 53 & MMP13 & X75308 & Matrix metalloproteinase 13 \\
\hline 54 & MMP14 & D26512 & mRNA for membrane-type matrix metalloproteinase 1 \\
\hline 55 & MMP15 & D86331 & Matrix metalloproteinase 15 (membrane-inserted) \\
\hline 56 & MMP16 & D83646 & Matrix metalloproteinase 16 (membrane-inserted) \\
\hline 57 & MMP2 & J03210 & Matrix metalloproteinase 2 (gelatinase A, 72 kD) \\
\hline 58 & MMP3 & X05232 & Matrix metalloproteinase 3 (stromelysin 1, progelatinase) \\
\hline 59 & MMP7 & X07819 & Matrix metalloproteinase 7 (matrilysin, uterine) \\
\hline 60 & MMP8 & NM 002424 & Matrix metalloproteinase 8 (neutrophil collagenase) \\
\hline 61 & MMP9 & $\mathrm{J} 05070$ & Matrix metalloproteinase 9 (gelatinase B, 92 kD) \\
\hline 62 & MTA1 & U35113 & Metastasis associated 1 \\
\hline 63 & MUC1 & NM 002456 & Mucin 1, transmembrane \\
\hline 64 & MYC & X00364 & v-myc avian myelocytomatosis viral oncogene homolog \\
\hline 65 & NCAM1 & U63041 & Neural cell adhesion molecule 1 \\
\hline 66 & NGFB & X52599 & Nerve growth factor, beta polypeptide \\
\hline 67 & NM23A & NM 000269 & Homo sapiens non-metastatic cells 1 \\
\hline 68 & NME4 & NM 005009 & Homo sapiens non-metastatic cells 4 \\
\hline 69 & ODC1 & M16650 & Human omithine decarboxylase gene \\
\hline 70 & PDGFA & $\mathrm{X06374}$ & Platelet-derived growth factor alpha polypeptide \\
\hline 71 & PECAM1 & NM 000442 & Homo sapiens platelet/endothial cell adhesion molecule \\
\hline 72 & PIK3C2B & Y11312 & Phosphoinositide-3-kinase, class 2, beta polypeptide \\
\hline 73 & PLAU & D00244 & Plasminogen activator, urokinase \\
\hline 74 & PLAUR & NM 002659 & Human urokinase-type plasminogen activator receptor \\
\hline 75 & PTEN & U96180 & Phosphatase and tensin homolog \\
\hline
\end{tabular}




\begin{tabular}{|c|c|c|c|}
\hline 76 & PTGS2 & NM 000963 & Homo sapiens prostaglandin-endoperoxidase synthase 2 \\
\hline 77 & RAC1 & NM 006908 & Ras-related C3 botulinum toxin substrate 1 \\
\hline 78 & RAF1 & X03484 & v-raf-1 murine leukemia viral oncogene homolog 1 \\
\hline 79 & S100A4 & NM 002961 & Homo sapiens S100 calcium-binding protein A4 \\
\hline 80 & SERPINB2 & J02685 & Human plasminogen activator inhibitor \\
\hline 81 & SERPINB5 & NM 002639 & Protease inhibitor 5 \\
\hline 82 & SERPINE1 & M16006 & Plasminogen activator inhibitor, type I \\
\hline 83 & SNCG & NM 003087 & Synuclein, gamma (breast cancer-specific protein 1) \\
\hline 84 & SPP1 & M83248 & Secreted phosphoprotein 1 (osteopontin) \\
\hline 85 & SRC & NM 005417 & Human C-src-1 proto-oncogene \\
\hline 86 & TGFA & NM 003236 & Transforming growth factor, alpha \\
\hline 87 & TGFB1 & $\mathrm{X02812}$ & Transforming growth factor, beta 1 \\
\hline 88 & THBS1 & NM 003246 & Homo sapiens thrombospondin 1 \\
\hline 89 & THBS2 & L12350 & Human thrombospondin 2 mRNA \\
\hline 90 & TIMP1 & NM 003254 & Tissue Inhibitor of metalloproteinase 1 \\
\hline 91 & TIMP2 & NM 003255 & Tissue Inhibitor of metalloproteinase 2 \\
\hline 92 & TIMP3 & NM 000362 & Tissue Inhibitor of metalloproteinase 3 \\
\hline 93 & TMPRSS4 & NM 019894 & Transmembrane protease, serine 4 \\
\hline 94 & VEGF & M32977 & Vascular endothelial growth factor \\
\hline 95 & VEGFC & X94216 & Vascular endothelial growth factor C \\
\hline 96 & VTN & $\mathrm{X03168}$ & Vitronectin \\
\hline 97 & PUC18 & L08752 & PUC18 Plasmid DNA \\
\hline 98 & PUC18 & L08752 & PUC18 Plasmid DNA \\
\hline 99 & PUC18 & L08752 & PUC18 Plasmid DNA \\
\hline $\begin{array}{c}100 \\
- \\
102\end{array}$ & Blank & Blank & Blank \\
\hline 103 & GAPD & M33197 & Glyceraldehyde-3-phosphate dehydrogenase \\
\hline 104 & GAPD & M33197 & Glyceraldehyde-3-phosphate dehydrogenase \\
\hline $\begin{array}{c}105 \\
- \\
108\end{array}$ & PPIA & NM 021130 & Homo sapiens peptidylprolyl isomerase $A$ \\
\hline 109 & RPL13A & NM 012423 & Ribosomal protein L13a (23 Kda highly basic protein) \\
\hline 110 & RPL13A & NM 012423 & Ribosomal protein L13a (23 Kda highly basic protein) \\
\hline 111 & ACTB & X00351 & Beta Actin \\
\hline 112 & ACTB & X00351 & Beta Actin \\
\hline
\end{tabular}




\subsection{Plasmid für die NIS-Transfektion}

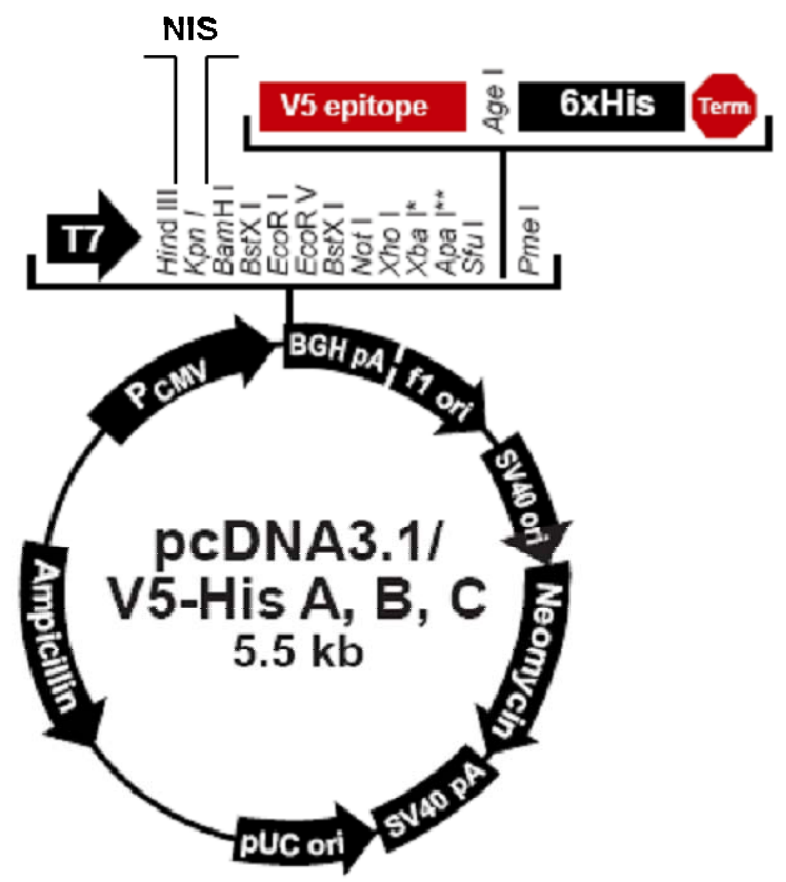

Abb. 7.1: Vektorkarte pcDNA3.1/V5-His A, B, C - 5,5 kb (Invitrogen, Karlsruhe). NIS liegt zwischen den Restriktionsenzymen Hind III und Bam HI. Als Promoter dient der CMV (Cytomegalievirus)-Promotor. Die Selektion stabil transfizierter Zellen wird über eine Ampicillin- oder Neomycinresistenz erreicht.

\subsection{Abkürzungsverzeichnis}

A

AP-1

APS

AS

ATCC

BHQ-1

$\mathrm{Bp}$

BRCA

BSA

C

CAV1

CD-FCS
Adenin

activator protein 1

Ammoniumperoxodisulfat

Aminosäure( $\mathrm{n}$ )

American Type Culture Collection

Black Hole Quencher-1

Basenpaare

breast cancer genes

Rinderserumalbumin (bovine serum albumin)

Cytosin

Caveolin 1

charcoal dextran-treated FCS 
$\mathrm{CDH} 1 \quad$ Cadherin 1

cDNA complementary DNA

CK-19 Cytokeratin-19

$\mathrm{C}_{\mathrm{t}} \quad$ cycle threshold

CTC circulating tumor cells

CTSB Cathepsin B

CYR61 cystein rich protein 61

DAB Diaminobenzidin

DAG Diazylglycerol

DNA Desoxyribonukleinsäure

Dnase I Deoxyribonuklease I

dNTP Deoxyribonukleosid-Triphosphat

ds doppelsträngig (double strand)

DSMZ Deutsche Sammlung von Mikroorganismen und Zelllinien

DTT Dithiothreitol

DTZ disseminierte Tumorzellen

EDTA Ethylendiamin-N,N,N',N'-Tetraessigsäure-Na-Salz

EGF epidermal growth factor

ER Endoplasmatisches Retikulum

ERK extracellular regulated kinase

$\mathrm{EtBr} \quad$ Ethidiumbromid

EZM extrazelluläre Matrix

FAM 6-Carboxy-Fluoreszein

FCS fötales Kälberserum (fetal calf serum)

FRET fluorescence resonance energy transfer

FSH Follikelstimulierendes Hormon

G Guanin

GnRH Gonadotropin-Releasing Hormon

GPCR G-Protein gekoppelter Rezeptor (G-protein coupled receptor)

GFP green fluorescent protein

GTP Guanosintriphosphat

HER2/neu human epidermal growth factor receptor 2 


\begin{tabular}{|c|c|}
\hline hOB & humane Osteoblasten \\
\hline HRP & Meerrettichperoxidase (horseradish peroxidase) \\
\hline IGF & insulin-like growth factor \\
\hline IL & Interleukin \\
\hline IP3 & Inositol-1,4,5-Triphosphat \\
\hline JNK & c-Jun N-terminal kinase \\
\hline LAN & Linker-Arm-modifiziertes-Nukleotid \\
\hline LH & Luteinisierendes Hormon \\
\hline LHRH & Luteinisierendes Hormon-Releasing Hormon \\
\hline MAPK & mitogenaktivierte Proteinkinase \\
\hline MMP & Matrixmetalloproteinasen \\
\hline mRNA & messenger-RNA \\
\hline MRT & Magnetresonanztherapie \\
\hline NFKB & nuclear factor kappa $B$ \\
\hline NIS & Natrium-lodid-Symporter \\
\hline n.s. & nicht signifikant \\
\hline NTC & no template control \\
\hline OPG & Osteoprotegerin \\
\hline PCR & Polymerase Kettenreaktion (polymerase chain reaction) \\
\hline pGlu & para-Glutamat \\
\hline PAGE & Polyacrylamid-Gelelektrophores \\
\hline PIP2 & Phosphatidylinositol-4,5-Biphosphat \\
\hline PKC & Proteinkinase C \\
\hline PLC & Phospholipase C \\
\hline $\mathrm{P} / \mathrm{S}$ & Penicillin/Streptomycin \\
\hline PTHrP & parathormone-related protein \\
\hline PTP & Phosphotyrosinphosphatase \\
\hline RANKL & receptor activator of $N F K B$ ligand \\
\hline RNA & Ribonukleinsäure (ribonucleic acid) \\
\hline rRNA & ribosomale RNA \\
\hline rpm & Umdrehungen pro Minute (rounds per minute) \\
\hline RPTK & Rezeptorphosphotyrosinkinase \\
\hline
\end{tabular}




\begin{tabular}{|c|c|}
\hline RT & Raumtemperatur \\
\hline RT & Reverse Transkription \\
\hline SDF-1 & stromal derived factor-1 \\
\hline SDS & Natriumdodecylsulfat (sodium dodecyl sulfate) \\
\hline SERD & selective estrogen receptor destructor \\
\hline SERM & selective estrogen receptor modulator \\
\hline SPET & single photon emission tomography \\
\hline ss & einzelsträngig (single strand) \\
\hline $\mathrm{T}$ & Thymin \\
\hline Taq & thermus aquaticus \\
\hline TAMRA & 6-Carboxy-Tetramethyl-Rhodamin \\
\hline TBE & Tris-Borat-EDTA-Puffer \\
\hline tBu & Butylgruppe \\
\hline TBST & Tween-TBS Puffer \\
\hline TEMED & N,N,N',N',-Tetramethylethyldiamin \\
\hline TFA & Trifluoracetat \\
\hline TIMP & tissue inhibitor of metalloproteinases \\
\hline TGF & tumor growth factor \\
\hline TMR & Transmembran-Rezeptor \\
\hline TNF & Tumornekrosefaktor \\
\hline Tris & Tris(hydroxymethyl)aminomethan \\
\hline TV & Tumorvolumen \\
\hline U & Uracil \\
\hline UV & Ultraviolett \\
\hline WHO & World Health Organization \\
\hline w & mit (with) \\
\hline w/o & ohne (without) \\
\hline
\end{tabular}

\subsection{Abbildungsverzeichnis}

Abb. 1.1: Prozess der Metastasierung ................................................ 5

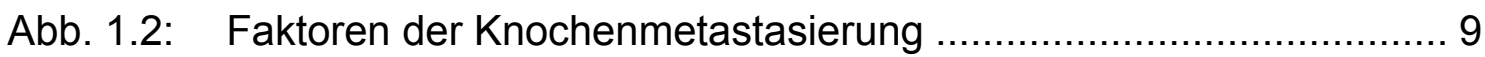


Abb. 1.3: Struktur des humanen GnRH-I Rezeptors (rechts) und des GnRH-II Rezeptors beim Affen (links)

Abb. 1.4: Signaltransduktion des GnRH-I Rezeptors in gynäkologischen Tumoren 16

Abb. 1.5: Aminosäuresubstitutionen des nativen $\mathrm{GnRH}-\mathrm{I}$. 19

Abb. 3.1: $\quad$ Schematische Darstellung des verwendeten Kokultursystems ..... 34

Abb. 4.1: Expression des GnRH-I Rezeptors in Mammakarzinomzellen ...... 54

Abb. 4.2: Expression von RANKL und OPG in Mammakarzinomzellen........ 55

Abb. 4.3: Immunzytochemischer Nachweis der Proteinexpression von RANKL und OPG in HCC-70 Zellen...

Abb. 4.4: Einfluss von Triptorelin auf die Expression von RANKL und OPG in HCC-70 Zellen

Abb. 4.5: Einfluss von GnRH Analoga auf die mRNA-Expression von PTHrP in MCF-7 (A) und MDA-MB-231 (B) Zellen 59

Abb. 4.6: Einfluss von GnRH Analoga auf die mRNA-Expression von PTHrP$\mathrm{R}$ in $\mathrm{hOB}$ 60

Abb. 4.7: Analysen zur Genexpression in MCF-7 (A) und MDA-MB-231 (B) Zellen mittels Human Tumor Metastasis Gene Array

Abb. 4.8: Einfluss von GnRH Analoga auf die mRNA-Expression von $\mathrm{CDH} 1$ in MCF-7 (A) und MDA-MB-231 (B) Zellen 63

Abb. 4.9: Einfluss von GnRH Analoga auf die mRNA-Expression von CTSB in MCF-7 (A) und MDA-MB-231 (B) Zellen. 64

Abb. 4.10: Vergleich der Expression von S100A4 und CYR61 in MCF-7 und MDA-MB-231 Zellen.

Abb. 4.11: Einfluss von GnRH Analoga auf die mRNA-Expression von S100A4 in MCF-7 (A) und MDA-MB-231 (B) Zellen 66

Abb. 4.12: Einfluss von GnRH Analoga auf die mRNA-Expression von CYR61 in MCF-7 (A) und MDA-MB-231 (B) Zellen

Abb. 4.13: Fluoreszenzsignal der Standardverdünnungsreihe von humaner DNA in muriner DNA während des Laufs einer TaqMan ${ }^{\circledR}$-Realtime PCR

Abb. 4.14: Tumorwachstumsverlauf von MDA-MB-435 in xenotransplantierten CD1 nu/nu Mäusen 
Abb. 4.15: Metastasierungsrate von MDA-MB-435 in der Lunge von xenotransplantierten CD1 nu/nu Mäusen

Abb. 4.16: Metastasierungsrate von MDA-MB-435 im Femur von xenotransplantierten CD1 nu/nu Mäusen

Abb. 4.17: Metastasierungsrate von MDA-MB-231 in der Lunge von xenotransplantierten CD1 nu/nu Mäusen

Abb. 4.18: Metastasierungsrate von MDA-MB-231 im Femur von xenotransplantierten CD1 nu/nu Mäusen

Abb. 4.19: Metastasierungsrate von MDA-MB-231 in der Leber von xenotransplantierten CD1 nu/nu Mäusen

Abb. 4.20: Detektion von CTC (MDA-MB-231) im Blut von xenotransplantierten CD1 nu/nu Mäusen mittels TaqMan ${ }^{\circledR}$-Real-time PCR

Abb. 7.1: Vektorkarte pcDNA3.1/V5-His A, B, C - 5,5 kb 127

\subsection{Tabellenverzeichnis}

Tab. 1.1: Aminosäuresequenz der Dekapeptide GnRH-I und GnRH-II 17

Tab. 2.1: Verwendete Zelllinien (Mammakarzinom, Osteosarkom). 27

Tab. 2.2: Verwendeter Mausstamm ..................................................... 27

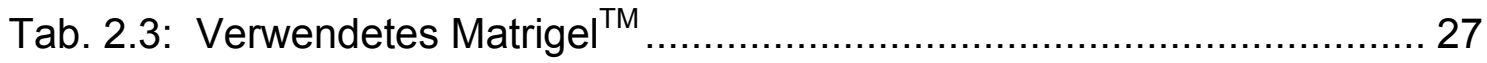

Tab. 2.4: Verwendete GnRH Analoga ............................................... 28

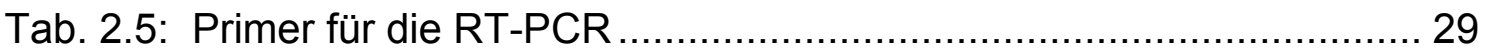

Tab. 2.6: TaqMan $^{\circledR}$-Sonde und Primer für die Real-time PCR ...................... 29

Tab. 2.7: Primärantikörper.................................................................. 30

Tab. 2.8: HRP-gekoppelte Sekundärantikörper...................................... 30

Tab. 3.1: Konzentrationen der verwendeten GnRH Analoga ....................... 35

Tab. 3.2: Faktoren zur Konzentrationsbestimmung von Nukleinsäuren .......... 40

Tab. 3.3: Enzym-Mix für die Reverse Transkription ............................... 40

Tab. 3.4: Standard-Reaktionsansatz für die PCR ................................. 41

Tab. 3.5: Parameter der spezifischen PCR-Programme ............................ 42 
Tab. 3.6: Enzym-Mix für den Gene Array ............................................ 44

Tab. 3.7: Enzym-Mix für die TaqMan ${ }^{\circledR}$-Real-time PCR ............................. 47

Tab. 3.8: Zusammensetzung eines 5 \%igen Sammelgels ......................... 50

Tab. 3.9: Zusammensetzung von Trenngelen ....................................... 50

Tab. 4.1: Ausgewählte Kandidatengene des Human Tumor Metastasis Gene Array

Tab. 7.1: Buchstabencode für natürliche und nicht-natürliche Aminosäuren 122

Tab. 7.2: Gentabelle 1 (Human Metastasis Gene Array) .......................... 123

Tab. 7.3: Gentabelle 2 (Human Metastasis Gene Array) 123

\subsection{Formelverzeichnis}

Formel 3.1: Berechnung des Tumorvolumens

Formel 3.2: Normalisierung der Emissionsintensität durch eine passive Referenz.

Formel 3.3: Normalisierung der $\mathrm{C}_{\mathrm{t}}$-Werte durch ein Housekeeping-Gen 48 


\section{DANKSAGUNG}

Frau Prof. Dr. Sigrid Hoyer-Fender danke ich für Ihr Interesse an meiner Arbeit, die stetige Diskussions- und Hilfsbereitschaft sowie die freundliche Übernahme der Betreuung und Vertretung meiner Arbeit seitens der Biologischen Fakultät der Georg-August-Universität Göttingen.

Herrn Prof. Dr. Gerhard Hunsmann danke ich für die freundliche Übernahme des Korreferats sowie den sehr angenehmen sowie hilfreichen Kontakt.

Ich danke Herrn Prof. Dr. Günter Emons für die Möglichkeit, diese Arbeit im Labor für Molekulare Gynäkologie der Universitätsfrauenklinik Göttingen unter der Leitung von Herrn Prof. Dr. Carsten Gründker durchführen zu können.

Ganz besonders herzlich bedanken möchte ich mich bei Herrn Prof. Dr. Carsten Gründker für die engagierte Betreuung meiner Arbeit und die damit verbundene umfangreiche Diskussions- und Hilfsbereitschaft.

Allen Mitarbeitern des Labors für Molekulare Gynäkologie danke ich für die sehr schöne Zeit und die entgegenkommende Hilfsbereitschaft.

Ein ganz besondes herzliches Dankeschön gilt Dr. Stefanie Fister, Dr. Martin Block, Dr. Fadi Hussein, Dr. Jan-Hendrik Streich und Teresa Olbrich für die tolle Unterstützung sowie die vielen schönen gemeinsamen Stunden.

Ich möchte mich bei der Deutschen Krebshilfe - Dr. Mildred Scheel Stiftung für die finanzielle Unterstützung dieses Projektes bedanken.

Mein besonderer herzlicher Dank gilt meiner Familie, die mich in jeder Hinsicht unterstützt und mir stets den nötigen Rückhalt gibt. 


\section{PUBLIKATIONEN}

Die Ergebnisse dieser Arbeit wurden zum Teil in den folgenden Publikationen veröffentlicht:

\section{$\underline{\text { Originalarbeiten }}$}

Schubert A, Schulz H, Emons G, Gründker C (2008). Expression of osteoprotegerin and receptor activator of nuclear factor-kB ligand (RANKL) in HCC70 breast cancer cells and effects of treatment with gonadotropin-releasing hormone on RANKL expression. Gynecological Endocrinology 24 (6), 331 - 338.

In Vorbereitung:

Schubert A, Hawighorst T, Emons G, Gründker C: GnRH analogs reduce metastasis of MDA-MB-435 and triple-negative MDA-MB-231 human breast cancer cells in vivo.

\section{Kongressbeiträge}

Schubert A, Schulz H, Emons G, Gründker C (2007). GnRH Analoga hemmen die Expression von RANKL in humanen HCC-70 Mammakarzinomzellen während der Kokultur mit primären humanen Osteoblasten. (123. Tagung der Norddeutschen Gesellschaft für Gynäkologie und Geburtshilfe, Göttingen)

Schubert A, Schulz H, Emons G, Gründker C (2009). Interaktion von GnRH Analoga mit Metastasierungsfaktoren in MCF-7 und MDA-MB-231 Mammakarzinomzellen während der Kokultur mit der Osteoblastenähnlichen Zelllinie MG-63. (125. Tagung der Norddeutschen Gesellschaft für Gynäkologie und Geburtshilfe, Hamburg)

Schubert A, Schulz H, Emons G, Gründker C (2009). Interactions between $\mathrm{GnRH}$ analogs and factors for metastasis in MCF-7 and MDA-MB-231 breast cancer cells co-cultured with osteoblast-like cell line MG-63. (3. Wissenschaftliches Symposium der Kommission Translationale Forschung der Arbeitsgemeinschaft Gynäkologische Onkologie, Bergisch Gladbach)

Gründker C, Schubert A, Emons G (2010). Einfluss von GnRH Analoga auf die Knochen-gerichtete Metastasierung humaner Mammakarzinomzellen in vitro und in vivo. (29. Deutscher Krebskongress, Berlin) 


\section{LEBENSLAUF}

\section{Persönliche Daten}

Name

Vorname

Geburtsdatum

Geburtsort

Familienstand

Staatsangehörigkeit

Anschrift
Schubert

Antje

17.02.1981

Zwickau

ledig

deutsch

Untere Karspüle 12

37073 Göttingen

\section{Promotion}

seit $01 / 2007$

Promotion im Labor für Molekulare Gynäkologie

Universitätsfrauenklinik Göttingen

\section{Studium}

$10 / 2000-08 / 2006$

Studium der Ernährungswissenschaften

Friedrich-Schiller-Universität Jena

Diplomarbeit zum Thema „Modulation von

Phase II-Enzymen und weiterer Parameter der Chemoprävention nach Verzehr von

Wasserkresse (Nasturtium officinale) - in vitro und in vivo Untersuchungen in peripheren humanen Leukozyten"

Lehrstuhl für Ernährungstoxikologie

Abschluss: Diplom-Trophologin

\section{Berufspraxis vor dem Studium}

09/1999-08/2000

Freiwilliges ökologisches Jahr

Wasserwerke Zwickau GmbH

Schulbildung

09/1992 - 07/1999

Gerhart-Hauptmann-Gymnasium Zwickau Abschluss: Allgemeine Hochschulreife

09/1987 - 07/1992

Nicolaischule Zwickau 